Das Werk im Werk

Karin Wetzel - 978-3-8467-6674-3 
Karin wetzel - 978-3-8467-6674-3

Downloaded from Fink.de@4/26/2023 03:14:51PM via free access 
Karin Wetzel

\section{Das Werk im Werk}

Konzepte des Poly-Werks

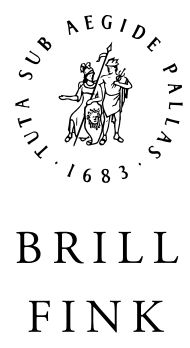




\section{Publiziert mit Unterstützung des Schweizerischen Nationalfonds zur Förderung der wissenschaftlichen Forschung.}

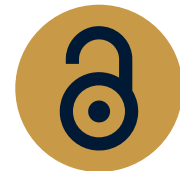

Dies ist ein Open-Access-Titel, der unter den Bedingungen der CC BY-NC-ND 4.o-Lizenz veröffentlicht wird. Diese erlaubt die nicht-kommerzielle Nutzung, Verbreitung und Vervielfältigung in allen Medien, sofern keine Veränderungen vorgenommen werden und der/die ursprüngliche(n) Autor(en) und die Originalpublikation angegeben werden.

Weitere Informationen und den vollständigen Lizenztext finden Sie unter https://creativecommons.org/licenses/by-nc-nd/4.o/

Die Bedingungen der CC-Lizenz gelten nur für das Originalmaterial. Die Verwendung von Material aus anderen Quellen (gekennzeichnet durch eine Quellenangabe) wie Schaubilder, Abbildungen, Fotos und Textauszüge erfordert ggf. weitere Nutzungsgenehmigungen durch den jeweiligen Rechteinhaber.

DOI: https://doi.org/10.30965/9783846766743

Bibliografische Information der Deutschen Nationalbibliothek

Die Deutsche Nationalbibliothek verzeichnet diese Publikation in der Deutschen Nationalbibliografie; detaillierte bibliografische Daten sind im Internet über http://dnb.d-nb.de abrufbar.

Die vorliegende Arbeit wurde an der Künstlerisch-Wissenschaftlichen Doktoratsschule der Universität für Musik und Darstellende Kunst Graz als Dissertation angenommen.

(C) 2022 bei der Autorin. Verlegt durch Brill Fink, Wollmarktstraße 115, D-33098 Paderborn, ein Imprint der Brill-Gruppe (Koninklijke Brill NV, Leiden, Niederlande; Brill USA Inc., Boston MA, USA; Brill Asia Pte Ltd, Singapore; Brill Deutschland GmbH, Paderborn, Deutschland; Brill Österreich GmbH, Wien, Österreich) Koninklijke Brill NV umfasst die Imprints Brill, Brill Nijhoff, Brill Hotei, Brill Schöningh, Brill Fink, Brill mentis, Vandenhoeck \& Ruprecht, Böhlau, Verlag Antike und V\&R unipress.

www.fink.de

Brill Fink behält sich das Recht vor, die Veröffentlichung vor unbefugter Nutzung zu schützen und die Verbreitung durch Sonderdrucke, anerkannte Fotokopien, Mikroformausgaben, Nachdrucke, Übersetzungen und sekundäre Informationsquellen, wie z. B. Abstraktions- und Indexierungsdienste einschließlich Datenbanken, zu genehmigen.

Anträge auf kommerzielle Verwertung, Verwendung von Teilen der Veröffentlichung und/oder Übersetzungen sind an Brill Fink zu richten.

Lektorat: Dr. Sylvia Zirden

Umschlagabbildung: Florina Leinß

Einbandgestaltung: Evelyn Ziegler, München

Herstellung: Brill Deutschland GmbH, Paderborn

ISBN 978-3-7705-6674-7 (hardback)

ISBN 978-3-8467-6674-3 (e-book) 
Für meine Eltern 
Karin wetzel - 978-3-8467-6674-3

Downloaded from Fink.de@4/26/2023 03:14:51PM via free access 


\section{Inhalt}

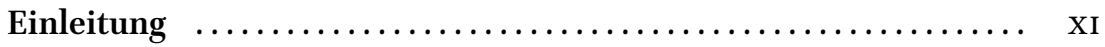

Vorgehen und Zielsetzung $\ldots \ldots \ldots \ldots \ldots \ldots \ldots \ldots \ldots \ldots \ldots \ldots \ldots \ldots \ldots \ldots$

Forschungsstand - Literatur $\ldots \ldots \ldots \ldots \ldots \ldots \ldots \ldots \ldots \ldots \ldots \ldots \ldots$

Danksagung $\ldots \ldots \ldots \ldots \ldots \ldots \ldots \ldots \ldots \ldots \ldots \ldots \ldots \ldots \ldots \ldots \ldots \ldots \ldots \ldots \ldots$

1. Werkästhetische Voraussetzungen $\ldots \ldots \ldots \ldots \ldots \ldots \ldots \ldots \ldots \ldots$

1.1 Simultane Werkkonstellationen $\ldots \ldots \ldots \ldots \ldots \ldots \ldots \ldots \ldots \ldots \ldots$

1.2 Zur Wandlung und Erweiterung der Werkästhetik im

Spannungsfeld von Offenheit und Geschlossenheit $\ldots \ldots \ldots \ldots .4$

1.3 Die Simultanaufführung bei John Cage $\ldots \ldots \ldots \ldots \ldots \ldots \ldots$

1.3.1 Leere versus Überfluss ...................... 8

1.3.2 Simultane Aufführungsformen bei Cage ............ 12

1.3.3 Werkverhältnisse: Beziehung statt Form ............ 16

1.3.4 Die Aufführung als Rahmenöffnung des Werks .......... 20

1.4 Die Dialektik von Form und Offenheit bei Umberto Eco ....... 22

1.5 Die Offenheitskonzepte von Cage und Eco im Vergleich ....... 24

1.6 Weitere Zweige und Formen simultaner Musik ........... 34

2. Im Delta des Poly-Werks - eine Annäherung $\ldots \ldots \ldots \ldots \ldots \ldots \ldots$

2.1 Die konzeptuelle Weiterentwicklung von Polyphonie und

Werk im Poly-Werk $\ldots \ldots \ldots \ldots \ldots \ldots \ldots \ldots \ldots \ldots \ldots \ldots .42$

2.2 Die konzeptuelle Weiterentwicklung der Werkidee im

Poly-Werk ............................. 45

2.3 Künstlerisches Gestalten in der Differenz $\ldots \ldots \ldots \ldots \ldots \ldots \ldots \quad 48$

2.4 Die Erweiterung des Begriffsfeldes $\ldots \ldots \ldots \ldots \ldots \ldots \ldots \ldots \ldots \ldots$

3. Die Interform im Poly-Werk $\ldots \ldots \ldots \ldots \ldots \ldots \ldots \ldots \ldots \ldots \ldots \ldots$

3.1 Homogene und heterogene Werkzyklen $\ldots \ldots \ldots \ldots \ldots \ldots \ldots 61$

3.2 Endliche und nichtendliche Werkzyklen $\ldots \ldots \ldots \ldots \ldots \ldots \ldots .63$

3.3 Monozentrische und multizentrische Werkzyklen ......... 64

3.4 Möglichkeiten der zeitlich-horizontalen Lageposition ....... 66

3.5 Möglichkeiten der vertikalen Lageposition $\ldots \ldots \ldots \ldots \ldots \ldots .67$

3.6 Synchrone und asynchrone Prozesse $\ldots \ldots \ldots \ldots \ldots \ldots \ldots . \ldots 6$ 


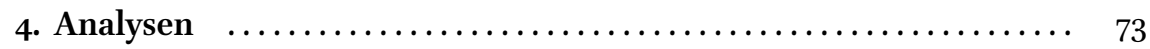

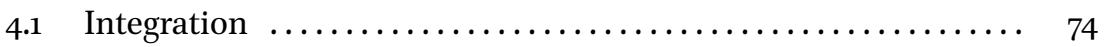

4.1.1 D'une œuvre à l'autre - Die Sequenzae und Chemins von Luciano Berio .............................. $7_{76}$

4.1.2 Claus-Steffen Mahnkopf-Konfliktäre Formstrategien in Medusa .................................. 88

4.1.3 Die Kontextualisierung des Solos durch Integration ....... 93

$4.2 \quad$ Addition homogener Werke $\ldots . \ldots \ldots \ldots \ldots \ldots \ldots \ldots \ldots . . \ldots 4$

4.2.1 Werkcluster - Vom Solo zum Ensemble - Transkriptionsund Variationsprozesse ....................... 94

4.2.1.1 Simultane Konstellationen - Ensemblespiel als freies Mit- und Nebeneinander $\ldots \ldots \ldots \ldots \ldots \ldots . \quad 95$

4.2.1.1.1 Bernd Franke - half-way house - Solo xfach ......................... 95

4.2.1.1.2 Juliane Klein - Aus der Wand die Rinne $\ldots . \ldots \ldots \ldots \ldots \ldots \ldots \ldots . . . \ldots 9$

4.2.1.1.3 Georg Friedrich Haas - ,... Einklang freier Wesen ..." ................. 100

4.2.1.1.4 Die Kontextualisierung des Solos bei Klein, Franke und Haas als freie Assoziation ..................... 105

4.2.1.2 Konzeptuelle Polyphonie - Parallelismus als Bindeglied ........................... 106 4.2.1.2.1 Julio Estrada-Yuunohui Cycle ....... 106 4.2.1.2.2 Simon Steen-Andersen - Next To Beside Besides ....................... 114

4.2.1.2.3 Die Kontextualisierung des Solos durch systematische Vervielfältigung $\ldots . \ldots \ldots \quad 118$

4.2.1.3 Die verschiedenen Variations- und

Transkriptionsprozesse im Vergleich .......... 121

4.2.2 Werkpaare - Simultaneisierung als Intensivierung in den

Hängebrücken von Adriana Hölszky

(zwei Streichquartette I) ...................... 123

4.3 Addition heterogener Werke $\ldots \ldots \ldots \ldots \ldots \ldots \ldots \ldots \ldots \ldots \ldots$

4.3.1 Darius Milhaud - Von der melodisch-harmonischen zur formalen Superposition (zwei Streichquartette II) $\quad \ldots \ldots \ldots \quad 131$

4.3.2 Chaya Czernowin-Kontextualisierung und

Perspektivierung durch Dialog im Anea Crystal Cycle (zwei Streichquartette III) 
4.3.3 Die Simultaneisierung von heterogenen StreichquartettenMilhaud und Czernowin im Vergleich ............. 151

4.3.4 Simultane Überlappung in den Protuberanzen für Orchester von Klaus Huber ................... 153

4.3.5 Simultane Verschachtelung in den Echoräumen für vier Ensembles von Ulrich Kreppein ................ 159

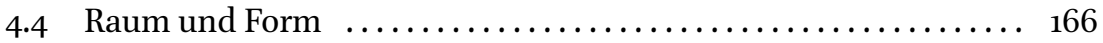

4.5 Zeitdimensionen im Poly-Werk .................. 169

5. Die Umkehrungsformen des Additiven im Poly-Werk .......... 179

5.1 Zwischen Dividuum und Dyade - Die Erschließung des

Poly-Werks aus einer performativen Perspektive $\ldots \ldots \ldots \ldots \ldots 180$

$5.2 \quad X$-Pieces für zwei Blockflöten $(2017) \ldots \ldots \ldots \ldots \ldots \ldots \ldots \ldots \ldots$

5.3 Komponieren in der Differenz $\ldots \ldots \ldots \ldots \ldots \ldots \ldots \ldots \ldots \ldots$

6. Zusammenfassung und Schlussresümee $\ldots \ldots \ldots \ldots \ldots \ldots \ldots \ldots$

Literatur- und Quellenverzeichnis $\ldots \ldots \ldots \ldots \ldots \ldots \ldots \ldots \ldots \ldots \ldots . \ldots \ldots$

Partituren .............................. 201

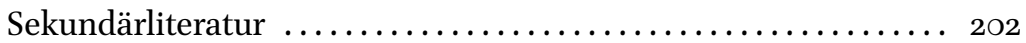

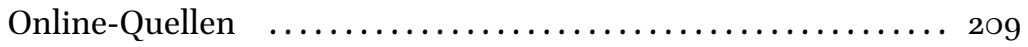

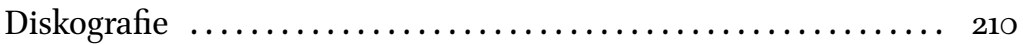


Karin wetzel - 978-3-8467-6674-3

Downloaded from Fink.de@4/26/2023 03:14:51PM via free access 


\title{
Einleitung
}

\begin{abstract}
„Wir sind in der Epoche des Simultanen, wir sind in der Epoche der Juxtaposition, in der Epoche des Nahen und des Fernen, des Nebeneinander, des Auseinander. Wir sind, glaube ich, in einem Moment, wo sich die Welt weniger als ein großes sich durch die Zeit entwickelndes Leben erfährt, sondern eher als ein Netz, das seine Punkte verknüpft und sein Gewirr durchkreuzt." ${ }^{\text {1 }}$
\end{abstract}

(Michel Foucault)

Ist ein musikalisches Werk "A“, das simultan zu einem anderen Werk „B“ erklingt, noch das gleiche Werk oder schon ein anderes? In welchem Verhältnis stehen diese beiden Werke zueinander, wenn sie gleichzeitig erklingen? Auf welchen Ebenen sind sie synchronisiert? Durchdringen sie einander, verschmelzen sie miteinander, oder sind sie weiterhin voneinander abgrenzbar? Ist das Resultat die Summe der einzelnen Teile, oder entsteht eine neue Ganzheit? Handelt es sich dabei um ein Zufallsprodukt oder um das Ergebnis ausgetüftelter Planung?

Bereits im 19. Jahrhundert komponierte der italienische Komponist Pietro Raimondi Fugen, Messen, Oratorien und Opern, die sowohl einzeln als auch simultan aufgeführt werden konnten. Für das 2o. Jahrhundert bilden die 1948/49 von Darius Milhaud komponierten Streichquartette Nr. 14 \& 15 den Auftakt für die Entwicklung simultaner Werkkopplungen in der Kompositionsund Interpretationspraxis. Beide Quartette können einzeln gespielt, aber auch zum Oktett kombiniert werden und wurden als Simultanpartitur herausgegeben. ${ }^{2}$ In der zweiten Hälfte des 20. Jahrhunderts wird die simultane Aufführungsform sowohl von Komponisten als auch von Interpreten mehr und mehr als Möglichkeit in Betracht gezogen. Zunehmend entstehen Werke und Zyklen, bei denen einzelne in sich abgeschlossene Werke in einer simultanen Form, das heißt zeitgleich mit anderen Werken, dargeboten werden können und die damit die sukzessive Aufeinanderfolge in der Programmgestaltung

1 Michel Foucault: „Andere Räume“ (1967), in: Aisthesis. Wahrnehmung heute oder Perspektiven einer anderen Ästhetik. Essais, hg. von Karlheinz Barck, 7. Aufl., Leipzig: Reclam, 2002, S. $34-46$, hier: S. 34.

2 Darius Milhaud: Octuor à cordes (14e et 15e Quatuors), Paris: Heugel, 1949. 
aufbrechen. Der Komponist und Musikwissenschaftler Claus-Steffen Mahnkopf prägte dafür den Begriff des Poly-Werks. ${ }^{3}$

Der Philosoph Umberto Eco schrieb in seinem Aufsatz „Form als Engagement", erschienen in dem Buch Das offene Kunstwerk:

„[...] die erste Behauptung, die die Kunst über die Welt und den Menschen aufstellt, diejenige, die sie Rechtens aufstellt, und die einzige, die einen wirklichen Sinn hat, stellt sie auf durch eine bestimmte Disposition ihrer Formen [...].4

Dieser Gedanke evoziert einen kritischen Formbegriff in Bezug auf den gesellschaftlichen Rahmen, aus dem heraus Kunst gedacht und praktiziert wird. Simultanen Werkkonstellationen könnte als Ursprung eine heterogene und plurale Welterfahrung zugrunde liegen, die in zeitlich parallelisierten Werkverläufen ihren Ausdruck findet. Bereits seit dem Übergang vom 19. zum 20. Jahrhundert spielen simultan-zeitliche Praktiken in den Künsten eine zunehmende Rolle und spiegeln einen Paradigmenwechsel im Umgang mit Zeitkategorien und ihrer Darstellbarkeit wider: Der Simultanvortrag von Gedichten im Dadaismus, die Collagetechniken, Verlaufssplittungen und disparaten Schichtungen bei Strawinsky, Ives oder Varèse, ${ }^{5}$ die Überlagerungstechniken bei Bernd Alois Zimmermann, die simultane Darstellung verschiedener Teilansichten im Kubismus, Mehrfachprojektionen und Split-Screen-Techniken in der Videokunst, Mashups im Pop, simultane Raumerfahrungen in der Architektur oder die Erfahrung von Simultaneität im postdramatischen Theater sind nur einige Beispiele, die Simultaneität auch als Gegenmodell zur reinen Linearität und Sequenzialität denken. ${ }^{6}$ Die Erfahrung der Gleichzeitigkeit ist dabei innerhalb einer Sinnesebene angesiedelt, als Gleichzeitigkeit von Bildern im Bild, von Texten im Text, von Räumen im Raum, von Werken im Werk.

3 Claus-Steffen Mahnkopf: „Kundgabe. Komplexismus und der Paradigmenwechsel in der Musik“, in: MusikTexte. Zeitschrift für Neue Musik 35 (199o), S. 20-28, hier: S. 22.

4 Umberto Eco: Das offene Kunstwerk, Frankfurt am Main: Suhrkamp, 1977 (1973), S. 268 (Originalausgabe: Opera aperta, Mailand: Bompiani, 1962).

5 Vgl. hier auch György Ligeti: „Wandlungen der musikalischen Form“, in: Gesammelte Schriften, Bd. 1, hg. von Monika Lichtenfeld (= Veröffentlichungen der Paul Sacher Stiftung, Bd. 10/1), Basel/Mainz: Schott, 2007, S. 85-104 (Erstveröffentlichung in: Die Reihe 7, Wien: Universal Edition, 1960, S. 5-17). In dem aus dem Jahre $195^{8}$ stammenden Text diskutiert Ligeti den Einfluss von Prozessen und Modellen der Verräumlichung auf zeitliche Bewegungen und Verläufe.

6 Siehe hierzu auch das Buch Simultaneität. Modelle der Gleichzeitigkeit in den Wissenschaften und Künsten, hg. von Philipp Hubmann und Till Julian Huss (Bielefeld: Transcript, 2013). Dieser Band bietet wesentliche weiterführende Anknüpfungspunkte zum Thema der Simultaneität in Kunst und Kultur. 
Diese vielfältigen Spuren und Parallelen in den Künsten bestätigen auf ihre Art die künstlerische Relevanz dieses bisher kaum erforschten Themas. Das Poly-Werk ist keine Randerscheinung, die als wunderliches Mischwesen ein unbewusstes Dasein in der Ecke eines musikalischen Kuriositätenkabinetts fristet, sondern vielmehr Ausdruck einer sich wandelnden Wahrnehmungsform und Welterfahrung. Es verkörpert den Anspruch, neue Formen zu finden, die die zeitgleiche Vereinbarung verschiedener Stränge ermöglichen, ohne zwingend auf eine Synthese, eine Einheit zu zielen.

Im Vergleich mit den vielfältigen simultanen Praktiken in den verschiedenen Künsten unterscheiden sich die simultanen Werkkopplungen in der Musik jedoch in einem wesentlichen Punkt: Die einzelnen Werke bleiben auch weiterhin als einzeln aufführbare, autonome und in sich geschlossene Werkeinheiten bestehen. Ihr simultaner Zusammenschluss auf einer höheren Werkebene existiert nur als optionale Möglichkeit, die der Existenz des einzelnen Werks gleichwertig zur Seite gestellt wird. Folglich handelt es sich bei einer simultanen Werkkopplung nicht um eine einfache Entweder-oderSituation, die ein lineares und zielorientiertes Formdenken hinter sich lässt und ausschließlich simultane Konstellationen bevorzugt. Vielmehr sind simultane Werkkopplungen - teils komplexe - Mehrebenengefüge, die sowohl in ihrer horizontalen Richtung als auch in ihrer vertikalen Beziehung durchdacht worden sind und eine wechselseitige Erfahrung beider Formrichtungen ermöglichen.

Durch diese formale Heterogenese wird ein in erster Linie monochrones, das heißt zeitlich in sich konsistentes und schlüssiges Werkmodell, zu einem polyoder heterochronen Werkmodell erweitert. Die Grundthese der vorliegenden Arbeit ist, dass die simultane Werkkopplung dabei einerseits die Möglichkeit bietet, die offene Form neu zu denken, ohne den Werkgedanken per se negieren zu müssen, sondern im Gegenteil ihn konstruktiv zu erweitern. Im Unterschied zum offenen Werk ist diese Öffnung andererseits nicht der eigentliche Zweck. Sie ist die Voraussetzung, um Relationen und Verknüpfungen zwischen autonomen Werkeinheiten zu etablieren und in den Vordergrund zu stellen. Diese Beziehungen zwischen den Werken sollen im Folgenden untersucht werden.

\section{Vorgehen und Zielsetzung}

Im Zentrum meiner Forschungsarbeit stehen Werke und Werkzyklen, die ein simultanes Aufführungsmoment enthalten. Um das Thema von anderen 
simultanen Praktiken in der Musik klar zu unterscheiden, grenzen zwei Kriterien den Gegenstand dieser Arbeit eindeutig ein:

1. Verschiedene schriftlich fixierte Einzelwerke können sich in einer simultanen Konstellation ergänzen.

2. Der Notentext der Werke bleibt in den allein stehenden Fassungen wie auch den simultan verknüpften Fassungen identisch oder wird allenfalls geringfügig verändert.

Die Arbeit verfolgt drei Ziele auf verschiedenen Ebenen: Erstens die Diskussion der ästhetischen Voraussetzungen und Vorentwicklungen, die zur steten Entwicklung simultaner Werkkopplungen geführt haben könnten. Zweitens die Schaffung einer Typologie und eines Begriffsfeldes auf der Basis von Werkanalysen. Drittens die Reflexion der künstlerischen Praktiken und eine Neubefragung des Konzepts anhand eines künstlerisch-experimentellen Ansatzes.

Entsprechend soll das Poly-Werk im ersten Teil zu Konzepten des offenen und geschlossenen Werkgedankens in Beziehung gesetzt werden. Da es die eine „offene Form“ nicht gibt, hingegen verschiedene Formen der Offenheit, wird einerseits auf die Entstehung und den Bedeutungshorizont des einst kunstgeschichtlichen Begriffspaars „offen - geschlossen“ eingegangen. Andererseits wird auch die weitere Entwicklung des Offenheitsbegriffs durch Umberto Eco in seiner Schrift Das offene Kunstwerk einbezogen. Im Verlauf der Forschungsarbeit zeigte sich die interpretative Praxis der Simultanaufführung als eine weitere, dem Poly-Werk verwandte Forschungslücke. Diese ist zwar durch die vorliegende Arbeit nicht zu schließen und wird daher nur in Form eines Überblicks behandelt. Jedoch ergeben sich verschiedene sinnfällige Bezugspunkte zwischen den Poly-Werken und den Arbeiten von John Cage, die die Möglichkeit einer Simultanaufführung vielfach einbeziehen. Seine künstlerischen Ansätze in diese Richtung werden mit den philosophischen und ästhetischen Überlegungen von Umberto Eco verglichen und in Hinblick auf simultane Werkkopplungen interpretiert. Beide fungieren hier als komplementäre Impulsgeber für mögliche Auslegungen eines „offenen“ Kunstkonzepts.

Der zweite Teil der Arbeit nähert sich dem Poly-Werk aus den ihm begrifflich eingeschriebenen Richtungen Polyphonie und Werk an. Die Polyphonie bildet eine wichtige kompositionstechnische Wurzel. Schließlich wird ihr zentraler Gedanke, einzelne selbstständige Linien in einem kontrapunktischen Satz zu vereinen, im Poly-Werk auf ganze Werke und Werkteile übertragen und damit sowohl der Polyphonie- als auch der Werkgedanke konzeptuell weiterentwickelt. Die Wandlung des kontrapunktischen Prinzips von einer satztechnischen zu einer Formkategorie erweitert sowohl die Bedingungen, unter denen Polyphonie entsteht, als auch jene, die sie hervorbringt. Die Erweiterung der Polyphonie von einem ineinandergreifenden Geflecht einzelner Stimmen 
zu einer „Figuration“ verschiedener Werke weist Parallelen zu einem in der Soziologie verwurzelten Identitätskonzept auf, das die Entwicklung der Identität an die Entwicklung der Alterität koppelt und auch vor dem Hintergrund dieser Beziehung wahrgenommen wird. Diese Konstellation bedeutet eine Herausforderung im kompositorischen Prozess und macht auf der Formebene die Einführung einer neuen qualitativen Ebene nötig, die die Beziehungsstruktur der Werke als ein interformales Verhältnis in den Blick nimmt.

Da die Werke mehrheitlich unabhängig von der Kategorie „Poly-Werk“ entstanden sind, existieren auch verschiedene Begriffsmöglichkeiten und Umschreibungen, die abschließend noch einmal zusammengefasst und miteinander verglichen werden.

Die Theoriebildung der Arbeit gründet sich hauptsächlich auf Analysen ausgewählter Beispiele, die eine große stilistische Breite abbilden und denen sich der dritte Teil als Hauptteil der Arbeit widmet. Die getroffene Auswahl gibt das Spektrum bereits realisierter Möglichkeiten wieder, die sich in groben Zügen systematisieren und zu einer Gattung zusammenschließen lassen. Die formale Gliederung in Werkzyklen, die auf einem homogenen Material beruhen, und Werkgruppen, die heterogene Werke zusammenführen, bildet eine maßgebliche Achse für eine typologische Einteilung. Aufgrund der großen Vielfalt an Konzepten und Lösungen ist bis zu einem gewissen Grad eine Modellbildung möglich, über die sich an bestimmte formale Traditionsstränge wie die Variation oder die Sonatenform anknüpfen lässt.

Für mich als Komponistin wäre es unvollständig gewesen, das Thema nur von seiner abgeschlossenen „Werkseite“ her zu untersuchen. Daher liegt meiner Arbeit ein künstlerisch-wissenschaftlicher Forschungsansatz zugrunde, der eine wechselseitige Vertiefung von Theoriebildung und künstlerischer Praxis integriert. Forschen über die Kunst wird gestützt durch ein Forschen mit Mitteln der Kunst. Dieser praxisbasierte Zugang eröffnet die Möglichkeit, sich von innen in das Konzept einzuarbeiten und neben einer systematischen Darstellung auch denjenigen Fragen und Prozessen Raum zu geben, die für die künstlerische Praxis der Hervorbringung und damit für die Weiterentwicklung des Konzepts direkt relevant sind. Folglich ging es mir dabei nicht einfach um eine affirmative Fortsetzung oder Illustration bereits vollzogener Entwicklungen, sondern um eine freie künstlerisch-experimentelle Suche, die die bestehende Distanz zwischen Theorie und Praxis auf zwei Ebenen überwindet: erstens indem die Erfahrung der künstlerischen Praxis in das Gesamtbild miteinfließen kann und zweitens indem sie das Konzept des Poly-Werks in Hinblick auf seine bereits vollzogene Entwicklung neu befragt. Mein eigenes kompositorisches Interesse hat sich im Verlauf des Forschungsprojekts zunehmend von einem kompositionstechnischen zu einem konzeptuellen 
Interesse verschoben und wurde von folgender Frage geleitet: Inwieweit reflektiert eine Simultankonzeption eine formale Ausdifferenzierung im Spannungsfeld von Offenheit und Geschlossenheit und fordert dadurch die Frage der Identität im Verschiedenen heraus? In dem Moment, in dem ein Werk in neue formale Zusammenhänge gestellt wird, wird es bereits in der Kompositionsphase unterschiedlich interpretiert und funktionalisiert. Der vor diesem Hintergrund entstandene Zyklus X-Pieces entspringt sowohl einer systematischen wie auch einer intuitiven Suche nach neuen Möglichkeiten und Anwendungen der Werkkopplung und Werkautonomisierung.

\section{Forschungsstand - Literatur}

Im musiktheoretischen und musikwissenschaftlichen Diskurs fanden simultane Werkkonstellationen bisher kaum Resonanz und wurden daher nur vereinzelt behandelt. Eine erste Auseinandersetzung mit dem Thema bietet der Artikel "On the Methodology and Aesthetics of Form-Polyphony" von Wieland Hoban, ${ }^{7}$ der die Werke Hyperion von Maderna, Berios Chemins, Estradas Yuunohui Cycle, Richard Barretts Opening of the Mouth, Claus-Steffen Mahnkopfs Werkzyklen und Mark Osborns The Fluid Pronoun hinsichtlich ihrer kompositionstechnischen Strategien knapp vorstellt. Hoban unterscheidet resümeeartig zwischen den Kategorien des Palimpsests, welches durch die bloße Überlagerung koexistierender Schichten entsteht, und des mosaikartigen Aufbaus, der einen enormen Aufwand an Planung bedingt. Während ein Palimpsest für einen Überschreibungsvorgang steht, ist ein Mosaik eine Zusammenfügung vieler kleiner Teilchen. Die eigentliche Besonderheit der Ver(un)gleichzeitigung wird durch diese Kategorien also gar nicht treffend erfasst, weshalb ich sie als solche auch nicht übernehme. Grundsätzlich macht Hobans Artikel die Notwendigkeit einer präzisen und bündigen Klarlegung eines Prinzips deutlich, das formale Kriterien für ein Poly-Werk bestimmt und festlegt, was der Begriff Poly-Werk bezeichnen soll. In diesem Zusammenhang wirkt auch die Kategorisierung der Werkzyklen Medeia, Angelus Novus und Kurtág-Zyklus von Claus-Steffen Mahnkopf als Poly-Werke - auch von

7 Wieland Hoban: „On the Methodology and Aesthetics of Form-Polyphony“, in: The Foundations of Contemporary Composition/Composing ( = New Music and Aesthetics in the 21st Century, Bd. 3), hg. von Claus-Steffen Mahnkopf, Hofheim: Wolke, 2004, S. 85-117. 
Mahnkopf selbst ${ }^{8}$ - sehr unkritisch, da nicht alle Werkzyklen dieses Versprechen auch tatsächlich einlösen.

In einem weiteren kurzen Abriss rekurriert Andreas Holzer in seinem Handbuch Zur Kategorie der Form in neuer Musik auf die Thematik ${ }^{9}$ und führt in dem Kapitel "Werkschichten“ verschiedene Beispiele von Robert HP Platz, Claus-Steffen Mahnkopf, Adriana Hölszky, Luciano Berio, Georg Friedrich Haas und Vinko Globokar an. Holzer beschränkt sich auf eine lose aneinanderreihte Vorstellung verschiedener Beispiele. In seiner Werkauswahl stellt sich mit dem Werk Masse, Macht und Individuum von Vinko Globokar die Frage, ob die Kontextualisierung der Solostücke, die bei Globokar mit einer Revidierung des musikalischen Textes einhergeht, wirklich für ein Poly-Werk spricht. Holzer thematisiert diese aus kompositorischer Sicht zentrale und spannende Frage nicht. Gerade weil Globokar - wie viele andere Komponisten auch dieses Werk nicht als ausdrückliches „Poly-Werk“ intendiert hat, scheint eine Abgrenzung zu verwandten und ähnlichen Werkkonzepten wichtig zu sein, um nicht missverständliche Kategorisierungen vorzunehmen und Werke in falsche Schubladen einzuordnen.

Im Lexikon Neue Musik wird im Artikel „Form“ der Begriff Poly-Werk kurz erwähnt. Es ist hier als Weiterentwicklung hybrider Doppelformen dargestellt, die verschiedene Formtypen miteinander kombinieren, beispielsweise die Kombination von krebsgängigem Doppelkanon und Variationsform im Mondfleck aus dem Pierrot Lunaire von Arnold Schönberg. ${ }^{10}$ Diese Schlussfolgerung ist nur teilweise richtig. Zwar bietet sich so eine Herangehensweise für ein Poly-Werk an und wurde beispielsweise von Claus-Steffen Mahnkopf im Medusa-Zyklus auch umgesetzt. Viele Poly-Werke überbrücken ihre Differenzen aber gerade durch ein gemeinsames Formmodell und tragen ihre Differenzen auf anderen Ebenen aus. Prinzipiell ist es unpräzise und irreführend, Form- und Werkpolyphonie gleichzusetzen, da es sich um zwei verschiedene kompositorische Kategorien handelt.

Im weiteren Rahmen der Formenlehre ist das Poly-Werk nicht verankert. Die meisten Formenlehren der letzten dreißig Jahre stellen ebenso wie der $M G G$-Artikel zur Form die Formenbildung älterer Musik in ihr Zentrum. ${ }^{11}$

8 Claus-Steffen Mahnkopf, Die Humanität der Musik. Essays aus dem 21. Jahrhundert, Hofheim: Wolke, 2007, S. 37.

9 Andreas Holzer: Zur Kategorie der Form in neuer Musik (= Musikkontext, Bd. 5), Wien: Mille-Tre, 2011, S. 506-510.

10 Vgl. Rainer Nonnenmann: „Form“, in: Jörn Peter Hiekel/Christian Utz (Hg.): Lexikon Neue Musik, Stuttgart/Kassel: Metzler/Bärenreiter, 2016, S. 233-238, hier: S. 236.

11 Vgl. etwa Herwig Knaus/Gottfried Scholz: Formen in der Musik, Wien: Österreichischer Bundesverlag, 1988/89; Clemens Kühn: Formenlehre der Musik, Kassel: Bärenreiter, 
Dagegen konnte zur Geschichte der offenen Form in der Musik und der Kunst auf eine große Fülle an Literatur zurückgegriffen werden. ${ }^{12}$ Auch Andreas Holzer stellt in seinem oben genannten Handbuch ausführlich und differenziert den Forschungsstand zur Negation des Werkbegriffs und zur offenen Formbildung in der Musik dar.

Um den Begriff des Offenen auch für das Poly-Werk fruchtbar machen zu können, war es sinnvoll, seine philosophische und ästhetische Entwicklung und Dimension unabhängig von seiner Entwicklung in der Neuen Musik zu rekonstruieren. Im Zentrum der Untersuchung stand hier Umberto Ecos einschlägige Schrift Das offene Kunstwerk, die im italienischen Original 1962 erschien..$^{13}$ Auch die frühe Entwicklung des Begriffspaares „offen - geschlossen“ durch den Kunsthistoriker Heinrich Wölfflin ${ }^{14}$ wird einbezogen. Im Kontext der offenen Form gehe ich außerdem auf den Offenheitsbegriff und die Möglichkeit der Simultanaufführung bei John Cage ein. Zu Cage existiert zwar eine Fülle an Sekundärliteratur, dennoch ist der Aspekt der Simultanaufführung bei Cage eine weitere Forschungslücke. Die vorliegenden Ergebnisse stützen sich daher vor allem auf seine eigene Aussagen und Texte sowie sein künstlerisches Schaffen.

Als Komponist und Musikwissenschaftler hat Claus-Steffen Mahnkopf von seinem eigenen Werk ausgehende theoriebildende Ideen zu simultanen Werkkopplungen entwickelt. Er erwähnt den Begriff des Poly-Werks erstmals in seinem Artikel „Kundgabe. Komplexismus und der Paradigmenwechsel in der Musik" ${ }^{\prime 15}$. Auf Mahnkopfs spezifischen Ansatz, der vor allem auf seine eigenen Werkkonzeptionen gerichtet ist, soll extra eingegangen werden, da seine ästhetischen und soziologischen Interpretationen und Überlegungen einen wichtigen Anknüpfungspunkt bilden. Auch die Dissertation von Klaas Coulembier über Multitemporalität geht auf das Konzept des Poly-Werks bei Mahnkopf differenziert ein. ${ }^{16}$

2007 (1987); Reinhard Amon/Gerold Gruber: Lexikon der Musikalischen Form, Wien/ München: Doblinger/Metzler, 2011; Barbara Dobretsberger: Formenlehre. Formen der Instrumentalmusik, Salzburg: Kulturverlag Polzer, 2014.

Vgl. zum Beispiel Ernst Thomas (Hg.): Form in der Neuen Musik (= Darmstädter Beiträge zur Neuen Musik, 10), Mainz: Schott, 1966; die Dissertation von Konrad Boehmer: Zur Theorie der offenen Form in der neuen Musik, Diss. Köln, 1966, und sein Aufsatz „Werk Form - Prozeß", in: Musik auf der Flucht vor sich selbst, hg. v. U. Dibelius, München: Hanser, 1969, S. 55-77; Walter Gieseler: Komposition im 2o. Jahrhundert, Celle: Moeck, 1975.

13 Eco: Das offene Kunstwerk.

14 Heinrich Wölfflin: Kunstgeschichtliche Grundbegriffe. Das Problem der Stilentwicklung in der neueren Kunst, München: Bruckmann, 1915.

15 Mahnkopf: „Kundgabe“.

16 Klaas Coulembier: Multi-temporality - Analyzing simultaneous time layers in selected compositions by Elliott Carter and Claus-Steffen Mahnkopf, Diss. Universität Leuven, 2013. 
Weitere Literatur betrifft Programmtexte, Analysen, Interviews und Schriften zu einzelnen Kompositionen, die im Rahmen des Projektes individuell untersucht werden und die verschiedenste relevante "Spuren“ und Hinweise enthalten. Eine wichtige und aufschlussreiche Quelle bilden von mir geführte Interviews und Gespräche mit Komponisten und Komponistinnen werkpolyphoner Werke, die die Möglichkeit boten, werkspezifische, kompositionstechnische und ideelle Aspekte des Themas eingehender zu thematisieren.

In Hinblick auf für das Poly-Werk relevante Aspekte wie Simultaneität, Zeitlichkeit, Ambiguität, Identitätsbildung oder Vergesellschaftung ergaben sich aufschlussreiche Schnittmengen zu anderen Gebieten der Kunst, Kulturwissenschaft und vor allem der Soziologie. Diese wurden im Verlauf der Arbeit immer wieder eruiert und haben zur inhaltlichen und gedanklichen Schärfung und Präzisierung des Themas direkt und indirekt beigetragen. Insbesondere das von Philipp Hubmann und Till Julian Huss herausgegebene Buch Simultaneität. Modelle der Gleichzeitigkeit in den Wissenschaften und Künsten ${ }^{17}$, das verschiedenste Beiträge unterschiedlicher Autoren und Gebiete zum Thema Simultaneität versammelt, ragt hier hervor.

\section{Danksagung}

Meinen Betreuern und Gutachtern Prof. Isabel Mundry, Prof. Dr. Jörn Peter Hiekel, Prof.Jörg Mainka und Prof. Dr. Hartmut Möller danke ich für ihr Interesse und ihre Unterstützung meiner Dissertation. Ganz besonders herzlich danke ich Chaya Czernowin, Ulrich Kreppein, Bernd Franke, Valerio Sannicandro, Adriana Hölszky, Claus-Steffen Mahnkopf, Simon Steen-Andersen und Julio Estrada für ihre Bereitschaft, mir in Interviews tiefer gehende Einblicke in ihre Werke und den spannenden Prozess der Werkgenese zu ermöglichen. Lydia Dietrich und Laura Kalchofner danke ich für ihr großes Engagement in der Erarbeitung meines Zyklus X-Pieces. Dr. Sylvia Zirden danke ich für die kritische Durchsicht des Manuskripts. Ich danke der Eidgenössischen Stipendienkommission (ESKAS) und dem Schweizer Nationalfonds, die Teile des Forschungsprojekts finanziell unterstützt haben. Ein großer Dank geht an meine Familie, besonders an meinen Partner Silvan, meine Mutter und meine Schwiegermutter für ihre vielfältige Unterstützung. Meinen Söhnen Jakob und Silas danke ich für ihren offenen Blick in die Welt. 
Karin wetzel - 978-3-8467-6674-3

Downloaded from Fink.de@4/26/2023 03:14:51PM via free access 


\section{Werkästhetische Voraussetzungen}

\subsection{Simultane Werkkonstellationen}

Grundsätzlich kann eine simultane Werkkopplung auf zwei verschiedenen Wegen erzeugt werden:

1. Die erste Möglichkeit ist eine nachträgliche, postkompositorische Überlagerung verschiedener Werke jenseits der ursprünglichen Intention der jeweiligen Komponisten. Das simultane Resultat existiert in diesem Fall nicht als kompositorisch ausgearbeitete und festgeschriebene Version. Die Vergleichzeitigung wird erst im Nachhinein vollzogen. Sie kann als interpretative Praxis beschrieben werden, die die sequenzielle Programmabfolge aufbricht. Für dieses Vorgehen soll im Folgenden der Begriff der "Simultanaufführung“ verwendet werden.

2. Die zweite Möglichkeit schließt Werke und Zyklen ein, die mindestens zwei Werke umfassen, die sowohl unabhängig voneinander als auch gleichzeitig aufgeführt werden können. Im Gegensatz zur interpretativen Simultanaufführung ist das Moment der Ver(un)gleichzeitigung hier bereits kompositorisch intendiert und nimmt sowohl Einfluss auf die Struktur und den Aufbau der Werke als auch auf die Form ihrer Verknüpfung. In diesem Fall handelt es sich also um eine kompositorische Praxis, da die optionale Aufführbarkeit durch den Komponisten bereits im Vorfeld antizipiert wurde. In Analogie zur Simultanaufführung wäre der Begriff des Simultanwerks ${ }^{1}$ durchaus geeignet, das Phänomen in seiner Breite zu erfassen. Der Begriff des "Poly-Werks“ ist allerdings mittlerweile auch etabliert. Im Vergleich zum Begriff des Simultanwerks schwingt hier der Verweis auf das qualitative Moment der Verknüpfung von selbstständigen Werkverläufen mit, auf das in dieser Arbeit der Fokus gerichtet ist. Aus diesem Grund wird er im Folgenden von mir auch

1 In der Kunstgeschichte existiert der Begriff des Simultanbilds, das es bereits seit dem Mittelalter gibt. Gemeint ist hier die Zusammenfassung verschiedener zeitlicher und räumlicher Etappen einer Erzählung, die so auf einen Blick erfassbar werden. Analog gibt es im Theater des Spätmittelalters die Simultanbühne, die die verschiedenen Szenen nebeneinander abbildet. Der Zuschauer kann in beiden Fällen selbst wählen, ob er die einzelnen Szenen nacheinander verfolgt oder gleichzeitig überblickt. Die zeitlich chronologische Abfolge entspricht der räumlichen Anordnung. Vgl. Claudia Blümle, „Augenblick oder Gleichzeitigkeit. Zur Simultaneität im Bild“, in: Hubmann/Huss (Hg.), Simultaneität, S. 37-55. 
verwendet. Die von Mahnkopf verwendete Schreibweise „Poly-Werk“ betont das Präfix „Poly“, während die Schreibweise „Polywerk“ (ohne Bindestrich) eher den Werkcharakter hervorhebt. Eine ausführliche Diskussion weiterer Begriffsmöglichkeiten findet sich in Kapitel 2.4. Die Gruppe der komponierten Poly-Werke bildet den Kern meiner Arbeit. Beide Strategien sind miteinander verwandt und Ausdruck der gleichen Fragestellung. Dennoch unterscheiden sie sich in ihrer Genese grundsätzlich voneinander: Das erste Vorgehen ist seinem Wesen nach eine genuine Aufführungspraxis, die ausgewählte Werke in eine simultane Konstellation bringt und auf diese Weise neu kontextualisiert. Da dieser Vorgang postkompositorisch ist, bleiben die Werke in ihrem Kern, ihrer Identität und ihrer Unabhängigkeit davon unberührt. Das zweite Vorgehen ist eine kompositorische Praxis, die bereits im präkompositorischen Prozess ansetzt. Die Werke werden aus der Differenz der verschiedenen Aufführungsoptionen heraus gedacht, mit den formalen, konzeptionellen und qualitativen Konsequenzen für ihr Einzeldasein. Zwar verfügen die Werkstränge über ihren eigenen Abschluss und sind autonom, aber sie sind trotzdem nicht gänzlich unabhängig voneinander entstanden. Auf eine bestimmte Art und Weise sind sie in ihrer Identität zwangsläufig miteinander verbunden und verwandt.

Aus der Perspektive des Rezipienten geben beide Strategien dem Hörer die Möglichkeit einer heterogenen und dezentrierten Hör- und Zeiterfahrung. In seiner Schrift Dauer und Gleichzeitigkeit stellte der Philosoph Henri Bergson fest, dass bei der „instantane[n] Wahrnehmung[...]“ der "Gleichzeitigkeit zweier Prozesse“ die Aufmerksamkeit „sich teilen kann, ohne sich aufzuspalten“. Unteilbarkeit und Teilbarkeit der Aufmerksamkeit fallen zusammen und sind deswegen im Bewusstsein eines Dritten "zugleich einer und $z w e i^{“ 4}{ }^{2}$

„Wenn wir am Ufer eines Flusses sitzen, sind für uns das Vorbeiströmen des Wassers, das Vorübergleiten eines Schiffes oder der Flug eines Vogels, das ununterbrochene Gemurmel unseres tiefen Lebens entweder drei verschiedene Dinge oder ein einziges, ganz wie es uns beliebt.“3

Bei einer simultanen Werkkopplung steht nicht mehr die Entfaltung einer einzigen, sich zeitlich-linear entwickelnden Spur im Fokus der Aufmerksamkeit von Komponist, Interpret und Hörer. Das Hinzufügen einer konkurrierenden Spur, die sich in ihrem Charakter und ihrer formalen Entwicklung anders

2 Henri Bergson: Dauer und Gleichzeitigkeit. Über Einsteins Relativitätstheorie, Hamburg: Philo Fine Arts, 2014, S. 136 f. und S. 366 (Durée et simultaneité. À propos de la théorie de Einstein, Paris: Félix Alcan, 1922).

3 Ebd., S. 137 f. 
verhalten kann, lenkt die Gerichtetheit der Aufmerksamkeit auf den einen Werkverlauf ab. Diese Ablenkung wird in das Werkkonzept integriert. Denn auch wenn in Abhängigkeit von der Besetzung, der Struktur, der Informationsdichte oder der räumlichen Aufstellung die Werke akustisch zurVerschmelzung tendieren können, so ist in den meisten Fällen eine akustische Mehrspurigkeit das Resultat. Diese bietet der Wahrnehmung einen neuen ästhetischen Reiz: Sie stimuliert koordinative Hörfähigkeiten und erschließt ein Feld an neuen Deutungsmöglichkeiten, denn nun treten auch die entstehenden Wechselwirkungen zwischen den Werken in den Vordergrund. Das sich daraus ergebende Verhältnis mutiert nun ebenso zum Gegenstand der Erfahrung und erfährt eine Objektivierung. Der Hörer ist jetzt selbst gefragt, Grenzen zu ziehen und sich zwischen den verschiedenen Angeboten zu entscheiden: $\mathrm{Er}$ kann die Gesamtversion als neue Einheit synthetisieren oder als gebrochenen Zusammenhang auffassen. Er kann die Aufführung als rein absolutes Ereignis hören oder den Verweis auf die anderen Optionen imaginieren. Der größte Reiz wird vermutlich entfaltet, wenn der Hörer einen Abgleich zwischen den verschiedenen akustischen Erscheinungsbildern eines Werkes vornehmen kann und aus der Überfülle des akustischen Informationsflusses heraus ein Prozess der Wiedererkennung, Entschlüsselung und Identifizierbarkeit des Werkobjekts in Gang gesetzt wird. Diese Form eines beweglichen Wahrnehmungsverhaltens führt dazu, dass keine Perspektive mehr das Ganze umfassen kann.

Umberto Eco schrieb 1962 über das offene Kunstwerk:

„[...] jede Ausführung schließlich gibt uns das Werk ganz und befriedigend und gleichzeitig unvollständig, weil sie uns nicht die Gesamtheit der Formen gibt, die das Werk annehmen könnte. ${ }^{4}$

Diese Aussage trifft im Kern auch das Wesen eines Poly-Werks und lässt es als neue Möglichkeit erscheinen, die offene Form zu denken.

Wie in der Einleitung bereits dargestellt, sind zwei Kriterien zur Identifikation eines Poly-Werks ausschlaggebend:

1. Verschiedene Werke können sich in der simultanen Konstellation einer Gruppe von Werken ergänzen beziehungsweise auch umgekehrt aus einer Werkganzheit herausgeeinzelt werden.

2. In den verschiedenen Konstellationen werden die Einzelwerke in ihrer Identität nicht verändert oder nur geringfügig angepasst.

Damit sind bereits die grundlegenden Strukturmerkmale zusammengefasst, die ein Poly-Werk als solches charakterisieren.

4 Eco, Das offene Kunstwerk, S. 49. 


\section{Zur Wandlung und Erweiterung der Werkästhetik im Spannungsfeld von Offenheit und Geschlossenheit}

Das Begriffspaar „offen - geschlossen“ bildet eine zentrale Achse in der Werk- und Formästhetik des 2o. Jahrhunderts. Beide Begriffe rekurrieren auf ein werkästhetisches Spannungsverhältnis, das auf der einen Seite mit einer fixierten Objektgerichtetheit, die reproduzierbar ist, und auf der anderen Seite mit Prozessgerichtetheit, die auch Wandelbarkeit und Nichteindeutigkeit einschließt, assoziiert wird.

Schon aufgrund ihrer immateriellen Medialität haben sich Musik und Komposition in der westlichen Tradition immer in diesem Spannungsfeld bewegt. Zwar hat die Erosion des geschlossenen Werkbegriffs im 2O. Jahrhundert zu einer Vielzahl neuer Sparten geführt, die sich nicht zuletzt auch über den Anspruch entwickelt haben, eine auf Vollendung gerichtete Werkästhetik als ein regressives Modell hinter sich zu lassen. ${ }^{5}$ Im Gegenzug kann jedoch ebenso festgestellt werden, dass das „Werk“ als tradierte, bewährte und fixe Größe weiterhin der Mittelpunkt des zeitgenössischen westlichen Konzertbetriebs ist. Möglicherweise ist der Werkabschluss gerade deshalb für die Komponisten weiterhin attraktiv, weil aus ihrer Sicht die Erfüllbarkeit eines in sich geschlossenen Paradigmas in letzter Konsequenz immer eine Utopie bleiben wird. Denn für den Künstler hat der dynamische Schaffensprozess eine größere Bedeutung als das fertige Produkt. Aus dem Blickwinkel des Komponisten wohnen nahezu jedem „zu Ende gebrachten“ Werk auch andere Möglichkeiten des Abschlusses inne. Umgekehrt präsentiert sich für den Hörer auch das „offenste“ Werk zwangsläufig als fixierte Gestalt. „Wo ein Komponist Möglichkeiten sieht, realisierte neben unterdrückten, sucht der Analysierende nach Notwendigkeit“6, schreibt Carl Dahlhaus 1969. Vor diesem Hintergrund erscheint das Poly-Werk als integratives Werkkonzept, das beide Seiten in sich vereint: einerseits die Notwendigkeit einer finalen Ausformulierung und Präzisierung, die immer auch mit einem Prozess des Verwerfens und des Ausschlusses anderer Möglichkeiten verbunden ist. Andererseits aber auch den Einschluss ausgewählter Möglichkeiten, die Einbindung konträrer Gegenentwürfe, die über eine zufällige Permutation von Elementen - wie sie den offenen Formen der Musik vielfach eingepflanzt wurde - hinausgehen. Dieser

5 Beispielsweise Aktionskunst, Fluxus, Happening, Konzept-, Performance-, Installations- und Klangkunst.

6 Carl Dahlhaus: „Plädoyer für eine romantische Kategorie. Der Begriff des Kunstwerks in der neuesten Musik“, in: ders.: Gesammelte Schriften in zehn Bänden, Bd. 8: 20. Jahrhundert. Historik - Ästhetik - Theorie - Oper - Arnold Schönberg, hg. von Herrmann Danuser u. a., Laaber: Laaber-Verlag, 2005, S. 216-224, hier: S. 224. 
Ansatz erweitert die verbindliche kompositorische Entscheidung um weitere Optionen. Er ist weder radikal negierend noch rein affirmativ und dennoch kritisch und konstruktiv. Wie keine andere Werkform hat das Poly-Werk das Potenzial, auf der formal-organisatorischen Ebene das opus perfectum et absolutum zu spezifizieren, um es im gleichen Atemzug zu differenzieren und zu relativieren. Claus-Steffen Mahnkopf schreibt über das Poly-Werk:

\begin{abstract}
„Damit wird außerdem der Werkbegriff, den das 2o. Jahrhundert immer wieder zu negieren suchte, mit einer neuen Fassung von Identität versehen, denn die Dichotomie von geschlossener und offener Form ist bei einem Poly-Werk überwunden. ${ }^{7}$
\end{abstract}

Doch was genau meinen Begriffe wie Geschlossenheit und Offenheit? Wie haben sie sich entwickelt und im 20. Jahrhundert möglicherweise selbst eine Wandlung erfahren?

Die Aufwertung des Offenen

Geht man etwas weiter zurück, dann findet sich das Begriffspaar „offen geschlossen" auch bei dem Kunsttheoretiker Heinrich Wölfflin, der es in seinem Hauptwerk Kunstgeschichtliche Grundbegriffe. Das Problem der Stilentwicklung in der neueren Kunst ${ }^{8}$ als sinngleiche Entsprechung der Ausdrücke "tektonisch“ und „atektonisch“ einführt. Es ist eines von fünf Begriffspaaren, die Wölfflin entwickelte, um den "geschlossenen“ klassischen Stil des 16. Jahrhunderts vom „offenen" barocken Stil des 17. Jahrhunderts zu unterscheiden. Wölfflins Untersuchungen beziehen sich auf die Malerei, die Plastik und die Architektur und gehen von der Analyse des Bildaufbaus und der Komposition auf der formalen Ebene aus. Während beispielsweise der klare Aufbau einer klassischen Komposition im Einklang mit der rechtwinkligen begrenzenden Bildrahmung steht - den vertikalen und horizontalen Bildachsen entsprechend -, wird diese strenge Bildgliederung im Barock aufgelöst und die Diagonale der Figuren in ein Spannungsverhältnis zum Bildrahmen gesetzt.

Wölfflin stellt die Darstellung „einer in sich selbst begrenzten Erscheinung [...], die überall auf sich selbst zurückdeutet", dem Stil der offenen Form gegenüber, die „überall über sich selbst hinausweist, unbegrenzt erscheinen will, obwohl eine heimliche Begrenzung immerfort da ist und eben den Charakter der Geschlossenheit im ästhetischen Sinne möglich macht" ${ }^{9}{ }^{9}$ Die

7 Claus-Steffen Mahnkopf: Kritik der neuen Musik. Entwurf einer Musik des 21. Jahrhunderts, Kassel: Bärenreiter, 1998, S. 118.

8 Wölfflin: Kunstgeschichtliche Grundbegriffe, S. 147.

9 Ebd. 
offene Form ist in Wölfflins Darstellung eine Spielart, eine Aufweichung des Geschlossenen, eine Überführung des Stabilen, Gewollten, Starren und Begrenzten ins Fließende, Zufällige, Ungewollte oder Unendliche. Nicht nur das Bedürfnis nach „Ordnung, Gesetz, Rahmung und Festigkeit, Dauerhaftigkeit" hat seine Daseinsberechtigung, sondern ebenso das "Nichtgewollte, Nichtgeschlossene, das Zufällige, Vorübergehende und Unbegrenzte“. Die "Werte des Seins“ werden den „Werte[n] der Veränderung“ gegenübergestellt. ${ }^{10}$ Auch ob etwas "gewollt erscheint oder nicht" ${ }^{\text {"11 }}$, scheint ihm bereits ein entscheidendes Unterscheidungsmerkmal zu sein. Mit seiner Kategorisierung nimmt Wölfflin vermutlich erstmals eine Aufwertung der Kategorie des „Nichtgeschlossenen“ - die bis zu diesem Zeitpunkt wohl nie konkret benannt wurde - vor. ${ }^{12}$

Auch Umberto Eco - der als erste „bewußte“ Poetik des offenen Kunstwerks den Symbolismus in der zweiten Hälfte des 19. Jahrhunderts ausmach ${ }^{13}$ - stellt in seinem viel rezipierten Hauptwerk Das offene Kunstwerk die „statische und unmißverständliche Bestimmtheit der klassischen Renaissanceform "14 der „offenen Form“ des Barock gegenüber, die dem zentrierten Renaissanceraum durch ein Auflösungsstreben entgegengesetzt ist. Durch ihre dynamische Form bewirkt sie beim Betrachter eine bewegliche und flexible Rezeptionshaltung, eine analog zur Unbeständigkeit von Kunst, Wissenschaft und Welt multiperspektivische Sichtweise. ${ }^{15}$

„[...] das Streben nach Bewegung und Illusion bewirkt, daß die plastischen Massen des Barock niemals die Feststellung eines bevorzugten, frontalen, definiten Standpunktes gestatten, von dem aus sie zu betrachten wären, sondern den Betrachter ständig dazu veranlassen, den Standort zu wechseln, um das Werk unter immer neuen Aspekten zu sehen, so als ob es in beständiger Umwandlung begriffen wäre."16

\footnotetext{
$10 \quad$ Ebd., S. 159.

11 Ebd., S. 149.

12 Neben dem Barock lassen sich auch andere Parallelen zu offenen Formbildungen finden, wie Hans-Ulrich Reck beispielsweise anhand der Alhambra zeigt. Vgl. hierzu Hans Ulrich Reck: Grenzziehungen. Ästhetiken in aktuellen Kulturtheorien, Würzburg: Königshausen und Neumann, 1991, S. 158-159. Werner Hofmann wiederum zieht Parallelen zwischen einem „polyfokalen“ Mittelalter und einer „polyfokalen“ Moderne. Er grenzt diese von der „monofokalen“ Renaissanceform ab, denn „sie verlangt vom Betrachter kein wanderndes Fokussieren, d. h. kein Umschalten der Wahrnehmung von einem Fokus zum anderen“ (Werner Hofmann: Die Moderne im Rückspiegel. Hauptwege der Kunstgeschichte, München: Beck, 1998, S. 16-17).

13 Eco, Das offene Kunstwerk, S. 36.

14 Ebd., S. 34.

15 Siehe ebd., S. 35.

16 Ebd.
} 
Offene Formen - Geschlossene Werke

In der Neuen Musik vermittelt der Begriff des geschlossenen Werks die Idee eines in sich stimmigen, abgrenzbaren und reproduzierbaren Objekts. Die Kritik an einer Ästhetik des Werkabschlusses ist dabei vor allem eine Kritik an einem kohärenten und konsistenten Formbegriff. Form als primäre Kategorie der Komposition ist eine Errungenschaft der klassischen Instrumentalmusik und gleichermaßen ihr Relikt. Ihre Ineinssetzung mit dem Werkbegriff bedeutet allerdings die missverständliche Vermischung zweier verschiedener Ebenen. ${ }^{17}$ Zu den werkkonstituierenden Eigenschaften zählen zuallererst Autorschaft, Individualität, Originalität, Fixierung, Handelbarkeit, Reproduzierbarkeit und ein vom Autor unabhängiges Eigenleben. Einheitlichkeit, Eindeutigkeit und Vollendung sind dagegen Merkmale einer formalen Physiognomie. Die Formebene ist aber eine der Werkebene nachgeordnete Kategorie, denn die Werkebene ist in ihrem Wirkungs- und Bedeutungsfeld weitreichender, schließt die postkompositorischen Prozesse mit ein und geht über die rein komponierte Form eines Musikstückes hinaus. Auch da, wo Form keine primäre Kategorie mehr oder Musik vermeintlich „formlos“ ist, gibt sie ihren werkhaften Geschlossenheitscharakter nur graduell, nie vollständig auf. Die allgemeinen oben genannten Werkeigenschaften bleiben erhalten. Auch ein geschlossenes Werk kann eine offene Form besitzen.

Die Überführung der Kategorie des „Offenen“ von einem interpretatorischen Spielraum - der sich aus dem Zusammentreffen von Werkobjekt und individueller Rezeption ergibt - zu einem "produktiven Programm“ wird von Eco mittels einiger Werkbeispiele europäischer Komponisten der Darmstädter Schule wie Klavierstück XI von Karlheinz Stockhausen, Scambi von Henri Pousseur, 3. Klaviersonate von Pierre Boulez oder Sequenza per flauto solo von Luciano Berio illustriert. ${ }^{18}$ Der als offen, mobil oder auch variabel bezeichneten Form in der Musik kam ab der Mitte des 20. Jahrhunderts bis ungefähr in die 8oer Jahre eine essenzielle Bedeutung zu. Sie wurde gleichgesetzt mit Spontanität, Indetermination oder Zufall und Werken zugeschrieben, in denen der eindeutige, normative Formverlauf durch ein Möglichkeitsfeld verschiedener Formabschnitte, Module, Partiturseiten, Formstränge etc. mit oder ohne Regeln ersetzt wurde und der Interpret bestenfalls während der Ausführung eine Auswahl traf. Der Entscheidungsspielraum des Interpreten wurde auch auf andere Organisationsebenen (beispielsweise Tempi, Tonhöhen, Dauern, Notation etc.) ausgedehnt und außerdem die Möglichkeit des Improvisierens eingebaut. Dadurch floss ein Moment von Unvorhersehbarkeit

\footnotetext{
17 Eine konzentrierte Zusammenfassung der Problematik der Gleichsetzung von Form und Werk bietet Holzer: Zur Kategorie der Form in neuer Musik, S. 53-59. 
und Variabilität in die Werkbildung ein. Aus der Utopie des fixierten "Seins“ wurde ein potenziell fortlaufendes „Werden“. Das Werk verfügte nun nicht mehr über einen eindeutigen vorbestimmten und geschlossenen Ablauf, aber dafür über mehrere Ausführungsmöglichkeiten in Bezug auf ausgewählte Parameter. Der Zeitpunkt ihrer definitiven Auswahl lag nicht mehr innerhalb der Kompositionsphase. Sie fiel idealerweise mit dem Zeitpunkt der Ausführung zusammen und erweiterte dadurch scheinbar den Interpretationsradius. Grundsätzlich schien Offenheit eine Freiheit zu sein, die sich vor allem in einem vom Komponisten festgelegten Rahmen bewegte und damit vor allem die Formalisierung jener Freiheit bedeutete. So spricht Boulez selbst von der Notwendigkeit einer vom Komponisten kontrollierten, dirigierten und geplanten interpretatorischen Freiheit. ${ }^{19}$ Die „bausatzartige“20 Offenheit der Komponisten der Darmstädter Schule minderte weder den kompositorischen Gestaltungsanteil- und aufwand noch den konventionellen geschlossenen Werkcharakter. Auch löste sie die Hierarchie zwischen Komponist und Interpret nicht auf. Diese wurde dagegen umso mehr von John Cage infrage gestellt, der sich für eine Indetermination jeglicher musikalischer Kategorien und - im Gegensatz zu Boulez - für eine Aufgabe kompositorischer Kontrolle aussprach.

\subsection{Die Simultanaufführung bei John Cage}

\subsubsection{Leere versus Überfluss}

„Daß zwei oder / mehrere Dinge / gleichzeitig geschehn / ist ihre Beziehung." ${ }^{21}$

(John Cage)

In dem Stück 4'33" aus dem Jahre 1952 von John Cage (1912-1992) wird das komponierte Werk zurückgenommen. An die Stelle eines aufführbaren Werks tritt die Stille als leeres Werk. Das „Werk“ fungiert in erster Linie nur noch als Rahmensetzung, um die Aufmerksamkeit des Hörers für die äußeren Geräusche der Umwelt, die jenseits einer subjektiven und gestaltenden Intention eines Autors existieren, empfänglich zu machen. Anstatt diese

19 Siehe Pierre Boulez, Alea, 1957, nachzulesen in: Rainer Nonnenmann (Hg.): Mit Nachdruck. Texte der Darmstädter Ferienkurse für Neue Musik, Mainz: Schott, 2010, S. 173-186.

$20 \quad$ Siehe hierzu auch Carl Dahlhaus in Thomas (Hg.): Form in der Neuen Musik, S. 74.

21 John Cage, 45' für einen Sprecher (1954), in: ders.: Silence, hg. von Ernst Jandl, 9. Aufl., Frankfurt am Main: Suhrkamp, 2017, S. 85 f. 
Klänge zu unterdrücken oder (un)bewusst auszublenden, sollen sie in den Mittelpunkt des Bewusstseins rücken und zur neuen klanglichen Erfahrung mutieren. Für Cage gibt es keine Stille an sich. „[...] it is full of sound, but sounds which I did not think of beforehand, which I hear for the first time the same time others hear.“22 Damit wird die - bis dahin eindeutige - Trennung zwischen den Klängen des Werks und den Klängen der Welt aufgehoben.

4'33" ist nicht unbedingt an den räumlichen Rahmen einer Konzertaufführung gebunden. Allein dass ein Mensch an einem beliebigen Ort, zu beliebiger Zeit eine Rezeptionshaltung einnimmt und sich für eine beliebige Dauer auf die Geräusche und Klänge des ihn umgebenden Ortes als erweiterte Klangerfahrung einlässt, stellt nach Cage eine Aufführung von 4'33" dar. Ist die Stille nach Cage also nicht steril, sondern ein lebendiger und fruchtbarer Raum des Erlebbar-Machens wahrnehmbarer Klang- und Geräuschereignisse, die unabhängig von einer gestaltenden kompositorischen Intention existieren, dann könnte konsequenterweise bereits jegliche Werkaufführung als verschränkte Simultanaufführung eines „Werks" und seiner „Umgebung“ gedacht werden. ${ }^{23}$

Die extreme Reduktion der musikalischen Werkidee, die Cage im Alter von vierzig Jahren vollzog, steht einer entgegengesetzten Tendenz in seinem Gesamtschaffen gegenüber: der gleichzeitigen Aufführung verschiedener Werke. Sein größtes Orchesterwerk 108 aus dem Jahre 1991 ist gleichzeitig sein letztes großes Werk, das auch mit zwei anderen musikalischen Werken simultan aufgeführt werden kann. ${ }^{24}$ Seine zeitliche Dauer von 43:30 Minuten ist wohl kein zufälliger Verweis auf 4'33". Beide Werke markieren den zeitlichen Anfangs- und Endpunkt einer Entwicklung im Schaffen von Cage, die Stille und Klang, Stille und Werk sowie Werk und Werk immer wieder miteinander verschränkt. So steht der leere Zustand der Stille in 4'33" einer bisweilen massenhaften Akkumulation verschiedenster Werke gegenüber, wie sie beispielsweise in A House Full of Music im Bremer Überseemuseum am 10. Mai 1982 realisiert wurde: Innerhalb von neunzig Minuten wurden ca. 15 o verschiedene Stücke verschiedenster Komponisten und Traditionen aus verschiedenen Zeiten

22 Zitiert aus einem Brief an Helen Wolff in John Cage: „Es wird niemals Stille geben ..., Ein bisher unveröffentlichter Briefwechsel zwischen Helen Wolff und John Cage“, in: MusikTexte. Zeitschrift für Neue Musik 106, 2005, S. 47-5o, hier: S. 48.

23 Ebenso könnte jene "Stille“ auch als Verweis auf das eigene innere Bewusstsein des Hörers gedeutet werden, das während einer Konzertaufführung ebenso unabhängig wie unwillentlich auf die eigenen Gedankengänge gerichtet sein kann, wodurch sich beide „Spuren“ in der Aufmerksamkeit miteinander vermischen.

24108 ist sowohl mit $O n e^{8}$ für Cello mit Rundbogen als Cellokonzert 1oga, mit One ${ }^{9}$ für Shō als 1ogb und mit $T w o^{3}$ für Shō und Conch Shells als Doppelkonzert 110 aufführbar. 
überlappend und simultan durch ca. 8oo Kinder und Jugendliche aufgeführt. ${ }^{25}$ Diese Aufführung wurde darüber hinaus als Radiostück weltweit übertragen. Für den Radiohörer mündete das Spektakel, das vor allem eine rein quantitative Schichtung verschiedenster Werke aus verschiedensten Epochen war, vermutlich in eine schwer zu durchdringende Klangtotalität.

Geräuschhafte Stille und klanglicher Überfluss markieren die grundlegenden Achsen zweier Tendenzen, die im Gesamtwerk von Cage auch in den dazwischenliegenden Abstufungen ihren Ausdruck finden. Während die geräuschhafte Stille auf eine Befreiung des Klanges von der Intention eines Autors zielt, ist die Massenaufführung auf eine Befreiung des Werks aus der Klammer der idealerweise sterilen "Stille“ des abgeschlossenen Konzertraumes gerichtet. In beiden Fällen findet eine situative Neukontextualisierung statt. „Stille“ fungiert nicht mehr nur als hintergründige Rahmenbedingung, die es dem Hörer ermöglicht, seine Aufmerksamkeit für eine bestimmte Dauer, auf eine einzige, sich linear entfaltende musikalische Spur zu bündeln. Indem die sekundären Störgeräusche eine ästhetische Aufwertung erfahren, emanzipieren sie sich als eigenständige Ebene mit einer eigenen klanglichen Qualität. Folglich mutiert nach Cage jegliches klangliches Umgebungsgeschehen, das eine Werkaufführung begleitet, zu einer zusätzlichen, gleichwertigen Dimension. Die entstehenden Wechselwirkungen entziehen sich wiederum der Kontrolle des Autors.

„Wenn die Musik Umweltgeräusche zulassen kann, ohne davon beeinträchtigt zu werden, so handelt es sich um moderne Musik“26, gibt John Cage als Kriterium für gelungene moderne Musikwerke an. In der Juillard Lecture, die Cage 1952 vor Studenten der Juillard School of Music hielt und die zeitgleich mit der Aufführung von Klavierwerken von Morton Feldman, Christian Wolff und John Cage durch den Pianisten David Tudor stattfand, wird eine Episode über Christian Wolff zum Ausgangspunkt der Deutung von Simultaneität als erweiterter Hörerfahrung, die unabhängig voneinander existierende Klänge und Ereignisse als gleichwertig anerkennt: Während Wolff ein eigenes Klavierstück spielte, das auch Pausen der Stille in sich trug, drangen die Geräusche der Straße durch ein offenes Fenster in den Raum und übertönten bisweilen sein Spiel. Nachdem das Stück zu Ende war, schloss ein Freund Christian Wolffs, der als Hörer anwesend war, die Fenster und fragte, ob er das Stück nun noch

25 Für eine detaillierte Beschreibung der Aufführung siehe auch Philipp Schäffler: Die Idee der Bildung im Schaffen von John Cage, Mainz: Schott, 2009, S. 182-217.

26 Richard Kostelanetz:John Cage im Gespräch. Zu Musik, Kunst und geistigen Fragen unserer Zeit, Köln: DuMont, 1989, S. 162. 
einmal ohne Störgeräusche hören dürfe. Wolff klärte ihn daraufhin auf, dass die zufällig eindringenden Geräusche keine Störung gewesen seien. ${ }^{27}$

Die Trennung von Alltagsgeräuschen und musikalischem Werk und damit von Alltag/Leben und Kunst verliert ihre Eindeutigkeit. Scheinbar zufällig auftretende akustische Umgebungsgeräusche während einer Aufführung sind in ihrer Unvorhersehbarkeit nicht als Störung oder Ablenkung aufzufassen, sondern als gleichwertige klangliche Erfahrung. Die zufälligen Reize sollen in die kontrollierte und auf die Musik gerichtete Aufmerksamkeit des Hörers integriert werden. Cage passt sich in seiner kompositorischen Praxis seinen Beobachtungen klanglicher Umgebungsgeräusche strukturell an. Durch die Einbindung geräuschhafter Klänge oder auch durch Ausschaltung der eigenen subjektiven Intention mittels objektivierender Zufallsstrategien, der Befragung des I Ging etc. wird die Schaffung eines Klangbildes ermöglicht, das seine enge Bindung an die persönliche und selbstbezogene Imagination des Autors auflöst und sich in der Unbestimmtheit des Resultats der peripheren klanglichen Außenwelt annähert und zuwendet. Es findet eine qualitative Öffnung füreinander statt, die die Kluft zwischen Werk/Kunst und Alltag/ Leben aufweicht. ${ }^{28}$

Die Aufweichung der traditionell den musikalischen Werkcharakter mitkonstituierenden Werkgrenzen findet sich bei Cage auf verschiedenen Ebenen wieder. Die Aufhebung der Trennung zwischen Kunst und Leben, Musik und Alltagsgeräusch oder zwischen Komponist, Interpret und Hörer wird ebenso propagiert wie eine Aufhebung der Trennung zwischen den Künsten, wie sie beispielsweise auch in der Koexistenz von Musik und gesprochenem Vortrag in der Juillard Lecture der Fall ist. ${ }^{29}$ Handelte es sich hier aber um eindeutig

27 John Cage, Juillard Lecture, in: ders.: A Year from Monday. New Lectures and Writings by John Cage, London: Boyars, 1985, S. 101.

28 Versteht man die Schließung eines Kunstwerks aber nicht nur in einem qualitativen Sinn, sondern bezieht sie ebenso auf den zeitlichen Rahmen, so verweisen umgekehrt gerade die Titel vieler Cage-Stücke auf fixe zeitliche Außengrenzen, die die Dauer einer Aufführung übergenau determinieren und formalisieren. Beispielsweise sind die Titel 3'57.9864" für Klavier und 34'46.776" für Klavier auch gleichzeitig die Dauern der Stücke. Beide können gleichzeitig mit 45' für einen Sprecher aufgeführt werden, wobei 45' ebenfalls eine Dauernangabe ist. Auch die Zahl der Aufführenden findet sich in den späten Werken der Number Pieces als Titel wieder und gibt eine klare Begrenzung der Zahl der aufführenden Musiker vor. So besteht das bereits erwähnte Orchesterwerk 108 auch aus 108 Aufführenden. Wenn es zeitgleich mit $O n e^{8}$ (als achtes Solostück innerhalb der Number Pieces) für einen Cellisten aufgeführt wird, resultiert daraus 109.

29 Das bekannteste Beispiel ist zweifellos das Black Mountain Happening aus dem Jahre 1952. Die Zahl der Mitwirkenden und die Dauer des Ereignisses sind unbestimmt, und die verschiedenen Genres Musik, Tanz, Poesie, Film etc. werden frei kombiniert. An der Aufführung im Sommer $195^{2}$ waren John Cage, Mary Caroline Richards, Charles Olson, 
voneinander unterscheidbare und abgrenzbare Wahrnehmungsmodi, können in den rein musikalischen Simultanaufführungen die Komponenten einander auf andere Weise durchdringen. Diese Praxis findet sich in Cages Schaffen in dem langen Zeitraum von 1953 bis 1991, seiner gesamten zweiten Lebenshälfte.

\title{
1.3.2 Simultane Aufführungsformen bei Cage
}

\begin{abstract}
„In Sevilla bemerkte ich an einer Straßenecke die Vielfalt von gleichzeitig sichtbaren und hörbaren Ereignissen, die alle in der Erfahrung zusammenlaufen und mir gefallen. Für mich war es der Anfang von Theater und Zirkus.“30
\end{abstract}

(John Cage)

John Cage kann als der einzige Komponist gelten, der seine Werke mit einer gewissen Konsequenz simultan aufführen ließ. Die Simultanaufführung war bei ihm kein beiläufiges Ereignis. Sie ist Teil einer Praxis, die sich aus der Haltung speist, den Werkcharakter - im Hinblick auf Abgeschlossenheit und Vollendung - auf der Ebene der Komposition aufzuheben und stattdessen eine Verschiebung dieser Kategorie in Richtung der Aufführung und der Rezeption zu erreichen. Die Werksimultaneisierungen sind daher auch nie schriftlich und werkhaft fixiert. Vielmehr handelt es sich um eine Aufführungspraxis. Das schriftlich Gegebene wird neu kontextualisiert, indem durch die Gegenwart anderer Werke neue akustische Umgebungsbedingungen geschaffen werden.

Die Liste der simultan aufführbaren Werke bei Cage ist lang und umfasst mehr als fünfzig seiner Werke. Es existieren mehrere Stufen der Simultaneisierung, die von einer sehr freien und beliebigen Kombination bis zu einer konkreteren Festlegung reichen. Insgesamt können vier Gruppen unterschieden werden:

1. Freie Kombination von Repertoirestücken

Die freieste und offenste Form der Werkschichtung ist zweifellos die beliebige Kombination beliebiger Repertoirestücke durch eine beliebige Anzahl von Spielern. Dabei handelt es sich um von Cage organisierte Events und Happenings, die unter Namen wie Musicircus (1967), Musicircus for Children (1984), A House Full of Music oder Scottish Circus (1990) stattfanden. Nach dem Motto „Mehr ist mehr“ wird pure Quantität zur entscheidenden Voraussetzung eines erfolgreichen Spektakels: Es gilt,

Nicholas Chernovitsch, Richard Buckminster Fuller, Merce Cunningham und Robert Rauschenberg beteiligt.

$3^{\circ}$ John Cage: „From Where'm Now‘. Eine autobiographische Skizze“, in: MusikTexte. Zeitschrift für Neue Musik 106, 2005, S. 21-26, hier: S. 21. 
möglichst viele Teilnehmer zu versammeln, um ein möglichst dichtes, komplexes und chaotisches Klangbild zu erzeugen. Zusätzlich wird durch den Eklektizismus von Repertoirestücken verschiedenster Epochen und Kulturen die "gesamte Musikgeschichte zum ,Materialfundus' da die einzelnen wie auch immer gearteten Musikstücke aus dem historischen Zusammenhang gelöst und so behandelt [werden], als wären sie Klänge oder Geräusche“31. Die Simultaneisierung verschiedener Musikstücke geht hier mit der Simultaneisierung verschiedener historischer Zeiten einher.

2. Freie Kombination einzelner simultaner Stimmen/Parts eines Werks In Werken wie Music for Piano $\left(1953^{-1956}\right)^{32}$, Radio Music $(1956)^{33}$, dem Concert for Piano and Orchestra (1957/58), Atlas Eclipticalis (1961-1962), HPSCHD (1967-1969) und Hymnkus (1967-1969) können die einzelnen instrumentalen, elektronischen oder radiophonischen Parts vom Solo bis zur vollen Instrumentation in allen denkbaren Besetzungen miteinander kombiniert werden. Damit ändert sich die Werkgestalt mit jeder Aufführung. Konzeptionell sind also alle Stimmen autonom, in der Ungleichzeitigkeit, aufführbar. Ihnen wird das Potenzial zugestanden, eine individuelle Aufführung auszufüllen oder sich mit einer anderen Stimme zu verbinden. Die Werke sind zumeist in Stimmen notiert, statt in Form einer Partitur. Die komplette Werkentität kann also nur gehört und nicht gelesen werden.

Bereits im Concert for Piano and Orchestra entfällt die Partitur als vertikale Organisationsform. Der ursprünglichen Intention eines Orchesterapparats entgegengesetzt, sind alle Stimmen Solostimmen, die beliebig simultan kombiniert werden können und eigene, typischerweise unspezifische Titel (beispielsweise Solo for Flute) erhalten. Auch eine Aufführung aller Orchesterstimmen ohne Klavier ist denkbar, womit es dann kein Klavierkonzert mehr wäre. Jeder Spieler trägt selbst die Verantwortung für seine Entscheidungen und entwickelt individuell einen Plan zur

31 Schäffler: Die Idee der Bildung im Schaffen von John Cage, S. 183 f.

32 Siehe hierzu die Dissertation von Martin Erdmann: Untersuchungen zum Gesamtwerk von John Cage, Diss. Bonn, 1993, S. 62 f.

33 Das Radio als Medium eines simultanen Zeitkonzepts ist in Cages Schaffen mehrfach vorhanden und verweist auf die Bedeutung der Simultaneität in seinem Denken. Vgl. hierzu Alana Pagnutti: Reception. The Radio-Works of Robert Rauschenberg and John Cage, Brooklyn: Smith + Brown, 2016. Ebenso sei hier auf die Radioarbeit Solitude Trilogy von Glenn Glould hingewiesen. Das Stück vereint drei einzelne Dokumentarfilme, die zwischen 1967 und 1977 entstanden sind. Gould legt die verschiedenen Stimmen aus den Interviews teilweise übereinander. 
Umsetzung der notierten Stimme. Der in der Gesamtbesetzung eingesetzte Dirigent entwickelt keine synchronisierende und koordinierende Kraft, sondern gibt nur noch rotierende Sekundbewegungen vor und eine Gesamtdauer. Heinz-Klaus Metzger sieht darin ein "positives Modell von Anarchie" und bezeichnet solche flexiblen Aufführungsformen mehrfach als „kollektives Modell von Individualanarchie“. ${ }^{34}$ Die soziale Dimension dieses kompositorischen Vorgehens wird von Cage selbst in verschiedenen Schriften und Interviews immer wieder thematisiert. Er sieht sich selbst einem zu Anarchie tendierenden Gesellschaftsmodell verbunden: „I'm interested in society, not for purposes of power, but for purposes of cooperation and enjoyment." ${ }^{\text {"3 }}$

3. Simultane Überlagerung sukzessiv angeordneter Stücke innerhalb einer Werkentität

Die freie Schichtung der Instrumentalebenen findet ihre Entsprechung in der offen gehaltenen Reihung oder der überlappenden oder gleichzeitigen Überlagerung des Materials, der Seiten- und der Stückreihenfolge. So in Quartet (Percussion Quartet, 1935), in She is Asleep (1943, für Stimme und präpariertes Klavier), in Music for Piano (1953-1956), in Winter Music (1957, 1-2o Pianisten), im Concert for Piano and Orchestra (1957/58), in den Song Books (1970) oder auch in Twenty-Eight, TwentySix and Twenty-Nine (1991). Beispielsweise sind die Song Books eine Sammlung vokaler Stücke, die notationell sukzessiv aneinandergereiht sind, aber beliebig und auch simultan miteinander kombiniert werden können. Analog zu Punkt 2 ändert sich durch die vielfältigen inwendigen kombinatorischen Möglichkeiten innerhalb des von Cage gesetzten Rahmens die äußere Werkgestalt mit jeder Aufführung. Werden ganze Werkentitäten miteinander simultan kombiniert, setzt sich dieser Prozess über die gesetzten Werkrahmen fort.

4. Konkrete Simultaneisierung einzelner Werke

Ab 1953 beginnt Cage, Werke aufzuaddieren. ${ }^{36}$ Wie bereits dargestellt, ist dieser Prozess bei ihm primär eine Aufführungspraxis, da die Simultaneisierung nicht notationell festgelegt und damit werkhaft

34 Heinz-Klaus Metzger: Die freigelassene Musik. Schriften zu John Cage, hg. von Rainer Riehn u. a., Wien: Klever, 2012, S. 97.

35 Richard Kostelanetz: Conversing with Cage, New York/London: Routledge, 2003, S. 274.

36 Neben der Akkumulation seiner eigenen Werke ist auch die Kombination mit Werken anderer Komponisten denkbar. 1977 kombinierte Cage Address mit der Musik von Erik Satie. Auch gibt es die bereits erwähnte Gleichzeitigkeit verschiedener Künste im Sinne einer Aufhebung der Trennung zwischen ihnen. Ein Beispiel ist hier auch das letzte Orchesterwerk 103, das mit dem Film One ${ }^{1 l}$ addiert werden kann. 
fixiert oder technisch synchronisiert ist. Prinzipiell ist jedes Werk mit jedem kombinierbar. Je nach Gelegenheit wird daraus ein „Musicircus“37 oder eine im Vorfeld konkret geplante Kombination eigener Werke. Die folgende Liste erhebt somit auch keinen Anspruch auf Vollständigkeit. Diese wäre im Sinne von Cage sicher auch nicht möglich. Es handelt sich um eine Auswahl, die auch einen Eindruck vermittelt wie Cage Werke kombiniert hat, die von ihrer Entstehungszeit eher nah beieinander liegen. Die Zeiträume umfassen zumeist zwei bis drei Jahre. Der größte Entstehungsabstand ist mit dreizehn Jahren zwischen Winter Music (1957) und den Song Books (1970) zu finden. Es ist anzunehmen, dass noch größere zeitliche Abstände zwischen den Werken prinzipiell keinen Hinderungsgrund für eine Kombination darstellen würden.

Beispiele für die von Cage intendierten Möglichkeiten der Werkkombination - 26’.1499" (für einen Streicher, 1953-1955) + 27'10.554" (für einen Schlagzeuger, 1956), 31'57.9864“ (für einen Pianisten, 1954), 34'46.776” (für einen Pianisten, 1954) oder $45^{\prime}$ (für einen Sprecher, 1954)

- 31'57.9864" (für einen Pianisten, 1954) + 45' (Sprecher, 1954)

- 31'57.9864" (für einen Pianisten, 1954) + 34'46.776" (für einen Pianisten, 1954)

- 34'46.776" (für einen Pianisten, 1954) + 45' (Sprecher, 1954)

- Winter Music (1-20 Pianisten, 1957) + Atlas Eclipticalis (variables Ensemble, 1-98 Orchestermusiker, 1961/62, Instrumente können elektronisch verstärkt und nach der grafischen Notation von Cartridge Music ausgesteuert werden)

- Aria (Stimme, 1958) + Fontana Mix (Tonband, 1958) ${ }^{38}$ oder Teile des Concert for Piano and Orchestra (1957/58)

- Solo for Voice 2 (Solostimme, 1960) + Teile des Concert for Piano and Orchestra (1957/58), Fontana Mix (Tonband, 1958) oder Cartridge Music (variables Ensemble, 1960)

- Concert for Piano and Orchestra (1957/58) + Rozart Mix (Tape, 1965) + Song Books (Solostimme, 1970)

37 Auf die Frage von Daniel Charles, was sich Cage unter einer „Zirkus-Situation“ vorstelle, antwortete Cage: „Der Prozeß öffnet sich, um Dinge einzubeziehen, die keine emotionalen Eigenschaften besitzen, aber ebenso, um Objekte wiedereinzubeziehen, die durch Bedeutung und Zweck belastet sind. Diese Objekte werden innerhalb des Prozesses mitgetragen, sie dominieren ihn aber nicht mehr und verwandeln ihn nicht in ein Objekt.“ (John Cage: Für die Vögel. Gespräche mit Daniel Charles, hg. von Daniel Charles, Berlin: Merve, 1984, S. 179.).

38 Zur Kombination von Aria + Fontana Mix siehe auch Juan Parra Cancino: „Historical contextualization in live electronic music. Reconstructing Aria/Fontana Mix by John Cage", in: ders. u. a. (Hg.): Metacage. Essays on and around Freeman Etudes, Fontana Mix, Aria, Leuven: Leuven University Press, 2009, S. 17-42. 
- Concert for Piano and Orchestra (1957/58) + Aria + Solo for Voice I, Fontana Mix, Indeterminacy, Solo for Voice II, WBAI, Song Books

- Fontana Mix (Tonband, 1958) + Teile des Concert for Piano and Orchestra, Aria (Stimme, 1958), Solo for Voice 2 (Solostimme, 1960) und/oder Song Books (Solostimme, 1970)

- Winter Music (1-20 Pianisten, 1957) + Atlas Eclipticalis (variables Ensemble, 1961/62) oder Song Books (Solostimme, 1970)

- Atlas Eclipticalis (variables Ensemble, 1961/62) + Song Books (Solostimme, 1970)

- Concert for Piano and Orchestra (1957/58), + Atlas Eclipticalis (variables Ensemble, 1961/62)

- Atlas Eclipticalis (Schlagzeugteile, 1961/62) + Rozart Mix (Tape, 1965) + Song Books (Solostimme, 1970)

- Song No. 85 (Stimme, 1970) + Branches (variables Ensemble, Pflanzenmaterial, 1976)

- Child of Tree (Percussion solo, Pflanzenmaterial, 1975) + Branches (variables Ensemble, Pflanzenmaterial, 1976) + Inlets (4 Spieler, 1977)

- Etudes Boreales I-IV (Cello, 1978) + Etudes Boreales I-IV (Klavier, 1978)

- Apartment House (großes Ensemble, 1976) + Renga (78 Stimmen, (1975/76)

-108 (Orchester, 1991) + One 8 (Cello, 1991) = 109a (Cellokonzert)

- 108 (Orchester, 1991) + One $e^{9}($ Shō, 1991 $)=109 b$

- 108 (Orchester, 1991) + Two ${ }^{3}$ (Shō und Conch Shells) $=110$ (Doppelkonzert)

\subsubsection{Werkverhältnisse: Beziehung statt Form}

„Die Beziehung von Dingen, die / gleichzeitig geschehen, ist spontan / und nicht unterdrückbar.“39

(John Cage)

In Bezug auf die Simultanaufführungen seiner Werke probierte Cage aus, ersetzte das eine durch das andere, zweifelte daran und ließ sich abermals überzeugen. An mehreren Stellen beschreibt er seine künstlerische Haltung als eine immerwährende Suche:

„Ich kann mir zum Beispiel vorstellen, daß Rozart Mix nicht zur gleichen Zeit gespielt wird wie die Song Books, ich meine mit den Sängern. Ich kann mir vorstellen, es durch meine Cartridge Music zu ersetzen. Ich möchte nur wissen, ob es ebenso lebendig wäre. Ich weiß es nicht. Während ich die Song Books schrieb, kam mir der Gedanke, daß es ein Fehler wär, die Song Books mit Rozart Mix oder

39 Cage, 45' für einen Sprecher, in: ders.: Silence, 2017, S. 83 . 
den Schlagzeugteilen von Atlas Eclipticalis oder sogar mit beidem zu überlagern. Als ich dann aber die von Davorin Jagodic und den Studenten aus Vincennes hergestellten Bänder hörte, insbesondere die Aufnahme von den Proben, bei denen wir uns alle im Theater befanden und von den Stimmen umgeben waren, da war ich wirklich glücklich.“40

„Auf jeden Fall werden wir in dem kommenden Konzert in New York die Song Books ohne das Concert und ohne Rozart Mix spielen. Und das wird zu einer ungewöhnlichen Situation beitragen, weil die meisten Solos in den Song Books aus einfachen Linienführungen ohne jegliche Begleitung bestehen. Demnach werden Umweltgeräusche in die Musik eindringen können. Sie werden das Mix herstellen. ${ }^{41}$

Die beiden Zitate verdeutlichen, wie selbstverständlich Cage die Möglichkeiten der Simultanaufführung in seine Praxis integrierte. So selbstverständlich, dass der Gedanke an Einzelaufführungen der ursprünglichen Werke für ihn auch eine Herausforderung darstellen konnte. Das könnte einerseits Ausdruck eines ehrlichen Zweifels oder Unvertrauens in die eigenen Werke sein, deren mögliche Schwächen sich so unverhüllt zeigen würden. Es zeigt aber viel mehr noch den Respekt vor der verborgenen Macht der spontanen Situativität des Ortes mit seiner individuellen Atmosphäre, dessen Stimmung von der Handlungsweise und der Haltung und Einstellung der ausführenden Musiker und des anwesenden Publikums geprägt wird. Im Vordergrund der Rezeption steht folglich die Beziehung zwischen den verschiedenen anwesenden Komponenten. Ihr unvorhersehbares Zusammenspiel kann eine Aufführung in eine aleatorische Polyphonie zwischen Werk und Umgebung verwandeln, kann vermeintliche Schwächen des Werks oder des Orts ebenso offenlegen wie verdecken.

Die Spontaneität dieser Beziehung entspricht dabei auch der Beziehung, die sich Cage für die Töne und Geräusche innerhalb seiner Werke vorstellt. In einem Brief an Boulez aus dem Jahre 1951 heißt es, „[... ] daß jedes Ding es selbst ist, daß seine Verhältnisse mit anderen Dingen auf natürliche Weise entstehen und nicht durch irgendeine Abstraktion des ,Künstlers' geschaffen werden $[\ldots]^{\star 42}$. Dieser Gedanke ist auch auf das Werkverhältnis in einer Simultanaufführung übertragbar. Indem die Form der Beziehung der Werke untereinander nicht durch den Komponisten schriftlich fixiert und damit eindeutig vorgegeben wird, existiert sie vor allem als eine von den Interpreten zu

40 Cage: Für die Vögel, S. 61.

41 Ebd., S. 16o. (Cage weist in der Fußnote darauf hin, dass diese Aufführung nicht stattfand).

42 Jean-Jacques Nattiez (Hg.): Dear Pierre-Cher John. Pierre Boulez und John Cage-der Briefwechsel, Hamburg: Europäische Verlagsanstalt, 1997, S. 108. 
nutzende unbestimmte Chance. Sie entspricht dem Anliegen einer Befreiung des Werks aus einem objekthaften und identitätsstiftendem Denken, sucht eine strukturelle Übereinstimmung mit der ihn umgebenden Welt, die sich nach Cage nicht als Objekt, sondern als ein Prozess präsentiert. ${ }^{43}$

Ebenso wie das Aufeinandertreffen der (akustischen) Ereignisse aus den spontanen Koinzidenzen jenseits einer kausalen Beziehung entsteht, so ist auch das von Cage im Kompositionsprozess immer wieder befragte I Ging in seiner Methodik auf dem „Prinzip des akausalen oder Synchronizitätszusammenhanges gegründet ${ }^{44}$ :

„Kausalität ist die Art, wie wir uns die Brücke zwischen zwei aufeinanderfolgenden Ereignissen vorstellen. Synchronizität aber bezeichnet den zeitlichen und sinngemäßen Parallelismus von psychischen und psychophysischen Ereignissen, welche unsere bisherige Erkenntnis nicht auf ein gemeinsames Prinzip reduzieren konnte. [...] Die Parallelereignisse lassen nämlich im Prinzip keinen gegenseitigen Kausalzusammenhang erkennen, weshalb sie eben einen Zufallscharakter tragen." 45

Cage, dessen I-Ging-Ausgabe von C. G. Jung herausgegeben worden war, vertrat die Auffassung, dass zwischen allen Klängen und Ereignissen bereits Beziehungen existieren. Eine beziehungs- und zusammenhaltstiftende Form, die ihre einzelnen Teile für das Verständnis des Ganzen funktionalisiert und damit kausale Brücken schafft, wäre in der Konsequenz überflüssig. Cage begreift das passive Geschehenlassen von Beziehungen zwischen gleichzeitig ablaufenden Dingen als natürlichen spontanen Prozess, der nicht künstlich gestört oder gehemmt werden sollte.

Die simultane Akkumulation verschiedener Werkräume bedeutet zusätzlich einen noch höheren Grad an Unbestimmtheit. Im Gespräch mit Daniel Charles stellt Cage einen Vergleich zu offenen Kompositionstechniken an, deren Steuerungsmechanismen die Elemente lediglich in einer sukzessiven Aufeinanderfolge zufällig verteilen. Für Cage stellt sich in diesem Fall die Indeterminiertheit als eine "mehr oder weniger perfektionierte Variante der Determiniertheit ${ }^{46}$ dar, und er differenziert zwischen verschiedenen Richtungen oder Graden von Indeterminiertheit: Einer linear ausgerichteten Indeterminiertheit, die den Raum der kompositorischen Vorstellungskraft zwar öffnet, aber sich immer noch auf den Radius des Vorstellbaren

43 Vgl. Cage: Für die Vögel, S. 89.

44 Carl Gustav Jung: Über Synchronizität, Reprint, Zürich: Buchclub Ex Libris, 1972, S. 40.

45 Ebd., S. 112.

46 Cage: Für die Vögel, S. 25 o. 
zurückführen lässt, wird der „Sprung in die Nicht-Linearität“47 als Ausdruck des Unbestimmten gegenübergestellt. Demnach würde die Simultaneität, die für Cage vor allem ein Bruch mit der Linearität ist, den erwünschten Bruch mit der Determiniertheit bedeuten, sofern sich das klangliche Resultat außerhalb des imaginierbaren und damit auch des intendierbaren Raumes des Komponisten befände. Die erweiterte Hörerfahrung kann also ebenso als erweiterte Imaginationserfahrung interpretiert werden. Denn jegliche Hörerfahrung, die sich außerhalb der genuinen Vorstellungskraft und Intention befindet, erweitert diese als „lebendige Hörerfahrung“ unweigerlich. Die Zuordnung der Determiniertheit zur linear geprägten Imagination und der Indeterminiertheit zur simultanen Erfahrung ist allerdings anzuzweifeln. Warum sollte eine simultane Schichtung prinzipiell weniger determinierbar sein als ein rein linearer Verlauf? Denn auch dieses ist letztlich eine Frage der mit der Zeit erworbenen Hör- und Imaginationserfahrung. Dem Einwand von Daniel Charles, dass auch das Ganze letztlich als Einheit und als linearer Verlauf wahrgenommen werden könne, entgegnet Cage, dass diese Einheit "nicht die Einheit einer starren fertigen Figur, sondern die einer vibrierenden ,NichtFigur'48 sei.

Die Durchdringung der verschiedenen Werkebenen führt zu einer Vielgestaltigkeit in der Werkausführung und zu einer konsequenten Verhinderung der Identitätsbildung des einzelnen Werks. Es entstehen immer neue Konstellationen: in Form der einzelnen Werkgestalt, in der Gleichzeitigkeit verschiedener Werkgestalten und in der Gleichzeitigkeit der Werkgestalten und ihrer akustischen Umgebung. An die Stelle des objekthaften Werkbegriffs wie er sich in der europäischen Kunstmusik ab 1800 zuzuspitzen begann - tritt bei Cage die Konstellation verschiedenster Klangereignisse, die wandelbar und permanent im Werden sind, ohne an einem Punkt zu einem greifbaren Objekt zu erstarren. Cage vergleicht sie in den Gesprächen mit Daniel Charles sinnfällig mit dem Sternenhimmel:

„Was die Konstellation in ein Objekt verwandelt, ist die Beziehung, die ich ihren Komponenten auferlege. Aber ich kann davon absehen, diese Beziehung zu postulieren, ich kann die Sterne als getrennt, jedoch eng zusammenstehend betrachten, fast zu einer einzelnen Konstellation verbunden. Dann habe ich einfach eine Sternengruppe. ${ }^{49}$

47 Ebd., S. 251.

48 Ebd.

49 Ebd., S. 87. 
Ein fixes Sternbild wie den Großen Wagen entstehen zu lassen wäre nach Cage bereits zu objekthaft gedacht.

\subsubsection{Die Aufführung als Rahmenöffnung des Werks}

Das Werk wird von Cage auch in seiner Einzelaufführung nicht als abgeschlossenes Objekt aufgefasst, sondern als eine offene Konstellation, die in eine Beziehung zu anderen akustischen Ereignissen treten kann, die zufällig gleichzeitig stattfinden. Ob eine gegenseitige Durchdringung stattfindet oder nicht, ist nicht primär eine Frage der Komposition, sondern der performativen und rezeptiven Strategie sowie des zufallsabhängigen Zusammenwirkens aller drei Komponenten.

Das Zusammenspiel in den Number Pieces ist ein anderes als im Concert for Piano and Orchestra. In den Number Pieces sollen die Mitwirkenden aufeinander hören, im Concert soll es keine Probe geben..$^{50}$ Inwieweit sich die Musiker über die Musik tatsächlich miteinander verbinden oder im Nebeneinander verharren, bleibt offen. ${ }^{51}$ Ebenso müssen die Hörer offen dafür sein, die Verbunden- oder Unverbundenheit koexistierender Klangereignisse und Strukturen als gleichwertige und vor allem als lebendige Erfahrung anzunehmen. Ähnlich wie im postdramatischen Theater rückt der ursprünglich komponierte Text in den Hintergrund. Die Aufführung ist nicht primär eine Repräsentation des Textes, sondern ein Akt der Emanzipation von diesem. In diesem Sinn ist das Werk nicht reproduzierbar.

Wie bereits dargelegt, zielte die Kritik von Cage am objekthaft geschlossenen Werkbegriff vor allem auf die in seinen Augen künstliche Trennung zwischen Kunst und Leben. Cage sah seine Werke als wesentlich offen und empfänglich für sämtliche Umgebungsgeräusche an, die nicht künstlich ausgeblendet, sondern zugelassen und als gleichwertig wahrgenommen werden sollten. Eine künstliche Schließung des Werks nach außen, eine deutliche Abgrenzung von der Welt ist nicht gewollt. Im Gegenteil, das Werk öffnet sich für die äußeren, zufällig stattfindenden Ereignisse in der Umwelt. Dieses unmittelbare Eindringen der Umwelt ins Werk oder auch umgekehrt, des Werkes in

50 Vgl. hierzu Metzger: Die freigelassene Musik, S. 196.

51 Siehe auch Martin Iddon: John Cage and David Tudor. Correspondence on Interpretation and Performance, Cambridge: Cambridge University Press, 2013, S. 173. Iddon verweist auf die alternativen Beziehungsformen zwischen den Interpreten auf der Bühne, die nicht auf das traditionelle Ensemblespiel gerichtet sind: „[...] the relationship between Tudor's and Cage's approaches was broadly similar to the relationship between Cage's music and Cunningham's choreography, in that both would occur at the same time and in the same venue, but there would be no attempt to coordinate the activities of the two, as in traditional choreographic approaches." 
seine Umwelt, bedeutet die Aufhebung einer Rahmensetzung, die gewöhnlich immer auch eine stabilisierende Funktion für ein Werk hat. Luhmann spricht in Hinblick auf das Kunstwerk von einer „,doppelte[n] Schließung “'52. Die innere Schließung bezieht sich in dem Sinn auf die Werkidentität, dass „jede Formsetzung einschränkt, was an weiteren Möglichkeiten übrig bleibt“53. Die innere Schließung ist der Werkseite immanent. Sie ist qualitativer und formaler Natur, indem durch die Formbildung eine Grenze erzeugt wird, die in "Formenunterschieden" ${ }^{54}$ wahrnehmbar wird und gleichermaßen "Identität und Differenz" ${ }^{\text {“5 }}$ garantiert. Sie basiert auf dem Ausschluss von Möglichkeiten. „Ein Kunstwerk, das sich im Unterschied zu allem anderen als Kunstwerk behauptet, schließt zunächst also alles andere aus und teilt die Welt ein in sich selbst und den übrig bleibenden unmarked space. “56 Neben der Schließung nach innen gibt es die Schließung nach außen. Sie bezieht sich auf die räumlichen, architektonischen und institutionellen Rahmenbedingungen der Aufführung mitsamt den üblichen Konzertabläufen und Ritualen, die das Aufführungsereignis rahmen, es vom Leben abgrenzen und dadurch ,jenen Transitraum [erzeugen], in [dem] „Kunsterlebnis und (eigenes) Leben die Führerschaft wechseln“57. Ziel ist, eine bestimmte Spannung, Sensibilität und Erwartungshaltung zu erzeugen, um die Aufmerksamkeit und Konzentration für eine bestimmte Dauer auf das akustische Werk richten zu können. Beide „Grenzlinien“, die innere wie die äußere, werden in den Simultankonstellationen bei Cage überschritten und geöffnet. In einem Happening im öffentlichen Raum fällt die äußere Schließung, die Grenzziehung zwischen dem Werk und der (Um-)Welt weg. Im Concert for Piano and Orchestra dagegen gibt es unzählige verschiedene Ausführungsmöglichkeiten und damit eine Flexibilität bezüglich des inneren Abschlusses. Diese ist auch in einem Werk wie 4'33 gegeben. Zusätzlich treten hier die äußeren Rahmenbedingungen einer Aufführung, ebenso wie die Außenklänge eines Werks durch das „fehlende, innere“ leere Werk noch stärker ins Bewusstsein. Ähnlich wie bei Bildarbeiten von Ben Vautier (art) oder Imi Knoebel (Keilrahmen, 1968) die aus leeren an der Wand hängenden Rahmen bestehen, mutiert der schließende Rahmen zum Gegenstand der Kunsterfahrung. Die Rahmenbedingungen, die es für die Kunsterfahrung eines Werkes braucht, treten durch die Leere des Werks umso

\footnotetext{
$5^{2}$ Niklas Luhmann: Die Kunst der Gesellschaft, Frankfurt am Main: Suhrkamp, 1995, S. 53.

53 Ebd.

54 Ebd., S. 79.

55 Ebd., S. 83 .

56 Ebd., S. 61.

57 Mirjam Schaub: „Larger than life?!“, in: Uwe Wirth (Hg.): Rahmenbrüche Rahmenwechsel, Berlin: Kadmos, 2013, S. 179-197, hier: S. 179.
} 
stärker hervor und lassen die Korrelation zwischen den Innen- und Außenereignissen des Werks in den Vordergrund rücken. ${ }^{58}$

Aus dieser Perspektive scheint es ein naheliegender Schritt zu sein, ein musikalisches Werk nicht nur als implizit durchlässig für die Außenklänge, sondern auch als explizit durchlässig für das akustische Eigenleben eines anderen Werks zu betrachten. Die offene Form wird zum offenen Werk. Die zeitlichen, räumlichen und qualitativen Rahmensetzungen zwischen den Werken werden flexibilisiert und füreinander geöffnet, die Werk/Umweltverhältnisse verschoben. Die innere formale, identitätsstiftende und abgrenzende Rahmenlinie wird durchlässig für das Eigenleben eines anderen Stücks und mutiert zum Bindeglied zwischen dem Hier und dem Dort. Dagegen schafft eine Werkdifferenzierung nach innen neue Grenzen innerhalb des Werks und erzeugt neue Werk-Umwelt-Verhältnisse innerhalb einer gedachten Einheit.59

\subsection{Die Dialektik von Form und Offenheit bei Umberto Eco}

Während sich kaum ein Komponist von Poly-Werken, den ich befragt habe, auf John Cage berufen hat, gibt es zwischen Umberto Ecos Konzept der Offenheit, das er in seiner Schrift Das offene Kunstwerk ${ }^{60}$ entfaltet, und der Produktionsästhetik von Poly-Werken interessanterweise auffällige Schnittmengen. Das bedeutet nicht, dass Ecos Theorie die Komponisten bewusst geleitet hätte. Das wäre sehr unwahrscheinlich und wurde auch von keinem der Befragten thematisiert. Wahrscheinlicher ist es, dass - möglicherweise auch

$5^{8}$ Siehe auch: Anne Gilbert: „Leere Rahmen. Das Unsichtbare des Sichtbaren sichtbar machen“, in: Wirth (Hg.): Rahmenbrüche Rahmenwechsel, S. 217-237. Hier wird auch auf die Tradition leerer Ausstellungen hingewiesen, die die institutionelle Rahmung in der bildenden Kunst thematisieren. Beispiele sind die leere Ausstellung Le Vide von Yves Klein in einer Pariser Galerie 1958 oder auch die Ausstellung Von da an/A partir de là aus dem Jahre 1975 von Daniel Buren, der alle Kunstwerke aus dem Museum Mönchengladbach entfernen ließ. Auch die Berner Kunsthalle widmete sich 2009 einer großen Retrospektive leerer Ausstellungen.

59 Siehe dazu Armin Nassehi, Die Zeit der Gesellschaft. Auf dem Weg zu einer soziologischen Theorie der Zeit, Wiesbaden: VS Verlag für Sozialwissenschaften 2008 (1993), S. 238-245. Seine Ausführungen zum Zusammenhang zwischen Zeit und Gesellschaftsdifferenzierung im Kapitel „Systemdifferenzierung und Gleichzeitigkeit“ (S. 238-234) lassen sich für diesen Aspekt zum Teil auf simultane Werkkonstellationen übertragen: „So differenziert sich ein System in Teilsysteme aus, die füreinander Umwelt sind, wobei es sich bei dieser Umwelt um eine, innergesellschaftliche Umwelt handelt. [...] Ihre Teilsysteme dagegen erleben sich in einer kommunikativen Umwelt - und sind doch Systeme mit operativ geschlossener Autopoiesis." (S. 240 ff.)

6o Eco, Das offene Kunstwerk. 
in Abgrenzung zu Cage - eine bewusste oder auch unbewusste ästhetische Gegenposition eingenommen wurde, die auch noch mehrere Jahrzehnte nach Erscheinen von Ecos Schrift eine künstlerische Relevanz hat.

In groben Zügen zusammengefasst, unterscheidet Eco in seiner Theorie verschiedene „Intensitätsebenen “ von Offenheit ${ }^{61}$, die er graduell voneinander abgrenzt: Die Offenheit ersten Grades ist allen Kunstwerken immanent, denn auf einer rezeptiven Ebene ist jedes Kunstobjekt insofern offen, als es in seinem Sein immer auf eine theoretisch unendliche Vielzahl subjektiver Perspektiven trifft, die es erst vollenden würden. ${ }^{62}$ Eco spricht von einer "perzeptive $[n]$ Ambiguität" ${ }^{\prime 63}$ und bezieht diese Beobachtung vor allem auf den Akt der Rezeption durch den Empfänger der künstlerischen Botschaft. Die Offenheit zweiten Grades entwickelt diesen Gedanken weiter und formt ihn zum künstlerischen Programm in dem Sinne, dass es sich zwar um abgeschlossene Kunstwerke handelt, die „aber dennoch ,offen' sind für ständige Neuknüpfungen von inneren Beziehungen, die der Rezipierende im Akt der Perzeption der Reiztotalität entdecken und auswählen soll“64. Diese Ästhetik findet ihren konkreten Ausdruck in den sogenannten „Kunstwerke[n] in Bewegung“65, die den Gedanken der inneren Beziehungsvielfalt auf die innerformale Organisation eines Werks ausweiten und damit eine dritte Ebene der Offenheit verkörpern. Bereits auf der Stufe der Komposition wird nun statt eines einzigen festgelegten Verlaufs ein Möglichkeitsfeld geschaffen, das den ausführenden Musikern innerhalb eines vom Komponisten festgelegten Rahmens verschiedene Optionen bietet. Die Gestalt eines Werkes wird in der Aufführungssituation geformt. Damit wird die Zahl interpretativer Möglichkeiten nochmals gesteigert. Offenheit wird nun auch konzeptuell in das Werkobjekt integriert. ${ }^{66}$ Dieses Vorgehen richtet sich gegen Wiederholbarkeit, Gewohnheit und Eindeutigkeit zugunsten von Austauschbarkeit, Permutabilität und Mehrdeutigkeit. ${ }^{67}$ An die Stelle der Einsinnigkeit und des Absoluten tritt das

\footnotetext{
61 Ebd., S. 57 und S. 138 f.

62 Ebd., S. 3 .

63 Ebd., S. 50.

64 Ebd., S. 57.

65 Ebd., S. 42.

66 Das musikalische Werkobjekt durchläuft folglich zwei Interpretationsphasen. Eco versteht unter einem Interpretationsprozess sowohl das "passive“ Rezipieren als auch das „aktive“ Interpretieren. Er bezeichnet sie als „unterschiedliche Erscheinungen ein und derselben interpretativen Einstellung“" (Eco, Das offene Kunstwerk, S. 29).

67 Als Beispiele führt Eco hier die Mobiles von Alexander Calder, Kompositionen von Boulez, Stockhausen, Berio und Pousseur sowie Stéphane Mallarmés Livre an, ebenso Beispiele aus dem Industriedesign wie umbaubares und multifunktionelles Mobiliar und im Falle der Architektur die verschiebbaren Wände eines Gebäudes (ebd., S. 42 f.).
} 
Optionale, Relationale und Mehrfunktionale, das sich nicht mehr eindeutig bestimmen lässt. Eco schreibt das Streben nach einer programmatischen Offenheit den "modernen Poetiken“ zu.

Die Ergänzung der Werkversionen und die Unmöglichkeit, das Werk in seiner Gesamtheit gleichzeitig zu erfassen, entspricht dem Komplementaritätsmodell, das Eco nach naturwissenschaftlichen Beschreibungen Werner Heisenbergs und Nils Bohrs auf das Konzept offener Kunstwerke übertragen hat:68

„Von Mallarmés Livre bis hin zu den musikalischen Kompositionen, die wir untersucht haben, bemerken wir die Tendenz, das Kunstwerk so zu organisieren, daß keine Ausführung des Werkes mit einer letzten Definition von ihm zusammenfällt; jede Ausführung erläutert, aber erschöpft es nicht, jede Ausführung realisiert das Werk, aber alle zusammen sind komplementär zueinander, jede Ausführung schließlich gibt uns das Werk ganz und befriedigend und gleichzeitig unvollständig, weil sie uns nicht die Gesamtheit der Formen gibt, die das Werk annehmen könnte.“69

Der Rezipient eines offenen Kunstwerkes nimmt nur einen Ausschnitt der Möglichkeiten wahr: Die „unvollkommene Kenntnis eines Systems [ist] essentielle Komponente seiner Formulierung.“70 Eco verweist auf die Beziehung zu Aussagen, die in Bezug auf wissenschaftliche Erkenntnisse gemacht wurden, und zitiert Niels Bohrs Erkenntnis:

„Demzufolge kann das unter verschiedenen Versuchsbedingungen gewonnene Material nicht mit einem einzelnen Bilde erfaßt werden; es ist vielmehr als komplementär in dem Sinne zu betrachten, daß erst die Gesamtheit aller Phänomene die möglichen Aufschlüsse über die Objekte erschöpfend wiedergibt."71

\subsection{Die Offenheitskonzepte von Cage und Eco im Vergleich}

Der Begriff „offene Form“ in der Neuen Musik bezieht sich zunächst auf einen Paradigmenwechsel in der formalen Ästhetik, indem er das Beziehungsgeflecht sowohl quantitativ als auch qualitativ erweitert. Ein undifferenzierter

\footnotetext{
68 Eco, S. 49.

69 Ebd.

70 Ebd.

71 Niels Bohr: „Diskussion mit Einstein über erkenntnistheoretische Probleme in der Atomphysik“, in: Albert Einstein als Philosoph und Naturforscher, hg. von Paul Arthur Schilpp, Stuttgart: Kohlhammer, 1955, S. 115-15o, hier: S. 123.
} 
Gebrauch birgt die Gefahr eines unkritischen Umgangs mit dem Begriff wie die bereits angesprochene oberflächliche Ineinssetzung der Kategorien Form und Werk (vgl. Kapitel 1.2). Statt um die eine „offene Form“ handelt es sich vielmehr um verschiedene „Formen von Offenheit" - von denen auch der Werkgedanke betroffen sein kann und denen durchaus unterschiedliche Weltanschauungen zugrunde liegen können. In der Musik ist das Konzept der Offenheit als ästhetisches Programm im Verlauf des 20. Jahrhunderts effektiv auf drei verschiedenen Beziehungsebenen wirksam geworden:

1. in der Auflösung der eindeutig fixierten innerformalen Beziehungen und Verhältnisse eines Werks;

2. in der Auflösung eines eindeutigen Abgrenzungsverhältnisses zwischen Werk und kontextualisierender Umgebung und damit der Etablierung einer extra- oder interformalen Ebene, die sich mit der innerformalen Ebene verschränken kann;

3. in der Aufwertung der interpretativen Praxis.

Sowohl die Auflösung der eindeutig bestimmten innerformalen Beziehungen des "Werks" als auch die Auflösung der konventionellen extraformalen Beziehungen zur "Welt" brachten systematisch durchlässigere und flexiblere Relationsverhältnisse hervor. Für die werkinnere Formgestaltung konnten dies beispielsweise Austauschbarkeit, Verschiebbarkeit, freie Wahl formaler Abschnitte oder parametrischer Setzungen und Einbettung der Improvisation sein. Form wurde zunehmend zu einer Art Bausatz, aus dem die Interpreten die vorgegebenen Bausteine individuell zusammensetzen konnten.

Mit der Aufhebung einer eindeutigen Abgrenzung zwischen „Werk und Welt" weitete sich der Aktionsradius musikalischer Aufführungen aus. Bereits die Auflösung strenger frontaler Sitzordnungen im Konzertsaal, der Einbezug des Publikums, die Verlagerung des Konzertereignisses in den öffentlichen Raum oder die Integration von Umweltgeräuschen können einfache Mittel sein, um bestehende Ränder und Grenzen zu verwischen, da sie immer auf eine Veräußerlichung der Interaktionen zwischen den Teilnehmenden gerichtet sind und versuchen, die Kontextualisierung des Werkes bewusst zu gestalten. Diese verschiedenen Wahl- und Interaktionsmodi weiteten den Interpretationsradius der Musiker sowohl quantitativ als auch qualitativ aus und vergrößerten ihre Handlungsräume. Einerseits kamen neue Interpretationsebenen hinzu, auf denen der Interpret Entscheidungen und Individualisierungen vornehmen konnte, sei es die formale Anordnung von Abschnitten oder die individuell imperfekte Ausführung komplexer Partituren. Andererseits wurde ein erweitertes Engagement vorausgesetzt, das über den reinen und "schönen“ Vortrag hinausging und schließlich in die Performancekunst mündete. Nicht alle dieser Handlungsräume waren neu. 
Manche bildeten bereits einen selbstverständlichen Teil der Kompositionsund Interpretationspraktiken früherer Jahrhunderte. Im Zusammenhang des 20. Jahrhunderts erweiterten sie durch ihre Programmatik nicht nur die Werkbildung, sondern begründeten auch eine Reihe neuer Genres wie Konzept-, Klang-, Installations- oder Performancekunst.

Wie kein anderer Komponist vor und nach ihm hat Cage seine Stücke auch in simultanen Fassungen im Sinn gehabt. Schon aus diesem Grund ist sein Ansatz für das Thema relevant und voraussetzungsreich. Dennoch sind seine Werke auf eine ganz andere Art und Weise Ausdruck eines offenen Denkens und Vorgehens, als es im Poly-Werk der Fall ist. Dieses kann - im Gegensatz zu den Werken Cages - vor dem Hintergrund der Theoriebildung von Umberto Eco diskutiert werden. Um die unterschiedlichen Bedeutungsebenen des Offenen herauszuarbeiten und eine konstruktive formästhetische Verortung des Poly-Werks und der Simultanaufführung bei Cage vorzunehmen, lohnt sich ein direkter und überblicksartiger Vergleich zwischen den beiden unterschiedlichen Ansätzen.

Ecos Darstellung des „Offenen“ steht in vielen Punkten im Widerspruch zu den Aussagen, die Cage in seinen Schriften und Interviews gemacht hat. Cage ist politisch, bezieht die soziale Dimension mit ein, argumentiert religiös und beruft sich auf fernöstliches Denken und den Zen-Buddhismus. Die Theoriebildung von Umberto Eco stützt sich auf Beobachtungen, Analysen und Analogien. Sie spürt den kulturellen und historischen Bedingungen und dem Weltbild nach, die den offenen Formen in der Kunst zugrunde liegen. Um die Entwicklung der Kunst der Moderne nachzuvollziehen, ist sein Blick auch in die Vergangenheit gerichtet. Eco argumentiert auf der Basis naturwissenschaftlicher und informationstheoretischer Beschreibungsweisen und Analogien und mithilfe von Beispielen aus der modernen Physik, der Quantenphysik, der Metaphysik, der Kommunikationstheorie und der Semiotik. Eine vergleichende Reflexion beider Auffassungen und ihre Übertragung auf die kompositionstheoretischen Konzeptionsmöglichkeiten ist aufschlussreich für die Aufdeckung der zugrunde liegenden Weltbezüge. Zudem bestätigt sie, dass sich die Auflösung einer eindeutigen Werkvorstellung in der Mitte des vergangenen Jahrhunderts mitnichten einseitig als Negation des Werkbegriffs auffassen lässt. Sie führte vor allem zu einer Auffächerung der Möglichkeiten, den Werkbegriff weiterzuentwickeln.

Wie bereits mehrfach gesagt, besteht ein Hauptunterschied zwischen einer Simultanaufführung und einem Poly-Werk darin, dass die Simultanaufführung ein rein interpretativer und die Simultaneisierung im Poly-Werk ein kompositorischer Akt ist. Im ersten Fall müssen die Interpreten mithilfe ihrer Analysefähigkeit, ihres Wissens, ihrer Intuition, Fantasie und Erfahrung selbst 
herausfinden, welche Stücke sich mit anderen kombinieren lassen. Sie müssen Entscheidungen über die passenden Tempi treffen und Dauern und Ereignisverläufe der Stücke berücksichtigen, um zu einer neuen Form zu kommen. Die Simultaneisierung ist hier eindeutig Teil der Interpretation. Bei Cage sind die Simultanaufführungen zwar kompositorisch intendiert, jedoch gibt es keine eindeutigen Angaben zur Zusammenführung. Interpretation hat hier den Status einer sich von der Komposition emanzipierenden Praxis. Als solche vermag sie die ursprünglichen Intentionen eines Werks zu unterlaufen.

Es ist ein allgemeines Merkmal offener Kunstkonzepte, dass die interpretative Praxis eine Aufwertung gegenüber der Produktion erfährt und der Interpret und der Hörer sich vom Komponisten und seinem Werk emanzipieren. Jedoch kann diese Aufwertung mit unterschiedlich viel Spielraum für die Interpreten verbunden sein und dadurch unterschiedliche Konsequenzen auf das Verhältnis Komposition - Interpretation - Rezeption haben. Cage stellt die Getrenntheit der Elemente dieser dreistufigen klassischen Konstellation infrage..$^{72}$ Andererseits negiert er ihren natürlichen zielorientierten und linearen Zusammenhang in Bezug auf die musikalische Werkerfahrung.

„Ich habe einmal gesagt, Musik zu schreiben sei etwas anderes als Musik aufzuführen oder sich anzuhören. Das sind drei vollkommen verschiedene Dinge. Was man hört, was aus dem Geschriebenen entsteht, unterscheidet sich vollkommen von der Tatsache, daß ich es schreiben konnte."73

Dieser vermeintliche Widerspruch löst sich dann auf, wenn man Cages Kritik in beiden Fällen als Kritik an einer festgesetzten Hierarchie versteht. Um Hierarchiebildung zu umgehen, muss Beziehungslosigkeit hergestellt werden. Durch ein „zielloses Schreiben“, das er als „reines Schreiben“ anerkennt, würde auch eine „reine Aufführung“ und ein „reines Hören“ möglich, das jene Beziehungslosigkeit möglich macht. ${ }^{74}$

72 Siehe beispielsweise Cage im vierten Gespräch mit Daniel Charles in Cage: Für die Vögel, S. 153. Im Gespräch mit Richard Kostelanetz beschreibt Cage anhand einer stattgefundenen Aufführung an der University of Wisconsin, bei der er gemeinsam mit dem Publikum Klangrouten entwickelte und beging, einen möglichen Ansatz: „Aus diesem Grund versuche ich in meinen Aufführungen verstärkt auf eine Situation hinzuarbeiten, die den Unterschied zwischen Aufführenden und Publikum aufhebt. Dabei denke ich nicht an eine vom Komponisten einkalkulierte Publikumsbeteiligung. Vielmehr schwebt mir eine Musik vor, die sich aus den Aktivitäten der Interpreten und dem sogenannten Publikum ergibt." (Kostelanetz:John Cage im Gespräch, S. 101.)

73 Cage: Für die Vögel, S. 62.

74 Ebd., S. 62. 
Auch Eco geht von einer Interpretationsästhetik aus und wertet diese damit auf. Jedoch differenziert er zwischen diesen drei Stadien, indem er sie als drei perspektivisch unterschiedliche Ebenen des Kunstobjektes anerkennt. Das moderne Kunstwerk als Signifikant (Bedeutungsträger) enthält für ihn eine Mehrzahl von Signifikaten (Bedeutungen). Damit wird die Vielfalt der Deutungsmöglichkeiten bereits in den Werkgedanken integriert. An die Stelle einer „signifikanten Form“ tritt eine Form, die sich aus dem „Spiel der Signifikate ${ }^{\prime 75}$ ergibt. Diese Sicht entspricht auch dem Wesen des Poly-Werks. Auch hier integriert der Komponist mit den unterschiedlichen Kontextualisierungsmöglichkeiten von Anfang an mehrere Deutungsmöglichkeiten des musikalischen Textes und gibt diese an die Interpreten weiter. Sofern also das Verhältnis zwischen der schöpferischen und der interpretierenden Seite von Mehrdeutigkeit und Ambiguität geprägt ist, spiegelt Ecos „Modell des offenen Kunstwerks“ auch diese vielschichtige „Rezeptionsbeziehung “ wider $^{76}$ Darüber hinaus wird die interpretative Praxis im Poly-Werk bereits Teil der kompositorischen Praxis und verschränkt sich mit dieser, da der Komponist das Festgeschriebene durch die anderen Werke unterschiedlich kontextualisiert. Dadurch wird die Absolutheit des Werks und seiner Interpretation relativiert.

Aus Ecos Sicht ist das „Programm der Offenheit“ als Überbestimmung angelegt. Eine eindeutige Bestimmung wird dabei genauso vermieden wie Unbestimmtheit. Im Gegensatz dazu ist bei Cage Unbestimmheit oder auch indeterminacy das ästhetische Leitprogramm. Es wirkt hier als Möglichkeit der Auflösung von Bestimmung und Begrenzung. Um dies zu erreichen, strebt Cage nach Nichtintentionalität, die sich primär im Befolgen bestimmter äußerer Regeln, im Einbezug des Zufalls, im Befragen des I Ging etc. ausdrückt. Die Integration entsubjektivierter und damit objektivierter Strategien soll eine rezeptive Haltung, eine „entpersonalisierte[...] Komposition“"77 bewirken und die subjektive Intentionalität und Kontrolle des Komponisten über das Endresultat unterwandern. Auch simultane Verfahren wie ein "Musicircus“ oder eine konkrete Werküberlagerung sind bei ihm Ausdruck des Bedürfnisses, Ordnung, Linearität, Determination und die Intentionalität des Komponisten zu brechen (vgl. Kapitel 1.3.3). Dieser Gedanke markiert einen zentralen Gegensatz zu einer Produktionsästhetik die den absichtsvollen Willen und die Intentionen des Komponisten in den Mittelpunkt stellt. ${ }^{78}$ Aus Sicht von Eco

75 Vgl. hierzu Eco, Das offene Kunstwerk, S. 15.

76 Ebd., S. 15 .

77 Christoph Metzger: John Cage - abstract music. Zwölf Vorlesungen, Saarbrücken: Pfau, 2011, S. 31.

78 Für Martin Iddon markiert dieser Punkt den grundlegenden Unterschied zwischen der sogenannten „Darmstädter Schule“ und Cage: „The fundamental distinction, then, was not 
sollte der Komponist zwar außermusikalische Organisationsverfahren oder Zufallsprozesse integrieren, diese aber auch zu beherrschen lernen, um seine determinierende, bestimmende Kraft zu behalten. Damit ist er auf einer Linie mit Pierre Boulez, der vom „dirigierten Zufall“79 spricht. Der Komponist soll danach streben, Mehrdeutigkeit intentional zu gestalten, das Werk trotzdem zu einer organischen Einheit zu formen und die Kontrolle nicht vollständig abzugeben. Dabei wird der Dialektik von Information und Bedeutung oder von Qualität und Quantität auch wieder besondere Bedeutung geschenkt und sie als Problem diskutiert. Denn die Abkehr von der Eindeutigkeit hin zu einer mehrwertigen Ordnung bedeutet eben auch einen Zuwachs an Information mit einer Tendenz zum Rauschen und zur Unordnung. Eco unterscheidet zwischen

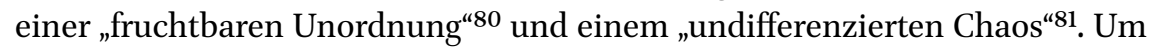
letzterem entgegenzuwirken, sei eine „beherrschte[...] Unordnung“ nötig, beispielsweise durch abgesteckte Möglichkeiten innerhalb eines abgegrenzten Rahmens und „Keime der Formhaftigkeit “82, die einem möglichen Chaos entgegenwirkten.

Eco grenzt das Programm der Offenheit nach zwei Seiten ab: Einmal gestaltpsychologisch von der "gute[n] Form“ mit der "geringste[n] Information“ und "größte[n] Redundanz“, die dem „,Zustand größter Wahrscheinlichkeit eines fluktuierenden Wahrnehmungsganzen “ 83 entspricht, sowie auf der anderen Seite von Willkür, Chaos, Beliebigkeit und Anarchie. Beide, Eindeutigkeit und Beliebigkeit (die keine Bedeutung hat), sind zwei Seiten einer Medaille, da sowohl Eindeutigkeit als auch Bedeutungslosigkeit das Aufkommen von Ambiguität verhindern. ${ }^{84}$

Die Prinzipien der Cage'schen Nichtintentionalität und Unbestimmtheit sind mit dem Poly-Werk nicht vereinbar. Ecos Argumentationslinie stimmt

between serial method and chance operations at all, but rather between Europeans, who wanted to be,composers' through the operations of their wills and compositional desires, and Americans, who were willing to allow music to occur unpurposively." (Martin Iddon: New Music at Darmstadt. Nono, Stockhausen, Cage, and Boulez, Cambridge: Cambridge University Press, 2013, S. 215.)

79 Boulez: Alea, S. 178.

8o $\quad$ Eco, Das offene Kunstwerk, S. 9.

81 Ebd., S. 13 .

82 Ebd.

83 Ebd., S. 15 o.

84 Vgl. hierzu auch Thomas Bauer: Die Vereindeutigung der Welt. Über den Verlust an Mehrdeutigkeit und Vielfalt, Stuttgart: Reclam, 2018, S. 29 f. Bauer unterscheidet zwei Möglichkeiten, Ambiguität zu verhindern: 1. die Eindeutigkeit und 2. den völligen Mangel an Bedeutung, sodass „alle Interpretationen gleich gültig“ sind und damit die Sache insgesamt bedeutungslos ist. 
insofern mit dem Poly-Werk überein, als ein einziges Werk immer auch mehrere Funktionen übernimmt und damit bereits auf der kompositorischen Ebene zu einer Überbestimmung und Mehrdeutigkeit des musikalischen Textes gelangt. Die sich ergebende Dichte der Überlagerung führt auch zu einer höheren Informationsdichte, basiert aber immer auch auf einer willentlich geformten Ordnung, welche Zufallselemente höchstens gezielt einkalkuliert, aber nicht die Kontrolle über das Endresultat aus der Hand gibt. Daher verkörpert das Poly-Werk weder die einfache "gute“ und leicht voraussehbare Form, von der Eco die "offene Form“ abgrenzt, noch ist es auf der anderen Seite Ausdruck einer "anarchischen“ Form.

Cage sieht sich selbst als Neuerer und seinen künstlerischen Weg als Gegenpol zur europäischen Tradition, Kultur und Werkästhetik. Eco hingegen leitet das Programm der Offenheit aus einem Traditionsstrang der europäischen Kultur ab, der vor allem eine Entwicklungslinie freiheitlichen Denkens abbildet. Offenheit ist ein Projekt der Moderne, das sich erstmals im Barock als Reaktion auf die kopernikanische Wende im 16. und 17. Jahrhundert ausdrückt, „weil sich hier zum erstenmal der Mensch der Norm des Kanonischen [...] entzieht und in Kunst und Wissenschaft einer in Bewegung befindlichen Welt gegenübersteht, die ein schöpferisch-erfinderisches Verhalten von ihm verlangt" ${ }^{485}$.

Aus dieser Traditionslinie heraus betrachtet Eco Kunst weiterhin als Komplement der Gesellschaft, die sie durch eine „bestimmte Disposition ihrer Formen ${ }^{486} \mathrm{zu}$ charakterisieren vermag: „Der eigentliche Inhalt des Kunstwerks wird somit seine Art, die Welt zu sehen und zu beurteilen, ausgedrückt in einem Gestaltungsmodus [...] $]^{487}$. Als „epistemologische Metapher ${ }^{488}$ spiegelt die Kunst die Realität und auch die Fortschrittlichkeit künstlerischen Denkens wider: "[...] der Komponist ist fortschrittlich in dem Maße, wie er auf der Formebene eine neue Art, die Welt zu sehen, durchsetzt [...] $]^{489}$ und als „offene Struktur [...] die Ambiguität unseres In-der-Welt-Seins reproduziert ${ }^{490}$. Das Verhältnis von Werk und Welt ist ein komplementäres, eine Gegenüberstellung, wobei die Weltsicht sich nach Eco primär über die Formgebung eines Werks artikuliert. Dieser Ansatz steht völlig konträr zum typischen Neue-Musik-Diskurs, der Fortschrittlichkeit in erster Linie über das Material definiert hat und lediglich die

85 Eco, Das offene Kunstwerk, S. 35. Ebenso führt Eco an anderer Stelle allerdings auch Gedichte von Petrarca als Beispiele offener Kunstformen an (S. 124 f.).

86 Ebd., S. 268.

87 Ebd., S. 271.

88 Ebd., S. 46.

89 Ebd., S. 269.

$90 \quad$ Ebd., S. 286. 
Negation der Form - parallel zur Negation der Werkkategorie - als Ausdruck für Fortschrittlichkeit interpretierte. ${ }^{91}$ Da es in vielen Poly-Werken Anhaltspunkte für ein Formdenken gibt, das auch als Ausdruck einer mehrdeutigen Weltsicht auslegbar ist - beispielsweise die mehrfache und polyvalente Einbettung des Einzelnen in ein funktional differenziertes System -, ist das Merkmal einer auf Ambiguität und Mehrdeutigkeit ausgerichteten Formendisposition einer der interessantesten Schnittpunkte zwischen den Poly-Werken und Ecos Theorie.

Die von Cage artikulierte Sicht hebt die Distanz zwischen Werk und Welt auf. Bereits die Überlagerung eines Werks mit seiner zufälligen akustischen Umwelt kann Cage zufolge eine Simultanaufführung sein (vgl. Kapitel 1.3.3). Cage strebt nach einer Aufhebung der in seinen Augen künstlichen (und ebenso institutionellen) Trennung zwischen Kunst und Leben. Beide sollten ineinander übergehen. „Ich glaube, die moderne Kunst hat das Leben zur Kunst gemacht, und jetzt finde ich es an der Zeit, daß das Leben [...] alles in Kunst verwandelt $[\ldots]]^{492}$ Das „Werk“ als isoliertes Pendant zur Welt erfährt auch so wieder eine Auflösung.

Bei Eco wird entsprechend seiner Argumentationslinie diese Auflösung nicht vollzogen, sondern er zielt auf eine „Dialektik zwischen Form und Offen-

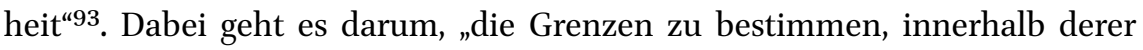
ein Kunstwerk die größte Mehrdeutigkeit verwirklichen und vom aktiven Eingriff des Konsumenten abhängen kann, ohne damit aufzuhören, Kunstwerk zu sein “94. Statt für die Negation spricht sich Eco für eine erweiterte und affirmative Auffassung der Werkästhetik aus und erkennt Form weiterhin als „Grundbedingung für die Kommunikation“95 an. Offenheit und Geschlossenheit stellen in seinem System keine einander ausschließenden Kategorien, keine Dichotomie dar. Stattdessen gibt es verschiedene Grade des Offenen in Bezug auf das Geschlossene, das weiterhin anerkannt wird. Auch damit entspricht sein Ansatz der Konzeption von Poly-Werken, denn bei ihnen erscheinen Geschlossenheit und Offenheit ebenfalls nicht als Dualität, sondern als gleichwertige und einander bedingende Formkategorien, die einander

$91 \quad$ Erst in den letzten Jahren sind einige Arbeiten erschienen, die diese Fehleinschätzung zu korrigieren versuchen oder alternative Sichtweisen und Zugänge zum Formbegriff vorschlagen. Siehe Holzer: Zur Kategorie der Form in neuer Musik, oder Cosima Linke: Konstellationen - Form in neuer Musik und ästhetische Erfahrung im Ausgang von Adorno. Eine musikphilosophische und analytische Untersuchung am Beispiel von Lachenmanns „Schreiben. Musik für Orchester“, Mainz: Schott, 2018. Kostelanetz: John Cage im Gespräch, S. 163 (nach Robin White/John Cage, Interview bei der Crown Point Press, View 1, Nr.1, Oakland, Point Publishers, 1978).

93 Eco, Das offene Kunstwerk, S. 129.

94 Ebd., S. 8.

95 Ebd., S. 182. 
nicht einfach negieren, sondern vor allem in ihrer Ausbalancierung präsent sind.

In einem Punkt stimmen Cage und Eco überein. Sowohl bei Cage als auch bei Eco geht die Öffnung des Werkkonzepts mit einer offenen geistigen Grundhaltung einher. Eco plädiert für einen „Menschentyp[...], der offen ist für eine ständige Erneuerung seiner Lebens- und Erkenntnisschemata, der produktiv an der Entwicklung seiner Fähigkeiten und der Erweiterung seiner Horizonte

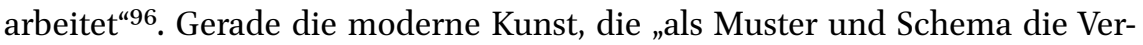
gänglichkeit der Modelle und Schemata erwählt ${ }^{497}$, wirke auf den heutigen Menschen stimulierend. Sie könne ihm in einer Welt, die permanent auf eine Übernahme von ",guten Formen “998 aus ist, „eine Möglichkeit zur Selbstfindung und Autonomie ${ }^{\prime 99}$ zeigen. Bei Cage artikuliert sich diese Haltung als Nichtintentionalität, die er auch als „response ability " ${ }^{100}$ bezeichnet. Es handelt sich um die Fähigkeit zu reagieren und empfänglich zu sein, durch Unbestimmtheit zu einer Offenheit und Neugier für Fremdes und Unbekanntes zu gelangen, die den eigenen Erfahrungshorizont übersteigt und für neue Erfahrungen bereit ist: „Ich glaube, wir müssen zu einer Erfahrung bereit sein, die nicht durch Verstehen, sondern durch Aufgeschlossenheit zustandekommt." ${ }^{\text {"101 }}$

Zusammenfassend lässt sich sagen, dass Offenheit und Geschlossenheit bei Cage als Dualismus auftreten, während Eco ähnlich wie Wölfflin (vgl. Kapitel 1.2) Offenheit als graduelle Modifikation des geschlossenen Werks ansieht. Bei ihm handelt es sich in erster Linie um eine innerformale Offenheit des geschlossenen Werks, da der Rahmen oder die "Werkgrenzen“ im traditionellen Sinn weiterbestehen. Dies entspricht auch der Anlage eines Poly-Werks: Aus der Perspektive der ganzen Werkentität handelt es sich um eine innerformale Flexibilität und Verschiebbarkeit, die sich allerdings hier auf konkrete gestaltete Werkstränge und nicht mehr nur auf einzelne Bausteine bezieht. Aus der Perspektive des einzelnen Werkstrangs sind die einzelnen Werke im Ganzen füreinander auch akustische Umgebungen, stellen eine Kontextualisierung dar, sodass es sich auch um interformale Beziehungen handelt, die auf die innerformalen zurückwirken können. Da diese allerdings immer den gleichen Wahrnehmungsmodus ansprechen und nie den medialen Rahmen des komponierten Werks verlassen, sind sie keine kontinuierliche

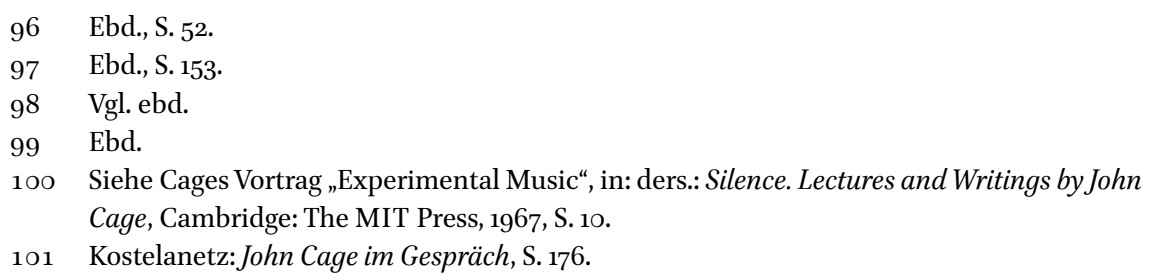


Öffnung zur Welt und zum Leben oder Fortsetzung derselben im Sinne von Cage. Das Poly-Werk ist weiterhin eindeutig von der Welt abgrenzbar, markiert eine Differenz, ist im Sinne von Ecos Theorie auch weiterhin ein Komplement der Welt, ein Spiegel zu ihr. Bei Cage wiederum greift diese innerformale Offenheit auch auf das Verhältnis zwischen Werk und Welt aus. Beides soll sich ineinander fortsetzen und ineinander übergehen.

Während der Begriff der Offenheit bei Cage sehr treffend mit Leere gleichgesetzt werden kann, die sowohl eine rezeptive Haltung als auch eine rezeptive Produktionsästhetik befördern soll, ${ }^{102}$ kann über Ecos offenen Formbegriff gesagt werden, dass er mehrere komplementäre Lösungen einschließt: „Offenheit und Dynamik eines Kunstwerks bestehen hingegen im Sich-verfügbarMachen für verschiedene Integrationen, konkrete produktive Ergänzungen, die es von vornherein in den Spielraum einer strukturellen Vitalität einfügen [...]." ${ }^{“ 103}$ Diese Aussage spricht in erster Linie eine aktive und dynamische Interpretationshaltung an. Vor allem das von Eco in die Diskussion eingeführte Komplementaritätsmodell, das besagt, dass keine einzelne Ausführung des Werks es in seiner Gesamtheit abzubilden vermag, schlägt eine weitere entscheidende Brücke zum Poly-Werk und stellt rückblickend die Möglichkeit bereit, simultane Integration, wie sie im Poly-Werk vollzogen wird, als auskomponierte Variante und Weiterentwicklung eines offenen, dynamischen und ambiguen Werkkonzepts im Sinne von Eco weiterzudenken.

Auch auf der interpretativen Ebene ist die Simultanaufführung näher bei Cage, das Poly-Werk dagegen näher bei Eco angesiedelt. Ist die Simultaneisierung bei Cage eindeutig eine rein interpretative Praxis, bleibt sie im Poly-Werk eine kompositorische Praxis. Dennoch weitet sich das interpretative Wirkungsspektrum aus. Einmal stellt das Poly-Werk für den Interpreten eine zusätzliche Herausforderung dar, da durch die verschiedenen Werkkontextualisierungen auch die Absolutheit einer Interpretation relativiert wird und eine Flexibilität erforderlich macht. Weitet man aber auch den Begriff des Interpretativen an sich, dann kann man außerdem sagen, dass der Komponist durch die verschiedenen Kontextualisierungsmöglichkeiten selbst ein Interpret seines Werkes wird.

102 Siehe beispielsweise Cage: Für die Vögel, S. 95, S. 184 f.; „Lecture on Something“, in: ders.: Silence. Lectures and Writings by John Cage, S. $129 \mathrm{f}$.

103 Eco, Das offene Kunstwerk, S. 56 . 
Cages Konzept eines „Musicircus“ wurde bereits 1753 von Joseph Haydn vorweggenommen. Haydn hatte den Einfall, mehrere Musiker am Tiefen Graben in Wien vor den Häusern und in den Ecken zu einem „Gassatim“-Konzert zu versammeln. Jeder Musiker war aufgefordert, das zu spielen, was er wollte. Das Konzert erregte damals schnell den Unmut der Anwohner und endete mit der Verhaftung des Paukers und eines Geigers. ${ }^{104}$ Olga Neuwirth beschreibt dieses Ereignis aus heutiger Perspektive als anarchisch, provokativ und herausfordernd und als Vorgriff auf die Schichtungsverfahren bei Charles Ives, ${ }^{105}$ von dessen Vater, dem Kapellmeister George Ives, ebenfalls überliefert ist, dass er einmal zwei Blaskapellen aneinander vorbeiziehen ließ und sich an den aufeinanderprallenden Klängen freute. ${ }^{106}$ Die Anekdote erinnert ebenso an Mahler, der einmal auf einem Jahrmarkt die durcheinanderklingende Klangkulisse als Polyphonie bejubelt haben soll. Von anderen Komponisten ist Ähnliches überliefert. Den jungen Haydn scheint die Aussicht auf ein unkalkulierbares mehrstimmiges Spektakel, das einer ordnungsstiftenden Kraft entbehrte und sich dem fixen Rahmen des institutionalisierten Konzertbetriebs entzog, jedenfalls schon damals begeistert zu haben. Derlei Aktionen im öffentlichen Raum greifen in einer sehr direkten und unmittelbaren Form die Lebendigkeit des akustischen Nebeneinanders der Straße, der Marktplätze oder anderer öffentlicher Plätze auf. Die Piazza San Marco ist dafür berühmt. Hier spielen drei Kapellen gleichzeitig verschiedene Stücke und Programme. Die Gleichzeitigkeit nimmt man am besten von der Mitte des Platzes aus wahr.

Wohnte Aktionen dieser Art früher ein subversiver Akt der Rebellion inne, haben in jüngster Zeit Veranstalter die Simultanaufführung für großformatige und aufsehenerregende monumentale Konzertevents entdeckt. An die Stelle von Spontanität und Unverbindlichkeit tritt nun eine präzise dramaturgische Planung im Vorfeld. 2016 präsentierte das Festival Wien Modern unter der Mitwirkung von fünfzehn Streichquartetten sämtliche Streichquartette von Schostakowitsch simultan und sich gegenseitig überlappend in einem Konzertsaal. ${ }^{107}$ Die sich zeitlich überlagernde Aufeinanderfolge wurde im Vorfeld genau kalkuliert (vgl. Abb. 1).

104 Siehe auch Howard C. Robbins Landon: Haydn. chronicle and works, in five volumes, London: Thames and Hudson, 1976-1980, Bd. I, S. 64.

105 Siehe http://www.olganeuwirth.com/text26.php (letzter Aufruf am 13.3.2020).

106 Siehe Alex Ross: The Rest is Noise. Das 20. Jahrhundert hören, München: Piper, 2009, S. 153.

107 Siehe auch https://www.mdw.ac.at/schostakowitsch/ (letzter Aufruf am 13.3.2020). 


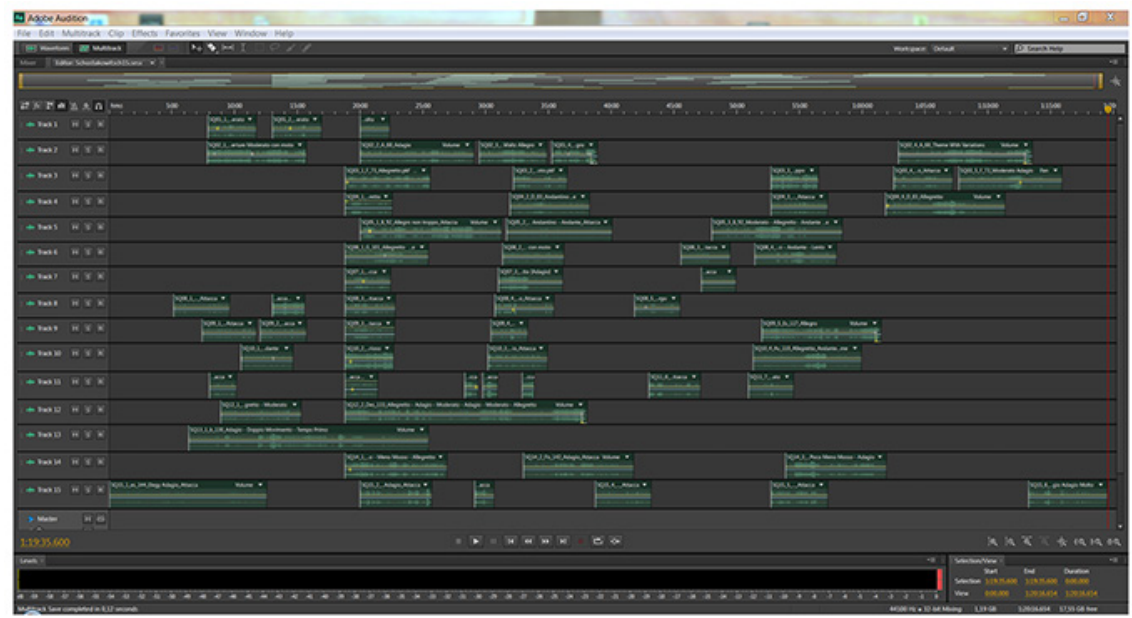

Abb. 1 Übersicht über die zeitliche Verteilung der fünfzehn Schostakowitsch-Quartette über den Gesamtablauf. Screenshot der Audiosimulation. Mit freundlicher Genehmigung von Wien Modern. ${ }^{108}$

Der technische Stand macht es möglich, auch räumlich weit auseinanderliegende Aufführungsorte miteinander zu verbinden, die verschiedenen Aufführungen perfekt zu synchronisieren und an einem Ort simultan für ein Publikum erlebbar zu machen. Zum 30o-jährigen Jubiläum der Stadt Karlsruhe fand 2015 ein Orgelwerk mit dem Titel Organum von Wolfgang Mitterer als Simultankonzert seine Uraufführung. Das Spiel von acht Organisten verschiedener Kirchen in Karlsruhe und den Partnerstädten wurde über eine Satellitenverbindung zeitgleich in den Lichthof der Hochschule für Gestaltung übertragen und dort in einer für die Zuhörer begehbaren Klang- und Videoinstallation zusammengeführt. ${ }^{109}$ Die einzelnen Stränge wurden von Mitterer auf dieses Ereignis hin konzipiert. Sie übersteigen daher den Begriff einer Simultanaufführung im Sinne einer reinen Aufführungspraxis. Viel wichtiger ist hier der Aspekt der telematischen Performancepraxis, die mittels der sich immer weiter entwickelnden Kommunikationstechnologien auch immer besser synchronisierte und inszenierte Performances hervorbringt. Es liegt auf der Hand, dass die dadurch mögliche Überwindung großer räumlicher Distanzen, die unterschiedliche Räume an einem Ort zusammenführt,

108 Aus dem „Letter and Overview of Cues“, unveröffentlichtes Dokument zum Konzertablauf (Version 25.10.2016).

109 Siehe auch https://www.film-tv-video.de/productions/2015/11/14/simultankonzert-achtorgeln-ein-werk-acht-organisten/ (letzter Aufruf am 13·3.2020). 
zukünftig auch für die Simultanaufführung programmatisch sein wird. Die Zusammenführung verschiedener historischer Zeitspannen zu einer Zeit findet in der Zusammenführung weit voneinander entfernter Räume an einem Ort ihre Fortsetzung.

So erregte in der Theaterwelt beispielsweise die Simultanaufführung Die Parallelwelt des Regisseurs Kay Voges, die 2018 am Berliner Ensemble und dem Schauspiel Dortmund ihre Premiere erlebte, großes Aufsehen. In der Aufführung spielen zwei Ensembles zeitgleich den Lebensweg eines Menschen in umgekehrter Abfolge: Hier setzt das Stück mit der Stunde der Geburt, dort mit der des Todes ein. Beide Bühnen sind über einen Videostream miteinander verbunden. Die reale Bühne präsentiert sich als realer Nebenraum zur Videoleinwand, die die Inszenierung aus der anderen Stadt zeitgleich überträgt. Beide Bühnen sind so für den Zuschauer parallel sichtbar. Der Verlauf des Theaterabends ist vom Nebeneinander beider Erzählstränge geprägt, die sich in der Lebensmitte zum Hochzeitsereignis (dem Moment der Vereinigung) überkreuzen. Plötzlich kommt es zu Interaktionen, Verwicklungen und Verwirrungen zwischen den Darstellern im Hier und Dort. Das Theaterstück existiert lediglich als Simultanversion. Die beiden Hälften für sich genommen wurden nicht einzeln aufgeführt. Voges bezieht sich außer auf eine Reihe von philosophischen, naturwissenschaftlichen und gesellschaftlich-sozialen Phänomenen und Gegebenheiten unter anderem auf den von Ernst Bloch (1885-1977) geprägten Begriff der "Gleichzeitigkeit des Ungleichzeitigen“, der für das parallele Nebeneinander und die Überkreuzung verschiedener Lebensstile und Weltanschauungen sowohl in der Gesellschaft als auch im einzelnen Individuum steht. ${ }^{110}$

Auch in der Popkultur gibt es im Genre des Mashups und der aus Coverversionen hervorgegangenen Remixkultur zahlreiche Beispiele für Fusionen einzelner Poptitel und -alben. Eines der bekanntesten Beispiele stammt von Danger Mouse (Brian Burton), der die A-cappella-Versionen des Black Album (2003) von Jay Z mit bearbeiteten Instrumentalspuren des White Album (1968) der Beatles zum Grey Album (2004) verband. Meistens werden im Titel des dritten neuen Songprodukts die ursprünglichen Interpreten durch „vs.“ (= versus) miteinander verbunden, also beispielsweise Jay Z vs. Beatles. Dadurch drückt sich bereits die intendierte „bipolare Konfrontation zweier Künstler“111 aus.

110 Siehe Programmheft zur Aufführung, 2018.

111 Frédéric Döhl: Mash Up in der Musik. Fremdreferenzielles Komponieren, Sound Sampling und Urheberrecht, Bielefeld: Transcript, 2016, S. 81. 
Beim Basic Mashup handelt es sich immer um ein Sampling einzelner isolierter Samples oder Spuren des Ganzen. In der Regel ist das Mashup ein Mix einer vokalen Tonspur des einen Songs mit der instrumentalen Tonspur eines anderen Songs, wobei beide Spuren auch bearbeitet werden können. Die vokalen Tonspuren sind oft Raps, was die harmonische Zusammenführung beider Songs leichter macht.

Demgegenüber rekontextualisiert der Zürcher Künstler Peter Tillessen unter dem Motto Whatever ${ }^{12}$ tatsächlich die kompletten Popsongs, indem er sie als Cover Mashup simultan übereinanderschichtet.13 Dafür wurden 3400 Songs der Rock- und Popgeschichte analysiert, in eine Datenbank eingeführt und auf ihre harmonischen Gemeinsamkeiten hin ausgewertet. Ausgewählt wurden Songs, die dasselbe harmonische Gerüst teilen und sich aufgrund der harmonischen Übereinstimmungen für eine Songpaarung eignen. Beispiele sind Frankie von Connie Francis (1959) kombiniert mit I was the one von Elvis Presley (1956), Let it be (1969) von den Beatles und Bob Marleys Three Little Birds, Stay von Maurice Williams (1960) und The Last Kiss von Pearl Jam (1961), So lonely von The Police (1978) und With or without you von U2 (1987). Durch die harmonisch-strukturellen Übereinstimmungen ergänzen sich die ursprünglich einander fremden Songs zu einer reizvollen Duokonstellation. Der differente Höreindruck der Songpaare, die Clemens Krümmel als "musikalische Vexierbilder" bezeichnet, ${ }^{114}$ entspringt vor allem aus der Vertrautheit mit den akustischen Originalen und entsteht in dem spezifischen Transitraum, der zwischen den beiden Singles angesiedelt ist. Trotz des kontrolliert-systematischen und auf Harmonie und Konsens ausgerichteten Auswahlverfahrens öffnet sich im Dazwischen der vertrauten Songstrukturen ein Raum für Zufallselemente und Unvorhersehbares, der aus dem nichtkalkulierten Aufeinanderstoßen der verschiedenen Melodien, Rhythmen und Texte hervorgeht. Tillessen knüpft mit Whatever (engl. = was auch immer) explizit an die Tradition des in der Renaissancezeit entstandenen und im Barock beliebten Quodlibets (lat. = wie es beliebt) an, bei dem ebenfalls verschiedene Lieder mit identischen harmonischen Akkordfolgen simultan kombiniert werden konnten. Ein bekanntes Beispiel aus dieser Zeit ist Ludwig Senfls Kombination der Volkslieder Ach Elslein, liebes Elselein und Es taget vor dem Walde aus dem Jahre 1544. Es gibt viele andere Beispiele auch

\footnotetext{
112 Siehe https://www.tillessen.info/whatever (letzter Aufruf am 13.3.2020).

113 Eine Darstellung des Projekts aus verschiedenen Perspektiven bietet der Band Whatever. Über doppelte Musik, hg. von Tania Prill und Peter Tillessen, Leipzig: Spector Books, 2020.

114 Clemens Krümmel: „Der Popsong und sein Double. Zu Peter Tillessens Quodlibets“, in: Whatever, S. 45-53, hier: S. $5^{2}$.
} 
für Kanonquodlibets, die verschiedene Kanons parallellaufen lassen. Gerade an bekannten Beispielen mit einer tonalen Basis lassen sich durch simultane Überlagerungstechniken, die den harmonischen Verlauf berücksichtigen, reizvolle Kontextualisierungen erzeugen, die das einst Vertraute in einem neuen Licht erscheinen lassen können.

Tillessen dachte die Idee noch weiter und schichtete in Algo sowohl alle Präludien als auch alle Fugen des Wohltemperierten Klaviers von Johann Sebastian Bach übereinander. Die dabei entstehende auf Vermassung und Verdichtung ausgerichtete Klangtotale, in der die einst individuellen Fugencharaktere vom Klangkontinuum vollständig absorbiert werden, lässt sich treffenderweise als jene „vibrierende ,Nicht-Figur' ' beschreiben, die John Cage im Gespräch mit Daniel Charles ${ }^{115}$ beschwört (vgl. Kapitel 1.3.3) und die aus ebenjenem Umschlag der Linearität in die Nichtlinearität hervorgeht.

Die Möglichkeit der wirklich "massenhaften“ Akkumulation präexistenter Songs und Alben wurde von diversen Komponisten und Künstlern elektroakustischer Musik und der Konzeptkunst recht ausgiebig betrieben. Im Mittelpunkt steht hier der Umschlag der Musik und der Werke in das Stadium des Rauschens. Der Komponist Marko Ciciliano verarbeitete in seinem Pop Wall Alphabet 26 Alben der Popmusikgeschichte nach einer einheitlichen Systematik, indem er sämtliche Songs eines Albums sowie ihre spektralen Freezes in einem zweiteiligen Prozess des Ab- und Aufbaus zu einem NoiseBand übereinanderschichtete. Das Verfahren ist für alle Alben gleich. Die Qualität des resultierenden Noise-Bands ist aber albumspezifisch und sowohl von musikalischen Parametern als auch den akustischen Parametern der Studioarbeit geprägt.

In der musikalischen Konzeptkunst gibt es seit den 7oer Jahren mehrere Beispiele von Werken, für die bekannte Meisterwerke der klassischen Musik zum Rauschen aufaddiert wurden und sich gegenseitig annullieren. Ihre Transposition in den Status einer reinen Materialschicht geht mit einer Neutralisierung ihrer Charakteristika einher und macht das Material offen für den folgenden Transformationsprozess: Aus horizontal-geschlossenen Werkverläufen werden statisch-vertikal kondensierte Klangobjekte. Deren neue Charakteristika, sei es als akustisches Rauschband oder als Klangsäule, sind primär von den verwendeten Verfahren der Überlagerung und sekundär von der Wahl der verwendeten Musikwerke geprägt. Der Prozess vom Werk

115 Siehe Cage: Für die Vögel, S. 251. 
zum Klangobjekt markiert einen qualitativen Umschlag in der Form- und Werksubstanz. ${ }^{116}$

Der Komponist Peter Ablinger $\left({ }^{*}\right.$ 1959) zerlegte in den 8oer Jahren im Studio alle neun Symphonien von Beethoven in 40-sekündige Abschnitte (Weiss/ Weisslich 22) und überlagerte diese simultan zu einem Rauschen. Dasselbe machte er mit den Symphonien von Haydn, Mozart, Beethoven, Schubert, Bruckner und Mahler. Sechs- bis achtstündiges symphonisches Material wird in 40-Sekunden-Einheiten geteilt, und diese Einheiten werden simultan überlagert. Diese Arbeit ist Teil des Zyklus Weiss/Weisslich, der sich in verschiedenen Studien mit den unterschiedlichen Klangqualitäten des Rauschens auseinandersetzt. Ablinger bezog sich mit dieser Arbeit auf eine Aussage von John Cage, ${ }^{117}$ der die Frage, ob er sich vorstellen könnte eine BeethovenSymphonie zu dirigieren, bejaht hatte unter der Voraussetzung, alle gleichzeitig dirigieren zu können. ${ }^{118}$ Cage wiederum verweist in einer Fußnote zu dieser Aussage ${ }^{119}$ auf den Komponisten Hal Freedman, der im Elektronischen Studio der Yale-Universität 1974-1975 in Ring précis alle Teile des Ring-Zyklus von Wagner und in einer weiteren Arbeit Précis 2 alle Streichquartette von Bartók übereinanderlegte. ${ }^{120}$

Ein weiteres radikales Beispiel simultaner Überlagerung unternahm der Komponist Nick Fells, der für das Stück Two - Capriccio aus Other Islands ${ }^{121}$ verschiedene Capriccios von Paganini übereinanderschichtete. Mithilfe eines Bildbearbeitungsprogramms legte Fells die einzelnen Capriccios in einer Bilddatei exakt übereinander, arbeitete dabei aber mit unterschiedlicher Deckkraft innerhalb der Graustufenskala. Die Notation wird angenähert an

116 Auch die Clusterbretter. Objekte für ein Klavier (1996) der Künstlerin Dodo Schielein fallen in diese Kategorie. Die Clusterbretter umfassen die Länge einer Klaviatur und können alle vorkommenden Töne einer von Schielein ausgewählten bekannten Komposition anschlagen, zum Beispiel des ersten Satzes der Pathetique von Beethoven. Je nach Kompositionsvorlage unterscheiden sich die resultierenden Clusterklänge in ihrer Farbe und Anschlagsform (das Debussy-Brett wird beispielsweise arpeggiert angeschlagen). Im Werkschaffen von Robert HP Platz findet sich auch eine vertikale Kondensation, die als einzelne Klangsäule den horizontalen Werkverlauf des Orchesterstücks Weiter in einem zweiten Orchesterstück Turm, das aus einem einzigen 4/4-Takt besteht, extrem verdichtet. Hier liegt allerdings kein technisch neutrales Verfahren zugrunde, sondern eine kompositorische Eigenbearbeitung.

117 Peter Ablinger: „Das Alte im Neuen. Über den Umgang mit musikalischer Weltliteratur in der Musik des 2o. Jahrhunderts“, Radiovortrag vom 7.12.1991, Deutschlandsender Kultur, https://ablinger.mur.at/docs/altneu.pdf (letzter Aufruf am 27.4.2020).

118 Siehe Cage: Für die Vögel, S. 113 .

119 Ebd.

120 Diese Arbeit erschien bei dem Label Opus One 1983 als LP.

121 Other Islands ist für Sopransaxophon, Violine, Klavier und Elektronik geschrieben. 
ein „bildliches Rauschen“, auf das der ausführende Musiker individuell zu reagieren hat (vgl. Abb. 2).
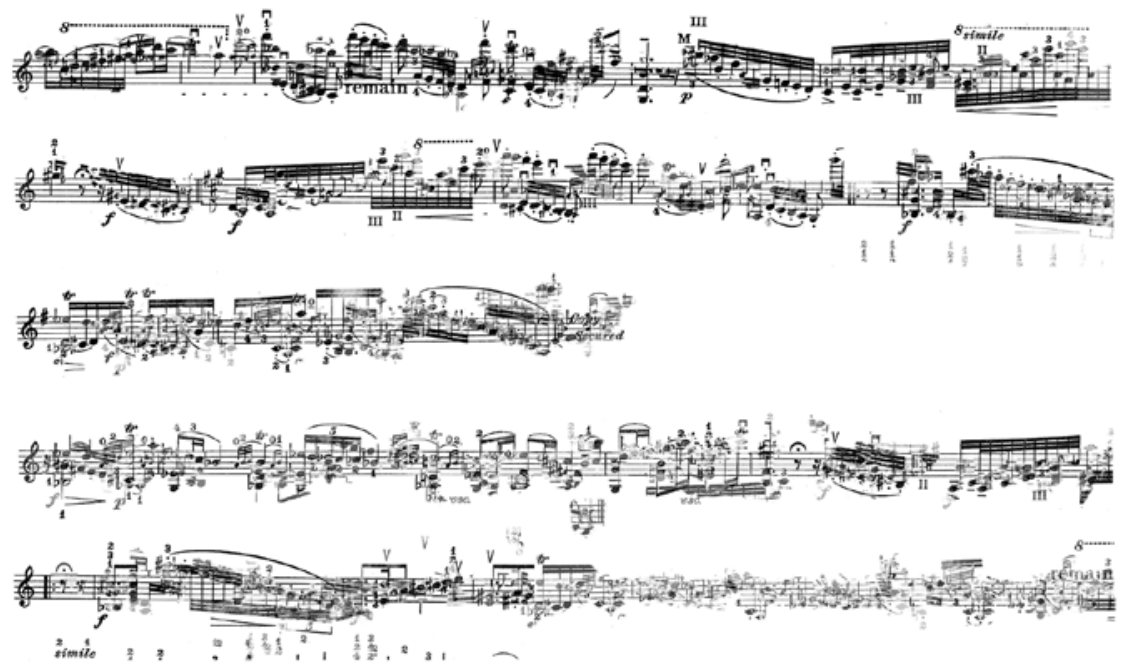

Abb. 2 Nick Fells: Other Islands (Ausschnitt) für Violine, 2009. Simultane Überlagerung verschiedener Capriccios von Paganini. Mit freundlicher Genehmigung des Komponisten. 


\title{
Im Delta des Poly-Werks - eine Annäherung
}

\begin{abstract}
„Luigi Nono äußerte einmal wie beiläufig $\mathrm{zu}$ seinem Streichquartett, daß diese Musik so erklingt und erklingen soll, wie er sie niedergeschrieben hat - daß sie aber auch eine ganz andere sein könnte ... Darin zeigt sich nicht nur der Gedanke des Fragmentalen einer einmal festgeschriebenen Gestalt, sondern ein grundsätzliches Infragestellen des Opus perfectum, verglichen mit den Ansätzen eines John Cage, aber in einer anderen utopischen Richtung."1
\end{abstract}

(Klaus Huber)

Während das Spektrum der Simultanaufführungen, wie bereits dargestellt, von losen und unverbindlichen Schichtungen verschiedener Werke im Sinne eines "Circus“ bis zu konkret inszenierten Verknüpfungen verschiedener Werke reicht und sich damit immer im Rahmen einer additiven Aggregation bewegt, sind die formalen Möglichkeiten komponierter Werkkopplungen vielfältiger gelagert. Wie auch die Simultanaufführungen sind komponierte Werksimultaneisierungen kein ausschließlich neues Phänomen des 2o. oder 21. Jahrhunderts, sondern lassen sich weiter zurückverfolgen. Der italienische Komponist Pietro Raimondi (1786-1853) schrieb bereits im 19. Jahrhundert groß angelegte Werke, die einzeln oder gleichzeitig aufgeführt werden konnten. ${ }^{2}$ Die 1948/49 von Darius Milhaud komponierten Streichquartette Nr. $14 \& 15$ sind wohl das erste Werkpaar, das sowohl eine singuläre als auch eine simultane Aufführung ausdrücklich vorsieht und damit zeitlich noch vor den Simultaneisierungen von John Cage datiert ist. In den letzten vierzig Jahren sind zahlreiche Kompositionen, beispielsweise von Klaus Huber, Adriana Hölszky, Chaya Czernowin, Julio Estrada oder Georg Friedrich Haas, entstanden, bei denen auf sehr unterschiedliche Weise die eigenen Werke der Komponisten entweder durch andere eigene Werke simultan kontextualisiert

1 Klaus Huber/Max Nyffeler (Hg.): Umgepflügte Zeit. Schriften und Gespräche (= Edition MusikTexte, Bd. 6), Köln: MusikTexte, 1999, S. 443.

2 Genauer: sechs Fugen, zwei Messen, drei Oratorien, zwei Opern. Auch im Finale des ersten Akts des Don Giovanni von Wolfgang Amadeus Mozart gibt es eine berühmte Tanzstelle, die drei verschiedene Tänze übereinanderlegt. 
oder umgekehrt geschlossene Werkeinheiten neu aufgespalten werden und so zu einer Koexistenz verschiedener Perspektiven gelangen. Damit umfasst die "Geschichte“ der Werksimultaneisierungen im 20. und 21. Jahrhundert mittlerweile einen Zeitrahmen von siebzig Jahren. Während das Aufbrechen der geschlossenen zur offenen Form von einem regen Diskurs begleitet war, wurde die Entwicklung des Poly-Werks nicht bewusst gefördert oder vorangetrieben. Sie fand abseits von Moden, Trends, Strömungen oder Debatten des Neue-Musik-Diskurses statt. Das sich zusammenfügende Gesamtbild ist das Resultat einer weitgehend unbewussten Entwicklung. Wenige Komponisten wie Claus-Steffen Mahnkopf oder Robert HP Platz thematisierten ihre Ansätze auch schriftlich, jedoch immer nur in Bezug auf das eigene künstlerische Werkverständnis. Aus diesem Grunde ist eine zusammenfassende theoretische und systematische Betrachtung überfällig.

\subsection{Die konzeptuelle Weiterentwicklung von Polyphonie und Werk im Poly-Werk}

Wie bereits in der Einleitung dargestellt, wurde der Begriff des „Poly-Werks“ 1990 von Claus-Steffen Mahnkopf in seiner Schrift „Kundgabe. Komplexismus und der Paradigmenwechsel in der Musik" eingeführt. ${ }^{3}$ Das Präfix "poly“ ist vor allem aus dem Kontext der Polyphonie vertraut. Während "poly“ erst einmal nur "mehr" meint, drückt der Begriffskontext „Polyphonie“ etwas über das Verhältnis der Dinge zueinander aus. Im Zusammenhang mit der Organisationsform des Kontrapunkts impliziert er eine simultane Verbindung selbstständiger, nach Unabhängigkeit strebender Linien und das sich daraus ergebende Spannungsverhältnis zwischen unabhängiger Linearität und vermittelnder Vertikalität.

Die Idee, ein Werk mit einem zweiten Werk zu synchronisieren, sodass ein drittes neues Werk entsteht, obwohl die Einzelwerke auch weiterhin unabhängig davon existieren, greift auch die alte polyphone oder kontrapunktische Idee, die eine lange Geschichte hat, auf faszinierende Weise wieder auf. Folglich ist auch der Begriff des Poly-Werks von der Vorstellung eines Weiterdenkens von Polyphonie auf formal-werkhafter Ebene geprägt. Mit der zunehmenden schriftlichen Auskomposition von Werksimultaneisierungen entstanden, dient er als Modell für die Übertragung divergierender Linienverläufe auf die Metaebene der Werkverläufe. Der Komponist Klaus Huber, in dessen Schaffen seit den 7oer Jahren auch Poly-Werke einen Platz haben,

3 Mahnkopf: „Kundgabe“. 
zieht eine direkte Verbindung zwischen Kontrapunkt und Formgestaltung und plädiert für einen erweiterten Begriff von Polyphonie: Eine „weitere Stufe von Kontrapunkt ist in diesem Sinne der formale Kontrapunkt, sozusagen ein FeldKontrapunkt oder Schichten-Kontrapunkt. Das alles kann Polyphonie sein.“4

Ein erweiterter Polyphoniebegriff erstreckt sich ebenso auf andere Anwendungen. Begriffe wie Polytonalität, Polymetrik, Polystilistik, Polyrhythmik oder Polytempo sind vertraute Kategorien, wenn es um Anordnungen geht, die den Zusammenfall des Verschiedenen ermöglichen. Claus-Steffen Mahnkopf entwickelte gar eine ganze Typologie von Polyismen, die Polymorphie, Polyprozessualität, aber auch Polyvektorialität und Polykonzeptualität ${ }^{5}$ umfasst und auf deren höchster Stufe die Kategorie des Poly-Werks als „Dissoziation des in sich geschlossenen und integralen Werks" ${ }^{\text {“6 }}$ steht. Der zugrunde liegende Leitgedanke entspricht der "Dissoziation musikalischer Diskursivität".7 Als rein satztechnische Kategorie ist Polyphonie für Mahnkopf die Dissoziation von Linien. Polymorphie definiert er als die Dissoziation von Gestalten, Polyprozessualität als die Dissoziation formaler Prozesse. Als Polyvektorialität beschreibt er die Dissoziation kompositorischer Techniken, und die Polykonzeptualität betrifft für ihn die Ebene der Semantik. Mahnkopf spricht von einem ideellen Splitten des Werks in mehrere Werke. Mündet die ideelle Splittung auch in eine materialisierte Werksplittung, ist der Fall eines Poly-Werks gegeben. ${ }^{8}$

Das Poly-Werk erscheint hier als letzte Steigerung eines kontrapunktischen Denkens, das sich in der Moderne mit den Worten Klaus Hubers als „Dialektik von materialen Möglichkeiten“9 ${ }^{9}$ zeigt. Das Prinzip „Note gegen Note“ wird zum „Werk gegen Werk“. Dazwischen existiert eine Skala polyistischer Varianten, die die verschiedenen Kategorien der Komposition einschließt und in vielen Fällen als Mittel bewusst eingesetzt wird, um die Stücke in ihrer Identität und Individualität einander noch markanter gegenüberzustellen. Die Relation dissonanter versus konsonanter Bewegungen findet ihren Ausdruck in der komplexen Wechselbeziehung synchroner und asynchroner Prozesse. Das schließt die Möglichkeit ein, die Verläufe der verschiedenen Parameter einer

4 Klaus Huber: Von Zeit zu Zeit. Das Gesamtschaffen. Gespräche mit Claus-Steffen Mahnkopf, Hofheim: Wolke, 2009, S. 155 .

5 Vgl. Mahnkopf: „Kundgabe“, S. 22.

6 Claus-Steffen Mahnkopf: „Theory of Polyphony“, in: ders. (Hg.): Polyphony \& Complexity (= New Music and Aesthetics in the 21st Century, Bd. 1), hg. von Claus-Steffen Mahnkopf, Hofheim: Wolke 2002, S. 38-53, hier: S. 49 .

7 Vgl. Mahnkopf: „Kundgabe“, S. 21 oder auch Kritik der Neuen Musik, S. 118.

8 Vgl. Mahnkopf: „Theory of Polyphony“, S. 47-5o.

9 Huber: Von Zeit zu Zeit, S. 156. 
Komposition auch gegeneinanderzusetzen, sie aneinander brechen zu lassen, sie zu enthierarchisieren, um jegliches gemeinsames Streben nach einer Synthese und einer vereinheitlichten Syntax auszuhebeln. ${ }^{10}$ Dieser Ansatz integriert Verfahren, die vor allem das Nebeneinander, das Differente, die Unabhängigkeit der Ereignisse ermöglichen und betonen. Zum ästhetischen Ideal der Polyphonie in der europäischen Tradition verhält er sich allerdings konträr, da dort der Entwurf der einzelnen Stimmen immer im Hinblick auf die Bildung einer Einheit gerichtet war. Musikalische Ereignisse und Entwicklungen wurden in einer mehrstimmigen Anlage so geplant und verknüpft, dass sie in der vollkommenen Synthese aufgingen. Der Kontext des Poly-Werks dagegen ermöglicht es ebenso, Kompositionen zu schaffen, die in ihrem Zusammengang in eine gebrochene Synthese münden. Ein derart erweitertes polyphones Denken fungiert hier in erster Linie als gemeinsamer Rahmen, der die Wahrnehmung des Verschiedenen ermöglicht und in unterschiedlichen Abstufungen eine formale, materielle und organisatorische Verbindlichkeit erzeugt - im Gegensatz zur Schichtung als pluralistischem Übereinander heterogener Stücke und Materialien ohne intendiertes Konnektiv. Wie bei einem rein polyphonen Hörerlebnis (z. B. einer Fuge) oszilliert der Hörer in unterschiedlichen Graden und je nach Exposition der Stimmen zwischen dem selektiven Verfolgen des einzelnen Werkverlaufs und dem Gesamteindruck.

Die gebrochene Synthese im Delta des Poly-Werks ist eine Möglichkeit, das ursprünglich polyphone Miteinander um ein Neben- und ein Gegeneinander der Einzelstränge zu erweitern. Gegenüber dem historischen Modell der Polyphonie erweitert sich der Polyphoniegedanke im Poly-Werk noch um eine weitere Richtung. Denn das „Poly“ muss gar nicht mehr nur einseitig als eine Ver,mehr"ung zu verstehen sein, sondern kann umgekehrt auch eine Abspaltung, eine Dissoziation, evozieren. So ist Mahnkopfs theoretische Konzeption des Poly-Werks ausschließlich auf die „Dissoziation“ des Werkgedankens ausgerichtet. Diese subtraktive Möglichkeit markiert eine weitere qualitative Unterscheidung zur Simultanaufführung, die prinzipiell immer additiv ist. Beide Formen, die gebrochene Synthese und die Desynthese, gehen auf ein entscheidendes Kriterium in der Werkgenese eines Poly-Werks zurück: das selbstständige und autonome Dasein der Einzelstränge. Während beispielsweise in einer Fuge die verschiedenen Stimmen in ihrer Beweglichkeit gegenüber einem homophonen Satz lediglich eine gewisse Eigenständigkeit

10 Aus Mahnkopfs Sicht erwächst diese Möglichkeit direkt aus dem mit der Auflösung der Tonalität einhergehenden Wegbrechen formstiftender Syntax. Zwölftontechnik und Serialismus kritisiert er als unzulängliche Versuche, „über vereinheitlichtes Material Einheit zu stiften“. Vgl. hierzu Mahnkopf: Kritik der neuen Musik, S. 111. 
innehaben, ist diese Eigenständigkeit mitnichten so stark, dass sich die einzelnen Stimmen auch außerhalb des Kontextes Fuge aufführen ließen. Die Stimmen haben hier den Status von Modulen, die ineinandergreifen und einander auch in ihrer Hervorbringung bedingen, sich aber nicht voneinander lösen können. Dagegen ist im Poly-Werk die selbstständige Aufführbarkeit einzelner Teile eine unhintergehbare Grundbedingung. Die der Polyphonie immanente Spannung zwischen Horizontalität und Vertikalität erstreckt und verlagert sich damit auch auf eine Spannung zwischen dem „Einen“ und dem "Mehr", zwischen "Werk" und „Poly“. Während es sich bei einem polyphonen Werk immer nur um eine einzige Werkidentität handelt, setzt sich das PolyWerk aus mehreren Werkidentitäten zusammen. In den Vordergrund rückt nun die Qualität ihres wechselseitigen Verhältnisses, ihre Lagebeziehung im Raum und in der Zeit. Vor diesem Hintergrund sind Kategorien wie Polyphonie und Kontrapunkt nicht mehr nur rein satz- oder kompositionstechnische Organisationsformen. Sie entfalten auch eine konzeptionelle Dimension, die die Frage nach der Identität im Verschiedenen stellt und vor allem auf diese Weise über den offenen und geschlossenen Werkbegriff hinausweist und einen dritten Weg einschlägt.

„[D]as im Erscheinenden noch nicht Erschöpfte, im Manifestierten vermittelte, aber nicht selber ganz Manifestierte - ist Identität."11

(Ernst Bloch)

Der erweiterte Polyphoniegedanke im Poly-Werk überführt die ursprüngliche Selbstständigkeit einzelner Stimmen auf eine neue Stufe einer tatsächlichen und realen Verselbstständigung. Dieser Schritt hat wesentliche Folgen für die Werkkonzeption. Er führt dazu, dass das „Werk“ nicht mehr als eine deutlich abgeschlossene und vor allem unteilbare Einheit betrachtet werden kann, sondern dass es verschiedene, aber trotzdem weiterhin in sich geschlossene Teilwerke in sich integriert, dass es also damit auch "teilbar" wird. Damit entzieht sich der Werkbegriff seiner Eindeutigkeit, denn es stellt sich die Frage: Was ist jetzt das Werk? Weder ist es eindeutig das Ganze, das alles umfasst, noch ist es nur das geteilte Werk, das ebenso für sich selbst stehen kann. Jede

11 Ernst Bloch, Subjekt-Objekt. Erläuterungen zu Hegel, Frankfurt am Main: Suhrkamp, 1962, S. 510 . 
Werkversion zeigt nur eine mögliche Seite und bleibt damit immer nur ein Ausschnitt des Ganzen.

Ein Seitenblick auf den Identitätsbegriff in den Sozialwissenschaften macht eine interessante Analogie sichtbar. Die Vorstellung vom menschlichen Subjekt als einer singulären, in sich selbst geschlossenen zentrischen Einheit mit einer eigenen unteilbaren Identität ist dort längst korrigiert worden. Ab Mitte des 20. Jahrhunderts wurde Identitätsbildung zunehmend vor dem Hintergrund eines komplexen und interaktiven Werdensprozesses diskutiert. ${ }^{12}$ Im Zuge der "dialogischen Wende“ galt das Individuum zunehmend nicht mehr als unteilbare Einheit. Vielmehr setzte sich die Vorstellung einer Zusammensetzung verschiedener Teilidentitäten durch, die sich auf der Grundlage intersubjektiver Prozesse entwickeln und deren verschieden gelagerte Anforderungen in ein individuelles Gleichgewicht gebracht werden müssen. Die Entwicklung von Identität bindet sich damit an ein Gefüge von Beziehungen, die außerhalb der Identität selbst liegen. Ebenso entspricht das Werkkonzept im Poly-Werk nicht mehr nur einer einzelnen individuellen oder originellen Werkidentität. Die Zusammensetzung verschiedener Teilwerke und damit auch verschiedener Teilidentitäten bedingt folglich entweder die Öffnung der Werke hin zu einer Beziehung oder aber die Hervorbringung der Teilwerke aus einer konkreten Beziehung.

„D'un point de vue anthropologique, l'identité est un rapport et non pas une qualification individuelle comme l'entend le langage commun. Ainsi, la question de l'identité est non pas ,que suis-je?', mais ,qui je suis par rapport aux autres, que sont les autres par rapport à moi?' Le concept d'identité ne peut pas se séparer du concept d'altérité." ${ }^{13}$

12 Aus der Überfülle der Literatur siehe hierzu beispielsweise Heiner Keupp u. a. (Hg.): Identitätskonstruktionen. Das Patchwork der Identitäten in der Spätmoderne, Hamburg: Rowohlt, 2002; Heiner Keupp/Renate Höfer (Hg.): Identitätsarbeit heute. Klassische und aktuelle Perspektiven der Identitätsforschung, Frankfurt am Main: Suhrkamp, 1998. Es würde den Rahmen dieser Arbeit sprengen, diese Debatte in der Fülle ihrer Stimmen hier angemessen aufzugreifen. Der Verweis auf die Diskussion in den Sozialwissenschaften ist lediglich als Anregung zu verstehen, das geschlossene Werkkonzept zu erweitern, ohne es negieren zu müssen. Analogien zwischen den beiden Sphären wären für musikwissenschaftliche oder transdisziplinäre Forschungen zum Werkkonzept sicher produktiv.

13 Äußerung von Jean-Francois Gossiaux im Juni 1997 auf einer Konferenz der DIF POP (Entreprise de diffusion des revues scientifiques) über "L'identité nationale“, zitiert nach Jean-Claude Ruano-Borbalan, L'identité. L'individu, le groupe, la societé, Paris: Sciences Humaines Éditions, 1998, S. 2. Übersetzung des Verf.: „Aus anthropologischer Sicht ist Identität eine Beziehung und keine individuelle Eigenschaft, wie sie in der Umgangssprache verstanden wird. Die Frage nach der Identität lautet also nicht: ,Wer bin ich?‘, sondern: ,Wer bin ich im Verhältnis zu anderen, wer sind die anderen im Verhältnis zu mir?' Das Konzept der Identität kann nicht vom Konzept der Alterität getrennt werden.“ 
Diese Verschiebung von einem einheitlich gedachten und abgrenzbaren Subjekt hin zu einer Konstellation von Identitäten ist vor dem Hintergrund eines gesellschaftlichen Transformationsprozesses und des gesteigerten Anspruchs an Identitätsbildung ein interessantes Modell in Bezug auf die Situation der Form und der Werkidentität im Poly-Werk. Hier wird der musikalische Text aus der Spannung zwischen einer Einheit und einer Vielfalt verschiedener Funktions- und Rollenanforderungen heraus entwickelt. Selbst wenn der traditionelle Werkbegriff im Konzept des Poly-Werks eingeschlossen ist, geht der Schritt vom Mono- zum Poly-Werk mit einer Modifikation, wenn nicht gar einer Umkehrung etablierter Normen und Maßstäbe im Hinblick auf den Werkbegriff einher. Denn ebenso wie Harmonik, Rhythmik und Klangfarblichkeit im 20. Jahrhundert eine Ausdifferenzierung erfahren haben, liegt im Falle von Poly-Werken eine Ausdifferenzierung von Form, Werk und Werkidentität vor. Statt auf die Zuschreibung einer zentrisch geschlossenen und vollendeten Werkidentität gerichtet zu sein, konstituiert sich "Werk“ nur noch im Plural. Die intraformale Gestaltung des musikalischen Textes ist nur noch ein Teilaspekt und als solcher nicht mehr maßgebend für die Komposition des Ganzen. Die (Teil-)Werke entstehen nunmehr in einer ein- oder wechselseitigen Abhängigkeit. Die intraformale Entwicklung und Wirkung ist sowohl für sich als auch in Bezug auf ein Formgeschehen zu sehen, das sich außerhalb der werkeigenen Entwicklung vollzieht und ein interformales Verhältnis, ein Geflecht der Wechselwirkungen hervorbringt. Maßstab ist nun nicht mehr die Individualität eines Werks, sondern die Vereinbarkeit von Singularität und Individualität einerseits und Wandlungsfähigkeit und Adaptivität andererseits und damit auch die Korrelation zwischen Intra- und Interform. Das Konzept von Werkidentität im Poly-Werk ist also immer an das Konzept einer anderen Identität gebunden, die ebenso für sich stehen und existieren kann. „Die Innenbeziehung, das Selbstverhältnis und die Beziehung zum anderen bilden die beiden ineinander verschlungenen und einander bedingenden Bestandteile von Identität."14

In dieser chamäleonartigen Konstellation wird das Werk zur Schnittstelle verschiedener Identitäten. Jedes Werk ist als Teilwerk auch ein Erfahrungsraum für ein anderes Teilwerk. Je nach Kontext wird die Wirkungsdimension eines musikalischen Textes dadurch entweder gesteigert, gefördert oder umgekehrt auch unterdrückt, entstehen Spannungen zwischen einer forminneren Logik und einer kollektiven Metaform. Krappmanns Metapher der

14 Sigrun Anselm, „Identifizierung und Selbstbehauptung. Überlegungen zu einer aktuellen Dimension des Anerkennungskonflikts“, in: Keupp/Höfer (Hg.): Identitätsarbeit heute,

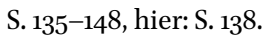


„balancierende[n] Identität ${ }^{415}$, die trotz der divergierenden Ansprüche, Widersprüche und Reibungen gefordert ist, eine spezifische Form der Kohärenz zu finden, drückt diese Dichotomie sinnfällig aus.

\subsection{Künstlerisches Gestalten in der Differenz}

Im Gegensatz zum alleinstehenden, absoluten Werk zeichnet sich das PolyWerk durch die Option einer simultanen Verkopplung innerhalb einer Werkgruppe aus. Die eingangs genannten Kriterien der Ergänzbarkeit verschiedener in sich geschlossener Werke und der Originalübertragung des Notentextes in die verschiedenen Kontexte sehen grundsätzlich keine Möglichkeit der Überarbeitung und Adaption des primären Notentextes für die verschiedenen Konstellationen vor. Die Freiheit, den Notentext für den neuen Zusammenhang noch einmal zu ändern, ihn zu überdenken und in seine Struktur einzugreifen, entfällt beim Poly-Werk. Aus künstlerischer Sicht stellen die Bewahrung des Notentextes versus seine Überarbeitung zwei unterschiedliche Herangehensweisen im kompositorischen Prozess dar. ${ }^{16}$ Hier liegt die entscheidende Weggabelung zwischen der Komposition eines einfachen Werks und der eines Poly-Werks. Werke innerhalb der Werkgruppe sollen in sich schlüssig, untereinander anschlussfähig und trotzdem verschiedenartig sein. Das absolut zu denkende Werk muss im gleichen Moment offen für eine Vernetzung oder eine Abspaltung sein. Die von Darius Milhaud komponierten Streichquartette Nr. 14 und 15, die sich zum Oktett zusammenschließen können, sind in diesem Zusammenhang musikgeschichtlich ein erster Meilenstein (vgl. Kapitel 4.3.1). Beide Stücke sind explizit auf den Zusammengang konzipiert und vom Verlag auch als Simultanpartitur herausgegeben worden. Die Gestalt beider Streichquartette ist festgeschrieben, der Notentext ändert sich in der simultanen Version nicht, wirkt sich aber natürlich ganz anders aus. Es ist bemerkenswert, dass es sich bei diesem frühen Beispiel bereits um eine heterogen angelegte Konstellation handelt. Beide Quartette teilen zwar die gleiche Besetzung, die

\footnotetext{
15 Siehe beispielsweise Lothar Krappmann, „Die Identitätsproblematik nach Erikson aus einer interaktionistischen Sicht“, in: Keupp/Höfer (Hg.): Identitätsarbeit heute, S. 66-92, hier: S. 81.

16 Beispielsweise integriert das Orchesterstück Masse, Macht und Individuum von Vinko Globokar vier Solostücke als Dialoge über Wasser, Erde, Feuer und Luft für Percussion, Kontrabass, elektrische Gitarre und Akkordeon in die Partitur. Zwar bleiben die Soli als solche klar erkennbar und behalten auch ihren solistischen Status und ihre Identität. Jedoch weichen die Fassungen der Einzelsoli und Orchestersoli voneinander ab, denn Globokar hat Abschnitte vertauscht, variiert, ergänzt oder auch ganz weggelassen.
} 
gleiche Dauer, das gleiche Metrum und Tempo. Trotzdem exponiert Milhaud in den Quartetten sehr unterschiedliche Charaktere. So ist das erste Quartett des ersten Satzes vor allem melodisch-linear, das zweite Quartett eher scherzoartig. Trotz des unterschiedlichen Charakters gibt es kleine Brücken im Tonsatz. So werden in beiden Quartetten die Themen durch die ersten Geigen gespielt. Beide Themen beginnen mit demselben Anfangston a, der Dreiklangston sowohl in F-Dur als auch in D-Dur ist, den tonalen Durzentren beider Quartette. Der Synkopenrhythmus beider Quartette verbindet sich im zweiten Takt zu einem Rhythmus und harmonischen Block. Die chromatische Linie der Bratsche aus dem Quartett Nr. 14 (vgl. Kapitel 4.3.1) hat damit je nach Kontext eine andere Funktion. Kompositionstechnisch ist hier vor allem interessant, wie Milhaud die Vergleichzeitigung zweier Werke auf der Basis seiner polytonalen Kompositionsverfahren heraus entwickelt. Vor diesem Hintergrund erscheint das Stück nicht als isoliertes, singuläres Experiment in seinem Schaffen, sondern als natürliche Konsequenz eines polytonalen und polylinearen Denkens und Experimentierens, das auch bei Milhaud - nach seiner eigenen Aussage - seine Wurzeln in der bewussten Wahrnehmung des Verschiedenen hat. Er selbst spricht von Kindheitserinnerungen, von der Wahrnehmung verschiedener Klänge und Geräusche des Straßentreibens vor seinem Haus. ${ }^{17}$

Milhaud hat seine Werke in einer Simultanpartitur komponiert. Bei der Niederschrift des einen Quartetts musste er die Gegenwart der anderen beiden Versionen mitdenken und seine Entscheidungen von Anfang an in Bezug auf die verschiedenen Kontexte treffen. Dieses Vorgehen markiert einen qualitativen Umschlag im kompositorischen Prozess. Ich nenne diesen Prozess frei nach Wolfgang Welsch, der in Bezug auf die Praktiken der Postmoderne vom „Operieren inmitten der Differenz" gesprochen hat, ${ }^{18}$ ein „künstlerisches Gestalten in der Differenz". Meiner Meinung nach veranschaulicht diese Denkfigur die Besonderheit und das Wesen dieser Praxis sinnfällig. Denn sie verweist auf die gespaltene Werkintention, die Stücke als Einzelne auszuarbeiten und gleichzeitig ihr Verhältnis zueinander zu komponieren. Dadurch erweitert sich der Interpretationsraum eines Werks bereits in der Phase der Komposition. In dem Moment, in dem ein Komponist ein Werk, Werkteil oder einzelne Stimmen in andere formale Zusammenhänge stellt, legt er sich nicht auf einen Blickwinkel fest, sondern entscheidet sich dafür, das Material unterschiedlich interpretieren, umfunktionieren und in einen diskursiven Verlauf stellen zu

17 Darius Milhaud, Notes sans musique, Paris: Juillard, 1949, S. $16 f$.

18 Wolfgang Welsch: „Einleitung“, in: Wege aus der Moderne. Schlüsseltexte der PostmoderneDiskussion, hg. von Wolfgang Welsch, Weinheim: VCH, 1988, S. 1-43, hier: S. 40. 
können. So gibt beispielsweise ein Solostück, das sich mit anderen Stücken zu einem kammermusikalischen Werk verbinden kann, in der simultanen Version seinen solistischen Status auf, erlebt einen Funktionswandel und eine Neuinterpretation seines Textes durch denselben Komponisten. Das Möglichkeitsfeld an festgeschriebenen gültigen Werkversionen, die variable Funktionalität eines Werkes in verschiedenen Zusammenhängen, erweitert auch die interpretatorischen Möglichkeiten der Interpreten und Rezipienten und macht eine flexible und dynamische Haltung zum musikalischen Text erforderlich.

Die Janusköpfigkeit der Werke ist gleichermaßen auch eine Janusköpfigkeit der künstlerischen Praxis, speziell des kompositorischen Prozesses. In diesem bedeutet sie nicht einfach nur Öffnung. Auf der einen Seite werden zwar neue Möglichkeiten der Materialentwicklung geschaffen, auf der anderen Seite aber ebenso limitiert und begrenzt. Jedes Einzelwerk stellt Bedingungen auf, die das andere Werk in seiner Entfaltung einschränken. Ein einmal gesetzter Parameter beeinflusst auch die Parametersetzung im anderen Stück und führt zu einer wechselseitigen Determination der endgültigen Form.

Eine wichtige Rolle für die Gestaltung des Verhältnisses der Werke untereinander spielt dabei bereits die Herangehensweise im Kompositionsprozess, in dem die Stücke entweder sukzessive oder simultan komponiert werden. Bei einer sukzessiven Kompositionsweise ist das erste Stück in seiner Entstehung unabhängiger als das zweite, das "gezwungen“ wird zu reagieren. Valerio Sannicandro beispielsweise hat seine beiden Orchesterwerke Windströme und Seelenströme nacheinander komponiert. ${ }^{19}$ Auch Chaya Czernowin komponierte die Werke des Anea Crystal Cycle nacheinander, legte aber das erste Stücke Seed I für die Komposition des zweiten Stückes bewusst zur Seite. Die zweite Möglichkeit der Werkgenese ist die simultane Komposition der Werke. Hier wird es meistens so sein, dass am Anfang ein übergreifender Plan entworfen wird, der zur Orientierung dient und festhält, inwieweit die Stücke aufeinander reagieren und welche Funktionen sie in Bezug aufeinander haben. Mithilfe dieses Plans können dann die einzelnen Stücke wiederum auch sukzessive auskomponiert werden, eine Mischung aus beiden Vorgehensweisen.

19 Das Orchesterstück Windströme ist eine differenzierte Orchestration tonloser Luftgeräusche. Es entstand zuerst, erlebte vor der Komposition des zweiten Stückes seine Uraufführung und gab dem Orchesterstück Seelenströme, das im Gegensatz zum ersten Stück eine Entfaltung klanglichen und melodischen Materials ist, mehrere Bedingungen wie die Dauer der Formabschnitte und die Metrik vor. 


\subsection{Die Erweiterung des Begriffsfeldes}

Der Begriff des Poly-Werks wird von den meisten Komponisten nicht verwendet oder sogar abgelehnt. Der Grund ist vermutlich, dass er eine Anknüpfung an traditionelle ästhetische Konzepte suggeriert und ihm im Kern die Objekt- und Werkhaftigkeit eingeschrieben ist. Tendenziell wird eher auf Beschreibungsformen zurückgegriffen, die das spezifisch Prozesshafte der jeweiligen Zusammenführung herausstellen. Lediglich Ulrich Kreppein bezeichnet seine Echoräume tatsächlich als „Polywerk“. ${ }^{20}$ Claus-Steffen Mahnkopf schrieb über das Konzept des Poly-Werks: „Dieses Formprinzip ist äußerst wandlungsfähig und offen für eine Unzahl von Kombinationen“21. Das spricht auch erst einmal für eine Vielfalt an Beschreibungsformen und Begriffen. Chaya Czernowin beschreibt ihren Zyklus Anea Crystal Cycle einfach mit der Möglichkeit einer simultanen Aufführbarkeit. ${ }^{22}$ Adriana Hölszky untertitelt ihre Hängebrücken mit „Doppelquartett an Schubert“23. Juliane Klein bezeichnet den Zyklus Aus der Wand die Rinne als einfache „Werkgruppe“24. Bernd Franke spricht von einem „komplexen Vernetzungsprinzip“25 in Bezug auf seinen Solo-xfachZyklus, Aaron Cassidy beschreibt seine Stücke als „conglomeration of three interconnected, simultaneous trios for seven players“26, Georg Friedrich Haas nennt „... Einklang freier Wesen ..." ein „interlacing of ten completely, independent autonomous solos, smaller sub-ensembles“, und Simon SteenAndersen beschreibt Next To Beside Besides als „choreographical translations“27. Robert HP Platz verwendet an verschiedenen Stellen den metaphorischen Begriff der „Raumpolyphonie“ oder spricht auch von einer „Polyphonie verschiedener Formen“28.

Bis auf Ulrich Kreppein vermeiden alle Komponisten einen Werkbegriff, obschon die Möglichkeit der Simultaneisierung im kompositorischen Prozess

$20 \quad$ Ulrich Kreppein, Echoräume für vier Ensembles, Partitur, 2016/17, Berlin: Edition Juliane Klein.

21 Mahnkopf: Kritik der neuen Musik, S. 118.

22 Chaya Czernowin, Anea Crystal Cycle, Partitur, 2009, Mainz: Schott.

23 Adriana Hölszky, Hängebrücken. Streichquartette/Doppelquartett an Schubert, Wiesbaden: Breitkopf \& Härtel, 1991.

24 Juliane Klein, Aus der Wand die Rinne 1-14, 1996-2014, Berlin: Edition Juliane Klein.

25 Vgl. http://berndfranke.de/werke-2/solo-xfach/ensemble/ (letzter Aufruf am 14.3.2020).

26 Vgl. http://aaroncassidy.com/product/the-green-is-either/ (letzter Aufruf am 14.3.2020).

27 Vgl. Simon Steen-Andersen, Next To Beside Besides 0-11, 2003-2007, Frederiksberg: Edition S.

28 Vgl. https://www.rhpp.de/index.cfm?id=3664 (letzter Aufruf am 14.3.2020); siehe auch Richard Toop: „Immer weiter. ,Formale Polyphonie“ und Robert HP Platz' Donaueschinger Zyklus“, in: Musik \& Ästhetik, Heft 6, 1998, S. 61-76. 
fast immer auf die einzelne Individualstruktur der Werke zurückwirkt und teilweise auch Simultanpartituren existieren. ${ }^{29}$ Die meisten Umschreibungen und Begriffe verweisen etwas unbestimmt auf die von vornherein intendierte qualitative Werkverknüpfung. Die eigentliche Besonderheit, nämlich die gleichzeitige Aufführbarkeit bei gleichzeitiger Autonomie der Einzelwerke ist dagegen nicht immer auf den ersten Blick greifbar. Aufgrund der unklaren Begriffslage im Umfeld des Poly-Werks soll im Folgenden ein Überblick über die Begriffsmöglichkeiten und ihre Einordnung versucht werden.

Die "Simultanaufführung“ ist eine simultane Zusammenführung präexistenter Werke durch Interpreten und damit eindeutig eine Aufführungspraxis, die verschiedene Werke im Nachhinein additiv zusammenführt. Die Zusammenführung kann das Resultat analytisch bestimmter Verbindungslinien der musikalischen Texte sein. Sie kann aber ebenso auch lose und unverbindlich sein, wie bei einem "Circus“. Ein "Circus" stellt zudem den Wert der Quantität der zu schichtenden Stücke über den Wert der Qualität der Verbindung. Das begriffliche Äquivalent "Simultanwerk“ wird bis zu diesem Zeitpunkt wohl noch nicht verwendet. Der Begriff würde auf die parallele Zusammenführung als kompositorische Praxis verweisen und ebenso einen additiven Zusammenschluss von Werken implizieren. Dagegen kann das „PolyWerk" neben den additiven auch subtraktive Verfahren, innere qualitative Aufspaltungen von Werkentitäten, Dissoziationen und Externalisationen beinhalten. Bildlich gesprochen handelt es sich bei den subtraktiven Vorgängen um eine Umkehrung oder Negation des additiven Prinzips und damit bereits um eine Variation des Polyphonieprinzips.

Der entscheidende Unterschied zur Simultanaufführung besteht darin, dass im Poly-Werk die Form der Verbindung vom Komponisten von vornherein antizipiert wird. Das hat Folgen für den Charakter und den Aufbau der Einzelwerke und die Gesamtdisposition, die oftmals eine formale Herausforderung darstellen und genaue präkompositorische Planungen und Überlegungen bezüglich der Anschlussstellen und der Synchronisierung erforderlich machen. Der Begriff des Poly-Werks wird bei Mahnkopf in Verbindung mit einem polyphonen Denken verwendet und zielt auch hier auf das qualitative Moment der Verknüpfung. Aus diesem Grund ist er nicht für alle Werkkopplungen der passende Begriff. Vermutlich wird er auch deswegen von

29 Die Zyklen Anea Crystal Cycle (Chaya Czernowin), Hängebrücken (Adriana Hölszky), Medusa (Claus-Steffen Mahnkopf) oder auch „... Einklang freier Wesen ...“ (Georg Friedrich Haas) existieren als Simultanpartituren. In anderen Fällen sind die Werke einzeln oder im sukzessiven Verbund erhältlich. Ist ein Poly-Werk als Simultanpartitur werkhaft fixiert, kann es als solches gehandelt, gelesen und studiert werden. 
den meisten Komponisten gemieden, weil er in den Schriften von Mahnkopf Teil eines Denkmodells ist, das spezifische Ansprüche an die Werkkonzeption und die Werkrezeption formuliert, und bei ihm im Zusammenhang mit dem Komplexismus gebraucht wird..$^{30}$

Claus-Steffen Mahnkopf geht in seiner Definition des Poly-Werks - die in erster Linie aber für seine eigenen Werke Gültigkeit hat und in vielen Punkten nicht generalisierbar ist - von der Dissoziation, der Spaltung einer Einheit, statt einer Addition aus:

\begin{abstract}
„The poly-work, finally, is the dissociation of the work as an organically defined whole: within a consistently integrally and organically composed work are located independent, in themselves equally organically composed works which, like organelles (cellular sub-components), make indispensable contributions to the overall organization and can, in their ex-corporated form, be played as autonomous works. The very attraction of the poly-work lies in the formal strategy of distributing the internal components with differing (but shorter) durations than the composite structure, in order thus to effect an internal dissociation of the temporal organization without destroying it. ${ }^{431}$
\end{abstract}

Mahnkopfs Entwurf einer integrativ-verschachtelten „Reinform“ des PolyWerks beschreibt vor allem den Aufbau seiner eigenen Poly-Werke. Bereits die Integration von kleineren Subwerken ist auf viele andere Fälle nicht mehr übertragbar und damit auch nicht die Definition als solche. Für eine allgemeine Verwendung des Begriffs ist meines Erachtens die Antizipation einer qualitativen Verknüpfbarkeit im kompositorischen Prozess unter Einschluss sowohl additiver als auch subtraktiver Verfahren ausschlaggebend.

Der Begriff „Werkschichten“ wird von Andreas Holzer in seinem Buch Zur Kategorie der Form in Neuer Musik $k^{32}$ synonym zum Begriff des Poly-Werks verwendet. Die Begriffe werden nicht voneinander abgegrenzt. Der Begriff Werkschichten impliziert zwar die zentrale Bedeutung des Simultanen, ist aber insofern missverständlich, als es sich auch um einzelne Schichten eines Werks handeln könnte. Außerdem wird das Verhältnis der Einzelwerke zueinander auf diese Weise von vornherein auf eine Schichtung, also eine einfache Überlagerung reduziert und nicht auf das konstruktive und verknüpfende interformale Moment Bezug genommen.

Der Begriff „Formpolyphonie“ wurde im Zusammenhang mit den Werken von Robert HP Platz geprägt, dessen Schaffen vielfach von Werksimultaneisierungen durchzogen ist. Das Phänomen der Werküberlagerung nimmt

3 Vgl. z. B. Mahnkopf: Kritik der neuen Musik, S. $112 \mathrm{ff}$.

31 Mahnkopf: „Theory of Polyphony“, S. 49.

32 Holzer: Zur Kategorie der Form in neuer Musik, S. 506-510. 
einen zentralen Platz in seinem Gesamtwerk ein. Viele seiner Werke sind untereinander anschlussfähig, überlappen sich oder können parallel aufgeführt werden. Beispiele sind:

- up $(+)$ down $(+)$ strange $(+)$ charme

- Wunderblock

- dur (+) moll (+) hören

- Branenwelten

- Unter Segel (+) Boutaden (+) Hülle 2

- Horizont $(+)$ Architektur

- Hülle 1

- Grenzgänge (+) STEINE

- Flötenstücke für Altflöte und Ensemble etc. ${ }^{33}$

Der Terminus „Formpolyphonie“ streicht den Aspekt der Form heraus und ist eher geeignet, die Divergenz von Formen, Formtypen und musikalischen Abläufen innerhalb einer Werkentität zu bezeichnen. Diese ist nicht auf das Poly-Werk beschränkt. Die Schichtung und Fusion verschiedener Formtypen innerhalb einer Form wurde weit früher praktiziert, insbesondere in einigen Werken der Zweiten Wiener Schule. ${ }^{34}$ Da es nun aber auch Poly-Werke gibt, die gerade in ihrer Formhaftigkeit einheitlich sind und ihre Divergenzen auf anderen Ebenen austragen, ist dieser Begriff auch bei Robert HP Platz als übergeordnete Kategorie eher missverständlich. Hier scheint der - bis jetzt wohl auch noch nicht verwendete - Begriff der "Werkpolyphonie“ besser geeignet zu sein, da er sich nicht nur auf ein formales Spannungsverhältnis verengt. Im Gegensatz zum „Poly-Werk“ zielt er außerdem weniger auf einen Abschluss, sondern deutet auf ein offenes Metaprojekt im Gesamtschaffen hin, wie es bei Platz auch tatsächlich der Fall ist.

Neben den bereits aufgezählten Varianten können weitere Begriffe nützlich sein, gerade wenn sie assoziativ auf den Charakter der Kopplung verweisen. Der Begriff „Werkpaar" ist bei der Konstellation zweier gleichstarker Werkeinheiten zutreffend, beispielsweise im Fall eines verdoppelten Streichquartetts. Der Begriff „Werkcluster“ ist treffend, wenn es um ähnliche und einander nahe Solostücke geht, die sich zu Ensemblestücken kombinieren lassen. Ich verwende ihn für die Werkzyklen von Julio Estrada, Simon SteenAndersen und Juliane Klein. Als „Subwerke“35 bezeichnet Claus-Steffen

33 Siehe auch https://www.rhpp.de/index.cfm?id=3251 (letzter Aufruf am 14.3.2020).

34 Siehe hier zum Beispiel Theodor W. Adorno in seinem Vortrag über die „Form in der Neuen Musik" in Thomas (Hg.): Form in der Neuen Musik, S. 18 f.

35 Claus-Steffen Mahnkopf: „Medusa. Concerning Conception, Poetics and Technique“, in: ders. (Hg.): Polyphony \& Complexity, S. 245-265, hier: S. 247. 
Mahnkopf die kleineren Kammermusikkompositionen als Teilkompositionen seines Zyklus Medusa. Das übergreifende Orchesterstück kann wiederum als „Dachkomposition“ oder „umbrella composition“36 bezeichnet werden. Klaas Coulembier plädiert in seiner Dissertation außerdem sinnvollerweise für eine präzise Unterscheidung zwischen autonomen und unabhängigen Werken. Die Einzelwerke im Poly-Werk sind zwar autonom, aber nicht vollständig unabhängig voneinander, da sie ja in Bezug aufeinander, entstanden sind. ${ }^{37}$

Berücksichtigt man die verschiedenen Aspekte, scheint der Terminus „Poly-Werk" - trotz der spürbaren Ablehnung von Seiten der Komponisten als Oberbegriff das Phänomen meines Erachtens doch am genauesten zu fassen. Der Bezug zum Konzept der Polyphonie verweist auf das spannungsvolle Kräfteverhältnis zwischen einer sich verselbstständigenden Sukzessivität und einer verbindenden Simultaneität. Der Bezug zum Kontext des Werks bringt durch die Nebeneinanderstellung der Wortkomponenten "Poly“ und „Werk“ die Spannung zwischen der ausgedrückten Mehrzahl und dem als Einzahl gedachten Gebilde des "Werks“ aus. Damit erweitert der Begriff sowohl das Werkkonzept als auch das Konzept von Polyphonie und stellt so eine konstruktive Alternative zur Negation des Werkbegriffs dar. Denn ein Werkbegriff, der entweder nur zur Eindeutigkeit oder zur Negation verdammt ist, ist keiner Weiterentwicklung fähig.

Die folgende Liste umfasst Werke, auf die die Kriterien des Poly-Werks zutreffen. Auch diese Liste erhebt keinen Anspruch auf Vollständigkeit. Da sich der Begriff „Poly-Werk“, für den ich als Oberbegriff plädiere, für die Neue Musik erst langsam durchsetzt, ist es aufgrund der Diversität der Bezeichnungen und mitunter auch der Nichtbezeichnung bisweilen schwierig, Poly-Werke „ausfindig“ zu machen. Zudem gibt es eine Reihe von Werken, die sich auf den ersten Blick sehr stark an das Konzept annähern, es dann aber doch nicht in derselben Konsequenz realisieren, beispielsweise indem einzelne Module, wenn sie unabhängig von der simultanen Version gespielt werden, noch einmal überarbeitet werden. Die Unterscheidung ist nicht herabsetzend gemeint, aber es ist einfach etwas anderes. Die folgenden Werke sind mehrheitlich auch nicht explizit als Poly-Werke konzipiert worden. Was sie vereint, sind die gleichartigen Bedingungen, die sich die Komponisten bei der Komposition als Aufgabe gestellt haben, das heißt die Möglichkeit einer Neukontextualisierung und Vergleichzeitigung eines autonomen Werks durch eine simultane Aufführung in oder mit mindestens einem anderen Werk oder umgekehrt die Herauseinzelung eines autonomen Werks aus einem größeren Werk

36 Coulembier: Multi-temporality, S. 161.

37 Ebd., S. 170. 
und damit die Verungleichzeitigung eines Werks. In beiden Fällen bleibt der musikalische Text jeweils unverändert. Nicht eine bewusste äußere Maßgabe, sondern gerade die unabhängige Realisierung dieser Bedingungen durch die verschiedenen Komponisten bestätigt und festigt diese als Voraussetzung für die Entstehung des Poly-Werks als eine neue Gattung.

Beispiele für Poly-Werke in chronologischer Reihenfolge

$1948 / 49$

1975

1977

1973-1985

1982

$1982-2020$

$1985 / 86$

$1989 / 90$

1989/1992-1993

1990-1992

1994/95

1995-1996

1992-1997

1996-1998

$1997-2001$

1996-2011

1999

2001

2003

2003/05

2005/06
Darius Milhaud: Streichquartette Nr. 14 \& 15

Klaus Huber: Schattenblätter für Bassklarinette, Cello und Klavier

Klaus Huber: Oiseaux d'argent für drei Flöten

Vinko Globokar: Laboratorium für diverse Instrumente

Robert HP Platz: Flötenstücke für Altflöte und Kammerensemble

Julio Estrada: Yuunohui Cycle für diverse Instrumente

Klaus Huber: Protuberanzen für Orchester

Adriana Hölszky: Hängebrücken für zwei Streichquartette

Robert HP Platz: Grenzgänge STEINE für Sopran, zwei Klaviere und Orchester

Claus-Steffen Mahnkopf: Medusa für Oboe und Orchester

Georg Friedrich Haas: „... Einklang freier Wesen ... “ für Ensemble

Claus-Steffen Mahnkopf: Kammerzyklus für Klavier und Ensemble

Richard Barrett: Opening of the Mouth für Ensemble

Robert HP Platz: up down strange charm für diverse Instrumente

Bernd Franke: half-way house - Solo xfach für diverse Instrumente

Juliane Klein: Aus der Wand die Rinne für diverse Instrumente

Mark Randall Osborn: The Fluid Pronoun für Piccolo/Flöte, Ensemble und Tape

Bernd Franke: CUT I-III für Ensemble

Aaron Cassidy: the green is either für drei Trios

Simon Steen Andersen: Next To Beside Besides für diverse Instrumente

Robert HP Platz: Horizont Architektur Kern für Violine, Orchester, Tonband 
2007 Robert HP Platz: Unter Segel Boutaden Hülle 2 für diverse Instrumente

2008 Marko Ciciliani:Jeanne of the Dark für Ensemble, Licht und Video 2008 Chaya Czernowin: Anea Crystal Cycle für zwei Streichquartette

2008/10 Robert HP Platz: Wunderblock für Ensemble

2009 - $\quad$ Robert HP Platz: Branenwelten 1-6 für diverse Instrumente

2012 Valerio Sannicandro: Windströme und Seelenströme für zwei Orchester

2015/16 Robert HP Platz: dur moll hören für diverse Instrumente und Elektronik

2016/17 Ulrich Kreppein: Echoräume für vier Ensembles

$2017 \quad$ Karin Wetzel: X-Pieces für zwei Blockflöten

2017/18 Georg Friedrich Haas: Blumenwiese

2017/18 Valerio Sannicandro: Tactile Songs I und II für zwei Quartette

2019/20 Karin Wetzel: Dividuum für Violine 
Karin wetzel - 978-3-8467-6674-3

Downloaded from Fink.de@4/26/2023 03:14:51PM via free access 


\section{Die Interform im Poly-Werk}

Durch die teils anspruchsvollen und formal mehrbödigen Organisationsstrukturen kommt der Form im Poly-Werk auf dreifache Weise der Status einer grundlegenden Kategorie zu: erstens als Metaform, die die Konzeption des Ganzen umfasst; zweitens als Interform, die die Verhältnisse zwischen den Werken und ihre Situierung im Ganzen bestimmt, und drittens als Intraform, womit hier die konventionelle lineare Formrichtung des einzelnen Werks gemeint ist.

Im Mittelpunkt des folgenden Kapitels stehen die Interform, die die Möglichkeiten der simultanen Werkverbindung fokussiert, die Konvergenz und Divergenz der Werke, ihre gegenseitige Ergänzung als entweder stützende oder schwächende Kraft und die hieraus entstehenden Synergieeffekte. Die Möglichkeiten der simultanen Werkverbindung spiegeln einerseits die Spannbreite an Beziehungsmöglichkeiten des Zu-, Mit-, Neben- oder Gegeneinanders wider, situieren aber ebenso das einzelne Werk im Ganzen, seine Integration in den Werkzusammenhang, die mit unterschiedlichen Funktionen - beispielsweise der eines Solos oder eines Ensembleparts - einhergeht.

Um innerhalb eines simultanen Werkkontextes voneinander unabhängige Werke hervorzubringen, geht vielen Poly-Werken ein Prozess präkompositorischer Planung voraus. Manche Poly-Werke wachsen gar in einem jahrelangen Entstehungszeitraum. Auf den ersten Blick handelt es sich um ein sehr diverses Feld, das von sehr unterschiedlichen Komponisten und Komponistinnen individuell ausgelotet wurde. Mahnkopfs Zuschreibung eines höchst anpassungsfähigen und offenen Formkonzepts ${ }^{1}$ charakterisiert bereits die existierende Vielförmigkeit. Dennoch stehen die meisten Komponisten vor demselben Spagat, gleichzeitig das Werk als Einzahl und das Werk als Vielzahl zu realisieren.

Viele Komponisten haben ihre Ideen in räumlichen Bildern und Modellen, die außermusikalischen Terrains entlehnt sind und die simultane Disposition der Stücke zueinander in der Vorstellung abbilden, ausgedrückt. Luciano Berio vergleicht den Zyklus der Chemins, der den Zyklus der Sequenzae in sich aufnimmt, mit den Schichten einer Zwiebel: „[...] distinctes, séparées et pourtant collées l'une sur l'autre, chaque couche nouvelle créant une surface nouvelle, bien que rattachée à la précédente, et chaque couche ancienne assumant

1 Vgl. Mahnkopf: Kritik der neuen Musik, S. 118.

(C) KARIN WETZEL, 2022 | DOI:10.30965/9783846766743_004

This is an open access chapter distributed under the terms of the CC BY-NC-ND Aarlicense ze l - 978-3-8467-6674-3 
une nouvelle fonction dès qu'elle est recouverte .....2 Für Robert HP Platz sind naturwissenschaftliche Vorstellungen prägend: „Mich hat der Gedanke fasziniert, dass ,Up, Down, Strange and Charm physikalische Teilchen, so genannte Quarks, sind, die je nach ihrem Anregungszustand entweder separat oder im Verbund auftreten können. Und das entspricht ganz genau der Aufführungsmöglichkeit meiner Stücke. ${ }^{3}$ Für Claus-Steffen Mahnkopf ist das Poly-Werk eine Spiegelung des „heutige[n], plurale[n] 'Mensch[en] [...], der in unvereinbare Mehrfachexistenzen aufgespalten zu sein scheint und dennoch ,irgendwie‘ ein Eines ist ${ }^{\text {"4 }}$. Aber auch das Verhältnis verschiedener Individuen zueinander findet im Formkonzept des Poly-Werks seinen Ausdruck. Der Titel des Ensemblestücks „... Einklang freier Wesen ..." von Georg Friedrich Haas entstammt einem Text von Hölderlin. Das Stück besteht aus zehn völlig in sich selbstständig aufführbaren Instrumentalstimmen, die dann unter dem Titel „,... aus freier Lust ... verbunden ..." zu beliebigen Ensembleformationen verbunden werden können. Haas knüpft nach Reinhard Kager an das Modell eines Zusammenschlusses „mündiger, selbstständiger Individuen [an], die nicht unters Joch eines Systems gespannt wären, ob dies nun Kommunismus heißt oder Kapitalismus“5.

All diesen Vorstellungen und Stücken ist gemeinsam, dass sie eine neue formale Ebene benötigen, die auf die Verbindung und Verknüpfung der Einzelwerke gerichtet ist und die im folgenden Kapitel thematisiert wird. Ich nenne

2 Vgl. Luciano Berio, Paris, 19.6.1979, zitiert nach Ivanka Stoianova: Luciano Berio - Chemins en musique (= La Revue Musicale 375-377), Paris: Richard-Masse, 1985, S. 431.

3 Egbert Hiller: „Formpolyphonie als Zukunftsmusik. Der Komponist Robert HP Platz“, in: Neue Zeitschrift für Musik 6, 2005, S. 54-55, hier: S. 54.

4 Mahnkopf: Kritik der neuen Musik, S. 118. Dieser Satz findet sich bezogen auf das Lebenskunstwerk (LKW) fast identisch auch bei Paolo Bianchi und wurde im selben Jahr im Kunstforum International veröffentlicht: „Das LKW ist ein Flickwerk, das die Vielfalt und den Irrsinn des heutigen pluralen Menschen (und nicht eindimensionalen Menschen) spiegelt, der aufgespalten ist in unvereinbare Mehrfachexistenzen und dennoch irgendwie eine Einheit bildet." (S. 8) Bianchi verwendet ebenfalls den Begriff des Polywerks, allerdings bezogen auf das viel freiere und offenere Lebensgesamtkunstwerk (LKW) und nicht auf simultane Werkkonstellationen in der Musik: „Das LKW ist ein Polywerk, ein Werk, das sich aus mehreren Werken zusammensetzt, ein Werk, das andere Werke integriert. Keinerlei Sieg und keine Eindeutigkeit ist gefragt, sondern die Unendlichkeit von Beziehungen. Die Integration diverser Werke führt zur Simultaneität (statt zur Simulation) und erhöht die Interaktivität." (Paolo Bianchi: „Das LKW. Vom Gesamtkunstwerk zum Lebenskunstwerk oder ästhetisches Leben als Selbstversuch [Teil 1]“, in: Kunstforum 142, 1998, S. 50-61, III. „Crossover oder Hybrides, Simultanes und Polymorphes“, https://www.kunstforum.de/artikel/das-lkw/, S. 7 f. [letzter Aufruf am 7.5.2020].)

5 Georg-Friedrich Haas: „... Einklang freier Wesen ...“, Klangforum Wien, Sylvain Cambreling, Kairos, 2002, CD-Beiheft, S. 4. 
diese Ebene eine interformale Ebene. Sie kann wie ein Querschnitt profilhaft bestimmt werden und ermöglicht eine Gruppierung, Vergleichbarkeit und Einordnung der mitunter sehr unterschiedlichen Strategien. Die hieraus entstehenden, teilweise binären Reduktionen machen übergreifende Tendenzen und Merkmale sichtbar und systematisieren die vertikalen Werkverhältnisse. Dadurch entsteht ein relativ klarer Überblick über die Möglichkeiten. Dennoch gibt es auch Beispiele, die sich gerade nicht so einfach einordnen lassen. Manche Werke sind interessante Mischformen, auf die teilweise auch hingewiesen wird. Andere Werke wiederum schaffen Paradoxien. Eine eindeutige Zuordnung, wie sie Modelle gerne suggerieren, ist nicht in jedem Fall sinnvoll. Trotzdem schafft die Systematisierung die Voraussetzung, mit diesen Kategorien bewusster umzugehen, neue Mischformen zu erdenken und interessante Zwischenräume zu erkennen. Das Schema ist offen für Erweiterungen und soll in erster Linie als Leitfaden dienen, um ein PolyWerk in seinen formalen Grundzügen einordnen zu können. Es umfasst die Ebenen des Materials, des Werks, der Form und der Polylinearität. Das interformale Profil ersetzt keine vollständige Formanalyse. Diese kann erst aus dem Zusammenspiel der intra-, inter- und metaformalen Verläufe, Eigenschaften und Wechselwirkungen erwachsen.

\subsection{Homogene und heterogene Werkzyklen}

Es gibt zwei Gruppen von Poly-Werken, die sich aufgrund ihrer Materialverwandtschaft in homogene und heterogene Werkzyklen gruppieren lassen.

1. Homogene Werkzyklen

Bei der Zusammenführung homogener Werke stammen die einzelnen Werke von einem einzigen oder einem sehr ähnlichen Ausgangsmaterial ab oder basieren auf einer einzigen „Urform“.

Letzteres ist der Fall, wenn dem Zyklus ein verbindendes Ausgangsstück oder -modell zugrunde liegt und die Folgewerke als Ableitungen, Bearbeitungen, Transkriptionen oder Variationen dieser "Urform“ konzipiert sind. Ein Beispiel dafür ist der Yuunohui Cycle von Julio Estrada (vgl. Kapitel 4.2.1.2.1). Diesem Zyklus liegt als Modell eine grafische Struktur zugrunde, die auf die verschiedenen Versionen gleichermaßen übertragen wird, das heißt die entstehenden Versionen sind auf eine einzige Quelle zurückführbar und Variationen desselben Modells. Sie können entweder einzeln gespielt oder in beliebiger Anzahl simultan miteinander kombiniert werden. Auch Simon Steen-Andersens Zyklus Next To Beside Besides (vgl. Kapitel 4.2.1.2.2) und Juliane Kleins 
Werkserie Aus der Wand die Rinne (vgl. Kapitel 4.2.1.1.2) verfolgen ähnliche Ansätze. Beiden Werkclustern liegt ein Cellostück zugrunde, das als Initialstück am Anfang der Serie steht. Die anschließend komponierten Stücke für andere Soloinstrumente sind zu unterschiedlichen Graden Ableitungen und Variationen des Cellostücks. Sämtliche Stücke können sowohl einzeln als auch simultan gespielt werden. Gerade bei diesen sukzessive entstehenden Werkzyklen mit einer gemeinsamen Wurzel, die als Work in progress innerhalb eines mehrjährigen Entstehungszeitraums komponiert werden, kann es interessant sein zu sehen, inwieweit Differenzen zwischen den Stücken entwickelt werden und sich die Stücke im Verlauf des Entstehungszeitraumes auch voneinander "wegentwickeln" können. Typisch hierbei ist, dass diese Herangehensweise keine im Vorfeld gesetzte Metaform voraussetzt. Diese bildet sich immer wieder neu und kann daher als resultierende Form bezeichnet werden. ${ }^{6}$ Die beiden Stücke des Werkpaars Hängebrücken für zwei Streichquartette von Adriana Hölszky (vgl. Kapitel 4.2.2), die sowohl einzeln als auch simultan gespielt werden können, sind auf eine andere Art sehr eng verwandt. Beide Stücke verstärken sich und intensivieren einander. Im Gegensatz zu den oben beschriebenen Werkclustern gibt es hier kein eigentliches „Urmodell“. Dennoch schöpfen beide Werkstränge aus einem gemeinsamen Materialfundus, der im Skizzenstadium entwickelt und dann von Hölszky auf beide Werkstränge verteilt wurde.

2. Heterogene Werkzyklen

Bei der Zusammenführung heterogener Werke basieren die Teilwerke auf unterschiedlichem Ausgangsmaterial und sind daher in ihrer Werkidentität sehr verschiedenartig.

Beispielsweise führt Klaus Huber in seinem Orchesterstück Protuberanzen die drei kleinen Orchesterminiaturen Die Enge des Marktes, Implosion und Stäubchen aus Licht zusammen, die in ihrem Material und ihrem Charakter von vornherein unterschiedlichen Ideen entstammen und nicht die Vermehrfachung einer einzigen Idee verkörpern (vgl. Kapitel 4.3.4). Auch die Streichquartette Nr. 14 \& 15 von Darius Milhaud, die sich zum Oktett zusammenschließen lassen (vgl. Kapitel 4.3.1), exponieren unterschiedliche und kontrastierende Charaktere, die teilweise sehr unvermittelt aufeinanderprallen. Weitere Beispiele für heterogene Werkzusammenführungen sind der Anea Crystal Cycle von Chaya Czernowin

6 Eine Ausnahme bildet der Zyklus Next To Beside Besides von Simon Steen-Andersen. Denn hier wird die einmal gesetzte Form für alle Versionen beibehalten. 
(vgl. Kapitel 4.3.2), der Medusa-Zyklus von Claus-Steffen Mahnkopf (vgl. Kapitel 4.1.2) oder die Echoräume von Ulrich Kreppein (vgl. Kapitel 4.3.5). Um die heterogenen Werkverläufe zu einem Werk zusammenführen zu können, ist für diese Gruppe eine sehr plastische, schlüssige und architektonische Metaformbildung - sowohl bei den simultanen Fassungen als auch bei den Einzelfassungen - typisch. Anders als bei den homogenen Poly-Werken ist hier die Bildung von Brücken und Verbindungen zwischen den Stücken in der Analyse interessant.

\subsection{Endliche und nichtendliche Werkzyklen}

Die Unterscheidung von endlichen und nichtendlichen Werkzyklen leitet sich von der Frage ab, ob ein Poly-Werk-Zyklus als Work in progress theoretisch ins Unendliche wachsen kann oder ob von vornherein ein Rahmen gesetzt wird: entweder durch eine Maximalbesetzung, die nicht überschritten werden kann, oder durch eine vorab festgelegte Metaform, die die verschiedenen Werkverläufe festlegt und damit den zu vergebenden „Raum“ genau aufteilt.

1. Nichtendliche Werkreihen

Gerade bei homogenen Werkreihen, die auf Transkriptions- und Vervielfältigungsprozessen eines Ausgangsstückes basieren, ist es typisch, dass die Reihen in einem mehrjährigen Prozess nach und nach entstehen und in ihrer Anlage theoretisch unendlich erweiterbar und eigentlich nie abgeschlossen sind. Der bereits beschriebene Yuunohui Cycle von Julio Estrada (vgl. Kapitel 4.2.1.2.1) ist ein Beispiel für einen „unendlichen" wachsenden Kompositionszyklus. Der Entstehungszeitraum des Zyklus erstreckt sich mittlerweile über einen Zeitraum von fast vierzig Jahren. 1982 entstand das Cellostück Yuunohui'yei als Nukleus der Reihe. Weitere Fassungen für Violine, Viola, Kontrabass, Noisemaker, Cembalo, Orgel folgten in den 8oer Jahren. 2012 entstand mit Yuunohuiehecatl eine Version für Blasinstrumente, 2018 mit Yuunohui'sa eine Version für Gesang. Die ursprünglich sehr strenge Struktur der Streicherfassungen wurde dabei nach und nach zugunsten einer sehr viel offeneren Struktur, die den Performern mehr Freiräume und Optionen lässt, aufgegeben.

2. Endliche Werkreihen

Diesem Ansatz entgegengesetzt ist das „endliche Werk“, das in der Regel eine vorab bestimmte Rahmenbesetzung nicht überschreitet. Ein Gegenbeispiel zum Yuunohui Cycle stellt das Ensemblewerk „,... Einklang freier Wesen ..." (vgl. Kapitel 4.2.1.1.3) von Georg Friedrich Haas dar. Das Werk setzt sich aus zehn Solostimmen zusammen. Diese können einzeln 
aufgeführt werden oder sich zu beliebigen simultanen Kombinationen innerhalb dieser Rahmenbesetzung frei zusammenschließen. Statt eines Wachstumsprozesses erscheint dieses Werk als ein geschlossener Organismus, der sich ins Innere werkhaft ausdifferenziert, wobei die Zahl der Kombinationsmöglichkeiten durch den eindeutig definierten Gesamtrahmen klar begrenzt ist.

Ob ein Zyklus nichtendlich oder endlich ist, muss nicht in jedem Fall eindeutig zu bestimmen sein, denn einerseits verfügt der Komponist ja theoretisch immer über die Möglichkeit, im Nachgang Werke hinzuzufügen, andererseits ist auch sein Leben endlich, sodass eine „unendliche Fortsetzung“ eines Zyklus natürlich utopisch ist. Die Unterscheidung ist also eher auf eine mögliche Intention des Komponisten gerichtet: Entweder stellt sich der Werkzyklus aus Sicht des Komponisten als unabschließbar dar und es existiert die offene Option, weitere Versionen und Werke hinzuzufügen, oder das Werk stellt sich aus seiner Sicht an einem bestimmten Punkt als abgeschlossen in dem Sinne dar, dass die Hinzufügung weiterer Stücke dem Zyklus keinen Mehrwert mehr geben würde.

\subsection{Monozentrische und multizentrische Werkzyklen}

Hier ist zu bestimmen, ob die einzelnen Werke in einem hierarchischen oder eher einem gleichrangigen Verhältnis zueinander stehen. Gibt es beispielsweise ein zentrales Hauptwerk, an das kleinere Nebenwerke andocken können, dann handelt es sich um eine monozentrische Konstellation. Verbinden sich mehrere gleichrangige Werke, die einander auch in ihrer Besetzungsstärke und Dauer ungefähr entsprechen, dann handelt es sich um eine multizentrische Konstellation, da kein Werk dem anderen übergeordnet ist. Statt monozentrisch/multizentrisch könnte hier je nach Werk auch die Unterscheidung Parataxe versus Hypotaxe sinnvoll sein. Mit Parataxe ist ein ebenbürtiges Verhältnis "gleichrangiger" Stücke gemeint, während Hypotaxe auf eine integrativ-verschachtelte Form zielt, die beispielsweise kleine Nebenwerke in ein größeres Hauptwerk integriert.

1. Multizentrische Werkzyklen

Die multizentrale Konstellation ist „nichthierarchisch“. Hier handelt es sich um eine Verbindung von mindestens zwei Stücken, die in einem gleichrangigen Verhältnis zueinander stehen. Gleichrangig bedeutet erst einmal kein Werturteil über die Stücke an sich. Gemeint ist, dass die Werke in ihrer Besetzung, ihrer Dauer und ihrem zeitlichen Zusammenfall einander entsprechen, also gemeinsame äußere Merkmale haben 
und keine Werkversion einer anderen im Zusammenspiel übergeordnet erscheint, das Verhältnis ausbalanciert ist. Der Yuunohui Cycle von Julio Estrada geht von verschiedenen gleich starken Solostücken aus, die sich dann untereinander frei verbinden können. Sowohl jedes Solostück als auch jede zusammengesetzte Version hat ihren individuellen Charme und lässt jede Stimme gleichberechtigt zu Wort kommen. Keine Version scheint einer anderen übergeordnet zu sein, wirkt stärker oder schwächer, sodass sich hier von einer tatsächlichen Gleichrangigkeit sprechen lässt.

2. Monozentrische Werkzyklen

Eine monozentrische Werkdisposition geht meistens mit einer Hierarchiebildung unter den Werken einher. Innerhalb einer Werkentität können die Werke beispielsweise in Haupt- und Nebenwerke unterteilt werden. Claus-Steffen Mahnkopf verwendet für die Kammermusikstücke seines Orchesterwerks Medusa etwa den Begriff des "Subwerks" ${ }^{4}$. Darin schwingt bereits eine untergeordnete Stellung der Werke im Gesamtkontext mit. Zwar handelt es sich bei den Solo- und Kammermusikstücken nicht um „schwache“ Versionen - in dem Moment, in dem sie für sich stehen und sich der Wahrnehmungsfokus auf sie richten kann, sind sie in sich stimmig -, in einer Gesamtaufführung werden sie vom Orchester aber teilweise einfach geschluckt, insbesondere das Cembalostück Pegasos geht in der Orchesterversion gnadenlos unter.

Auch ob es sich um eine mono- oder multizentrische Werkdisposition handelt, ist nicht bei jedem Poly-Werk eindeutig und objektiv zu bestimmen. Denn es geht ja nicht nur um die Frage, welche Werke sich aufgrund ihrer Besetzungsstärke oder Satzdichte akustisch am besten durchsetzen können, sondern auch darum, inwieweit es sich um qualitativ stärkere oder schwächere Versionen handelt. Diese Frage schneidet das Feld der Interpretation und der Rezeption, unterliegt also auch einer subjektiven Bewertung. Beispielsweise handelt es sich bei dem Zyklus „... Einklang freier Wesen ... “von Georg Friedrich Haas um eine multizentrische Anlage, da sich zehn für sich stehende Einzelstimmen auch untereinander zu dem Stück mit dem Titel ,... aus freier Lust ... verbunden ..." zusammenschließen können. Dennoch würde ich dazu tendieren, die Gesamtfassung ,... Einklang freier Wesen ...", die alle zehn Stimmen umfasst, in der Rezeption als eine Hauptfassung wahrzunehmen, dagegen die Aufführung einer Einzelstimme als eine Nebenfassung. Damit würde dieses Werk beide Möglichkeiten in sich tragen. Mit der Gesamtfassung hätte das Werk ein eindeutiges Zentrum. Die anderen Versionen haben - im Vergleich zur

7 Mahnkopf: „Medusa“, S. 245 . 
Hauptfassung - zwar eine Nebenstellung, sind untereinander aber mehr oder weniger gleichrangig und damit multizentral.

\subsection{Möglichkeiten der zeitlich-horizontalen Lageposition}

Dieser Punkt betrifft das Verhältnis von Sukzessivität und Simultaneität, meint also das Ausmaß der zeitlich horizontalen Ineinanderschiebung der Werke. Die Spannbreite reicht von einer Überlappung, die nur wenige Takte umfasst, bis zu einer vollständigen Überlappung. Eine nur wenige Takte andauernde Überlappung ist meines Erachtens zu marginal, um unter der Rubrik „PolyWerk" thematisiert zu werden. Kompositorisch stellt sie nicht die gleiche substanzielle Herausforderung bezüglich der Verknüpfung von Werken dar wie das Übereinanderlegen längerer Abschnitte. Die folgenden drei Möglichkeiten umfassen erstens die teilweise Überlappung - wobei als Faustregel gilt, dass die simultane Dauer gegenüber der Einzel- oder der rein sukzessiven Dauer als dominierend wahrgenommen wird -, zweitens die verschachtelte Überlappung - die die Möglichkeit vorsieht, die Einzelstücke in zeitliche Abschnitte zu schneiden und diese in ihrer Originalreihenfolge über die Gesamtdauer zu verteilen - und drittens die vollständige Überlappung.

1. Teilüberlappungen

Die Werke überlappen sich nur für einen Teil ihrer Dauer. Diese simultane „Teilstrecke“ sollte nicht viel kürzer sein als die „Einzelstrecke“, damit die Simultaneität auch tatsächlich einen Effekt entfalten kann. Ein Beispiel für eine simultane Teilüberlappung stammt von Klaus Huber, dessen Protuberanzen drei Orchesterstücke vereinen, die sowohl sukzessive als auch simultan überlappend aufführbar sind (vgl. Kapitel 4.3.4). Dieser Zusammenführung liegt eine genau kalkulierte Konzeption zugrunde, die die Voraussetzung für die Synthese der drei Stücke zu einem Stück ist.

2. Verschachtelung

Die zweite Möglichkeit umfasst Stücke, die zwar vollständig Teil einer Simultaneisierung sind, aber in der simultanen Form nicht am Stück durchgespielt werden. Stattdessen werden sie in Abschnitte geteilt, die über die Gesamtdauer verteilt werden. Dadurch ergibt sich eine formale Ineinanderverschachtelung der Stücke, die auch Pausen und Unterbrechungen in den musikalischen Text einlässt, die ein reizvolles dramaturgisches Gestaltungsmittel sein können. Als Beispiel kommen die Echoräume von Ulrich Kreppein in Betracht (vgl. Kapitel 4.3.5). Hier vereinigen sich vier Kammermusikstücke zu einem Ensemblestück. Die Stücke werden nicht durchgehend gespielt, sondern in kurze Abschnitte 
zerteilt, die der Gesamtdramaturgie entsprechend über die Gesamtdauer von zwanzig Minuten gelegt werden. Mithilfe eines Planes und der Angabe von Orientierungszeiten werden die jeweiligen Einsatzpunkte für die vier Ensembles vermittelt.

3. Vollständige Überlappung

Die Form einer vollständigen Überlappung ist die verbreitetste Variante. Anfangs- und Endpunkt der Stücke fallen zusammen, und auch im Verlauf gibt es keine Schnitte und Unterbrechungen. Beispiele sind die beiden Streichquartette Nr. 14 \& 15 von Darius Milhaud, der Zyklus „... Einklang freier Wesen ..." von Georg Friedrich Haas, der Yuunohui Cycle von Julio Estrada oder auch Simon Steen-Andersens Zyklus Next To Beside Besides.

\subsection{Möglichkeiten der vertikalen Lageposition}

Neben den verschiedenen Möglichkeiten der Lagepositionierung in der horizontal-zeitlichen Dimension gibt es auch verschiedene Optionen, die Stücke in ihrer Körperlichkeit zusammenzubringen, sie einander entweder frontal gegenüberzustellen oder sie miteinander zu verschränken. Grundsätzlich handelt es sich bei den meisten Vorgehensweisen um additive Praktiken. Aber auch die Subtraktion als umgekehrte Form der Addition ist möglich, wenngleich sie nicht immer eindeutig als solche zu bestimmen ist.

1. Einfache Addition

Bei der einfachen Addition handelt es sich um eine Gegenüberstellung der verschiedenen, oft "gleichrangigen“ Werke. Denn häufig entsprechen die Werke einander in ihrer Dauer und ihrer Besetzung und überlappen sich vollständig oder fast vollständig. Ähnlich wie die vollständige Überlappung ist die einfache Addition die verbreitetste Variante. Beispiele sind auch hier die beiden Streichquartette Nr. 14 \& 15 von Darius Milhaud, der Yuunohui Cycle von Julio Estrada oder auch Simon Steen-Andersens Zyklus Next To Beside Besides.

2. Integration

Integration bedeutet, dass „kleinere“ Stücke in eine größere Werkentität integriert werden. Es handelt es sich also um eine Zusammenführung ungleich starker Werkteile. So ist beispielsweise Claus-Steffen Mahnkopfs Medusa-Zyklus organisiert. Das Oboenkonzert als Dachkomposition nimmt verschiedene kleinere Subwerke, die solistisch oder kammermusikalisch besetzt sind, in sich auf. Die Solo- und Kammermusikstücke sind in ihrer Besetzung dem Orchesterstück zahlenmäßig unterlegen, haben aber auch eine kürzere Dauer. Weitere Beispiele sind 
Berios Chemins - eine Ensemblereihe, die einige der Sequenzae weiterkomponiert - und Richard Barretts Opening of the Mouth. Alle drei Beispiele sind unidirektional, das heißt das größere Werk kann ohne das aufzunehmende Werk nicht selbstständig aufgeführt werden (vgl. Kapitel 4.1).

3. Kreuzende Addition

Bei der kreuzenden Addition wird der musikalische Text zwar im Original beibehalten, aber einzelne musikalische Ebenen können in der Simultanversion bidirektional ausgetauscht und dadurch sehr eng miteinander verschränkt werden. Dieses Verfahren setzt bei den Werken in der Regel den gleichen zeitlichen Rahmen und die dieselbe Anzahl von Instrumenten voraus. Ein Beispiel stammt von Valerio Sannicandro. Seine Tactile Songs I-II (2017-2018) umfassen zwei Quartettreihen, die auch simultan gespielt werden können. Die erste Reihe ist mit Bassflöte, Violoncello, Gitarre und Percussion besetzt, die zweite Reihe mit Bassflöte, Klarinette, Viola und Percussion. Beide Quartette können eigenständig oder auch simultan aufgeführt werden und darüber hinaus auch in Fassungen, in denen die Instrumentenschichten teilweise ausgetauscht werden, sodass also Bassflöte und Percussion aus dem ersten Zyklus gleichzeitig mit Klarinette und Viola aus dem zweiten Zyklus gespielt werden. Durch diese zusätzliche Option können trotz einer zahlenmäßig festgelegten Rahmenbesetzung zusätzliche Aufführungsformen erzeugt werden. Auch mein Stück X-Pieces ist ein Beispiel für eine kreuzende Addition. Hier werden die Sologanzheiten in eine Artikulations- und Fingerebene aufgespalten, die werk- und spielerübergreifend austauschbar sind. Beispielsweise kann sich die Artikulationsebene des einen Stückes mit der Fingerstimme des anderen Stückes als Solo/Duo auf einer Flöte, gespielt von zwei Spielern, verbinden (vgl. Kapitel 5.2).

4. Subtraktion

Hier handelt es sich um eine Umkehrung des Integrationsprozesses, also die Herausnahme kleinerer Stücke aus einem größeren Werkkontext. $\mathrm{Ob}$ eine Schicht hinzugefügt oder weggenommen wird, ist einerseits lediglich eine Frage der Perspektive - denn ein Poly-Werk kann von zwei Seiten gedacht und gehört werden - und kann andererseits das Resultat einer komplexen Werkgenese sein. Entscheidet der Komponist erst im Nachhinein oder in einem weit fortgeschrittenen Stadium des Kompositionsprozesses, eine oder mehrere Stimmen aus einem größeren Kontext als selbstständige Werke herauszueinzeln, dann wird das "Mehr“ an Werkversionen tatsächlich durch eine Reduktion, ein Wegnahme von Schichten erzeugt. Klaus Hubers Trio Schattenblätter (1975) könnte 
ein Beispiel für eine subtraktive Werkgenese darstellen. Im Mittelpunkt steht die Trioversion. Es sind jedoch sowohl alle Duokombinationen als auch der asketische und karge Solopart des Klaviers mit dem Titel Blätterlos unabhängig aufführbar. ${ }^{8}$ Die Frage, ob eine Addition oder eine Subtraktion vorliegt, ist nicht immer eindeutig zu beantworten. Ich würde beispielsweise bei Georg Friedrich Haas' Zyklus ,... Einklang freier Wesen ..." dazu tendieren, die Herauseinzelung der Solo- und Kammermusikversionen als einen subtraktiven Prozess zu bezeichnen. Ähnlich wie bei Hubers Schattenblätter steht die Gesamtfassung als eine Art Hauptwerk und Mittelpunkt über dem Ganzen. Beide Werke sind nicht in einem Wachstumsprozess entstanden, wie es bei Julio Estradas Yuunohui Cycle der Fall ist, sondern gehen von einer klaren Rahmensetzung aus, die nicht überschritten, sondern nur unterschritten werden kann.

\subsection{Synchrone und asynchrone Prozesse}

Eine weitere Schlüsselkategorie im interformalen Verhältnis ist der Grad der Synchronität oder Asynchronität zwischen den einzelnen Werken, unabhängig von der Materialverwandtschaft. Dieses Kategorie verteilt sich auf die verschiedenen musikalischen Ebenen eines Stückes wie die Metrik, das Tempo, die Harmonik, die Form usw. Man könnte diesen Punkt auch als Polysierung bezeichnen, da es darum geht, den Grad der Unabhängigkeit verschiedener Verläufe zu bestimmen. Es ist immer die Frage, welche Ebenen synchronisiert, möglicherweise sogar identisch sind und auf welchen Ebenen die Differenzen zwischen den Stücken geschaffen werden. Jedes Poly-Werk kombiniert und ordnet diese Möglichkeiten für sich neu. Im Schnitt gibt es aber in allen PolyWerken Ebenen, die stark übereinstimmen, und Ebenen, die divergierende Verläufe ermöglichen. Wahrscheinlich ist gerade diese Ausgewogenheit zwischen Konvergenz und Divergenz die Voraussetzung, um auf der einen Seite keine zu große Übereinstimmung und auf der anderen kein beliebiges Chaos zuzulassen, sondern die konvergenten und divergenten Prozesse sehr bewusst gestalten zu können.

8 Klaus Huber hat seine Intention zu Werkreduktionen in einem anderen Zusammenhang einmal folgendermaßen beschrieben: „Während einige Komponisten dazu neigen, früher komponierte Werke dergestalt zu rekomponieren, daß sie allen denkbaren Ansätzen zur Erweiterung und Komplexierung nachspüren (exemplarisch Pierre Boulez in ,Notations'), bevorzuge ich seit mehr als zwanzig Jahren den umgekehrten Weg. Ich suche nach möglichen Reduktionen." Siehe auch Klaus Huber in: Huber/Nyffeler (Hg.): Umgepflügte Zeit, S. 442 . 
1. Dauer

Bereits die Dauer der Stücke ist eine wichtige Kategorie bei ihrer Zusammenführung. Entweder sie haben denselben zeitlichen Rahmen und können sich dadurch auch vollständig überlappen, oder sie unterscheiden sich in ihrer zeitlichen Dauer sehr stark voneinander, sodass für die Zusammenführung ein eigener Plan nötig wird, der festlegt, wie sich die Stücke entweder überlappen oder ineinander verschachtelt werden.

2. Instrumentation, Klangfarben, Spielpraxis

Die Ebene der Instrumentation betrifft einerseits die Anzahl der Besetzungen, aber auch die Frage, inwieweit sich identische, ähnliche oder sehr unterschiedliche Besetzungsformen gegenüberstehen, die den Grad der Verschmelzung zwischen den Werken entweder fördern oder auf Kontrast zielen.

Beispielsweise handelt es sich bei den beiden Streichquartetten Nr. 14 \& 15 von Darius Milhaud um zwei völlig unterschiedliche Werkidentitäten, was das Material betrifft. Trotzdem wird durch die gleiche Besetzung von zwei mal vier Streichern auch eine starke Verschmelzung der beiden Werke gefördert (vgl. Kapitel 4.3.1). Ein Gegenbeispiel stammt von Chaya Czernowin. Ihr Anea Crystal Cycle ist ebenso für zwei Streichquartette komponiert, die auch gleichzeitig gespielt werden können. Czernowin allerdings unterstreicht die Heterogenität des Materials durch die unterschiedlichen Spieltechniken beider Quartette, zum Beispiel Pizzicatospiel im ersten und Arcospiel im zweiten Quartett. Dadurch sind beide Quartette bei einer Simultanaufführung über weite Strecken gut voneinander abgrenzbar und unterscheidbar (vgl. Kapitel 4.3.2).

3. Metrum

In der Regel ist das Metrum der Puls des Stückes und daher eine sehr zentrale Kategorie in der zeitlich-organisatorischen Gestaltung. Entweder die Werke sind metrisch synchronisiert oder polymetrisch. Die meisten Poly-Werke teilen dasselbe Metrum. In Chaya Czernowings Anea Crystal Cycle sind die Metren dagegen teilweise extrem gegensätzlich. Die Heterogenität des Materials wird so durch eine zeitliche Heterogenität unterstrichen. Während das zweite Quartett in geradtaktigen Metren gruppiert ist, ist die Metrik des ersten Quartettes sehr stark von Doppelbruchmetrik geprägt (vgl. Kapitel 4.3.2).

4. Tempo

Auch das Tempo ist ein Schlüsselfaktor auf der zeitlich-organisatorischen Ebene. In den meisten Poly-Werken sind die Teilwerke im Tempo synchronisiert. Nicht jedoch im Anea Crystal Cycle von Chaya Czernowin. 
Die Tempoangaben für beide Quartette sind unterschiedlich und wechseln zu unterschiedlichen Zeiten. Auch in den Echoräumen von Ulrich Kreppein sind die Tempi für jedes Einzelwerk individuell (vgl. Kapitel 4.3.5).

5. Lineare Formprozesse

Der Formverlauf der Einzelwerke, ihre Ereignistemporalität, ist als Polylinearität das wahrscheinlich aufschlussreichste Kriterium, um den Grad der Individualität der Einzelwerke zu bestimmen. Sind Zäsuren, Formabschnitte, Höhepunkte, dramaturgische Entwicklungen etc. über die Werkgrenzen hinweg synchronisiert oder gerade nicht? Ein wesentlicher Grund für die kohärente Wirkung des Werks „... Einklang freier Wesen ..." von Georg Friedrich Haas ist die Übereinstimmung der Abschnitte, Zäsuren und Entwicklungen, die für alle Instrumente verbindlich sind.

Für die Gestaltung der Formverläufe entfaltet der Begriff der Formpolyphonie, der mit den Werken von Robert HP Platz in Verbindung gebracht wird, hier seine eigentliche Bedeutung. Er bezeichnet entweder die Anwendung unterschiedlicher Formtypen innerhalb eines Ganzen oder den Entwurf individueller unterschiedlicher Formen, die in einem Poly-Werk miteinander kombiniert werden. In beiden Fällen zielt er auf eine Divergenz der kombinierten Formen. Im Medusa-Zyklus entwirft Mahnkopf entweder für jedes Einzelwerk eine individuelle Form oder wendet einen spezifischen Formtypus an, passt diesen aber präzise in die Gesamtform ein. Auch hier ist also der Fall einer Formpolyphonie gegeben. Das ist ebenso im Yuunohui Cycle von Julio Estrada der Fall. Simultane Formereignisse wie ein gemeinsamer Höhepunkt oder eine gemeinsame Zäsur entstehen hier vor allem zufällig zwischen den Soli. Estrada zielt trotz der übereinstimmenden Metrik, Tempi und Dauer eher auf ein zeitliches Nebeneinander in den linearen Formprozessen. Häufig liegen allerdings auch Mischformen vor, das heißt die Makrooder Metaform eines Werks ist beispielsweise für alle Teilwerke verbindlich, aber die mikroformalen Entwicklungen der einzelnen Abschnitte weichen voneinander $a b$ und sind individualisiert. Beispiele dafür sind die Streichquartette von Milhaud und der Anea Crystal Cycle von Czernowin.

6. Harmonik

Auch die harmonische Behandlung ist eine wesentliche Komponente in Bezug auf Individualität, Divergenz, Verschmelzungsfähigkeit etc. Georg Friedrich Haas hat für das Werk ,... Einklang freier Wesen ...“ im Vorfeld einen harmonischen Plan entworfen, an den alle 
Instrumentalschichten gebunden sind, das heißt alle Solostimmen folgen derselben Harmonik. Das lässt sie einerseits sehr gut miteinander verschmelzen, andererseits werden sie dadurch in ihrer melodischen Beweglichkeit sehr eingeschränkt (vgl. Kapitel 4.2.1.1.3).

Im Gegensatz dazu ist in Milhauds Streichquartetten der polytonale Tonsatz ein entscheidendes Kriterium, um Individualität und Divergenz zwischen den Quartetten zu erzeugen. Milhaud schichtet sorglos verschiedenste Tonarten übereinander und unterstreicht so die Heterogenität der Quartette. Ebenso ermöglicht ihm die Polytonalität, harmonische Brücken zwischen den Quartetten zu bauen. Durch die Kombination von Polytonalität und Poly-Werk wird harmonisch ein sehr hoher Grad an Mehrdeutigkeit erreicht (vgl. Kapitel 4.3.1). 


\section{Analysen}

In den ersten drei Kapiteln dieser Arbeit ging es in erster Linie um eine ästhetische, formale, ideengeschichtliche und begriffliche Verortung des Prinzips simultaner Werkkonstellationen und ihrer Genese. Der in Kapitel 3 entfaltete Leitfaden zur Interform hat nicht die Funktion eines hermetischen Modells. Vielmehr ging es um den Aufbau einer neuen Formenkategorie die im Dazwischen der Werke angesiedelt ist. Dies ermöglicht es, die Vielfalt der Werke unter der Perspektive der Werkzusammenführung zu bündeln und umgekehrt die Möglichkeiten des Poly-Werkes vielfältig aufzufächern.

Aufgrund der breiten Streuung der Poly-Werke über kulturelle, stilistische und ästhetische Grenzen hinweg bildet auch die folgende Auswahl sehr unterschiedliche künstlerische Positionen, Physiognomien, Stile, Techniken und Klangsprachen ab. Die Werke werden vorgestellt, in Hinblick auf eine Theoriebildung zusammengefasst und stellenweise auch miteinander verglichen. Gerade die Heterogenität auf „allen“ Ebenen bildet im Vergleichsprozess eine wesentliche Voraussetzung. Filtert man die Tendenzen und Züge der Formenbildung heraus, ist bis zu einem gewissen Grad tatsächlich eine Modellbildung möglich, die aus den Anlageformen der Werke selbst hervorgeht.

Die Gliederung der Analysen folgt einer formalen Einteilung der verschiedenen Möglichkeiten der Werkkopplung (vgl. Abb. 3). Der erste Teil behandelt den Prozess der Integration kleinerer in größere Werke. Als Hinführung zur Thematik des Poly-Werks werden hier Werke angesprochen, die nur einseitig ein einzelnes Werk oder mehrere kleine Werke in ein größeres Ganzes integrieren, aber nicht verschiedene eigenständige Werke simultan zusammenführen. Im zweiten und dritten Teil werden Beispiele und Möglichkeiten additiver Werkkopplungen entlang der Untergliederung in homogene und heterogene Werkgruppen diskutiert. Im Anschluss wird jeweils ein Beispiel für eine überlappende und eine verschachtelte Kopplung vorgestellt. Im Mittelpunkt der Werkbetrachtungen steht die Analyse der Beziehung, die die Werke zueinander einnehmen. 
a) Integration kleinerer Werke in ein größeres Werk

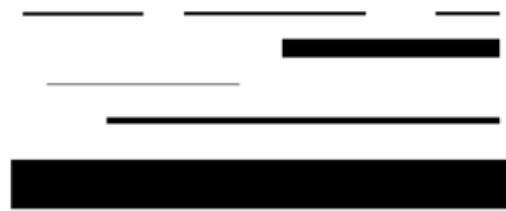

c) Überlappung
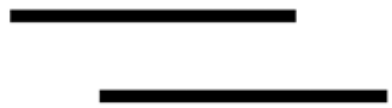

Abb. 3 Verschiedene Möglichkeiten der Werkkopplung. b) einfache Addition
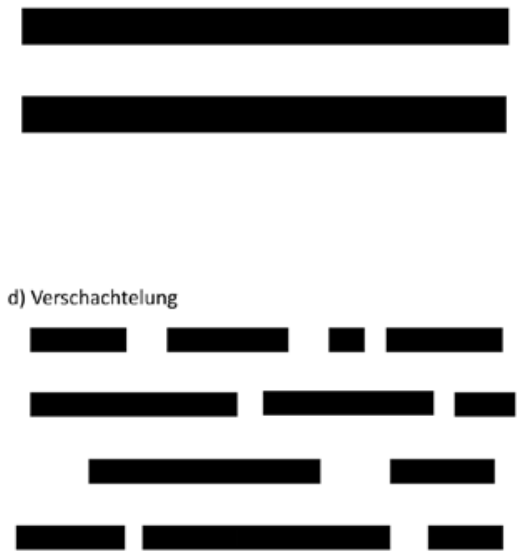

\subsection{Integration}

In den hier vorgestellten Beispielen geht es um Kompositionen, die vollständig und so gut wie originalgetreu in größere Werkkontexte integriert wurden. Zu den Werken, die so entstanden sind, gehört beispielsweise L'âge de notre ombre von Klaus Huber, das er 1998 für Altflöte, Viola d'Amore und Harfe komponiert hat und das als Stück in dem Septett L'ombre de notre âge aus dem Jahre 1999 enthalten ist. Ein anderes Beispiel ist Knights of the strange (2015) für elektrische Gitarre und Akkordeon von Chaya Czernowin, das vollständig in eine Ensembleversion mit dem gleichen Titel integriert wurde. Richard Barrett fasst in seinem vielschichtigen Rahmenwerk Opening of the Mouth (1992-1997) verschiedene Soli und Duos in ursprünglicher und modifizierter Form ${ }^{1}$ zusammen. Das Stück the green is either (2003) von Aaron Cassidy ist als Septett eine Verknüpfung dreier verschachtelter Trios und enthält darüber hinaus die drei Stücke the green is or für Oboe, the green is where für Solo Violine und a/grammatical study for three (quasi-)independent players für Violine, Oboe und Percussion.

All diese Stücke haben gemeinsam, dass sie innerhalb einer neuen Werkumgebung kontextualisiert werden und damit eine Perspektive erhalten, die außerhalb ihrer eigenen Werkgrenzen liegt. Damit teilen sie mit den PolyWerken das Merkmal der Überschreibung oder Einbettung des originalen

1 Zum Beispiel: CHARON für Bassklarinette, inward für Flöte und Percussion oder air für Violine. 
Textes in ein neues Werk, das das ursprüngliche singuläre Werk entweder als Überbau oder als palimpsestartige Überschreibung neu situiert. Der Unterschied ist, dass die neu geschaffene Werkumgebung nicht ohne das zugrunde liegende Werk existieren kann. Das so entstehende neue, dritte Werk entsteht also nicht aus einer Zusammenführung zweier eigenständiger Werke. Darin liegt ein entscheidender Unterschied zum Poly-Werk: Während das Palimpsest (oder der Überbau) von einem Werk zu einem zweiten weiteren Werk führt, müssen in einem Poly-Werk immer mindestens drei Werke entstehen, zwei singuläre und ein simultanes Werk.

Bei dieser Form der integrativen Variante ist die Werkpolyphonie nur in eine Richtung gegeben, denn die aufnehmenden Werkteile selbst sind nicht voll- und selbstständig aufführbar. Sie sind entweder Weiterkompositionen, Vergrößerungen oder Transkriptionen, die auf der Ausgangskomposition basieren, wie beispielsweise die Chemins von Luciano Berio (1925-2003) auf den verarbeiteten Sequenzae. Hier ist die Expansion einem Variationsgedanken verbunden, der auf Erweiterung beruht. Das schließt den Kontrast zwar nicht aus, trotzdem verdankt sich die Verbindung der einzelnen Werkstufen einer organisch wachsenden und dadurch tendenziell homogenen Weiterentwicklung des Werks. Umgekehrt ist der Medusa-Zyklus von Claus-Steffen Mahnkopf aus den Jahren 1990-1992 ein Beispiel für eine unidirektionale Werkintegration, die nicht auf dem Prinzip der Transkription beruht, sondern verschiedene heterogene Werke in einer umklammernden, in sich geschlossenen Rahmenkomposition zusammenbringt.

Im Kontext der Poly-Werk-Diskussion in dieser Arbeit werden die unidirektionalen Werke als zur Thematik hinführende Beispiele behandelt, da es mehrere Übereinstimmungen mit spezifischen Merkmalen des PolyWerks gibt. Wie beim Poly-Werk erhält das ursprünglich singulär gedachte Werk durch die Kontextualisierung eine neue Position und Funktion sowie eine neue Perspektive. Wenn beispielsweise aus dem ursprünglichen Solowerk eine flankierende Orchesterstimme wird, ändert sich quasi der Status des Werks. Dieser mögliche Rollenwechsel wirft die Frage auf, in welchem Bezug das Eine zu den verschiedenen Funktionen, in die es treten kann, steht?

Darüber hinaus sind die verschiedenen Kategorien des interformalen Profils auch für unidirektionale Werkentwicklungen relevant. Die zentrale Unterscheidung homogen/heterogen knüpft sich auch hier an die Materialentwicklung über die Stücke hinweg. Ist das aufnehmende Werk eine homogene Weiterentwicklung, die in der ursprünglichen Idee noch verwurzelt ist und diese durch Techniken der Variation, Bearbeitung, Transkription, Überschreibung weiter ausbaut, oder handelt es sich um einen völlig neuen Überbau, der das singuläre Werk in sich aufnimmt? Während man sich die erste 
Variante eher als unendliche Fortschreibung denken kann, verweist die zweite Variante auf eine neu gesetzte Rahmendisposition.

Weiterhin sind zwischen den uni- und den polydirektionalen Werktypen auch fließende Übergänge vorstellbar, die eine eindeutige Abgrenzung zum Poly-Werk gar nicht möglich machen, etwa wenn ein Werk mehrere eigenständige Werke umfasst, die sowohl untereinander kombiniert als auch in eine größere nichtselbstständige Dachkomposition eingegliedert werden können, wie es im Medusa-Zyklus von Claus-Steffen Mahnkopf der Fall ist.

\subsubsection{D'une ouvre à l'autre - Die Sequenzae und Chemins von Luciano Berio}

„Ich bin besessen von der Idee, dass man alles auch aus einer anderen Perspektive betrachten kann.“

(Luciano Berio)

In Das offene Kunstwerk führt Umberto Eco die Sequenza I für Flöte als Beispiel für eine „individualisierte[...] Formativität ${ }^{2}$ an. Berio hat in der ersten Version die Notendauern nicht exakt determiniert, sondern grafisch angedeutet, was dem Spieler einen gewissen Spielraum in der Gestaltung der Dauern einräumt. ${ }^{3}$ Offenheit bezeichnet in diesem Fall also eine bewusst uneindeutige Angabe in der Notation. Eine andere Form der Offenheit liegt dann vor, wenn der Interpret zwischen verschiedenen vorgegebenen Möglichkeiten eine Auswahl treffen kann. Diese zweite Form der Offenheit kann in gewisser Weise auch für das Poly-Werk geltend gemacht werden, denn auch hier stellt der Komponist verschiedene Möglichkeiten der Werkausführung zur Auswahl. Um diese zweite Form der Offenheit soll es im Folgenden gehen.

Die Sequenza I für Flöte bildet den Auftakt zur berühmten Werkreihe der Sequenzae, einer Sammlung von vierzehn Solostücken für verschiedene Soloinstrumente, entstanden im Zeitraum 1958-2002. Sieben Stücke dieser Reihe hat Berio zum Ausgangspunkt der Werkreihe Chemins (und des Corale) genommen, einer Serie von Ensemble- und Orchesterversionen, die parallel zu den Sequenzae entstandenen sind. Folgende Sequenzae wurden in die Chemins integriert:

2 Eco, Das offene Kunstwerk, S. 55.

3 In einer späteren Version überarbeitete Berio die Notation und transkribierte den Rhythmus in exakte Dauern. 
- Sequenza II für Harfe, $1963 \rightarrow$ Chemins I für Harfe und Orchester, 1965

- Sequenza VI für Viola, $1967 \rightarrow$ Chemins II für Viola und neun Instrumente, $1967 \rightarrow$ Chemins IIb/c, 1970/72 $\rightarrow$ Chemins III, 1968

- Sequenza VII für Oboe, 1969 $\rightarrow$ Chemins IV, 1975

- Sequenza VIII für Violine, 1981 $\rightarrow$ Corale für Violine, zwei Hörner und Streicher, 1980-1981

- Sequenza XI für Gitarre, $1988 \rightarrow$ Chemins $V$ für Gitarre und Kammerorchester, 1992

- Sequenza X für Trompete in C und Klavier (als Resonator), 1984 $\rightarrow$ Kol od/ Chemins VI für Trompete und Kammerorchester, 1996

- Sequenza XIb für Altsaxophon, 1981 $\rightarrow$ Récit/Chemins VII für Altsaxophon und kleines Orchester, 1996

Sind die Sequenzae einerseits eigenständige Solostücke, werden sie gleichzeitig auch als musikalisches Material aufgefasst, das mittels kompositorischer Techniken wie Transkription und Vergrößerung in einen neuen Ensembleoder Orchestersatz integriert wird.

„... Rien n'est jamais fini. Même l'œuvre achevée est le rite et le commentaire de quelque chose qui a eu lieu avant, de quelque chose qui arrivera plus tard. La question ne provoque pas une réponse, mais un commentaire ... et une autre question ..." 4

Das Zitat verdeutlicht, dass es in Berios Werkverständnis nicht um einen kompositorischen Abschluss ging, sondern vielmehr um eine Werkverkettung, deren einzelne Glieder neue offene Türen sind. Diese Grundhaltung ist essenziell für Berios kompositorisches Schaffen. Bearbeitungen, Transkriptionen, Revisionen, Weiterkompositionen, Arrangements, Instrumentationen und Collagen sind typisch für seine Arbeitsweise. ${ }^{5}$ Dahinter steckt auch der spielerische Ansatz, musikalisches Material als so modellierbar und anpassungsfähig aufzufassen, dass es immer wieder in neue Zusammenhänge gestellt werden kann. Mit diesem Verständnis kann man sich auch den Sequenzae nähern. Gelten sie allgemein als Stücke, in denen vor allem spieltechnische und klangfarbliche Möglichkeiten der verschiedenen Instrumente erforscht werden, ergibt sich aus kompositorischer Sicht vor allem eine konzeptionelle Perspektive auf den Zyklus, wenn man sich die eigentliche

4 Luciano Berio, Paris, 18.3.1978, zitiert nach Stoianova: Luciano Berio - Chemins en musique, S. 425 .

5 Siehe auch Thomas Gartmann: ... dass nichts an sich jemals vollendet ist. Untersuchungen zum Instrumentalschaffen von Luciano Berio (= Publikationen der Schweizerischen Musikforschenden Gesellschaft, Serie 2, Bd. 37), Bern: Paul Haupt, 1994, S. 99-156. 
Definition einer Sequenz vergegenwärtigt, die durch die imitatorische Fortsetzung musikalischer Motive und Bewegungen definiert wird: „Sequenzen wirken strukturbildend, indem sie unser Ohr darauf programmieren, eine Fortsetzung zu erwarten." ${ }^{\prime \prime}$

„Das Beharren auf einer einmal begonnenen Bewegung, die dabei entstehende innere Logik der Wiederholung und das gleichzeitige Zurücktreten der harmonischen Funktionen macht [sic] die Sequenz zum gestalterischen Gegenspieler der Kadenz, die stets auf einen Abschluss hinzielt. [...] Die Kadenz setzt eine deutliche Zäsur, während die Sequenz weiterdrängt. ${ }^{47}$

Anknüpfend an traditionelle Modelle wird das Variationsprinzip dabei zum wesentlichen Element, um die Initialidee einer Sequenza fortzuspinnen. Es wirkt von zwei Seiten: einmal als schrittweise, "graduelle morphologische Verwandlung der ursprünglichen Strukturelemente ${ }^{\text {“8 }}$ und zum anderen als Erweiterung der Strukturelemente. Als morphologische Verwandlung greift das Variationsprinzip vor allem innerhalb der Sequenzakomposition, als erweiternde Variation greift es vor allem nach außen, da die Sequenza zum Ausgangspunkt einer expansiven Transkription umgedeutet wird. Der musikalische Text der Sequenzae wird in der Transkription nicht variiert, sondern weitgehend originalgetreu übernommen. Seine Erweiterung durch die neuen Ensemblestimmen schließt variative, ergänzende und kontrastierende Elemente ein.

„... La transcription m'intéresse à partir du moment où elle échappe à une définition rigide, à partir du moment où elle n'est plus une opération de restauration d'un passé, que ce soit un passé personnel ou le passé de notre histoire culturelle. La transcription m'intéresse quand elle cherche à étudier et à découvrir la musique comme ensemble de virtualités et pas seulement comme objet réel et fini; Enfin, quand elle n'est plus seulement transcription, mais aussi invention consciente....99

6 Reinhard Amon, Lexikon der Harmonielehre, Wien/München: Doblinger/Metzler, 2005, S. 230.

7 Ebd.

8 Vgl. hier Stefan Drees/Kurt von Fischer: „Art. Variation. Das 2o. Jahrhundert, Variation in der Musik nach 1945“, in: MGG Online, hg. von Laurenz Lütteken, Kassel/Stuttgart/New York, 2016 ff., veröffentlicht November 2016, https://www.mgg-online.com $/ \mathrm{mgg} / \mathrm{stable} / 57672$ (letzter Aufruf am 3.5.2020).

9 Luciano, Berio, Paris, 20.3.1978, zitiert nach Stoianova: Luciano Berio - Chemins en musique, S. $428 \mathrm{f}$. 
Sequenza VI für Viola $\rightarrow$ Chemins II $\rightarrow$ Chemins IIb/c $\rightarrow$ Chemins III

Die Sequenza VI für Viola wurde 1967 komponiert. Dabei handelt es sich um die einzige Sequenza der Serie, von welcher mehrere Chemins ihren Ausgangspunkt nehmen: Chemins II für Viola und neun Instrumente von 1967, Chemins III für Orchester von 1968 und Chemins IIb/c für Orchester von 1970/72.

Sequenza VI $\rightarrow$ Chemins II

Chemins II kann in die drei Gruppen der drei Bläser (Flöte, Klarinette und Posaune), der drei Streicher (Viola solo, Viola und Cello) und der drei weiteren Instrumente elektrische Orgel, Harfe und Schlagwerk unterteilt werden. Die Violastimme als Trägerstimme der Sequenza ist die fundamentgebende, führende Stimme innerhalb des Ensemblesatzes. Ihren Text behält sie bis auf einige wenige Änderungen weitgehend bei. Die Sequenza besteht in weiten Teilen aus zwei- bis vierstimmigen tremolierenden Akkordtexturen, die in der Ausarbeitung der Ensemble- und Orchesterversionen als harmonisches Band auf die anderen Instrumente übertragen, verstärkt und koloriert werden. Vor allem in der Kombination mit der elektronischen Orgel wird das Akkordband permanent verdoppelt, stabilisiert, aber auch erweitert. Auf diese Weise kommt der Sequenza die Funktion eines stabilisierenden Gerüstes zu, welches das Stück trägt und durch seine elektrisierenden Impulse vorantreibt. Der etwas zähe und sperrige Charakter der Violastimme wird so zur Grundlage eines rasanten und spielfreudigen Satzes.

Teilweise können die formalen Entwicklungen des Solostücks durch die Instrumentation noch stärker nachvollzogen werden. Im ersten Teil folgt der Akkordprozess einem chromatischen Anstieg in die Höhe, bis er sich im Abschnitt E auf dem dreistimmigen Akkord $b^{1}-\mathrm{as}^{2}-\mathrm{es}^{3}$ festhakt. Die Repetitionen der Violaakkorde werden von den anderen Instrumenten zum fünfstimmigen Akkord $\mathrm{e}^{1}-\mathrm{b}^{1}-\mathrm{f}^{2}-\mathrm{as}^{2}-\mathrm{es}^{3}$ ergänzt. Der bis dahin auf Steigerung ausgerichtete Akkordprozess erstarrt in einem sieben Takte dauernden Repetitionsmuster und löst sich in Takt 78 in den Chemins über das $\mathrm{e}^{2}$ der Soloviola implosionsartig in eine neue Entwicklung auf.

Neben diesen eher formbestätigenden Verläufen existiert ebenso die Möglichkeit der Trennung der formalen Verläufe zwischen Solist und Ensemble. Ab Ziffer $\mathrm{O}$ wird eine schnelle Zweiunddreißigstelquintole der Viola vom Ensemble nach und nach aufgegriffen und verdichtet sich $\mathrm{zu}$ einem fünfzehn Takte andauernden Band. Dieses geht in neue Zweiunddreißigstelbewegungen über, die sich bei Ziffer $\mathrm{T}$ auf einem erstarrenden, repetierenden Cluster im Fortissimo in der Höhe festsetzen. Die Viola hat an der Entwicklung des Ensemblesatzes nicht teil und ist im Abschnitt O-S längst 


\section{sequenza VI \\ per viola sola}
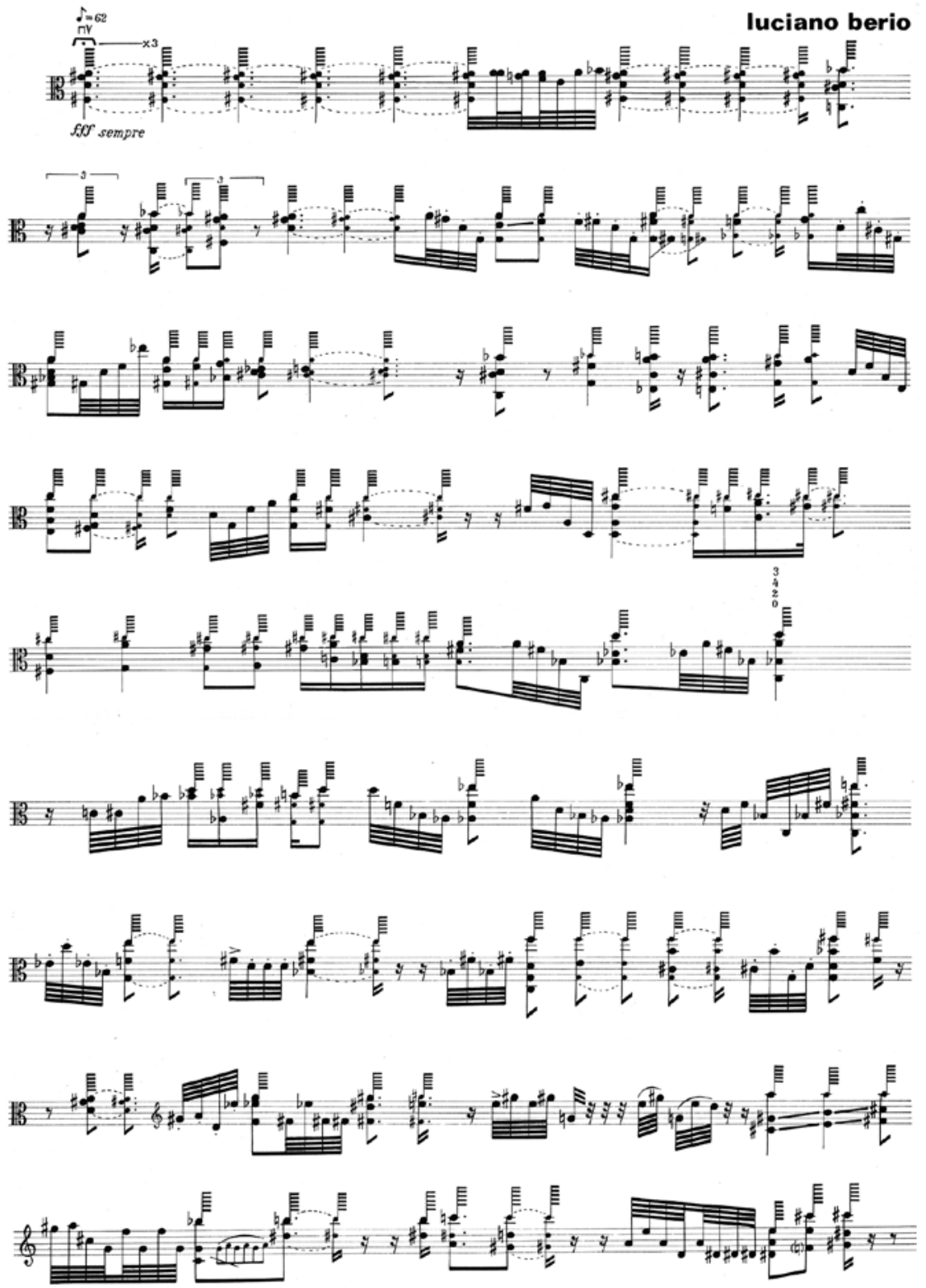

Abb. 4 Luciano Berio: Sequenza VI für Viola, 1967, S. 1. (c) 1970 by Universal Edition (London) Ltd., London. 

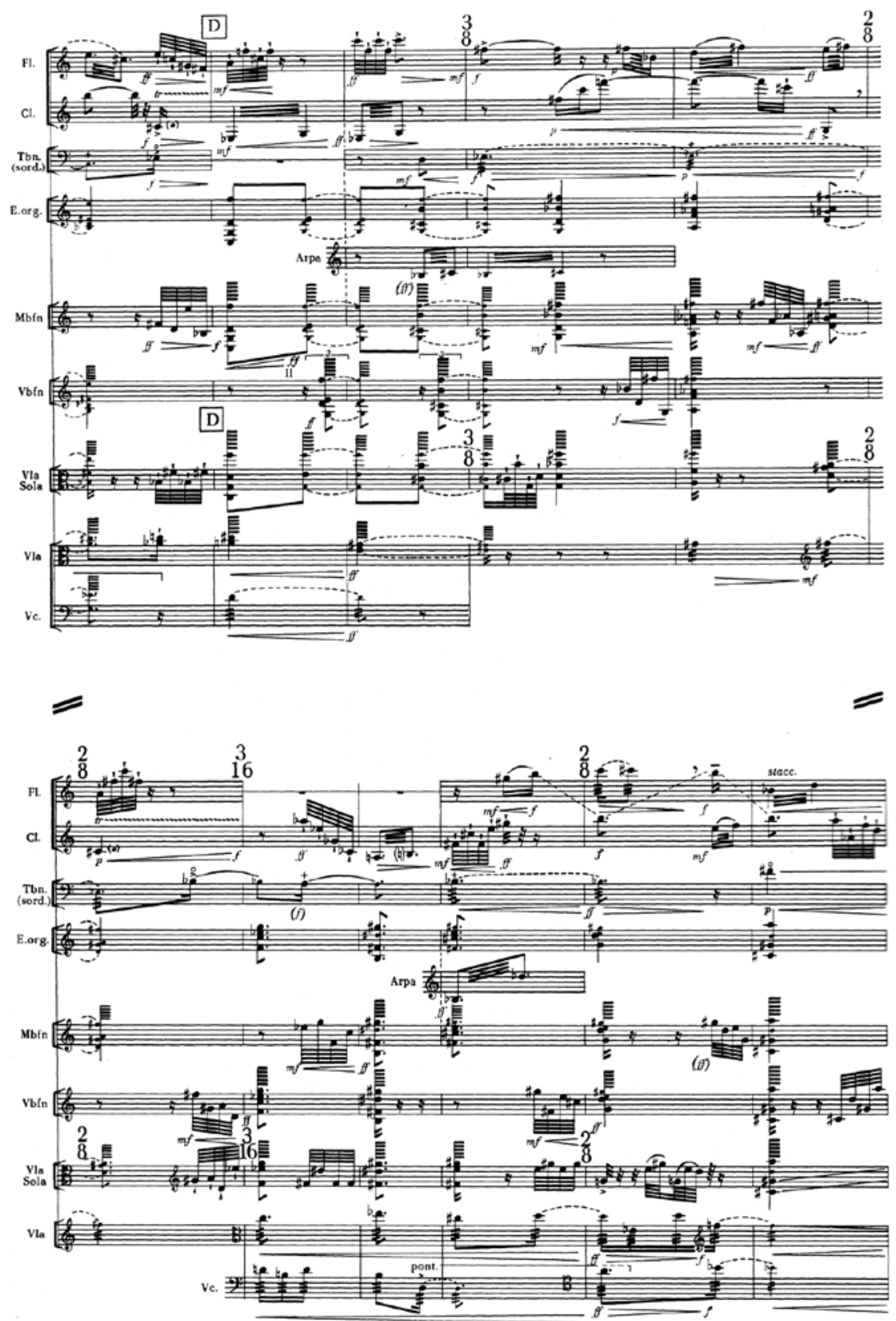

Abb. 5 Luciano Berio: Chemins II su Sequenza VI für Ensemble, 1967, Takte 47-57. (C) 1972 by Universal Edition (London), Ltd., London, (C) assigned to Universal Edition A. G., Wien. 
in ihren melodischen Mittelteil übergegangen, den sie während des Clusterabschnittes T vorübergehend unterbricht.

Chemins IIb/c

Das Instrumentarium wird in Chemins IIb/c auf ein unvollständiges Orchester erweitert. Neben der vorwiegend zweifachen Holz- und Blechbläserbesetzung gibt es drei Schlagzeuger, eine elektrische Gitarre, eine elektrische Orgel und Klavier. Die Soloviola wird durch eine Solovioline ersetzt, die Streicher setzen sich aus sechs Violen, vier Celli und drei Kontrabässen zusammen. Es gibt ein Bassklarinettensolo, das ad libitum gespielt werden kann. Ohne die Bassklarinette heißt der Werktitel Chemins IIb, mit Bassklarinette Chemins IIc. Die Bassklarinettenstimme ist in erster Linie eine Umspielung der SequenzaStimme und hat vor allem eine klanganreichernde Funktion. Die Töne und Akkorde der Sequenza werden auf das Ensemble aufgeteilt. Der Solovioline fallen dabei häufig die Oberstimme und die ein- bis zweistimmigen Passagen zu, teilweise auch im Wechselspiel und Dialog mit einer Soloviola. Auch in Chemins IIb/c gibt es von der Sequenza unabhängige, im Nachhinein eingefügte Formabschnitte in E1 und G1. Im Abschnitt G1 wird ein im ursprünglichen Verlauf nicht vorgesehener Höhepunkt aufgebaut. Im Ganzen ist diese Version aber vor allem ein Beispiel für eine orchestrierte Ausweitung der ursprünglichen Sequenza, deren Material zwar existent ist, sich aber durch die Verteilung auf andere Instrumente in ihrer geschlossenen Soloform längst aufgelöst hat.

Chemins III su Chemins II

Chemins III schließlich ist die orchestrale Erweiterung von Chemins II mit einer zwei- bis vierfachen Holz- und Blechbläserbesetzung, vier Schlagzeugern, zwei Harfen, Celesta und einer elektrischen Orgel, einem vollständigen Streicherapparat und der Viola solo. Das metrische Gerüst von Chemins II wird durchgehend übernommen, weitgehend auch die Tempoangaben. Bis auf einen 46-taktigen Einschub sechs Takte nach $\mathrm{T}$ ist die Vorgängerversion Chemins II original in der Orchesterversion erhalten, ebenso natürlich die Sequenza, die weiterhin durch den Solopart der Viola verkörpert wird. Neue instrumentale Schichten ergänzen und vergrößern das Stück. Ab Ziffer U beginnt sich der Klangkörper auf das Ensemble von Chemins II zu reduzieren, baut sich bei Dd noch mal zum Tutti auf, um sich erneut zu reduzieren, bis in den letzten sieben Takten wie auch in Chemins II die Solobratsche übrig bleibt. 


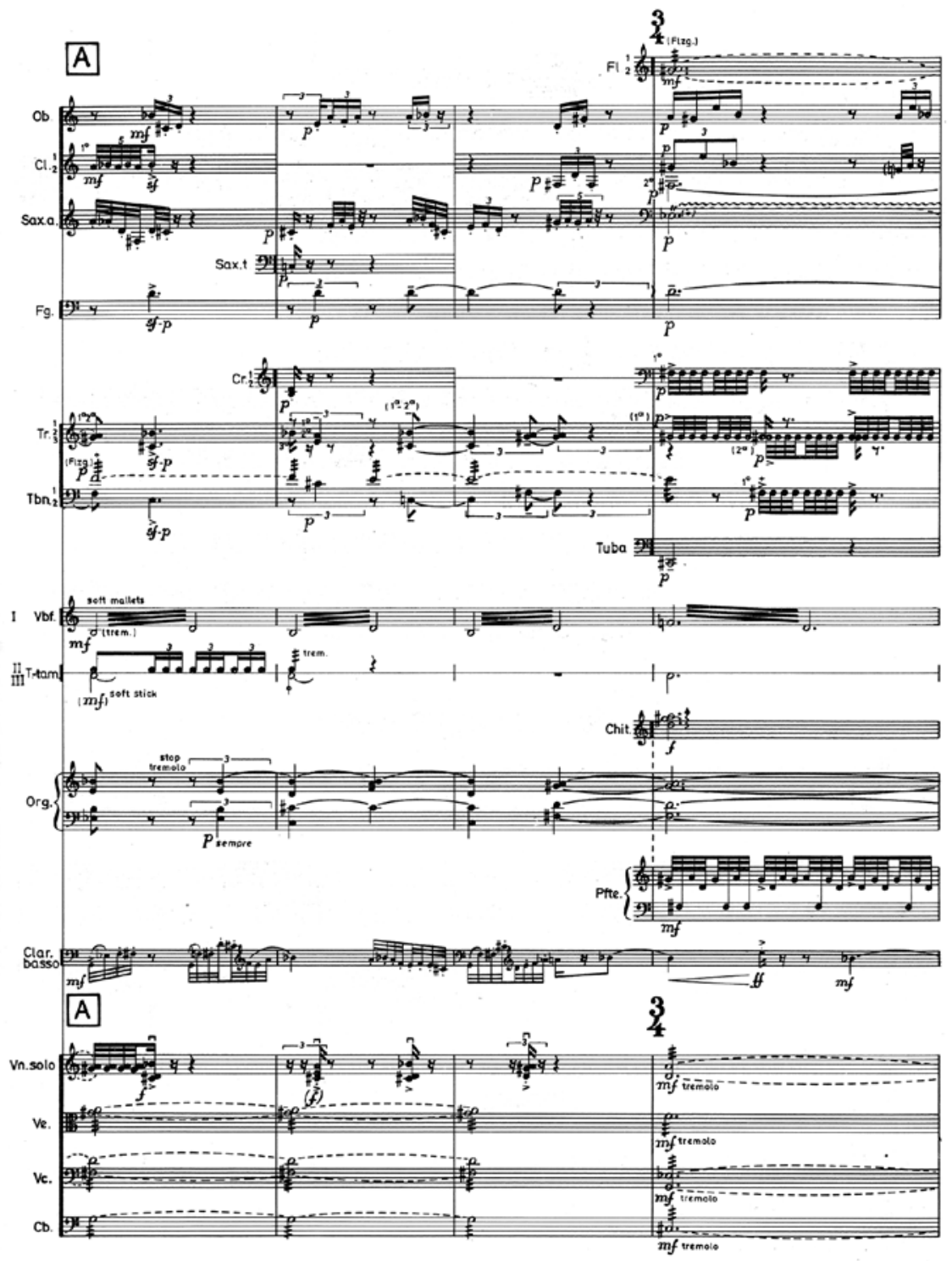

Abb. 6 Luciano Berio: Chemins IIb/c, 1970/72, Takte 11-14. (C) 1973 by Universal Edition (London), Ltd., London. 


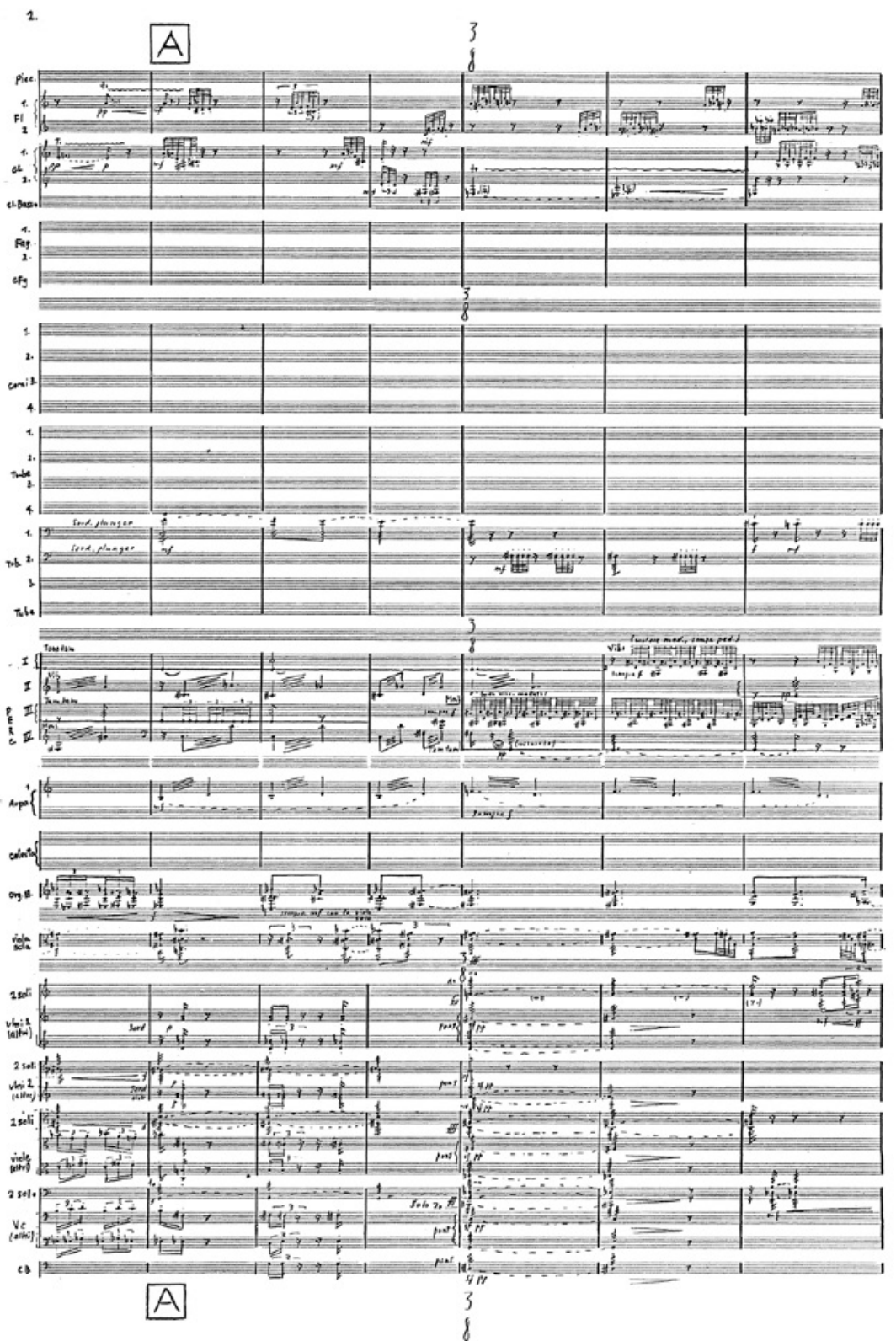

Abb. 7 Luciano Berio: Chemins III su Chemins II für Viola und Orchester, 1968, Takte 8-14. (C) 1968 by Universal Edition (London) Ltd., London; revised Edition: () 1973 by Universal Edition (London) Ltd., London. 
Merkmale im interformalen Verhältnis Sequenza - Chemins

Charakteristisch für Berios Transkriptionsprozesse im Kontext Sequenza Chemins sind die folgenden Elemente: Die Sequenza-Stimmen haben für die Chemins eindeutig eine Rahmenfunktion. Gleichzeitig verkörpern sie das Bild eines Flusses, der sich seinen Lauf durch das instrumentale Geschehen bahnt, hervortretend, begleitend, kontrastierend oder versteckt. Der freie Fluss der Sequenza bekommt durch die Chemins ein metrisches Bett, wird auf diese Weise nochmals rückwirkend geformt und vertieft, denn Berio hebt die teils offene Dauernnotation der Sequenzae in den Chemins wieder auf und rhythmisiert die Noten eindeutig (vgl. Abb. 8 und Abb. 9). Das Ensemble/Orchester dünnt sich zum Ende der Chemins oft aus. In den meisten Chemins ist das ursprüngliche Soloinstrument am Beginn und am Schluss exponiert, spielt beispielsweise die letzte Phrase solistisch und bekräftigt damit die Rahmenfunktion.
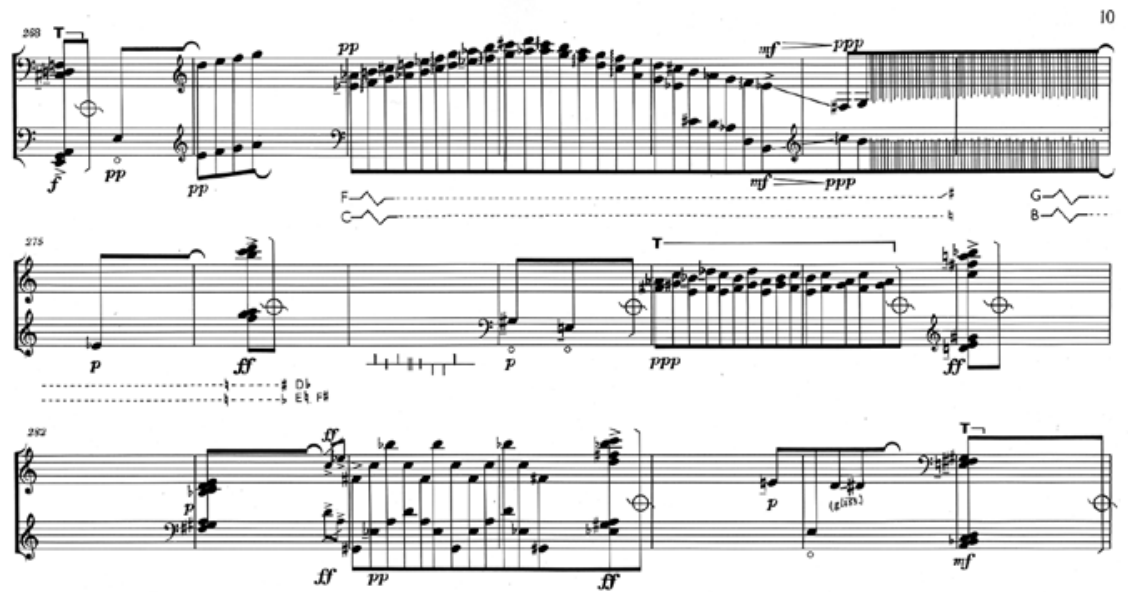

Abb. 8 Luciano Berio: Sequenza II für Harfe, 1963, Takte 268-288. (C 1965 by Universal Edition (London) Ltd., London, (c) assigned to Universal Edition A. G., Wien.

Die Integration von Objekten in die folgende Schicht wird oft flankiert von Verräumlichung und Pedalisierung. Beispielsweise erhält die Sequenzastimme der Harfe in Chemins I zwar eine Solistenfunktion, wird aber durch zwei weitere Harfen begleitet und dadurch räumlich und akustisch vertieft. Der „neutrale“ Zentralton h', der in der Sequenza VII für Oboe in Form einer selbstgewählten Klangquelle im Hintergrund permanent präsent ist, wird in Chemins IV für ein elfköpfiges Streicherensemble instrumentiert. Er wandert durch die Instrumente, wird klangfarblich aufgespalten und reflektiert das impulshafte Farbspiel der Oboe auf demselben Ton. Auch sonst haben die Streicher in Chemins IV vor allem die Funktion, einzelne Töne der Sequenza VII 


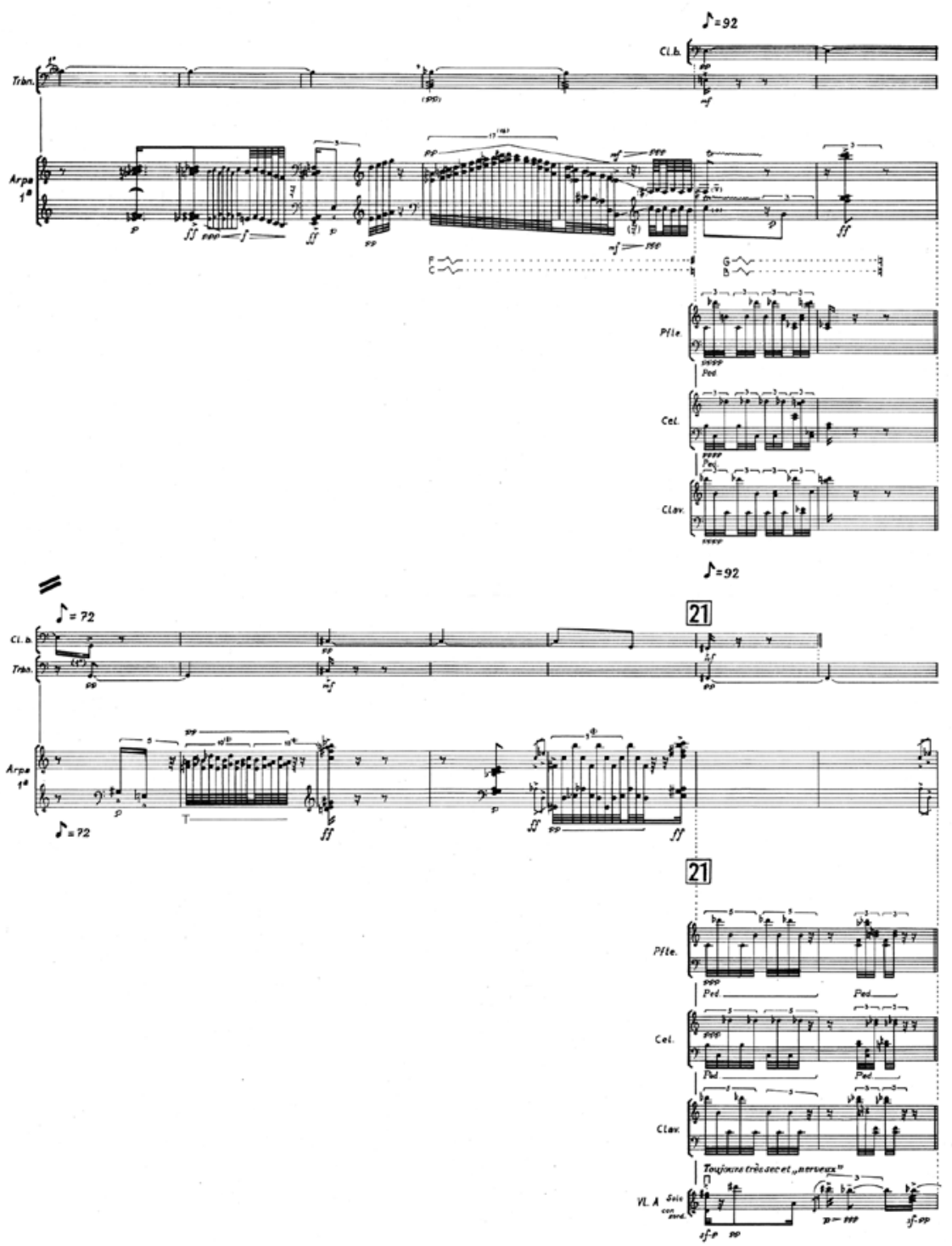

Abb. 9 Luciano Berio: Chemins I für drei Harfen und Orchester, S. 24, 1965. Im Vergleich zu Abb. 8 ist die einfach verbalkte rhythmisch freie Notation der Sequenza in Chemins I zeitlich viel präziser und differenzierter rhythmisiert. (c) 1970 by Universal Edition (London), Ltd., London. 
aufzunehmen, linear zu verlängern, zu pedalisieren und zu verräumlichen. Weitere gebräuchliche Strategien einer „affirmativen“ Integration sind beispielsweise die Instrumentation einer Solostimme auf eine größere Besetzung, die Weiterentwicklung latenter Mehrstimmigkeit, die Verstärkung und Bestätigung formaler Verläufe und die Harmonisierung linearer Phrasen. Zum Beispiel geht dem Einsatz des Saxophons in Chemins VII der Aufbau eines harmonischen Feldes in den Streichern voran, welches die Saxophonlinie in ihren sukzessiven Tonhöhen harmonisch vorwegnimmt.

In den Sequenzae bereits angelegte Ideen werden bisweilen neu kontextualisiert. Zum Beispiel sind die Schlussakkorde der Sequenza II in Chemins I von Anfang an präsent. Die eigentliche Öffnung des Materials vollzieht sich sowohl durch das Einfügen kontrastierender musikalischer Ideen als auch in unabhängigen Formentwicklungen. Denn auch wenn die Dramaturgie der Chemins größtenteils dem Formaufbau der Sequenzae folgt und diesen verstärkt, so schafft Berio in den Chemins auch immer wieder Situationen, in denen beide Formverläufe getrennte Wege gehen. Das führt bei den Sequenzae und den Chemins jeweils zu lokal divergierenden Formverläufen, Entwicklungen und Höhepunkten und damit zu temporären Formpolyphonien. Beispielsweise wird der dramaturgische Höhepunkt der Sequenza II für Harfe (Ziffer 16-18) nicht durch das volle Orchester gestützt, sondern durch ein Teiltutti der bis dahin eingeführten Instrumente: Harfen, Tasteninstrumente und Streicher. Das Orchester verselbstständigt sich aber ab Ziffer 17. Ab Ziffer 18, unmittelbar zur Pausierung der Harfe I, setzen die Bläser ein und vervollständigen das Orchestertutti zur vollen Besetzung. Es folgt ein Trio der drei Harfen, in das blockhaft das Orchestertutti einsetzt und einen eigenen Höhepunkt - dann ohne die Harfen - erreicht. In Chemins $I V$ verkürzen sich zum Ende des Ensemblestückes die Phrasen der Oboe immer weiter und verweisen bereits auf das Ende. Der Streichersatz dagegen wird immer dichter und aktiver und mündet in einen - vom Sequenzaverlauf unabhängigen Höhepunkt in den Takten 219-223.

Das Komponieren von Reflexionen wird bei Berio zum Programm der Chemins. Das eigentliche Stück, die Sequenza, wird als neue Quelle betrachtet und lässt den Komponisten quasi zum komponierenden Historiker werden, der sie aus der gewonnenen Distanz kommentiert. Ebenso greifen die Chemins bereits im Titel den spezifischen Topos des Weges auf, der auch bei anderen Komponisten mit der Auskomposition eines reflektierenden Blickes auf ein vergangenes Ereignis verbunden ist. ${ }^{10}$

10 Die Promenaden in den Bildern einer Ausstellung von Modest Mussorgski verklanglichen die Reflexion des Ausstellungsbesuchers über die betrachteten Bilder. Auch Schuberts 
Berios Chemins sind ein Beispiel für eine einseitige vertikale Werkverknüpfung, die vor allem dem Gedanken der Transkription und der Orchestration verbunden ist. Mit den Poly-Werken teilen sie dennoch das entscheidende Merkmal einer Neukontextualisierung. Das folgende "Gegenbeispiel“, der Medusa-Zyklus von Claus-Steffen Mahnkopf, ist ebenfalls unidirektional, das heißt, mehrere kleine Werke werden in eine umspannende Dachkomposition integriert, die für sich genommen nicht selbstständig aufführbar ist. Auch dieses Werk basiert auf einer Solokomposition - in diesem Fall für Oboe und exploriert neue Spieltechniken, vor allem die für die damalige Zeit neuen Multiphonics. Im Gegensatz zu Berios eher offenen, homogenen und stufenweisen Werkbildungen, die sich nach und nach in einem sukzessiv-linear verlaufenden Kompositionsprozess entwickelt haben, handelt es sich hier um ein Beispiel für eine vertikale Verknüpfung heterogener Stücke, die - simultan entstanden! - einem im Vorfeld festgelegten Plan folgen.

\subsubsection{Claus-Steffen Mahnkopf-Konfliktäre Formstrategien in Medusa}

Charakteristisch für die groß angelegten und bisweilen auch werkpolyphonen Zyklen von Claus-Steffen Mahnkopf (geboren 1962 in Mannheim) ist das protagonistische Hervorheben eines spezifischen Themas oder einer bestimmten Persönlichkeit. Seit ungefähr 1998 entwickelt Mahnkopf in seinem Schaffen kontinuierlich das Konzept der „Hommage an ...“. Es handelt es sich hierbei um Hommagen an ausgewählte Künstlerpersönlichkeiten und/oder Weggefährten. ${ }^{11}$ Die Gattungen Hommage, Poly-Werk und Zyklus treten oft im Verbund auf, wobei die Hommage das Zentrum eines Zyklus bildet, den Mahnkopf wiederum als Weiterentwicklung des Poly-Werkes ansieht. ${ }^{12}$ Für Mahnkopf ist die Hommage, die typischerweise eine Huldigung an eine bestimmte Person darstellt, eine "Schnittstelle, die zwischen meiner eigenen Musik [...] und der extrem verdichteten Individualität dessen, dem die Hommage gewidmet ist, eine enge Bindung herstellt ${ }^{\star 13}$. Mahnkopfs Intention zielt darauf ab, eine Verbindung zwischen seiner eigenen Ausdruckswelt und der spezifischen idiomatischen Welt des mit der Hommage Bedachten zu kreieren, um eine Erweiterung der eigenen Ausdrucksfähigkeiten zu erreichen. Durch die Öffnung des Eigenen für das Fremde - und zwar sowohl inhaltlich, konzeptuell als auch in Bezug auf technische Fragestellungen - wird die eigene Musik, das

Winterreise ist eine nachträgliche Auseinandersetzung mit einem vorangegangenen Ereignis als Objekt der Reflexion.

11 Beispielsweise an Thomas Pynchon, György Kurtag, Mark André oder Daniel Libeskind (Auswahl).

12 Vgl. Mahnkopf, Die Humanität der Musik, S. 37.

13 Ebd., S. 34. 
eigene Komponieren, kontextualisiert und provoziert, „als injizierte man sich Bakterien oder Viren, um die innere Chemie zu stimulieren"14.

Die Konstellation Solostück $\rightarrow$ Solokonzert im Rahmen eines Poly-Werks liegt einigen seiner Werkzyklen zugrunde. ${ }^{15}$ Die Exposition eines solistischen Instruments spiegelt bisweilen die Herausstellung eines spezifischen Themas oder einer einzelnen Persönlichkeit. Der Medusa-Zyklus basiert auf dem Solostück für Oboe Gorgoneion (1990), das in der Gesamtfassung zum Solopart eines Oboenkonzertes mutiert. Die metrische Unterteilung des Oboensolos wird für den gesamten Zyklus übernommen. Die übergreifende Zeit- und Formgestaltung wurde im Vorfeld der Komposition fixiert und damit über eine synchronisierte Tempo- und Metrikgestaltung ein wesentliches Verbindungsglied geschaffen. Die begleitende Orchesterschicht, bestehend aus Streichtrio, Streichquartett und Streichquintett, Gitarre und Cimbalon, ist als dependente Dachkomposition konzipiert. Diese kann für sich genommen zwar kein autonomes Werk ausbilden, integriert jedoch noch drei weitere Solo- und Kammermusikstücke, die eine autonome Existenz auch außerhalb des Zyklus besitzen: Die Schlangen der Medusa für vier Klarinetten (1991), Stheno und Euryale für zwei Harfen (1992, eine Harfe ist vierteltönig scordatiert) und das Solostück Pegasos für Cembalo (1991). Medusa verbindet als umspannendes Orchesterwerk folglich vier heterogene Werke in simultaner Anordnung, die in ihrer Materialität und Form unterschiedliche Charaktere abbilden. Gerade auf der Formebene tritt die konfliktäre formpolyphone Anlage deutlich hervor: Gorgoneion besteht aus einer A'-B-A-B'-Form. Dem Cembalostück Pegasos liegt die Form einer Passacaglia zugrunde, dem Harfendiptychon Stheno und Euryale eine symmetrische Spiegelform, und bei den Schlangen der Medusa handelt es sich um vier Miniaturen mit verschiedenen zyklischen, interpolativen und sich steigernden Formverläufen. In einer Einzelaufführung können diese sukzessive von einem Spieler aufgeführt werden, während sie in der Gesamtfassung einander überlappend von vier Spielern gespielt werden. Das Harfenduo kann in der externalisierten Fassung sowohl als Duo als aus pragmatischen Gründen auch als Solo aufgeführt werden, wobei dann auf die

\footnotetext{
14 Ebd., S. 35 .

15 Siehe auch: die Gitarre im Kurtág-Zyklus und das Klavier im Prospero-Zyklus. Ein weiteres Beispiel wäre der Kammerzyklus, der das Klavier als Soloinstrument (Kammerstück mit der wiederum separierbaren Kammerminiatur als Kadenz) exponiert. Das Klavier bleibt in der übergreifenden Dachkomposition Kammerkonzert klar das solistisch führende Instrument. Seine Solistenfunktion ändert sich mit der formalen Kontextualisierung nicht, während sich bei den flankierenden Trios Bläsertrio und Trio basso ein Rollenwechsel von der Begleitungsebene im Kammerkonzert zu autonomen Kammermusikwerken vollzieht.
} 
vierteltönige Skordatur verzichtet wird. Folglich wurde die Harmonik derart konzipiert, dass beide Aufführungsmöglichkeiten stimmig sind. Das Dachwerk Medusa schließlich hat die Großform A-B-A. ${ }^{16}$ Wie kaum eine andere Form steht die A-B-A-Form für Geschlossenheit und Konsistenz, die aber in diesem Fall intern vielfältig divergiert, da verschiedene Formmodelle in sich verschachtelt werden (vgl. Abb. 10).

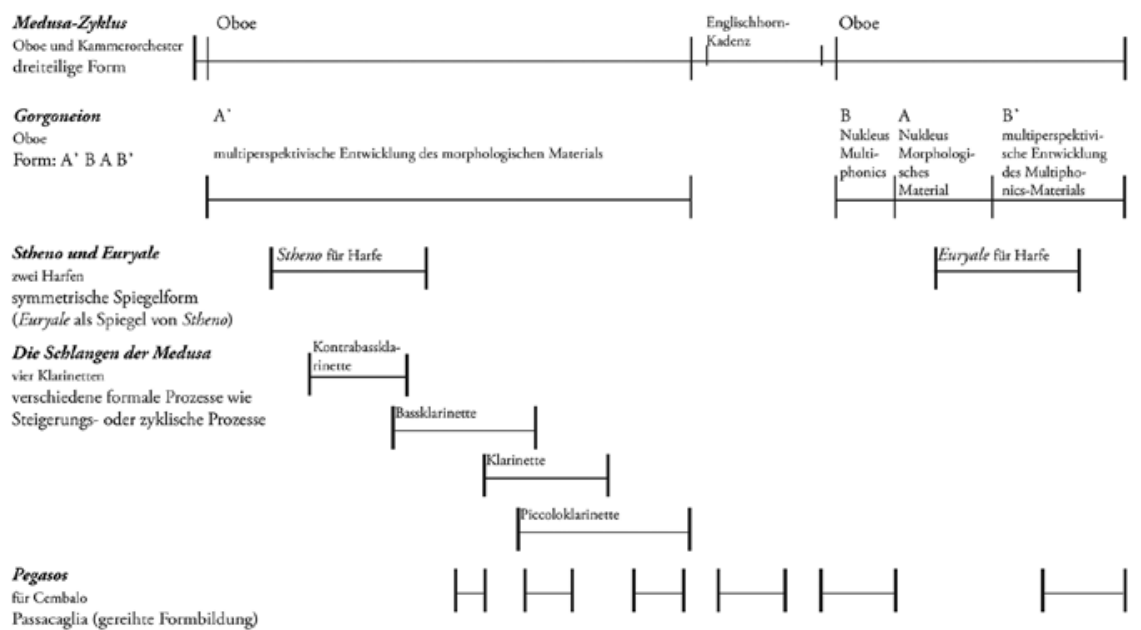

Abb. 10 Übersicht über den formpolyphonen Aufbau des Medusa-Zyklus von Claus-Steffen Mahnkopf.

Die mythologische Figur der Medusa verkörpert den Gegensatz zwischen Attraktion und Destruktion. Mahnkopf überträgt diesen Gegensatz auf das Oboensolo. Melodische Linien stehen für die attraktive, multiphonische Strukturen für die destruktive Seite. Damit wird nach Mahnkopf nicht nur der zwiespältige Charakter der Medusa dargestellt, sondern noch allgemeiner die „moderne Dichotomie von Klang und Diskurs ${ }^{“ 17}$. Diese beiden Pole werden über die Form A'-B-A-B' vermittelt, wobei A für melodisches und B für multiphonisches Material steht. Die Inszenierung von Oppositionspaaren und divergierenden Prozessen ist ein Moment, das sich konsequent durch das Werk zieht und zum Austragungsort des Gegensätzlichen wird. Medusa verkörpert

16 Eine detaillierte Untersuchung dieses Werks würde den Rahmen der Arbeit sprengen, deswegen sei an dieser Stelle auf eine ins Detail gehende Arbeit verwiesen: Coulembier: Multi-temporality, S. 165-213. Vgl. auch Mahnkopfs eigene Texte „Medusa“ und Kritik der neuen Musik, S. 120-124.

17 Mahnkopf: „Medusa“, S. 248. 


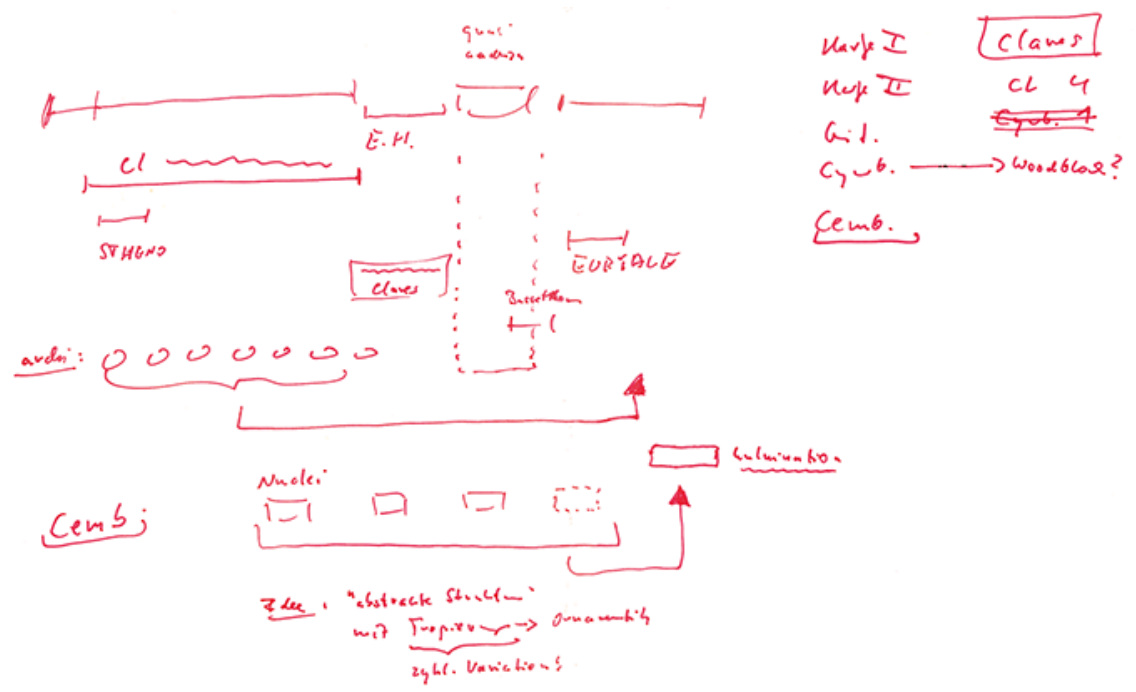

Abb. $11 \quad$ Skizzenhafte Fixierung des Formverlaufs des Medusa-Zyklus von Claus-Steffen Mahnkopf. Mit freundlicher Genehmigung des Komponisten.

dabei jene „Reinform des Poly-Werks“, die von Mahnkopf in Bezug auf sein eigenes Schaffen definiert wurde (vgl. Kapitel 2.4): Die Integration einzelner autonomer Subwerke in ein konsistentes Ganzes. Ihre Positionierung in der Gesamtform soll eine Dissoziation bewirken, ohne die Zerstörung des Ganzen zur Folge zu haben. ${ }^{18}$

Die formale Dissoziation eines Werkes ohne die Zerstörung und Negierung der Geschlossenheit ist ein Charakteristikum des Poly-Werks. Polyphone Prozesse werden bei Mahnkopf nicht als additive, sondern vor allem als dissoziative Vorgänge beschrieben (vgl. auch Kapitel 2.1). Die innere Dissoziation einer sich schließenden Einheit ist ein zentraler Aspekt seines Denkens, veranschaulicht auch durch den bereits erwähnten Vergleich: „Darin drückt sich par excellence der heutige ,plurale Mensch aus, der in unvereinbare Mehrfachexistenzen aufgespalten zu sein scheint und dennoch ,irgendwie' ein Eines ist. ${ }^{\prime 19}$ Mahnkopf rekurriert auf multiple Existenzformen des modernen Ichs, das seine Gesamtbildung vor allem durch die Verknüpfung verschiedener Identitäten erreicht. Das Individuum wird zum Träger verschiedener, einander überlagernder Rollen und Funktionen, die sich gleichzeitig durchdringen und in ein Spannungsverhältnis geraten können. Gemeint

18 Vgl. Mahnkopf: „Theory of Polyphony“, S. 49.

19 Mahnkopf: Kritik der neuen Musik, S. 118. 
sind etwa der Alltag erwerbstätiger Eltern, hybride Lebensstile, Multitasking als „Schlüsselkompetenz moderner Lebensbewältigung ${ }^{\text {“20 }}$, die generell große Auswahl an Möglichkeiten der Lebensgestaltung, die eigene Öffnung für das Fremde usw. Es handelt sich allerdings nicht in jedem Fall um „unvereinbare Mehrfachexistenzen“, wie es das Zitat ausdrückt. Denn die Aufgabe für den Menschen besteht ja gerade darin, eine Organisationsform zu finden, die die verschiedenen auseinanderstrebenden Rollen miteinander vereinbart. ${ }^{21}$ Nicht die klare Rollenverteilung und das Streben nach einer einzelnen und einheitlichen Lebensform stehen im Vordergrund, sondern die Erprobung verschiedener Rollen und Rollenwechsel, das Agieren im Übergang, das „Operieren inmitten der Differenz"22.

Die Figur des geteilten Individuums als Symbol für den Verlust von Einheit kann als konfliktäre Situation begriffen werden, auf die Mahnkopf kompositorisch reagiert. Kriterien wie Vereindeutigung, Stabilisierung, Verdinglichung und klare Identifizierbarkeit werden unterlaufen und durch Veränderung, Umwandlung, Variation und Mehrdeutigkeit subversiv zersetzt. Als Mittel dienen beispielsweise transitorische und kombinierte Spieltechniken, dichte Strukturen oder eben auch divergierende Formenverläufe, die gleichzeitig ablaufen. ${ }^{23}$ Musikalisch nimmt die Möglichkeit der Formenüberlagerung für Mahnkopf ihren Ausgang zwar in der additiven Überlagerung verschiedener musikalischer Schichten - eine Errungenschaft des frühen 20. Jahrhunderts, wenn man an Strawinsky, Carter, Zimmermann oder Ives denkt -, jedoch wird der Additionsprozess zum Dissoziationsprozess umgekehrt. Dieser Fokus auf das Dissoziative mag darin begründet sein, dass Mahnkopf sich von pluralistischen Stilen, die additiv das Nebeneinander der

20 Siehe hierzu ausführlich Stephan Rieger: „Multitasking. Zur Ökonomie der Spaltung“, in: Hubmann/Huss (Hg.), Simultaneität, S. 91-110.

21 Siehe dazu beispielsweise auch die Ausführungen von Armin Nassehi über die Rolle der einzelnen Individuen in funktional differenzierten Gesellschaften: „Personen sind gleichzeitig in verschiedene Funktionssysteme inkludiert [...]. Sie stehen gleichsam zwischen den funktional spezifizierten Teilbereichen der Gesellschaft und müssen die verschiedenen funktionalen Semantiken, die bisweilen völlig inkompatibel und kaum ,übersetzbar' sind, über ihre eigene Selbstreferenz sinnhaft miteinander verbinden. Also nicht die bloße Zugehörigkeit zu einem sozialen System sichert Identität, sondern die je individuelle Selbstbeschreibung der Person im Wirkungsbereich verschiedenster gesellschaftlicher Ansprüche." (Nassehi: Die Zeit der Gesellschaft, S. 319.)

22 Welsch: „Einleitung“, S. 40.

23 Vgl. hierzu ausführlich Mahnkopfs eigene Theoriebildung in „Reflexion, Kritik, Utopie, Messianizität. Kriterien moderner Musik - oder: Wie weit trägt die Idee musikalischer Dekonstruktion?“, in: MusikTexte. Zeitschrift für Neue Musik 99, 2003, S. 17-24, hier: S. 21 ff., und ders.: „Der Strukturbegriff der musikalischen Dekonstruktion“, in: Musik und Ästhetik 21, 2002, S. 49-68, ebenso: Die Humanität der Musik, S. 133-151. 
Vielheit betonen (z. B. Polystilistik), klar abgrenzt. Mahnkopf geht es um einen Pluralitätsbegriff, der von der Differenzierung eines einheitlichen Subjektes ausgeht und daher zumindest den äußerlich formalen Einheitsbegriff nicht aufgibt. Pluralität bedeutet für Mahnkopf innere Ausdifferenzierung und Beziehungsvielfalt unter der Voraussetzung von stilistischer und formaler äußerer Geschlossenheit. ${ }^{24}$ Nur im Rahmen der Einheit entstehe Vielschichtigkeit und Multiperspektivität. Wolfgang Welsch beschreibt diese Form der Einheit im Sinne einer offenen Ganzheit, die „aus postmoderner Perspektive aber die einzig legitime - weil die einzige nicht-unterdrückende - Form von Einheit“ ist $^{25}$. Ebenso grenzt sich Mahnkopf vom einsinnig geschlossenen Werkbegriff ab. Beide Möglichkeiten, Offenheit und Geschlossenheit, werden auch bei ihm als Dichotomie konstruiert, die wiederum durch die konfliktären Formmöglichkeiten des Poly-Werks überwunden werden könnte. Darüber hinaus entwirft Mahnkopf in diesem Zusammenhang als Reaktion auf den Verlust der Synthese von Rhythmik, Metrik, Syntax und Form in tonaler Musik einen mehrdimensionalen Zeitbegriff. ${ }^{26}$ Das Auseinanderfallen der musikalischen Parameter $^{27}$ zieht auch ein Zerfallen zeitlicher Einheitlichkeit nach sich. ${ }^{28}$ Eine maximal gesteigerte Polyphonie, die sich auf sämtliche Parameter, die ein Werk mitkonstituieren, erstreckt und diese in ein zeitliches Spannungsverhältnis zueinander bringt, wird modellartig als Lösungsmöglichkeit beschrieben, um einen "neuen Typus musikalischer Pluralität" hervorzubringen. ${ }^{29}$

\subsubsection{Die Kontextualisierung des Solos durch Integration}

Den beiden bisher untersuchten Beispielen von Berio und Mahnkopf lag jeweils ein Solowerk als Ausgangsform zugrunde. Beide Beispiele verfolgen einen Ansatz, der die Solostruktur in einen größeren instrumentalen und orchestralen Rahmen stellt, integrieren also eine kleine Werkeinheit in eine

24 Mahnkopf schließt aus, dass auch eine „offene“ Form zu einem Poly-Werk werden könnte, vgl. hierzu Mahnkopf: Kritik der neuen Musik, S. 120. Dem kann ich in dieser Ausschließlichkeit nicht zustimmen, da der Begriff der offenen Form nicht eindeutig ist, sondern unterschiedlich interpretiert und ausgelegt werden kann.

25 Welsch: „Einleitung“, S. $16 \mathrm{f}$.

26 Claus-Steffen Mahnkopf: „Der Zerfall der musikalischen Zeit. Prolegomena zu einer Theorie der Atonalität", in: Musik in der Zeit. Zeit in der Musik, hg. von Richard Klein, Eckehard Kiem und Wolfram Ette, Weilerswist: Velbrück, 200o, S. 354-372.

27 Parameter bedeutet in diesem Fall nicht nur Rhythmus, Tonhöhe, Klangfarbe etc., sondern kann auch innerhalb dieser Ebenen differenziert werden, beispielsweise die Notendauern (Sequenza I), Col-legno-Spiel etc.

28 Vgl. Mahnkopf: „Der Zerfall der musikalischen Zeit“, S. 367.

29 Ebd., S. 371 f. 
größere Werkentität. Bei Berio ist der Vorgang auf Wachstum ausgerichtet. Das Solo als konzentriertes Ausgangsstück wird in einen instrumentalen und dependenten Ensemblesatz inkorporiert. Bei Mahnkopf ist die Dachkomposition ebenso unselbstständig, umfasst zusätzlich allerdings kleinere Kompositionen, die sich wiederum überlappen und dadurch miteinander verschachtelt werden. Beide Beispiele vereinigen Werkeinheiten, die in ihrer Dauer und ihrer Besetzung nicht "gleich stark“ sind. Im folgenden Teil sollen Beispiele untersucht werden, deren einzelne Werkkonstituenten sich in ihrer Dauer und ihrer Besetzungsstärke auf „Augenhöhe“ begegnen und die eindeutig nichthierarchisch organisiert sind.

\subsection{Addition homogener Werke}

Dieser zweite Analyseabschnitt befasst sich mit Werkkopplungen, die ungefähr gleichrangige Stücke in eine additive simultane Konstellation bringen. Wie in Kapitel 3.1 bereits dargestellt, gibt es homogene und heterogene Konstellationen. Die homogenen Werkgruppen haben in der Regel einen gemeinsamen Ursprung im Material und sind auf eine Quelle zurückführbar. Sie verkörpern die Vermehrfachung eines Gedanken. Das schließt nicht aus, dass sie sich in ihrer Genese auch voneinander wegentwickeln können. Insbesondere der Grad der Differenzbildung zwischen einzelnen Stücken kann hier interessant sein.

Der Block „Werkcluster“ stellt Stücke vor, die auf beliebig kombinierbaren Solostücken basieren und in ihrer Entstehung vor allem auf Variations- und Transkriptionsprozessen aufgebaut sind. Das Kapitel schließt mit einem Beispiel von Adriana Hölszky. Ihr Werk Hängebrücken vereint zwei eigenständige Streichquartette, die sich zu einem dritten neuen Werk verbinden können. Beide Quartette entstammen demselben Materialfundus.

\subsubsection{Werkcluster - Vom Solo zum Ensemble - Transkriptions- und Variationsprozesse}

Die Werke half-way house - Solo xfach von Bernd Franke, Aus der Wand die Rinne von Juliane Klein, ,... Einklang freier Wesen ... “von Georg Friedrich Haas, der Yuunohui Cycle von Julio Estrada und Next To Beside Besides von Simon Steen-Andersen sind in ihrem Ansatz und ihrer Klangsprache verschiedenen Stilen verhaftet, haben aber formale Merkmale in Bezug auf simultane Werkverbindungen gemeinsam. Die Zyklen von Klein, Estrada und Steen-Andersen basieren alle auf Soloserien, das heißt das "Solo“ bildet die kleinste unteilbare Werkeinheit. Zudem fungiert das erste Solo der Reihe als Ausgangskomposition, 
die den weiteren Soli als modellhafte Vorlage dient. Diese sind Ableitungen, Anlehnungen, Varianten und Vervielfältigungen des Ausgangssolos. Dadurch entsteht eine übergreifende Homogenität in der Form, der Dauer und im Erscheinungsbild. Die Soli können einzeln gespielt, aber auch simultan in verschiedenen Kombinationen zu Kammermusik- oder Ensemblestücken gruppiert werden. Jede Version ist gleichwertig, und es gibt keine Hierarchie untereinander. Da der Entstehungsprozess oft lange Zeiträume von mehreren Jahren umfasst, stellt sich die Frage, ob er je abgeschlossen ist oder ob es sich um einen prinzipiell offenen Prozess handelt, denn bis auf den Zyklus von Georg Friedrich Haas existiert keine festgelegte Rahmenbesetzung.

Das folgende Kapitel thematisiert die unterschiedlichen Formen der Transkriptionsprozesse anhand verschiedener Beispiele. Um die unterschiedlichen Ansätze nicht zu bunt zu vermischen, wird eine weitere Unterteilung vorgenommen. Im ersten Teil werden die Werkzyklen von Bernd Franke, Juliane Klein und Georg Friedrich Haas besprochen und miteinander verglichen. Diese sind explizit aus der Motivation heraus entstanden, tradierte musikalische Kommunikationsmuster und Hierarchien unter den Musikern zu hinterfragen und das soziale Miteinander der Musiker während einer Aufführung zum Ausgangspunkt der kompositorischen Reflexion zu machen. Im zweiten Teil sollen die Zyklen von Julio Estrada und Simon Steen-Andersen vorgestellt werden. Im Mittelpunkt steht hier die kompositorische Transkription als konzeptueller und sehr systematischer Prozess.

\subsubsection{Simultane Konstellationen - Ensemblespiel als freies Mit- und Nebeneinander}

4.2.1.1.1 Bernd Franke - half-way house - Solo xfach

Der Zyklus half-way house - Solo xfach des Leipziger Komponisten Bernd Franke, 1959 in Weißenfels/Saale geboren, ist eine Mischung aus nachträglich arrangierten Simultanaufführungen, im Stadium der Komposition antizipierten Poly-Werken und für sich stehenden Werken. Er baut sich in mehreren untereinander vernetzbaren Teilzyklen auf, die innerhalb eines mehrjährigen Zeitraums entstanden sind. Es existieren:

- ... in Annäherung für Klavier solo (1997/98) (Soloversion)

- Solo 2fach - in Annäherung (I-IV) (1997/98/2001)

- Solo 3fach - für Violine, Horn und Klavier (im Gedenken an Joseph Beuys) (1988)

- Solo 4fach- überlagernd (1999-2000)

- Solo 5 fach-zerbrechend (1998/99)

- Solo 6fach - erstarrt für Schlagzeugensemble (1994)

- Solo 7fach - in Distanz (1996) 
- Solo 8fach - in Bewegung (2003)

- Solo gfach - ins Unendliche (2001)

- Solo xfach - tape (I-IV) (2000)

Die Teile Solo zfach (1988) und Solo 6fach (1994) stehen für sich und sind nicht Teil des Überlagerungsprinzips. Erst ab Solo 7fach (1996) setzte sich die Idee durch, die Einzelstimmen auch als Einzelstücke zu denken. Die Stücke folgen konsequent einem übergeordneten vierteiligen Form- und Zeitplan mit einer einheitlichen und festgelegten Dauer von zwanzig Minuten. Vierteiligkeit bedeutet hier, dass die Stücke formal in die vier Abschnitte I, II, III und IV gegliedert sind, zwischen die wiederum kurze Interludien, die eine dreimalige Crescendofigur wiederholen, eingelassen sind. Die Vierteiligkeit der Form verweist konzeptuell noch auf die Viersätzigkeit der Symphonie als klassische Werkform schlechthin, übernimmt aber lediglich deren grobe Gliederung. Die von Franke verwendeten musikalischen Materialien und Figuren sind durchgängig sehr elementarer Natur. So beginnt das Stück in den Bläserfassungen sehr einfach mit lange ausgehaltenen Lufttönen und Atembewegungen, in den anderen Fassungen entweder mit leise gestrichenen, einzeln gezupften oder akzentuierten Tönen oder Akkorden. Ob Klang auf Klang oder Impuls auf Impuls, jede zusätzliche Stimme, jeder weitere Baustein schichtet den Klangraum weiter auf. Die einfache Anlage der einzelnen Stimmen ruft und sucht geradezu nach dem Mehr der anderen Stimmen, nach einer sukzessiven und simultanen Auffüllung des Raums und einer kraftvollen Kollektivität des Klangs, die dennoch fragil ist und jeden Moment wieder in sich zusammenbrechen kann.

Eine organisierende Partitur und einen Dirigenten gibt es nicht. Die Spieler synchronisieren sich mittels Stoppuhren und Orientierungszeiten, die einen gewissen flexiblen Spielraum von fünf bis zehn Sekunden lassen. Es gibt festgeschriebene Fassungen („2fach“ bis " $\left.9 \mathrm{fach}^{“}\right)$ und flexible Fassungen, die eine Vernetzung einzelner Instrumente über die Grenzen der verschiedenen Fassungen hinweg erlauben. Beispielsweise wurde bereits eine Simultanversion aus Solo 2fach (Oboe und Klavier), der E-Gitarre aus Solo 4 fach und der kompletten Besetzung von Solo 7 fach aufgeführt. Die Musiker können selbst probieren, was an Kombinationsformen zyklenübergreifend umsetzbar ist. Auch Solofassungen mit und ohne Tape sind möglich.

Bernd Franke geht es kompositorisch, aufführungspraktisch und aufführungsräumlich um die Reflexion tradierter formaler Organisationsstrukturen, die Abwendung von diesen und die Suche nach einer neuen Form der Ungebundenheit. Diese Suche lässt sich sowohl auf die Behandlung des Materials als auch auf die Erprobung alternativer Kommunikationsstrukturen beziehen, da in beiden Fällen eine Hierarchiebildung vermieden wird. Die Idee 
zu Solo-xfach wurzelt in den Erfahrungen in der als einengend empfundenen DDR-Diktatur und dem daraus entstandenen Drang nach Freiheit. Den endgültigen Impuls gab eine Beschäftigung mit Joseph Beuys' Idee einer „sozialen Plastik“. Die sozialen Gefüge der Lebensrealität, die nicht nur als Miteinander, sondern auch im gleichwertigen, selbstbestimmten und antihierarchischen Nebeneinander gesellschaftlicher Gruppen und Lebensformen existieren, sollen sich im musikalischen Ensemblespiel widerspiegeln. Es geht um die Möglichkeit einer Haltung, die während der Aufführung sowohl ein „Bei-sichBleiben" als auch den Versuch des Weghörens zulässt. Parallel wird durch den Probenprozess ein Bewusstsein für das Spiel der anderen erzeugt, um sich im Stück zeitlich und harmonisch orientieren zu können und die Möglichkeiten der Aktion, Reaktion und Interaktion auszuschöpfen. Auch der Aufführungsraum wird in die Aufführung einbezogen, indem es spezifische räumliche Aufstellungen und Choreografien für die einzelnen Stimmen gibt, die bei einer Überlagerung neue räumliche Figuren ausbilden können.

\subsection{Juliane Klein - Aus der Wand die Rinne}

Der Zyklus Aus der Wand die Rinne der Komponistin Juliane Klein, 1966 in Berlin geboren, ist einer Raumskulptur von Britta Brückner nachempfunden. Er besteht aus vierzehn Solostücken für Cello (1996), Violine (1996), Oboe (1998), Akkordeon (1998), Klavier (1999), Klarinette (1999), Schlagzeug (zurückgezogene Fassung), Saxophon (2003), Horn (2009), Elektronik (2006), Theremin (zurückgezogene Fassung), Video (2006), Flöte (2011) und Kontrabass (2014). Der Zeitraum der Entstehung umfasst achtzehn Jahre. Alle Solostücke können auch simultan aufgeführt werden. Die Besetzungsgröße ist frei variabel und reicht vom Solo bis zur maximalen Ensemblebesetzung.

Das Cellostück kann als Ausgangstück des Zyklus gesehen werden. Die Reihenfolge musikalischer Figuren, sei es zum Beispiel das hohe Eingangssignal, der lang ausgehaltene Ton, die darauffolgende fluktuierende Bewegung, Triller- und Tremolofiguren, eine Glissandofigur oder auch Repetitionsflächen usw. sind hier quasi als prototypischer Ablauf gegeben. In ihrer linearen Abfolge sind sie zwar nicht in allen, aber in vielen Fassungen in modifizierter Form immer wieder zu erkennen (vgl. Abb. 12-15). Auch hier wird das Material immer wieder in seiner Elementarität exponiert und an vielen Stellen durch Pausen getrennt, aneinandergereiht. Verdichtungen entstehen entweder durch eine Differenzierung und Individualisierung des Materials oder durch Repetitionen. Jedes Stück ist eine abgeleitete Variation der vorausgehenden Versionen, wobei der Grad der Ähnlichkeit beziehungsweise der Differenz natürlich jedes Mal schwankt. 


\section{Aus der Wand die Rinne 1}
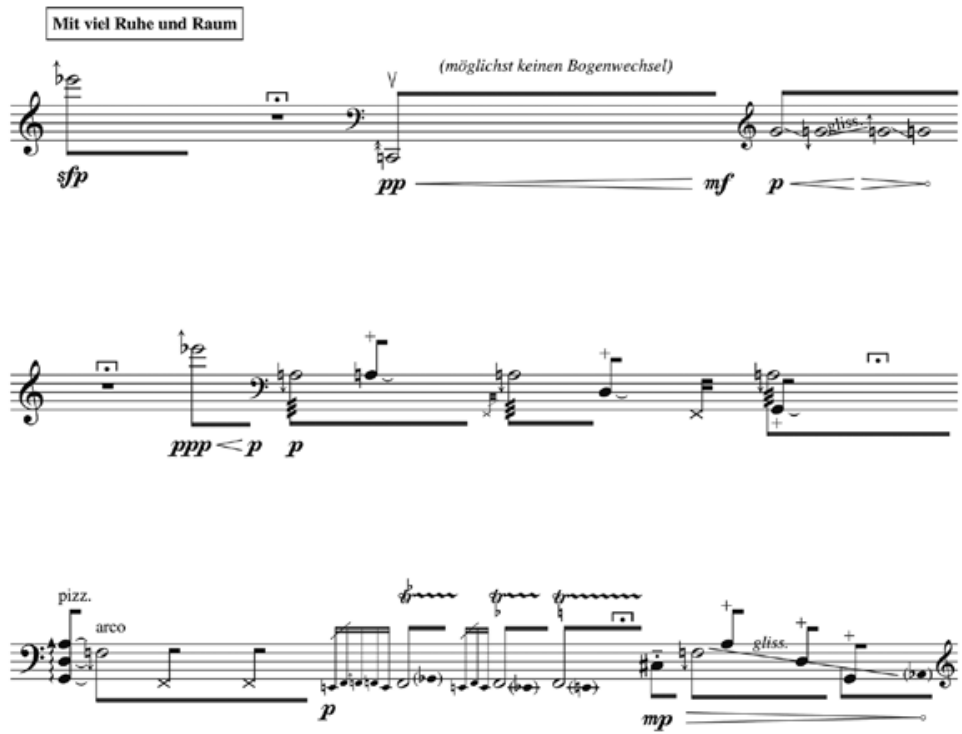

Abb. 12 Juliane Klein: Aus der Wand die Rinne 1 für Cello, 1996. (C) Edition Juliane Klein, Berlin.

\section{Aus der Wand die Rinne 2}
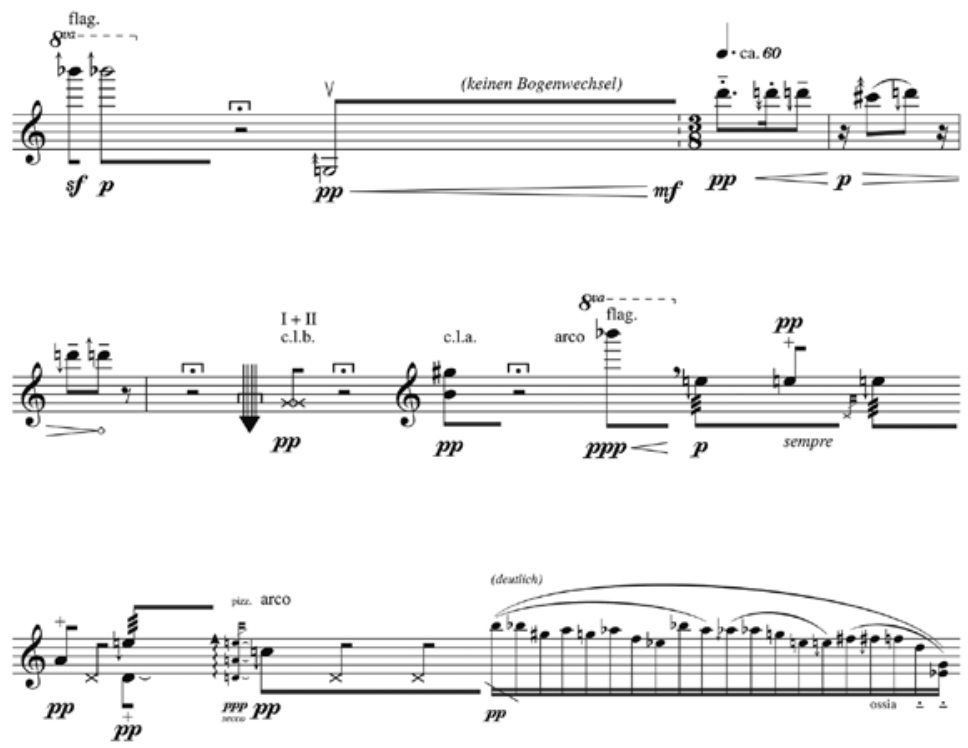

Abb. 13 Juliane Klein, Aus der Wand die Rinne 2 für Violine, 1996. (C) Edition Juliane Klein, Berlin. 


\section{Aus der Wand die Rinne 5}
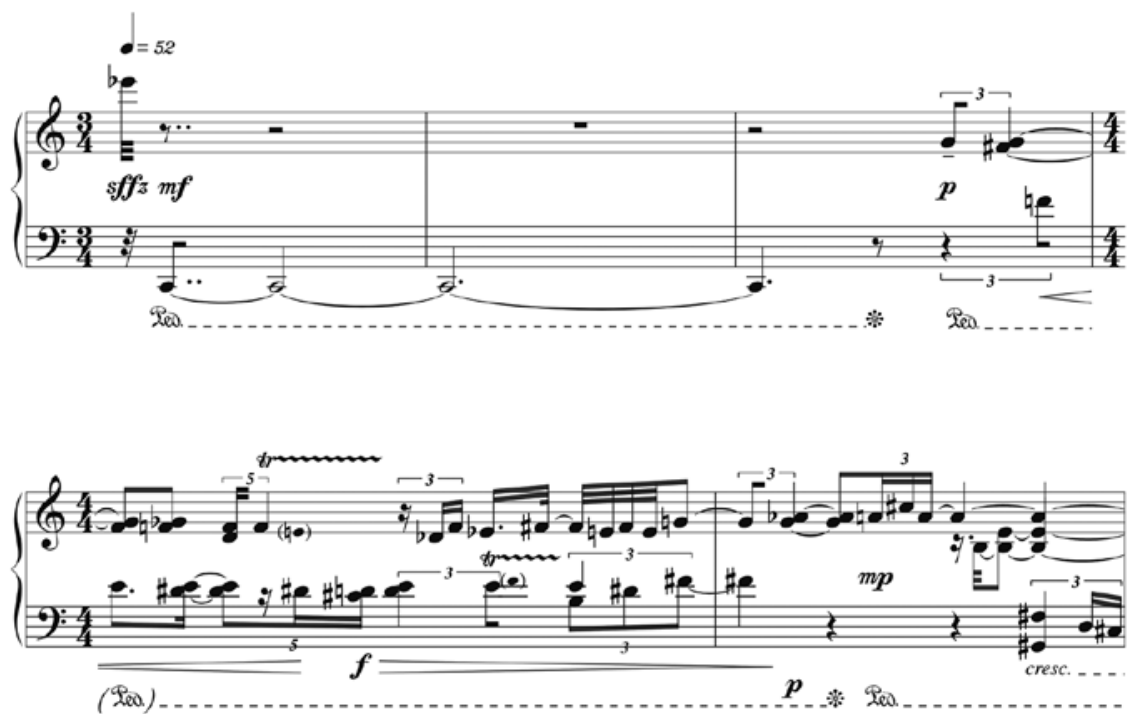

Abb. 14 Juliane Klein: Aus der Wand die Rinne 5 für Klavier, 1999. (c) Edition Juliane Klein, Berlin.

\section{Aus der Wand die Rinne 13}
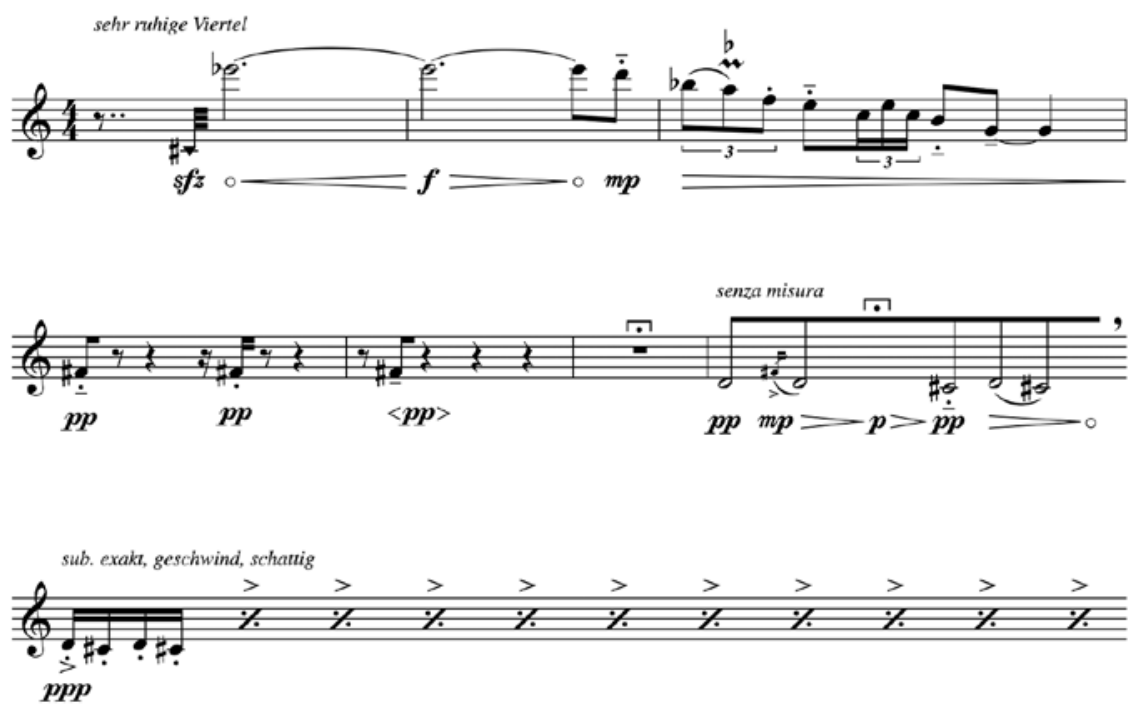

Abb. 15 Juliane Klein: Aus der Wand die Rinne 13 für Flöte, 2011. @ Edition Juliane Klein, Berlin. 
Sowohl zum Probenprozess als auch zur Aufführungssituation gibt die Komponistin den Musikern einige klare und einfache Vorgaben an die Hand. Die Interpreten sollen die Stücke als Solostücke im ersten Schritt selbstständig einüben und sie den anderen Musikern vorspielen. Das gegenseitige Vorspielen und Zuhören ist Voraussetzung für das gemeinsame Spiel, das keinerlei weitere Übereinkünfte bezüglich der Zeitgestaltung beinhaltet, abgesehen davon, dass alle Spieler gleichzeitig beginnen. ${ }^{30} \mathrm{Ab}$ diesem Startpunkt obliegt es den Spielern, wie sie ihren musikalischen Text in das Gesamte einbringen. Wie bei Franke reflektiert die Form des Zusammenspiels ein gesellschaftliches Miteinander, das nicht auf Unterordnung und Hierarchiebildung basiert. Die Gleichwertigkeit des Einzelnen wird herausstellt. Indem getroffene Entscheidungen auf die einzelnen Mitwirkenden zurückzuführen sind, werden solistisches und kollektives Spiel in eine neue Balance gebracht. ${ }^{31}$

\subsection{Georg Friedrich Haas - „... Einklang freier Wesen ...“}

Das zwischen 1994 und 1996 entstandene Werk „... Einklang freier Wesen ..." von Georg Friedrich Haas (geboren 1953 in Graz) vereint zehn Instrumentalstimmen. Diese können entweder separat aufgeführt werden oder sich zu mehrstimmigen Werkversionen in beliebigen Kombinationen unter dem Titel „... aus freier Lust ... verbunden ..." zusammenschließen. Die zehnköpfige in sich geschlossene Ensembleversion umfasst folgende Instrumente: Bassflöte, Bassklarinette in B, Trompete in C und B, Posaune, Basstuba, Schlagzeug I und II, Viola, Violoncello und Kontrabass. Die Abwesenheit von Instrumenten des hohen Registers, wie Flöte und Violine, erzeugt einen dunkel gehaltenen

30 Vgl. den Werkkommentar in den einzelnen Partituren: Juliane Klein, Aus der Wand die Rinne.

31 In dieser Form weist die Werkreihe auch Parallelen zu Klaus Hubers Zyklus Ein Hauch von Unzeit auf. Dieser Zyklus basiert auf einem Flötenstück für Aurèle Nicolet. Davon abgeleitet gibt es Transkriptionen des Stücks für andere Soloinstrumente, die entweder von Klaus Huber selbst (für Singstimme, Bratsche) oder von anderen Interpreten geschaffen wurden. Diese verschiedenen Versionen sind in beliebiger Kombination auch simultan aufführbar. In einer simultanen Aufführung dürfen die Spieler auch einzelne Passagen ihrer Solostücke überspringen, allerdings im Stück nie zeitlich zurückgehen. Siehe Klaus Huber, Werkkommentar zu Ein Hauch von Unzeit, https://www.klaushuber. com/pagina.php?o,2,94,51,o,o (letzter Aufruf am 21.3.2020). Hier heißt es: „Die multiple Version - ,Ein Hauch von Unzeit III‘ - verwirklicht einen Schwebezustand zwischen strengem Kanon und Aleatorik, indem jeder der im Raum verteilten Musiker seine, idiomatische Umsetzung' des Flötenparts ins Ensemble einbringt. Die Omnipräsenz der Musik, ihrer Motive, ist nicht nur im Raum, sie ist auch in ,fluktuierender Gleichzeitigkeit vorhanden."Vgl. auch Huber/Nyffeler (Hg.): Umgepflügte Zeit, S. 419. 
Grundklang. Das Werk wurde für das Klangforum Wien (ein Solistenensemble) geschrieben. ${ }^{32}$

Der Titel ist dem Roman Hyperion von Hölderlin entnommen. ${ }^{33}$ Im Gegensatz zu den Werken von Bernd Franke und Juliane Klein, die nur als Einzelstimmen und nicht als Partitur veröffentlicht wurden, sind bei Haas sowohl die Einzelstimmen und verschiedene Kombinationsformen als auch eine Gesamtpartitur aller Stimmen beim Verlag erhältlich. Somit sind sie als simultane Fassungen auch lesbar und überblickbar.

Die harmonische Struktur des vorwiegend auf Quintschichtungen basierenden Werks ${ }^{34}$ wurde im Vorfeld der Komposition geplant und festgelegt. Sie ist ein übergeordnetes Gerüst, das die Stimmen einerseits aneinanderbindet, dem melodisch selbstständigen Verlauf der Einzelstimmen aber andererseits auch enge Grenzen setzt. Die beiden folgenden Notenbeispiele veranschaulichen das Vorgehen. Dem ersten Takt liegt ein vierstimmiger Akkord aus den beiden Quinten d-a und es'-b' zugrunde, der auf die zehn Instrumente verteilt ist (vgl. Abb. 16, Takt 1). Dieses Prinzip der Tonhöhenverteilung setzt sich im weiteren Verlauf fort. Im zweiten Beispiel pendeln sich alle Instrumente für acht Takte auf den Ton a' ein (vgl. Abb. 16, Takte 74-75).

Nicht nur die Harmonik ist kongruent. Auch musikalische Bewegungsmuster wie Skalenläufe, melodische Linien (Abb. 17, Takte 40-41 und Takte 144-146), mikrotonale Läufe (Abb. 17, Takte 119-121), Tonrepetitionen (Abb. 17, Takte 147-149), Geräuschfelder, Glissandi etc. fügen sich zu einheitlichen Klangflächen zusammen und verstärken die Homogenität der kompositorischen Anlage. Die Gesamtpartitur macht die homogene Gruppendynamik sichtbar, die permanente gegenseitige Imitation der Instrumente auf einer mikrotemporalen Ebene. In ihrer gleichförmigen und konsonanten Struktur und der lockeren Parallelität ihrer Bewegungen ähnelt das Partiturbild

32 Eine interessante multiperspektivische Präsentation des Werks ist hier zu finden: https:// einklangfreierwesen.de/ (letzter Aufruf am 1.7.2021). Die einzelnen Stimmen - eingespielt durch einzelne Musiker verschiedener Ensembles verschiedener Orte - lassen sich durch ein digitales Interface beliebig miteinander verknüpfen. Die Einspielungen entstanden im Frühsommer 2020 als Reaktion auf den Lockdown der Covid-19-Pandemie.

33 Der Ausschnitt lautet: „Ich fühl in mir ein Leben, das kein Gott geschaffen, und kein Sterblicher gezeugt. Ich glaube, daß wir durch uns selber sind, und nur aus freier Lust so innig mit dem All verbunden. [...] Was wär auch [...] diese Welt, wenn sie nicht wär ein Einklang freier Wesen? wenn nicht aus eignem frohem Triebe die Lebendigen von Anbeginn in ihr zusammenwirkten in Ein vollstimmig Leben, wie hölzern wäre sie, wie kalt?" (Friedrich Hölderlin: Hyperion: 2. Band, 2. Buch, XXVII).

34 Die Harmonik wurde von den sogenannten Wyschnegradsky-Akkorden (hier: régime 11, cycle imparfait) abgeleitet. 
T. 1 "...Einklang freier Wesen..."

für 10 Instrumente (1994/1995)

Neufassung 1996

Georg Friedrich Haas ("1953)

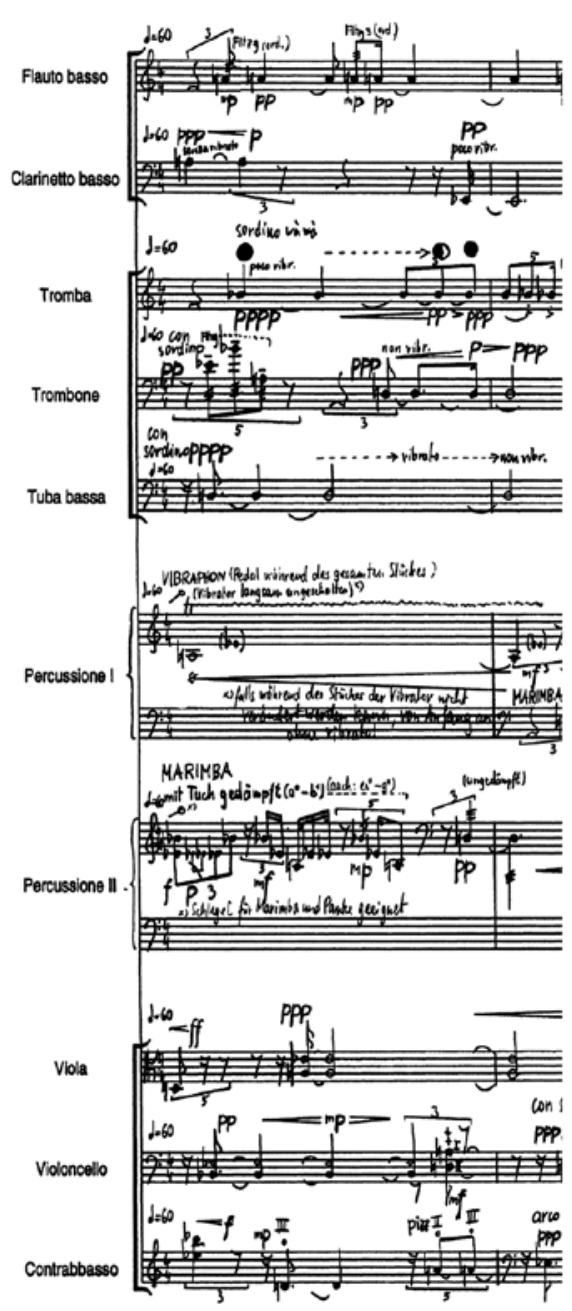

T. $74 / 75$

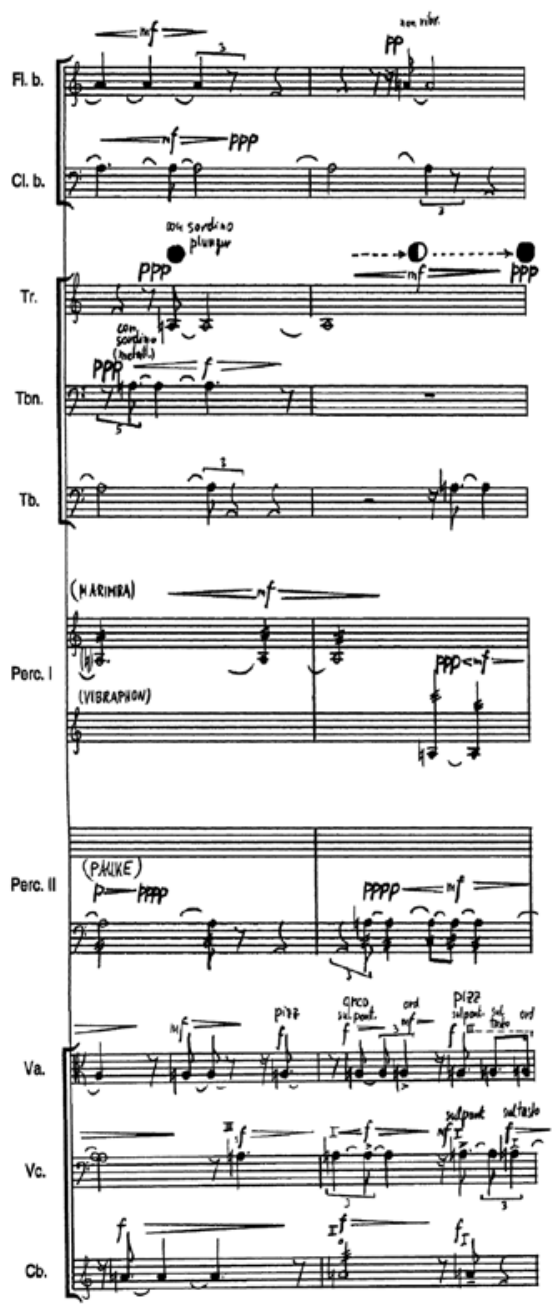

Abb. 16 Georg Friedrich Haas: „... Einklang freier Wesen ...“ für Ensemble, 1994-1996, Takt 1 und Takte 74-75. ( ) 1995, 1996 by Universal Edition A. G., Wien. 

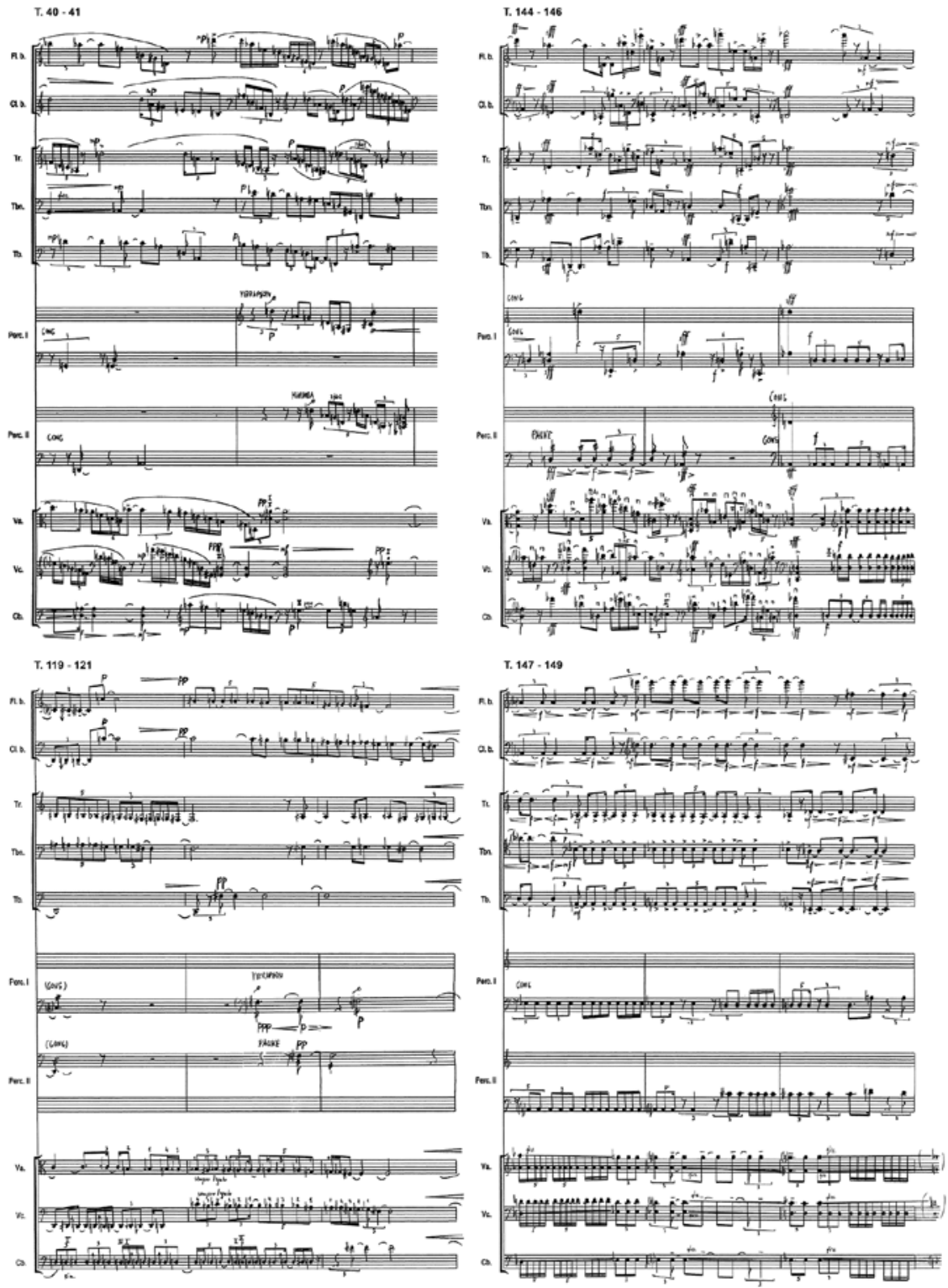

Abb. 17 Georg Friedrich Haas: „... Einklang freier Wesen ..." für Ensemble, 1994-1996. (C) 1995, 1996 by Universal Edition A. G., Wien. 
einem Schwarmorganismus, dessen Bewegungsmuster und Richtungen kollektiv gesteuert werden.

So, wie die einzelnen Stimmen in der vertikalen Organisation aneinandergekoppelt sind, ist auch ihr linear-zeitlicher Verlauf sehr eng aufeinander abgestimmt. Die Werkdauer mit Anfangs- und Endpunkt sowie Metren, Tempi, formale Zäsuren und Formabschnitte sind exakt synchronisiert. Zeitliche Freiheiten gibt es nicht. Auch werden die Musiker von einem Dirigenten geführt.

Haas selbst beschreibt sein Werk als „Vernetzung von zehn völlig selbstständigen und isoliert lebensfähigen Einzellinien“35. Die Stimmen besitzen in ihren Einzelversionen durchaus einen eigenen - oft fragmentierten Ausdruck, der sich in seiner Vereinzelung zwangsläufig von der klanglichen Wirkung der Gesamtfassung unterscheidet. Da die einzelnen Fassungen aber sowohl in ihrer zeitlich-linearen als auch in der vertikalen Struktur sehr eng an das übergeordnete Harmonik- und Formkonzept gebunden sind, bleibt für eine freie, selbstständige und individuelle Entfaltung nur sehr wenig Spielraum. Die individuelle Ausformung jeder Einzelstimme ist sehr fest an die übergreifenden Bewegungsmuster des Kollektivs gebunden. Tatsächlicher Individualismus ist kompositorisch nur zu einem geringen Grad gegeben, denn die Verschiedenartigkeit und die Varianz der Stimmen ergibt sich - wie bei den anderen "Werkclustern" - tendenziell eher aus den unterschiedlichen Registern, Klangfarben und Möglichkeiten der Instrumente als aus einer Individualisierung des Materials. Motivisch, rhythmisch und melodisch ist der Rahmen, innerhalb dessen die Stimmen ein eigenes freies Verhalten entfalten können, sehr eng gesteckt. Bereits der Titel „... Einklang freier Wesen ... “' verweist mit dem Ausdruck „Einklang“, auf die konsonantische Beziehung der Stimmen untereinander. Ebenso verweist die dominante Quintenharmonik, die die Intervallverhältnisse prägt, auf einen konsonantisch harmonischen Kontext. ${ }^{36}$

35 Siehe Werkkommentar zu „... Einklang freier Wesen ...", Universal Edition, https://www. universaledition.com/georg-friedrich-haas-278/werke/einklang-freier-wesen-16 (letzter Aufruf am 2.5.2020). Auch die formalen Zäsuren und Einheiten der einzelnen Instrumente beschreibt Haas hier als unabhängig.

36 Interessanterweise hat Haas in jüngerer Zeit das Stück Blumenwiese für 1-7 Instrumente komponiert. Auch dieses ermöglicht sämtliche Kombinationsformen (insgesamt 127 verschiedene Kombinationen), die laut Haas allesamt den Status einer eigenständigen Komposition haben. Hier soll es weder einen übergreifenden harmonischen Verlauf noch eine gemeinsame Form geben (aus einem E-Mail-Wechsel mit der Verfasserin vom 15.1.2020). 
4.2.1.1.4 Die Kontextualisierung des Solos bei Klein, Franke und Haas als freie Assoziation

In den besprochenen Werken soll sich der einzelne Musiker, auch wenn er Teil eines Kollektivs ist, weiterhin als Solist begreifen und aus dieser spezifischen Haltung heraus agieren, reagieren oder interagieren. Diese grundsätzliche Überlegung zum Aufführungsprozess, die auch an John Cage anknüpft, steht am Anfang der kompositorischen Phase. Wie bei Cage sind die Stimmen alle einzeln veröffentlicht, und im Fall von Solo xfach und Aus der Wand die Rinne wird ebenso wie bei Cage auf die synchronisierende Partitur verzichtet. Das Werk „... Einklang freier Wesen ... “ von Georg Friedrich Haas existiert dagegen sogar in mehreren Partiturausgaben mit verschiedenen simultanen Versionen. Doch in allen drei Beispielen geht es im Kern um die einzelne „freie“ Stimme, die mitunter auch einen fragmentierten Charakter besitzen kann. Dadurch wird sie einerseits anschlussfähiger und flexibler, anderseits lässt sich nicht immer eindeutig ein „echter“ und vor allem ein individualisierter Werkcharakter erkennen. Möglicherweise handelt es sich doch eher um den Status eines freien, flexiblen Moduls, um ein Hybrid aus „Stimme“ und „Werk“, das mindestens die Vernetzung mit einer weiteren Stimme braucht, um in einer Aufführung „bestehen“ zu können. Denn die Intention richtet sich ja ausdrücklich auf die Struktur einer musikalischen Kommunikation, auf die Suche nach einer Erweiterung des Kommunikationsspektrums jenseits eingespielter Reflexe und Muster. Es geht nicht nur um das Miteinander, sondern auch um das rezeptive Nebeneinander in der Ausführung. Dafür sind immer mindestens zwei Stimmen nötig. In allen Fällen ist die Form der Soloaufführung aber potenziell möglich, wurde durch Musiker vielfach realisiert und als Form der Einzelaufführung positiv bejaht. Der Flötist Arno Steinwider beispielsweise, der den Flötenpart aus „... Einklang freier Wesen ... “ gespielt hat, ist von der Selbstständigkeit des Flötenparts überzeugt. ${ }^{37}$ Ähnlich äußert sich der Tubist Jack Adler Mc Kean zur Tubastimme desselben Zyklus:

„I do think that it works as a stand-alone piece. One does feel that it could be counterpointed against other parts, but from my perspective it still functions on it's own. For example, there are long pauses, and also long held notes that feel very ,empty', but I personally feel that they add their own level of beauty to the piece. ${ }^{38}$

Sehr lange Pausen und lange Töne existieren auch in der Akkordeonstimme des Zyklus Aus der Wand die Rinne. Hier sind aufgrund der langen Pausen (die

37 Aus einem E-Mail-Wechsel mit der Verfasserin vom 27.4.2018.

38 Aus einem E-Mail-Wechsel mit der Verfasserin vom 5·5.2018. 
längste dauert zwanzig Sekunden) sowie des elementarhaften und sparsamen Materialgebrauchs ebenfalls Zweifel angebracht, ob diese Stimme, auch wenn sie einzeln verlegt wurde, wirklich als Solitär existieren kann oder ob es sich bei dieser Version um eine einfache Ensemblestimme des Ganzen handelt. Auf Nachfrage beharrte die Komponistin ausdrücklich darauf, dass es sich tatsächlich um ein Solostück handle, welches schon oft und gern von verschiedenen Akkordeonspielern aufgeführt worden sei. ${ }^{39}$ Der Komponist Bernd Franke legt sich demgegenüber gar nicht auf diese Möglichkeit der Einzelaufführung fest. Er schließt sie allerdings auch nicht aus, sondern überlässt die Entscheidung über diese Option den ausführenden Musikern und der Situativität des Orts.

Auch wenn die Einzelstimmen autonom aufführbar sind, liegt der eigentliche Reiz der Stücke in der Beziehung Individuum - Kollektiv, im sozialen und räumlichen Mit- und Nebeneinander der Musiker und auch im gemeinsamen Proben- und Aufführungsprozess. Im Zentrum stehen die Musiker, die als Individuen sowohl eine solistische Haltung einnehmen können, um sich ihren eigenen musikalischen Raum zu schaffen und Einfluss auf das Verhältnis der Spieler zueinander nehmen zu können, als auch eine rezeptive Haltung. Auch wenn die Möglichkeit einer Einzelaufführung grundsätzlich besteht, handelt es sich bei den einzelnen Stimmen doch eher um "latente Werke“, die vor allem im Übergang zwischen Stimme und Werk existieren, die freie Form des Zusammenspiels anstreben und damit vor allem eher auf eine soziale Identität als auf eine individuelle Identität gerichtet sind. Darin liegt auch ihr spezifischer Reiz.

\subsubsection{Konzeptuelle Polyphonie - Parallelismus als Bindeglied 4.2.1.2.1 Julio Estrada - Yuunohui Cycle}

Der Yuunohui Cycle von Julio Estrada (geboren 1943 in Mexico City) basiert auf dem Cellostück Yuunohui'yei aus dem Jahre 1983. „Yuunohui“ bedeutet in der Sprache der Zapoteken-Indianer etwa "frischer, feuchter Lehm ohne Steine ${ }^{4}{ }^{40}$ Gemeint ist eine fortschrittliche Hüttenbauweise mit flüssigem Lehm im Unterschied zur traditionellen Hüttenbauweise aus Steinen. Der Titel verweist auf die Priorisierung kontinuierlicher Vorgänge gegenüber der

\footnotetext{
39 Aus einem E-Mail-Wechsel mit der Verfasserin vom 11.10.2019.

40 Julio Estrada beschäftigte sich bereits seit den 1970er Jahren mit indianischen Traditionen und mit der Verbindung zwischen Musik und Mythen in prähispanischen Kulturen und versuchte, diese in die westliche Musik zu integrieren. 1987 studierte er in einem Tewa-Reservat in San Juan Pueblo in Neu Mexiko (bei Kwan-Faré-Tzé) und bei den HopiIndianern im Norden Arizonas indianische Musik. Die Sprache der Hopi-Indianer hat ähnliche Merkmale wie die der Azteken, und sie schafften es, ihre Traditionen vor der spanischen Eroberung zu bewahren.
} 
diskreten Stufung des Materials. In den Stücken der Werkserie geht es im Kern um stufenlose und gleitende Prozesse, transitionale Spieltechniken, die den Übergang von einer Spieltechnik zur anderen betonen, und um "stufenlose Werkbildungen“, die im Folgenden dargestellt werden sollen.

Die Werkserie umfasst die Stücke Yuunohuinahui' (1985) für Kontrabass, Yuunohui'ome für Viola (1990), Yuunohui'se (1989) für Violine, Yuunohuitlapoa (1999) für Klavier, Orgel oder Harpsichord, Yuunohui'wah (2008) für Noisemaker, Yuunohuiehecatl (2012) für verschiedene Blasinstrumente und Yuunohui'sa (2018/19) für Gesang. Bis auf Yuunohui'tlapoa, das keine kombinierte Fassung seiner drei Instrumentalversionen erlaubt, und Yuunohui'wah, das lediglich als Solostück komponiert wurde, sind die anderen Stücke der Serie sowohl als unabhängige Soli als auch in beliebigen simultanen Kombinationen aufführbar.

\section{Beschreibung}

Jede Yuunohui-Version besteht aus den sechs verschiedenen Abschnitten S1S6, die durch eine freie Introduktion und ein Finale eingerahmt werden. Die sechs Abschnitte entsprechen einander werkübergreifend in der Dauer und in der Unterteilung ihrer Zeiteinheiten. Dadurch werden die verschiedenen Versionen in der zeitlichen Organisation synchronisierbar. Da die Reihenfolge der Abschnitte in jeder Version variiert, gibt in den kombinierten Versionen jeweils die Fassung eines Instrumentes die Reihenfolge der Abschnitte vor. Werden zum Beispiel Yuunohuinahui für Kontrabass und Yuunohuiehecatl für ein Blasinstrument simultan miteinander kombiniert, so gibt die Abfolge einer Fassung die Abfolge der kombinierten Fassung vor. Das Stück wird dementsprechend Yuunohuinahui'ehecatl betitelt, das heißt die Abfolge beruht auf Yuunohuiehecatl.

Zusammenfassend kann gesagt werden, dass die äußere Formstruktur, die die zeitliche Organisation - das heißt die Dauer, das Tempo und die metrische Einteilung in gleichbleibende Zeiteinheiten - umfasst, für die Abschnitte S1S6 identisch ist.

In den Yuunohui-Versionen für Streicher ist das Notensystem mehrfach unterteilt. Dem System für die Notation der Tonhöhen ist ein System für die Notation der Positionen des Bogens auf der Saite hinzugefügt, das die Skala estremo sul pont bis estremo sul tasto abdeckt. Insgesamt sind in den Yuunohui der Streicherfassungen die folgenden fünf Parameter auskomponiert:

41 In Nahuatl: 'se, 'ome, 'yei, 'nahui = eins, zwei, drei, vier; tlapoa = Kristall, Kalkül. 
Bogenposition, Bogenpulsation, Tonhöhe, Dynamik und Vibrato. ${ }^{42}$ Die Hierarchie der Parameter, die der Tonhöhe traditionell eine übergeordnete Funktion einräumt, ist aufgehoben. Im Vordergrund steht die Bildung eines sogenannten „Makrotimbres“, eines Klang-Zeit-Kontinuums, das die resultierende Klangfarbe als Synthese klanglicher (Tonhöhe, Intensität und Klangfarbe der Saiten) und rhythmischer Komponenten (Puls des Bogens, Vibrato ${ }^{43}$ ) begreift und die rhythmische und klangliche Gestaltung in eine strukturelle Beziehung setzt.

Vergleicht man den Verlauf der Notenschrift mit der grafischen Linie im System der Bogenpositionen, erkennt man, dass beide Verläufe nicht zwingend aufeinander abgestimmt sind. Dasselbe gilt für die Ebene der Dynamik und des Vibrato. Diese mehrfache Aufspaltung, Polyphonisierung und Modularisierung der Solostimme auf rhythmischer, melodischer, klangfarblicher und dynamischer Ebene folgt präkompositorisch grafisch festgelegten Wellenfunktionen, die in eine kontrapunktische Beziehung zueinander gesetzt wurden (vgl. Abb. 18).

Die Übertragung der grafischen Linien auf die musikalischen Ebenen wie Tonhöhenverlauf, Rhythmus, Bogenpositionen, Dynamik und Vibrato hat zur Folge, dass die musikalischen Ereignisse und Verläufe zeitlich nicht zusammenfallen und unabhängig voneinander sind. Ein simultan geplantes Aufeinandertreffen musikalischer Ereignisse ${ }^{44}$ geschieht zufällig und ist nicht von vornherein intendiert. Diese asynchrone Modularisierung der Einzelstimme wirkt in erster Linie auf einer theoretischen und abstrakten Ebene. Das Ohr ist es nicht gewohnt, diese Ebenen getrennt zu verfolgen, und gewichtet die musikalischen Ebenen und ihr Zusammenwirken in der Wahrnehmung unterschiedlich. Die lineare Wellenform, die der kompositorischen Ausarbeitung voranging, verbildlicht Estradas Konzept eines „Kontinuums“ und macht die Übertragung auf die agogische, die dynamische und die Tonhöhenebene nachvollziehbar. Die Segmentierung des kontinuierlichen Frequenzspektrums in diskrete Tonstufen wird durch fließende Übergänge innerhalb eines festgesteckten Rahmens ersetzt. ${ }^{45}$

42 Estrada benennt die Parameter folgendermaßen: pitch, dynamics, string color, speed of bow, vibrato. Vgl. Ensemble Yuunohui, „Werkbeschreibung“, nicht veröffentlichtes Dokument, zur Verfügung gestellt von Julio Estrada, S. 3.

43 Vibrato wird als rhythmisches Element, als Unterteilung einer vorgegebenen Dauer definiert.

44 Zum Beispiel hoher Ton + Fortissimo.

45 „Wenn man zum Beispiel einen Hopi hört, der Glissando ohne Skalen singt, ohne unterscheidbare Tonhöhen - das gibt es in Europa nicht" (Julio Estrada, zitiert nach Monika Fürst-Heidtmann: „Auf der Suche nach der unverstellten Imagination. Der mexikanische Komponist Julio Estrada“, in: MusikTexte. Zeitschrift für Neue Musik 55, 1994, S. 39-45, hier: S. 40). 


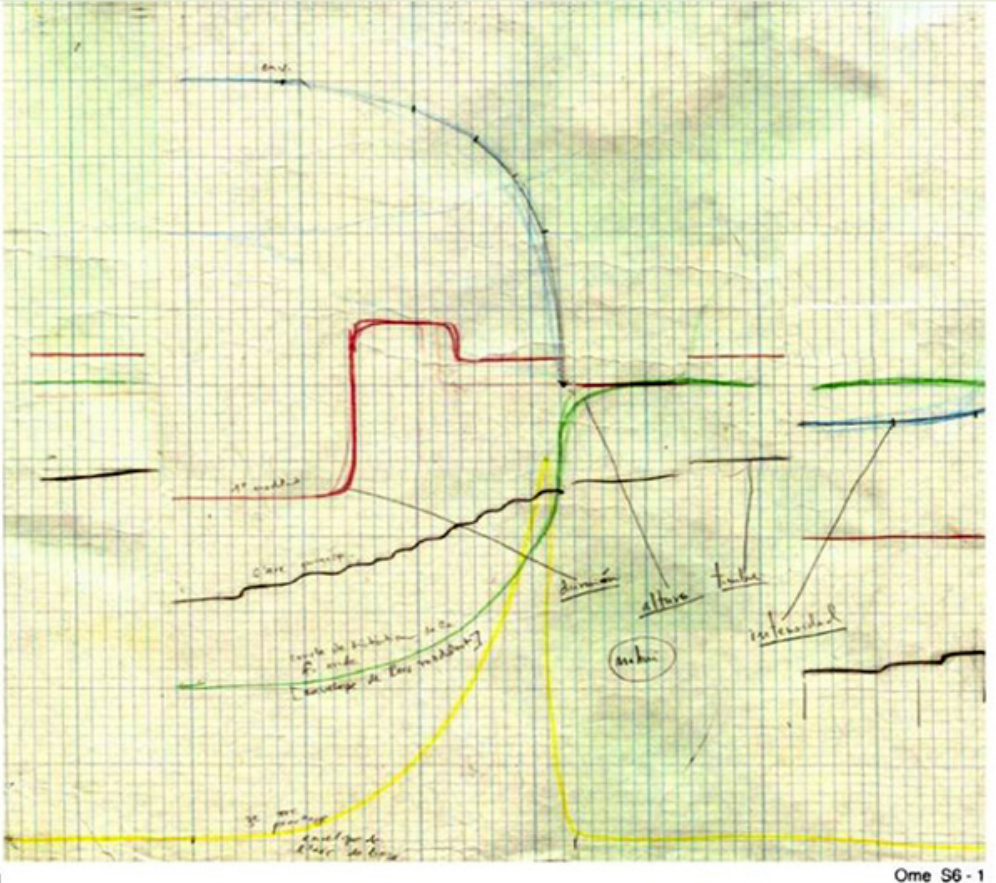

S6

Ome $56 \cdot 1$

56

Ome $56 \cdot 1$

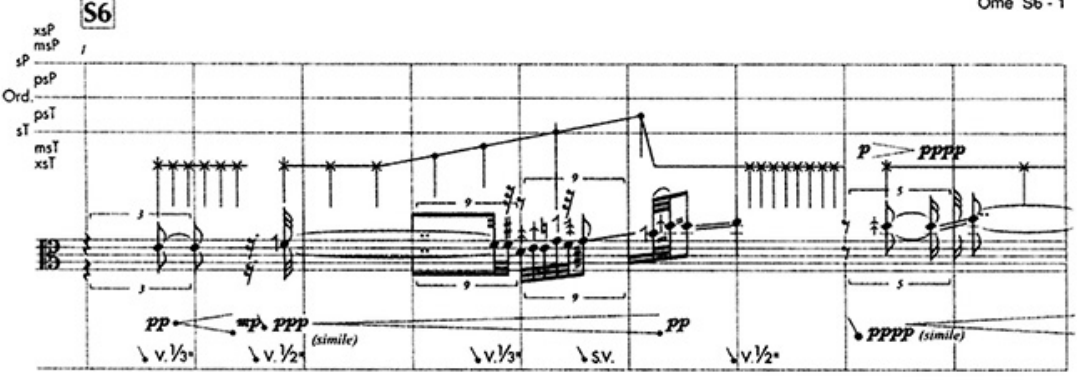

Abb. 18 Grafisch festgelegter Wellenverlauf als Vorlage für Yuunohui'ome S6,

Zeiteinheiten 1-9. Siehe Ensemble Yuunohui: „Werkbeschreibung“, S. 8.

Persönliches Archiv des Komponisten. Mit freundlicher Genehmigung von Julio Estrada. 
Transkriptionsprozesse

Beim Yuunohui Cycle handelt es sich um eine Werkpolyphonie, die mit einem in sich homogenen Materialsystem arbeitet. Alle Einzelstücke der Werkserie sind Ableitungen aus demselben Ausgangsmaterial: grafisch entworfenen Linienverläufen, die auf die Ebenen des Rhythmus, der Tonhöhen, der Dynamik und Klangfarbe übertragen werden. Die vorher festgelegten Wellenfunktionen werden in jeder Werkversion auf unterschiedliche musikalische Ebenen transkribiert und wie unabhängige Stimmen behandelt. Ein Wellenverlauf, der in einem Stück den dynamischen Verlauf festlegt, wird in einem anderen Werk auf den Klangfarbenverlauf projiziert. Die vorab fixierten Kurven können in den verschiedenen Fassungen transformiert als Lautstärke, Tonhöhe, Bogenbewegung etc. erlebt werden. Diese stimmeninwendig kontrapunktisch-asynchrone Aufspaltung der Einzelstücke wird auf diese Weise in den kombinierten Fassungen um synchrone Parallelbewegungen erweitert. Zum Beispiel entspricht die Bewegung des Dynamikverlaufs in Yuunohui'yei für Cello der Bogenbewegung zwischen Griffbrett und Steg in Yuunohuinahui für Kontrabass (vgl. Abb. 19). Werden die beiden Versionen nun simultan gespielt, entsteht folglich ein strukturelles Unisono, das es in den Einzelfassungen explizit nicht gibt. Der dynamische Verlauf der Cellostimme wird dadurch indirekt imitiert und verstärkt. Gleichzeitig interferiert dieser Effekt mit asynchronen Bewegungen in der Dynamik oder Melodik des Kontrabasses, wird also sofort auch wieder negiert. Der Reiz der Asynchronität wird um den Reiz der strukturellen Parallelbewegung in den simultanen Fassungen erweitert. Die Parallelbewegung stellt darüber hinaus das zentrale Verbindungsglied zwischen den einzelnen Teilwerken dar.

\section{Yuunohuiehecatl - Erweiterung des Yuunohui-Prinzips}

Die fünf Parameter der Streicherfassungen werden in Yuunohui'ehecatl (2012) für diverse Bläserstimmen auf fünfzehn Parameter erweitert (vgl. Abb. 20). Als Werkvorlage dient nunmehr ein Plan, der drei spieltechnische Komponenten zu einer Gruppe zusammenfasst, sodass sich fünf Gruppen ergeben:

1. a) Instrumental Pitch, b) Space vertical position, c) Lips pressure

2. a) Puls, b) Sordino, c) Bisbigliando

3. a) Voice pitch, b) Dynamik, c) Fingers pressure on keys

4. a) In-out breath, b) Color attack, c) Vibrato

5. a) Air pressure, b) Attack amplitude, c) Consonants noise

Je nach Blasinstrument und eigenen Interpretationsvorstellungen ist der Interpret gefragt, aus jeder der fünf Gruppen eine Komponente auszuwählen. Diese Auswahl und Kombination von fünf Techniken bildet den Rahmen einer möglichen Werkfassung. Innerhalb des vorgegebenen Rahmens ist in 

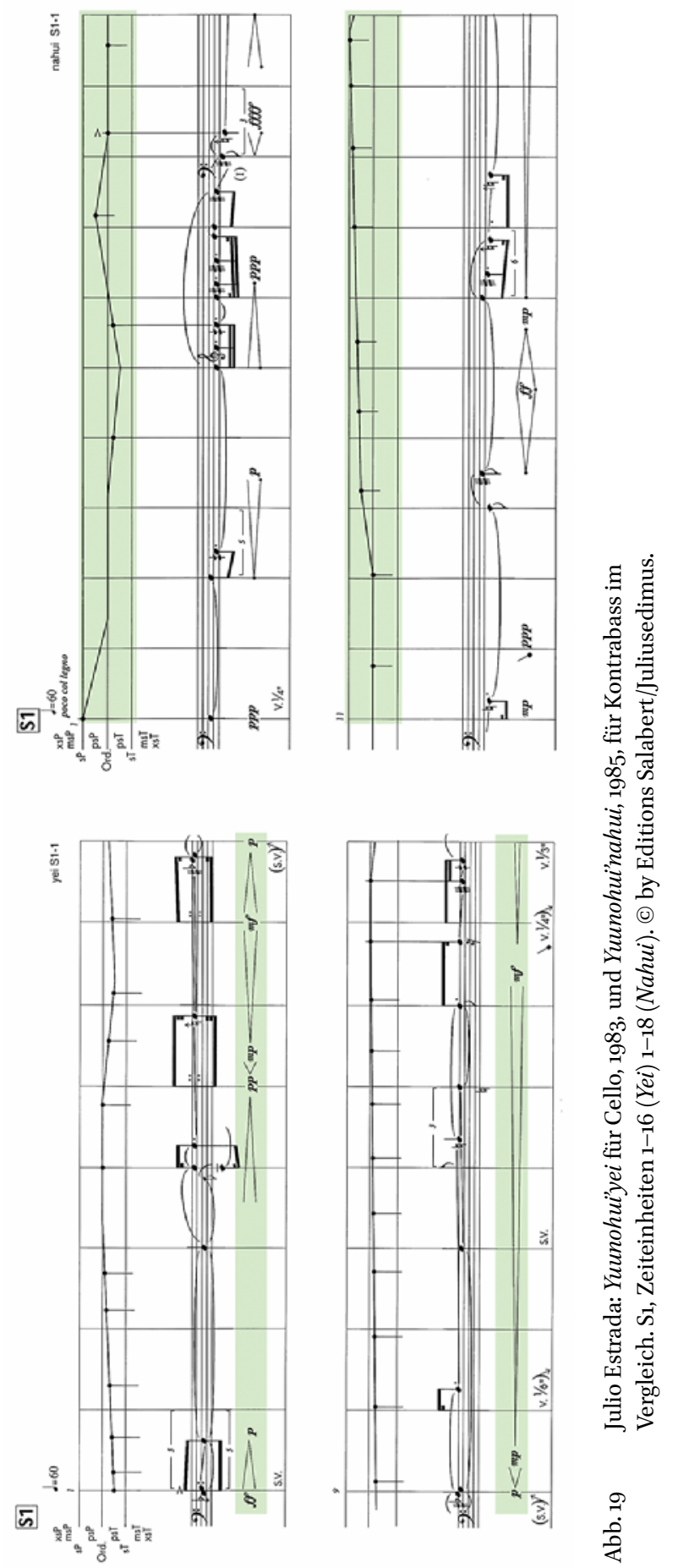


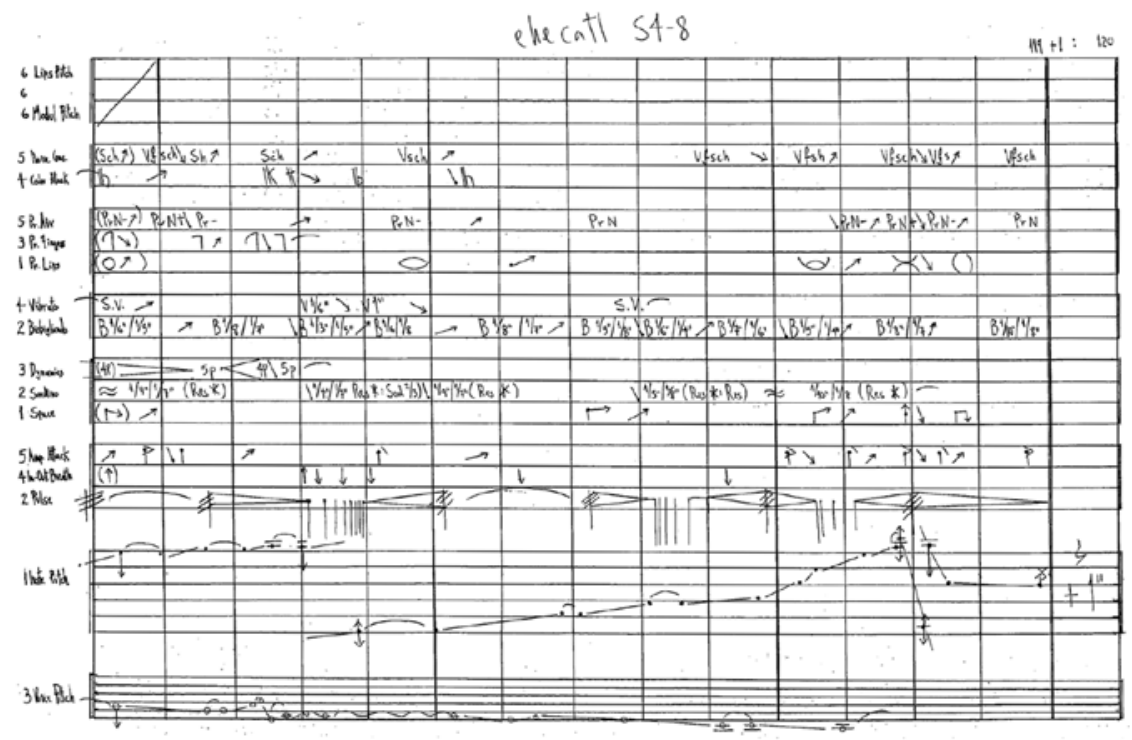

Abb. 20 Julio Estrada: Yuunohuiehecatl für Blasinstrument, 2012. Partiturausschnitt. @ by Juliusedimus.

Yuunohuiehecatl die Freiheit der Kombinationsmöglichkeiten, die in den Streicherfassungen nur werkübergreifend gegeben war, hier bereits innerhalb der Einzelversion gegeben. Das steigert wiederum bereits für Solofassungen den Grad der Individualisierung der Interpretation und vergrößert den Pool möglicher Werkversionen.

Polyphonie zwischen Synchronität und Asynchronität

In der westlichen Tradition zielt polyphones und kontrapunktisches Denken auf eine formale Synthese der Stimmen. Diese zielgerichtete und geplante Zusammenführung von Ereignissen wird von Estrada als künstlich angesehen. Die Kompositionsweise der Yuunohui orientiert sich an der indianischen Musik, die monophone Gesänge mit irregulären Rhythmen kombiniert. Die Nichtkoordination von Gesang und Rhythmus oder Klang und Rhythmus wird von Estrada als natürlicher empfunden und bewegt sich aus seiner Sicht näher an der Realität des Lebens. ${ }^{46}$

Durch die freie Werkschichtung werden die Kombinationsmöglichkeiten um ein Vielfaches gesteigert. Allein die vier Streicherfassungen ergeben fünfzehn Kombinationsmöglichkeiten der Aufführung. Mit seiner Strategie schafft

46 Vgl. Fürst-Heidtmann: „Auf der Suche nach der unverstellten Imagination“, S. 44. 
Estrada einen Rahmen für die Organisation einer vielfachen Werkbildung. Form ist nichts endgültig Konstruierbares, sondern bleibt flexibel und wird erst im Akt der Aufführung finalisiert.

Indem sich Estradas Konzept von Polyphonie über mehrere musikalische Parameter erstreckt, nimmt es Mahnkopfs Modell einer Polyphonie auf seine eigene Art und Weise vorweg. Zusammenfassend lässt sich sagen, dass es seine Komplexität durch die Synthese kontrapunktischer Extreme gewinnt, die in eine paradoxe Situation geführt werden: Polyphonie setzt an der Einheit einer Einzelstimme an. Diese wird aufgespalten und in ihre parametrischen Komponenten wie Tonhöhen, Dynamik, Vibrato und Bogenposition zerlegt. Diese werden als voneinander unabhängige Größen behandelt und verhalten sich in ihren Bewegungsverläufen asynchron, da ihnen jeweils ein anderer Linienverlauf der präkompositorischen Ausgangsgrafik zugeordnet ist. Dabei wird die jeweilige Zuordnung, welche Linie auf welchen Parameter trifft, in jedem Einzelstück neu festgelegt. Diese verschiedenen Kombinationsmöglichkeiten stellen eine extreme Zuspitzung des doppelten oder mehrfachen Kontrapunkts dar, bei dem die Linienbewegungen über die Stimmen hinweg austauschbar sind. In den simultanen Aufführungen der Einzelwerke werden dadurch zudem strukturelle Parallelbewegungen erzeugt, die Information einer Linie wird im selben Augenblick auch immer auf einer anderen parametrischen Ebene vermittelt. Diese Synchronität ist in ihrer Konsequenz ebenfalls eine kontrapunktische Zuspitzung auf einer zeitlichen Ebene, denn die Imitationstechnik der kontrapunktisch-polyphonen Tradition macht die thematischen Bezüge ihrer Linien vor allem in der Diagonalität, in einer sukzessiv-simultanen Abfolge hörbar und nicht in der Parallelität. ${ }^{47}$

Mehrstimmigkeit wird in den Yuunohui also einerseits durch konsequent unabhängige, asynchrone Linienverläufe in den Einzelfassungen und andererseits durch die Kombination der asynchronen und der parallelen Bewegungen in den simultanen Fassungen erzeugt. Parallelführung - als historisch erster Schritt in die Mehrstimmigkeit - ist hier nicht in einer einfach nachvollziehbaren Form, sondern durch das Mapping auf andere Ebenen immer in einer transformierten Form gegeben. Durch die Zuordnung einer Linie zu unterschiedlichen Parametern wie Tonhöhe, Dynamik, Klangfarbe etc. entsteht eine Differenz zwischen der strukturellen Parallelität und unserer Wahrnehmung derselben, die die Parallelität als solche nicht eindeutig identifizieren kann. Das lässt in den simultanen Fassungen ein permanentes Spannungsfeld zwischen

47 Die Themeneinsätze der verschiedenen Stimmen werden im klassischen Kontrapunkt nacheinander vorgestellt, eine simultane Überlappung der Themen und ihre zeitliche Ineinanderschiebung gibt es nur im speziellen Fall der Engführung. 
synchronen und asynchronen Bewegungen entstehen. Die Synchronität und Synthese von Klang und Rhythmus, wie sie der westlichen Kompositionspraxis entspricht, wird durch die Emergenz der zufälligen Synchronizität klanglicher und rhythmischer Ereignisse ersetzt, die in jeder Fassung neue Synergien hervorbringt.

„Zum großen Teil beginnt die Herausforderung der Geschichte mit der ständigen Spannung, die zwischen der Symmetrie der Zeit und der labyrinthischen Anordnung der Erinnerung existiert - Faden und Kette, Zeit und Erinnerung. Geschichte muss sowohl eine einfache Treppe als auch ein intrikates vertikales Konstrukt in der Zeit sein.“48

Überträgt man den Vergleich mit der europäischen Tradition der Polyphonie auf die Ebene der Zeitgestaltung, wird hier außerdem ein anderes Zeitbewusstsein fassbar, das sich vom westlichen Zeitmodell unterscheidet. Die monochrone Zeitauffassung der westlichen Kultur, die die Zeit in feste Abschnitte gliedert und im Hinblick auf die unterschiedlichen Aktivitäten linear und zielorientiert organisiert, steht einem polychronen Zeitverständnis konträr gegenüber. Bei einem polychronen Zeitverständnis kann der zeitliche Rahmen sehr offen angelegt sein. Aktivitäten und Ereignisse können parallel ablaufen, sind nicht an einen festen Zeitplan gebunden und können sich spontan ändern. Das lässt im Gegensatz zum monochronen Modell eine Gleichzeitigkeit unabhängiger Ereignistemporalitäten zu.

\subsection{Simon Steen-Andersen - Next To Beside Besides}

Der „Re-Cycle“ Next To Beside Besides von Simon Steen-Andersen (geboren 1976 in Odder, Dänemark) basiert auf dem verstärkten Cellostück Beside Besides (2004), das bereits selbst eine Abspaltung des Endes des Ensemblestückes Besides (2003/10) für drei verstärkte Instrumente (Piccolo, Piano mit Whammy-Pedal und Violine) und drei gedämpfte Streicher ist. „Besides“ ist der nichtexistierende, frei erfundene Plural von "being next to“.

Die Werkreihe Next To Beside Besides beinhaltet neben der Celloversion (\# o) dreizehn weitere Soli für Kontrabass (zwei Stücke), Saxophon, Akkordeon (zwei Stücke) Percussion (zwei Stücke), Piccoloflöte, Violine, Klavier, Gitarre (zwei Stücke) und Video. Sie können alleine und in jedweder Ensemblekombination, sukzessive oder simultan, aufgeführt werden. Der Zyklus soll sich in den weiteren Transkriptionsreihen Self-reflecting Next To Beside Besides,

48 Julio Estrada: „Zerstört und wiedererschaffen. Das Entstehen des Mythos als Erklärung“, in: MusikTexte. Zeitschrift für Neue Musik 55, 1994, 45-51, hier: S. 45. 
Above Next To Beside Besides, Around Next To Beside Besides und Behind Selfreflecting Next To Beside Besides ${ }^{49}$ fortsetzen.

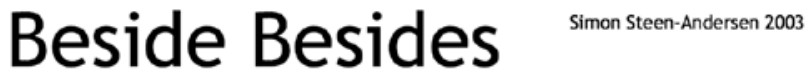

(or Next To Beside Besides \#0)

fragment for cello solo

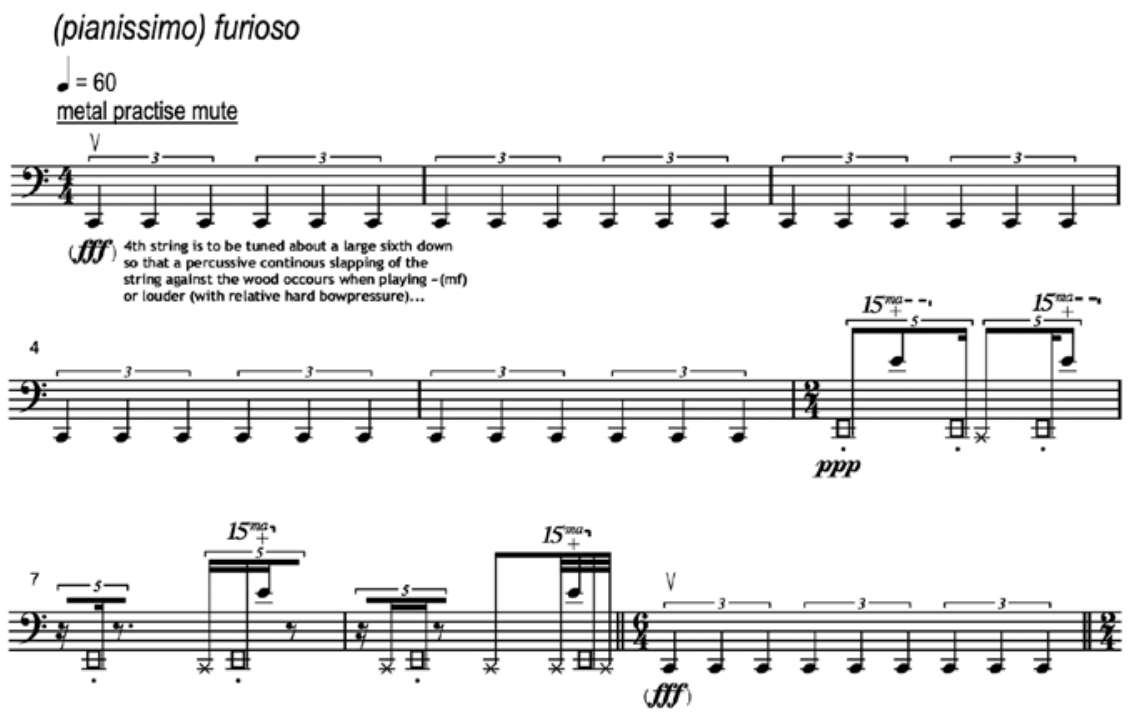

Abb. 21 Simon Steen-Andersen: Next To Beside Besides für Cello solo, 20o6, Takte 1-9.

(C) Edition·S, Kopenhagen, Dänemark, www.edition-s.dk. Printed with permission.

Als Beispiel für einen möglichen Transkriptionsvorgang greife ich aus dem Zyklus die Übertragung des Cellostücks auf die Variante für kleine Trommel (Version 4) heraus (vgl. Abb. 21 und Abb. 22). Ausgangspunkt der Transkription sind die horizontalen Links-rechts-Streichbewegungen des rechten Bogenarms des Cellisten, die für die Klangerzeugung auf dem Cello ausgeführt werden. Diese Bewegungen werden nun eins zu eins auf die rechten Armbewegungen des Schlagzeugers, dessen hölzerner Schlägel je eine flache und eine gerillte Seite hat, übertragen, indem sie konsequent parallelgeführt werden. Dieses Vorgehen hat zur Folge, dass die Klangerzeugung auf der kleinen Trommel statt aus einer vertikal schlagenden Bewegung aus einer horizontalen

49 Siehe den Werkkommentar in den Partituren Next To Beside Besides \# 1-11. Realisiert wurde nur die Möglichkeit von Self-reflecting Next To Beside Besides, die Video miteinbezieht. 


\section{Next To Beside Besides \#4}

\section{for amplified percussion solo}

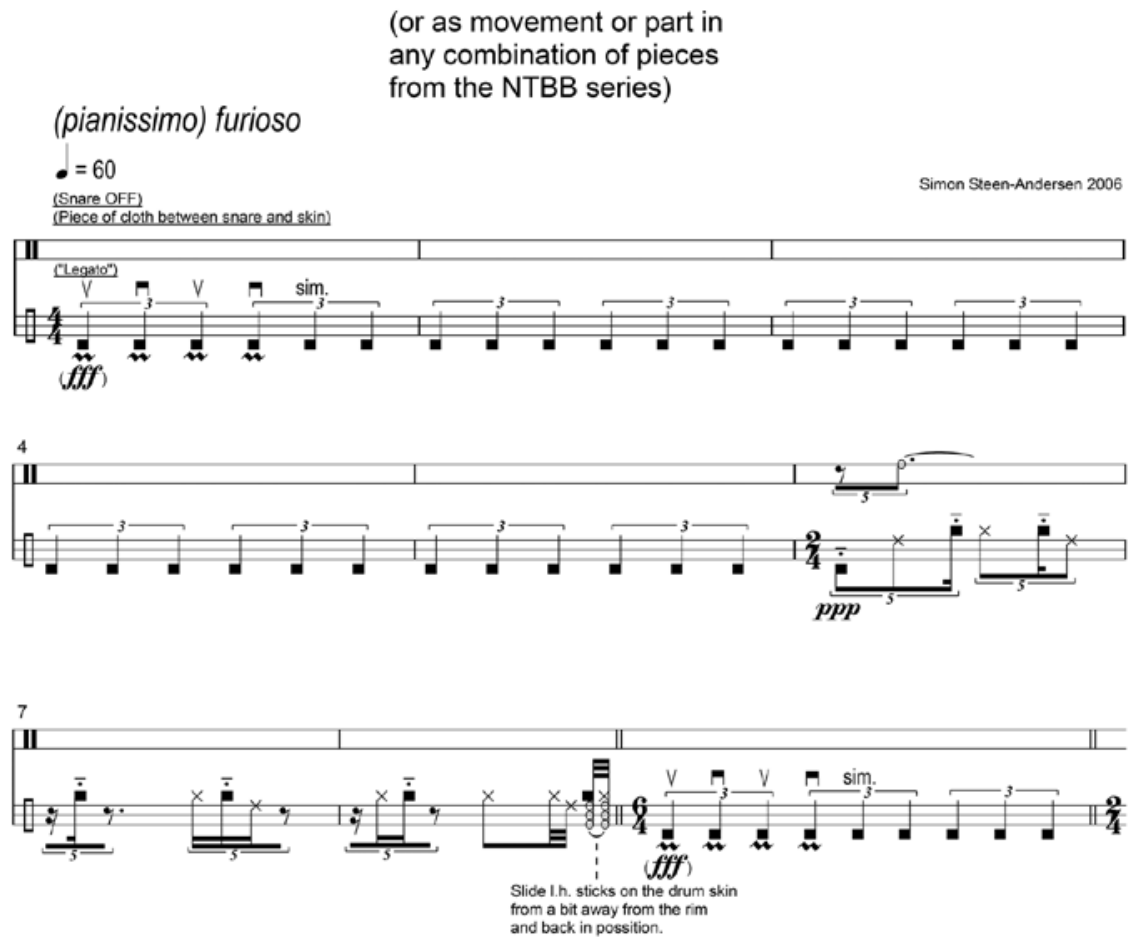

Abb. 22

Simon Steen-Andersen: Next To Beside Besides für kleine Trommel, 2006,

Takte 1-9. (C) Edition·S, Kopenhagen, Dänemark, www.edition-s.dk. Printed with permission.

Streichbewegung heraus erfolgt. Die kleine Trommel wird also synchron zum Cellisten an ihrem seitlichen Rand wie mit einem Bogen horizontal gestrichen. Die linke Hand des Schlagzeugers hält wiederum die Enden dreier Schlägel, die an ihrem anderen Ende quer über das Fell der Trommel gespreizt sind und auf diese Weise eine Saitenbespannung nachbilden.

Aus dieser extremen Bewegungsparallelität folgt die vollständige werkübergreifende Synchronisation der rhythmischen und zeitlichen Struktur als Zusammenspiel von Tempo, Metrum und Rhythmus. Denn die rhythmischzeitlichen Parameter des Stückes und die rhythmisch-zeitlichen Bewegungen der Musiker sind aneinander gekoppelt. Auch die sehr klare und übersichtliche Form des Stückes ist für beide Versionen einheitlich. 


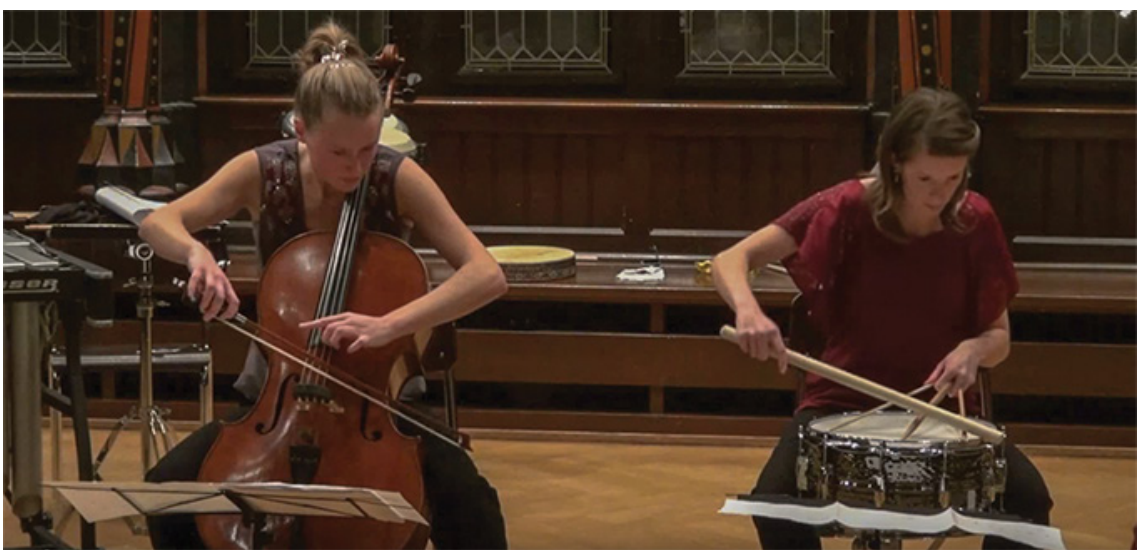

Abb. 23 Performance von Beside Besides für Cello und Next To Beside Besides für kleine Trommel. UmeDuo: Karolina Öhmann, Cello, und Erika Öhmann, kleine Trommel. Printed with permission.

Konventionell handelt es sich bei Bewegungsabläufen zur Klangerzeugung um einen sich aus dem Werk ergebenden performativen Faktor. In diesem Beispiel dagegen ist die Körperbewegung der Spieler durch ihre klare Rhythmisierung bereits auf der Stufe der Komposition ein struktur- und formbildender Faktor. Sie rückt in den Mittelpunkt der Wahrnehmung und wird zu einem übergreifenden konzeptionellen Verbindungsglied der Einzelstücke. Die Instrumentation des Cellostücks für die Trommelversion wird zur Transkription einer visuellen Bewegungschoreografie, die die übliche Praxis, dass der angestrebte Klang der Grund für eine bestimmte Spielbewegung ist, umkehrt. Durch die synchrone Übertragung der Bewegungsmuster entstehen visuell, aber auch rhythmisch, metrisch und motivisch parallele Stimmführungen und Musterbildungen. Eine visuelle Differenz entsteht für den Zuschauer durch das irritierende Paradoxon synchroner Spielbewegungen auf verschiedenartigen Instrumenten, wobei die dem Cello genuinen horizontalen Streichbewegungen maßgeblich auch für andere Instrumente sind.

Sowohl das visuelle Erscheinungsbild der Performance als auch die akustische Ebene sind für die Rezeption dieses Werkes relevant und gleich bedeutsam. Durch diese Gleichgestelltheit tritt die Gegensätzlichkeit dieser beiden Sinnesfunktionen deutlich hervor. Das tendenziell objektbezogen erfassende Auge wird dem tendenziell subjektiv erfassenden Gehör im gemeinsamen Rahmen des Werks gegenübergestellt. Gleichzeitig spielt das Stück mit der sinnesübergreifenden Synchronisierung von Aktionen und Abläufen und fokussiert neben der Vergleichzeitigung unterschiedlicher Stücke generell auch die bimodale Gleichzeitigkeit von visuellen und akustischen Bewegungsabläufen. 
Der Klangfarbenverlauf des Stückes resultiert aus dem spezifischen Zusammentreffen von (a) identischen und parallel geführten performativen Spielbewegungen, (b) ihrer Energetik und (c) den physisch charakteristischen Eigenschaften des jeweiligen Instruments. Je nach der Art und Weise dieses Zusammentreffens treten verschiedene Grade von Homogenität oder Differenz in der Klangfarbe auf. Man könnte von einem resultierenden freien Kontrapunkt der Klangfarbe sprechen, denn vor allem auf dieser Ebene entsteht die Möglichkeit von Identitäts- und Differenzbildung der verschiedenen Versionen. Um den klangfarblichen Verlauf noch stärker zu fokussieren und für die Wahrnehmung noch klarer greifbar zu machen, schließt Steen-Andersen in alle Versionen die Möglichkeit der Amplifikation der Instrumente ein.

\subsection{Die Kontextualisierung des Solos durch systematische Vervielfältigung}

Bei Steen-Andersen steht eine Komposition für Cello am Anfang des Prozesses. Diese Komposition ist der Primärtext, auf den sich alle folgenden Transkriptionen beziehen. Das hier diskutierte Beispiel von Steen-Andersen demonstriert die Möglichkeit eines auf visuellen und performativen Faktoren beruhenden Übertragungsprozesses. Während bei der Akkordeonversion die Links-rechts-Bewegung des Beginns direkt auf die Balgbewegung übersetzbar ist, erfordern andere Instrumente auch andere Übersetzungsstrategien und sind dadurch jeweils unterschiedlich nah an oder entfernt von der Ausgangsidee. Generell wird der repetierende Rhythmus des Beginns in den meisten Versionen beibehalten. Eine Ausnahme bildet die Saxophonversion, in der die Tonrepetition durch einen lang ausgehaltenen Ton ersetzt wird (vgl. Abb. 24). Von der formalen und zeitlich-rhythmischen Gliederung wird aber grundsätzlich nicht abgewichen. Sie ist für alle Transkriptionen das bindende Gerüst. Differenz soll sich vor allem im Klanglichen und in der Instrumentation manifestieren.

Bei Estrada steht zwar auch eine Komposition für Cello am Anfang der Reihe, diese ist jedoch bereits selbst eine Interpretation der im Vorfeld festgehaltenen Kurven. Der Transkriptionsprozess kann für den Yuunohui Cycle in drei Phasen unterteilt werden. Im ersten Schritt wird die Imagination des Komponisten, der kompositorische Einfall in eine sogenannte „chronografische“ Kurve übertragen. Dieses Material stellt für den Komponisten den primären Text dar, von dem aus sämtliche Werkvarianten gebildet werden..$^{50} \mathrm{Im}$ zweiten Schritt werden die Daten der chronografischen Kurve in eine Partitur übertragen.

50 Vgl.Julio Estrada: „Freiheit und Bewegung. Transkriptionsmethoden in einem Kontinuum von Rhythmus und Klang“, in: MusikTexte. Zeitschrift für neue Musik 55, 1994, S. 57-63. 


\section{Next To Beside Besides \#2}

for (any) saxophone solo

(or as movement or part in any combination of pieces from the NTBB series) Ensarationstut the

(pianissimo) furios
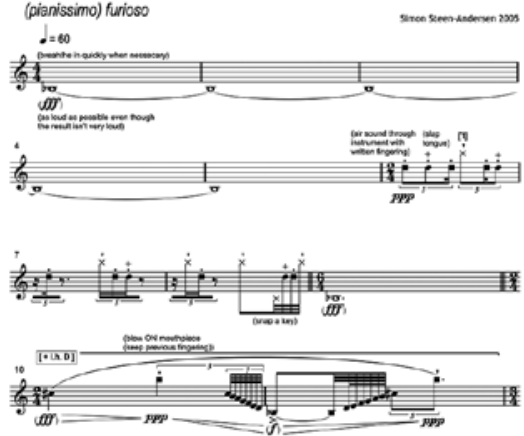

\section{Next To Beside Besides \#5}

for amplified piccolo flute solo

(or as movement or part in any combination of pleces from the NTBB series) (pianissimo) furioso

$d=00$

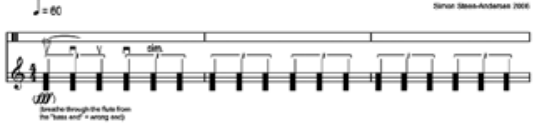

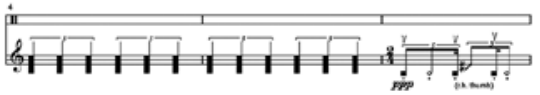
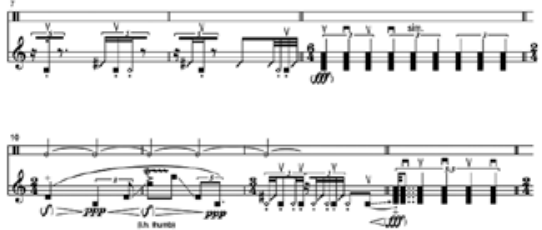

Next To Beside Besides \#8

for amplified (acoustic) guitar solo

(or as movement or part in any combination of pieces from the NTBB series)

(oianissimo) furioso

$J=60$

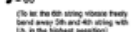
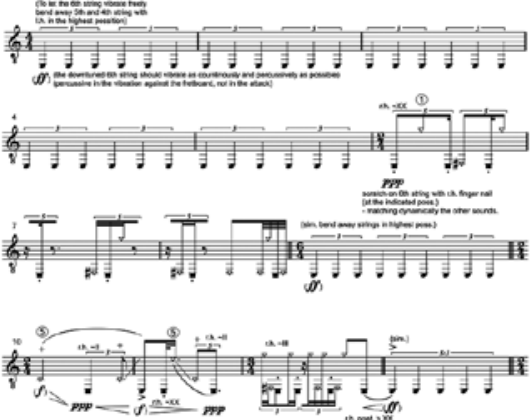

Next To Beside Besides \#10

for miniature camera solo

(or as movement or part in any combination of pieces from the NTBB series)
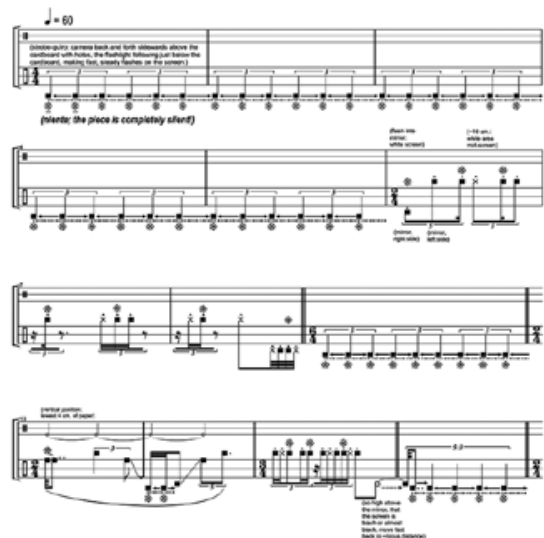

Abb. 24 Simon Steen-Andersen: Next to Beside Besides 2 für Saxophon, 2005, \# 5 für Piccoloflöte, 2006, \# 8 für Gitarre, 2006, \# 10 für Kamera, 2003/o7.

Gegenüberstellung der verschiedenen Anfänge. (C) Edition·S, Kopenhagen, Dänemark, www.edition-s.dk. Printed with permission. 
Dazu wird die kontinuierliche Kurve teilweise auch in diskrete Schritte aufgelöst. Der Grad der Auflösung richtet sich nach der Wahl des Parameters, der die Kurve in Form der musikalischen Notation interpretiert. ${ }^{51}$ Die Partitur ist

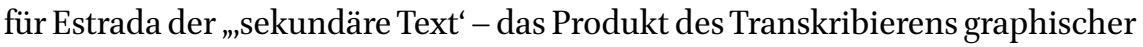
Daten in selbstgewählte Bezugsskalen“. ${ }^{52}$ Im dritten Schritt wird die chronografische Kurve für andere Versionen auf weitere Parameter übertragen. Für alle Versionen gilt, dass die ursprüngliche Information der Kurve zwar erhalten bleibt, jedoch für die einzelnen Parameter unterschiedlich interpretiert und daher auch unterschiedlich wahrgenommen wird. „Das Material ,arbeitet' in der gleichen Weise, ,wirkt' aber stets anders, die gleiche Information wird unter wechselnden Blickwinkeln betrachtet."53 Estrada bezeichnet diesen Vorgang als Permutationsvariation. Folglich ist jedes Yuunohui-Solo eine Permutationsvariation ${ }^{54}$ der zugrunde liegenden Wellenverläufe.

\begin{abstract}
„Die so entstandene Partitur - unser ,zweiter Text ${ }^{\star}$ - ist eine andere als die gewohnte Art schriftlicher musikalischer Aufzeichnung. Sie ist eine unter tausend möglichen Versionen. Auch wenn unsere Transkriptionsmethode einen hinreichenden Versuch darstellt, die gesamte Information jeder Dimension einer Kurve darzustellen, können wir nicht voraussetzen, daß irgendeine Reproduktion eines Modells als, definitiv' betrachtet werden kann. “55
\end{abstract}

Das Ziel dieses Vorgehens ist, die Imagination des Komponisten über den Weg der grafischen Aufzeichnung von seinem „präformierten musikalischen System zu befreien“. ${ }^{6}$ Zusätzlich soll eine hohe „objektive“ Variationsvielfalt generiert werden, die über die eigene subjektive musikalische Vorstellungskraft hinausgeht. Estrada charakterisiert diesen Prozess als Dichotomie zwischen „Determiniertheit und Relativität“.57 Auf diese Weise wird der

\footnotetext{
$51 \quad$ Vgl. ebd., S. 59 .

52 Vgl. ebd., S. 58.

53 Fürst-Heidtmann: „Auf der Suche nach der unverstellten Imagination“, S. 42.

54 Vgl. Estrada: „Freiheit und Bewegung“, S. 6o. Estrada definiert hier die Permutationsvariation folgendermaßen: „Dabei wird die Graphik einer oder mehrerer Parameter auf andere übertragen, was zu einer partiellen oder totalen Permutation der originalen Daten führt. Zum Beispiel kann die Frequenz zur Amplitude, die Amplitude zum harmonischen Gehalt und dieser wiederum zur Frequenz werden. Jede neue Zuweisung bewahrt eine dynamische Energie, die dem ursprünglichen musikalischen Objekt entspricht, auch wenn sie nun anders wahrgenommen wird. Wir entwickeln damit eine neue Art der Variation, in welcher die Makro-Klangfarbe modifiziert ist, ohne daß sich ihre innere Dynamik ändert."

55 Ebd., S. 59 .

56 Ebd., S. 62.

57 Ebd., S. 59 .
} 
Kompositionsprozess selbst zu einem interpretierenden Akt, über den versucht wird, sich der eigenen individuellen Imagination anzunähern. „Es ist durchaus möglich, daß wir unsere internen Vorstellungen gar nicht vollständig kennenlernen, sondern lediglich Versuche, sie zu interpretieren. ${ }^{458}$

Die Zusammenführung von Werken, die auf einem einzigen Ausgangsmaterial basieren, steht im Gegensatz zu einer Zusammenführung von Werken, die auf einem heterogenen Ausgangsmaterial basieren. Am Beginn des Prozesses der homogenen Werkkopplungen steht ein primärer Text, ein Nukleus. Dieser ist vergleichbar mit dem Thema in einem Variationszyklus und bildet den Ausgangspunkt für weitere Ableitungen. Aufgrund der monothematischen Ausgangssituation, die für die weiteren Stücke einen einheitlichen formalen Rahmen vorgibt, werden durch den Transkriptionsprozess spezifische Differenzen erzeugt, um die verschiedenen Versionen hinreichend voneinander abzusetzen. In den hier diskutierten Beispielen sind die Transkriptionsprozesse sehr unterschiedlich gestaltet. Während sich Juliane Klein in ihrer Variationsweise ein genuin musikalisches Komponieren bewahrt, das sich an traditionellen Techniken der Variation und der entwickelnden Variation orientiert und den Rahmen der traditionellen Parametersetzung nicht überschreitet, sind die Ansätze von Estrada und Steen-Andersen sehr systematisch und konzeptuell orientiert. Durch den theoretischen Überbau können sie das Spektrum parametrischer Setzungen und das Feld kontrapunktischer Möglichkeiten radikal erweitern. Bei SteenAndersen sind es visuelle und rhythmisch-zeitliche Parallelführungen, die in einen „Kontrapunkt der Klangfarben“ münden, durch den sich die Differenz der einzelnen Versionen manifestieren soll. Bei Estrada finden strukturelle Parallelbewegungen zwischen den einzelnen Stücken statt, die aber durch ihr unterschiedliches Parametermapping auf unterschiedlichen Instrumenten als solche nicht wahrnehmbar sind. Bei Steen-Andersen tritt die Parallelisierung für die Wahrnehmung sehr stark hervor, bei Estrada ist die Parallelisierung nicht wahrnehmbar. Trotz des entgegengesetzten Resultats für die Wahrnehmung ist die Parallelführung in beiden Zyklen das stärkte Bindeglied, quasi das Klebemittel zwischen den einzelnen Werkvariationen.

\subsubsection{Die verschiedenen Variations- und Transkriptionsprozesse im Vergleich}

Die Variation/variatio ist ein kompositorisches und gestalterisches Grundprinzip, das sich einerseits durch alle Stile und Epochen zieht und andererseits seit dem 16. Jahrhundert auch variationsartige Formtypen ausgebildet

$5^{8}$ Estrada: „Freiheit und Bewegung“, S. 6o. 
hat. ${ }^{59}$ Die Form des sich im 18./19. Jahrhundert ausbildenden klassischen Variationenzyklus ist eine vom Anfangsthema fortschreitende Wegentwicklung. Pro Variation werden einzelne Parameter wie Tempo, Dynamik, Artikulation, Tongeschlecht, Tonart, Melodik, Rhythmus, Metrum, Begleitung, Harmonik und Klangfarbe sukzessive verändert. Im Poly-Werk steht der Begriff der Variation in erster Linie für einen Wechsel der Perspektive. Prinzipiell gibt es zwei Möglichkeiten der Variation eines Themas. Zum einen durch Veränderung der Elemente, zum anderen durch Hinzufügung neuer Elemente. Übertragen auf die formale Metaebene, verfolgt die Weiterkomposition der Sequenzae in den Chemins von Luciano Berio das Prinzip der Erweiterung durch Hinzufügung neuer Werkelemente und Instrumentalschichten. Im Vergleich dazu basiert die Variantenbildung bei Estrada und Steen-Andersen auch auf parametrischen Veränderungen.

Statt sich wie im klassischen Variationenzyklus linear und sukzessive von einem Ausgangspunkt zu entfernen, befinden sich die einzelnen Versionen ungefähr gleich weit weg vom Ausgangspunkt. Sie sind lose um diesen gruppiert, bilden austauschbare und für sich stehende Varianten, Perspektiven und Interpretationen. Eine lineare Fortentwicklung gibt es nicht. Zudem können die einzelnen Varianten auch simultan aufgeführt werden und bilden dadurch neue Varianten. Konzeptuell handelt es sich weniger um eine lineare als um eine zirkuläre Vorstellung, bei der die einzelnen Variantenbildungen um den Ausgangspunkt herum platziert sind.

Es würde in die falsche Richtung führen, jeder Variante von vornherein eine unabhängige und eigenständige Identität zuzusprechen. Theoretisch sind zwar sämtliche Kombinationen selbstständig aufführbar, jedoch gibt es stärkere und schwächere Varianten, manifeste und latente, solche, die häufig aufgeführt werden, und andere, die nie gespielt werden. Während ein „Werk“ sich unter anderem dadurch auszeichnet, dass es postkompositorisch reproduzierbar ist und vervielfältigt werden kann, ist die extreme Vervielfältigung einer spezifischen Werkidee hier bereits in der Phase des kompositorischen Prozesses selbst angelegt. Indem die Möglichkeiten multipliziert und Vielfalt, Wandelbarkeit und Latenz über Eindeutigkeit und Klarheit gestellt werden, entsteht bereits während des Kompositionsprozesses die offene Frage: Was ist ein "Werk", und worin manifestiert es sich? Diese Frage ist weitreichend und setzt sich bis in den Publikationsprozess fort. Denn auch für Verlage und Verwertungsgesellschaften mit ihrem System der Werkanmeldungen und Abrechnungen stellen Poly-Werke, die serienhaft beliebig viele simultane Kombinationen ermöglichen, bereits eine Herausforderung dar. Beispielsweise 
umfasst das Stück Blumenwiese von Georg Friedrich Haas sieben Instrumente und 127 Kombinationsmöglichkeiten, die aus seiner Sicht allesamt als eigenständige Kompositionen gelten. Wird nur jede einzelne Stimme oder gar jede einzelne simultane Version als Werk angemeldet? Werden alle Kombinationen von einem Verlag herausgegeben oder auch wieder nur die Einzelstimmen? Damit gäbe es Fassungen, die in Form einer Partitur materialisiert sind. Es gäbe aber ebenso nichtmaterialisierte Fassungen, die möglicherweise viel häufiger aufgeführt würden. Durch ihre Nichtmaterialisierung würde ihr Werksein tatsächlich offen gelassen. Auf diese Weise würde aber auch eine Hierarchie zwischen den Werken als handelbare und nicht handelbare Werke geschaffen, wie es bei vielen Werken von John Cage bereits der Fall ist. Werke wie das Concert for Piano and Orchestra oder Atlas Eclipticalis werden vom Verlag Edition Peters nur als Einzelstimmen verlegt. Das treibt bei über achtzig Stimmen einerseits den Preis für das Ganze extrem in die Höhe. Andererseits sind die Einzelstimmen als Notenausgabe materialisiert und damit als „Werk“ anders positioniert als die vielen frei kombinierbaren Fassungen, die sicher auch durch ihre Nichtverlegung weniger ins Bewusstsein treten können. Vor allem die massenartige Vielförmigkeit im Poly-Werk bringt das System, das einzig auf das abgeschlossene Monowerk ausgerichtet ist, an seine Grenzen und wird in Zukunft neue Lösungen für erweiterte Werkformen erfordern, zum Beispiel in Form modulartiger digitaler Partituren, die jedweden Wechsel zwischen den verschiedenen Ansichten ermöglichen, oder in Form von differenzierten Anmeldeoptionen. Umgekehrt kann aber auch gerade die bewusste Nichtmaterialisierung einer Werkfassung, die dadurch einzig der ästhetischen Wahrnehmung zugänglich ist, die eigentliche Besonderheit des Werks mitkonstituieren. Die Entscheidung für Letzteres ist wiederum eine künstlerische Entscheidung.

\subsubsection{Werkpaare - Simultaneisierung als Intensivierung in den Hängebrücken von Adriana Hölszky (zwei Streichquartette I)}

„Man könnte so weit gehen, statt zwei Quartette hundert Quartette gleichzeitig spielen zu lassen."60

(Adriana Hölszky)

Adriana Hölszky (geboren 1953 in Bukarest, Rumänien) hat das Zitat im persönlichen Gespräch zwar etwas zurückgenommen, und die Zahl hundert

6o Adriana Hölszky, zitiert nach Christian Scheib: „Musikgeschichten“, in: Programmbuch der Wittener Tage für Neue Musik 1991, hg. von F. Hilberg und Harry Vogt, Saarbrücken: Pfau 1991, S. 66. 
durch vier ersetzt (was ein Streichorchester ergeben würde), ${ }^{61}$ aber es zeigt: Auch dreißig Jahre nach der Komposition der Hängebrücken ist das Interesse an der Frage, „wie weit man gehen kann“, für Adriana Hölszky noch aktuell. Im Folgenden soll es um das Doppelquartett Hängebrücken gehen. Es lässt sich eindeutig den homogenen Werkkopplungen zuordnen, wenngleich es nicht auf Transkriptionsprozesse im Sinne der vorigen Werkzyklen zurückführen ist und damit wieder ein anderes Modell der Überlagerung entwirft.

Das zweisätzige Doppelquartett Hängebrücken mit dem Untertitel „Streichquartette an Schubert", stammt aus den Jahren 1989/9o und ist für zwei Streichquartette komponiert, die einzeln und simultan aufgeführt werden können. Im Partiturbild sind die Quartette als Hängebrücken I und Hängebrücken II jeweils auf das obere und untere System verteilt. Die simultane Fassung ergibt sich aus der Überlagerung beider Quartette und trägt den Titel Hängebrücken III. Die simultane Doppelversion wurde vom Nomos- und vom Pellegrini-Quartett am 27. April 1991 in Witten uraufgeführt.

In den Einzelversionen beginnt das erste Quartett erst mit dem Auftakt zu Takt 9 und endet mit dem dritten Schlag des Taktes 97 im zweiten Satz. Das zweite Quartett beginnt seine Einzelversion in Takt 10 und spielt bis Takt 92 des zweiten Satzes. Nur in der Gesamtfassung wird das Werk von Takt 1 bis zum Schluss gespielt.

Das Werk gewinnt seinen zerspaltenen Charakter aus einer dichten Aneinanderreihung vieler kurzer Abschnitte. Darin eingelassen sind kurze Schubert-Felder, auf die sich der Titel Hängebrücken bezieht. Dabei handelt es sich im ersten Satz nicht um originale, sondern um angelehnte Zitatfelder aus dem Andante con moto des d-Moll-Quartetts D 810 von Franz Schubert. Im zweiten Satz erstreckt sich das Ursprungsmaterial der Zitate auch auf andere Quartette von Schubert. Die Schubert-Felder sind in erster Linie imaginäre Spuren, die einen bestimmten rhythmischen Gestus der Schubert'schen Klangsprache aufgreifen und auf diese Weise als eine Form der Erinnerung aus der in sich zerklüfteten Klanglandschaft herausragen, gleichsam wie Hängebrücken über ihr hängen und schweben. Ihnen werden im Quartett sogenannte Paganini-Gesten gegenübergestellt. Auch bei ihnen handelt es sich nicht um originale Zitate, sondern um sich annähernde Konturbildungen, die aus ihrem originalen Zusammenhang gelöst und neu kontextualisiert wurden.

Hölszky komponierte zuerst den zweiten und danach den ersten Satz. Beide Quartette sind in ihrer Besetzung, in Form, Metrum und Tempo synchronisiert, entstammen demselben Klangmaterial und wurden parallel komponiert. Hölszky legte in der Kompositionsphase einen großen Fundus an

61 Im Interview mit der Verfasserin am 30.9.2019 in Stuttgart. 


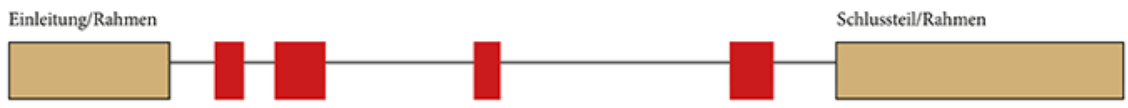

Schubert-Felder

Abb. 25 Formplan der Hängebrücken, 1. Satz von Adriana Hölszky. Die Abbildung zeigt die Verteilung der Schubert-Felder im ersten Satz.

Materialabschnitten an, aus dem sie dann im Hinblick auf Symmetrien und Entsprechungen eine Auswahl für die endgültige Fassung traf. Ungefähr die Hälfte der Skizzenmaterialien wurde wieder verworfen. ${ }^{62}$ Die vierstimmigen und linear gedachten Abschnitte wurden im Entwicklungsprozess der simultanen Dopplung des Quartetts zerschnitten, zerstückelt, neu kombiniert und flickenartig auf die Quartette verteilt. Durch dieses Vorgehen wurde die ursprüngliche Einheitlichkeit der einzelnen Abschnitte und Felder gebrochen. Die metrische Gliederung, die für beide Quartette einheitlich ist, folgte in einem späteren Schritt. Die zeitliche und räumliche Umordnung und Verteilung ursprünglich gedachter Einheiten kann als eine kompositorisch zugrunde liegende Vorgehensweise beschrieben werden. Einige Beispiele, an denen die „Nahtstellen“ noch sichtbar sind, sollen das verdeutlichen.

Das erste Beispiel (Abb. 26) zeigt eine typische Form der „Klangmigration“ zwischen beiden Quartetten. Hier wandert die Klangbewegung der Quartflageolettklänge von den beiden Violinen des zweiten Quartetts zu den beiden Violinen des ersten Quartetts.

Im zweiten Beispiel (Abb. 27) findet sich eine Nahtstelle zwischen Takt 35 des ersten und Takt 32 des zweiten Quartetts. Die crescendierende Triller- und Vibratobewegung der vier Streicher des ersten Quartetts wird jäh abgeschnitten und gefolgt von einem Schubert-Feld, obwohl sie in der ursprünglichen Skizzenform um einen weiteren Takt fortgeführt wurde. Diese abgetrennte zweite Hälfte wurde auf das zweite Quartett gelegt. Damit werden die Hälften nicht nur räumlich voneinander getrennt, sondern auch zeitlich umgekehrt.

Im dritten Beispiel (Abb. 28) ist ein zweitaktiges Schubert-Feld auseinandergeschnitten worden. Indem die erste Hälfte des Feldes dem Takt 15 des ersten Quartetts und die zweite Hälfte Takt 14 des zweiten Quartetts zugeordnet wird, entsteht auch hier wieder eine Umkehrung der ursprünglichen zeitlichen Ordnung, denn die ursprüngliche zweite Hälfte ist der ersten in der Simultanfassung zeitlich vorangestellt. Lediglich die Feldklammern oberhalb der Systeme weisen noch auf die ursprüngliche Form hin.

62 Adriana Hölszky im Interview mit der Verfasserin am 30.9.2019 in Stuttgart. 


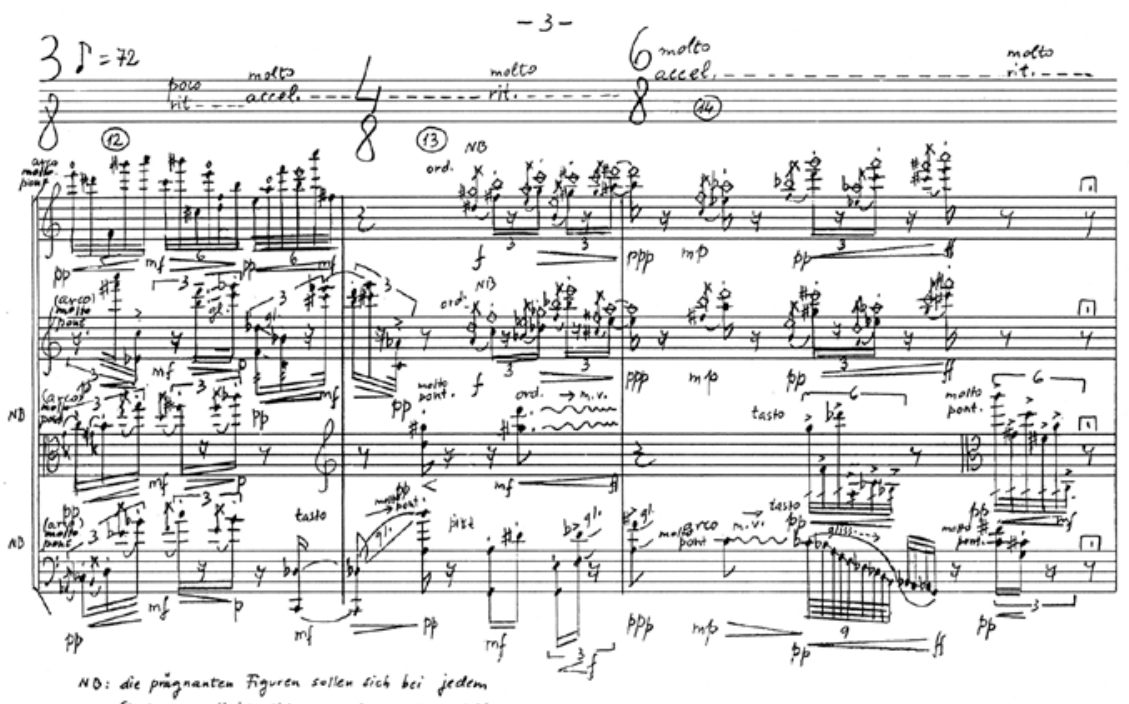

Streicher individualisieren und rom kiangfeld abheben.

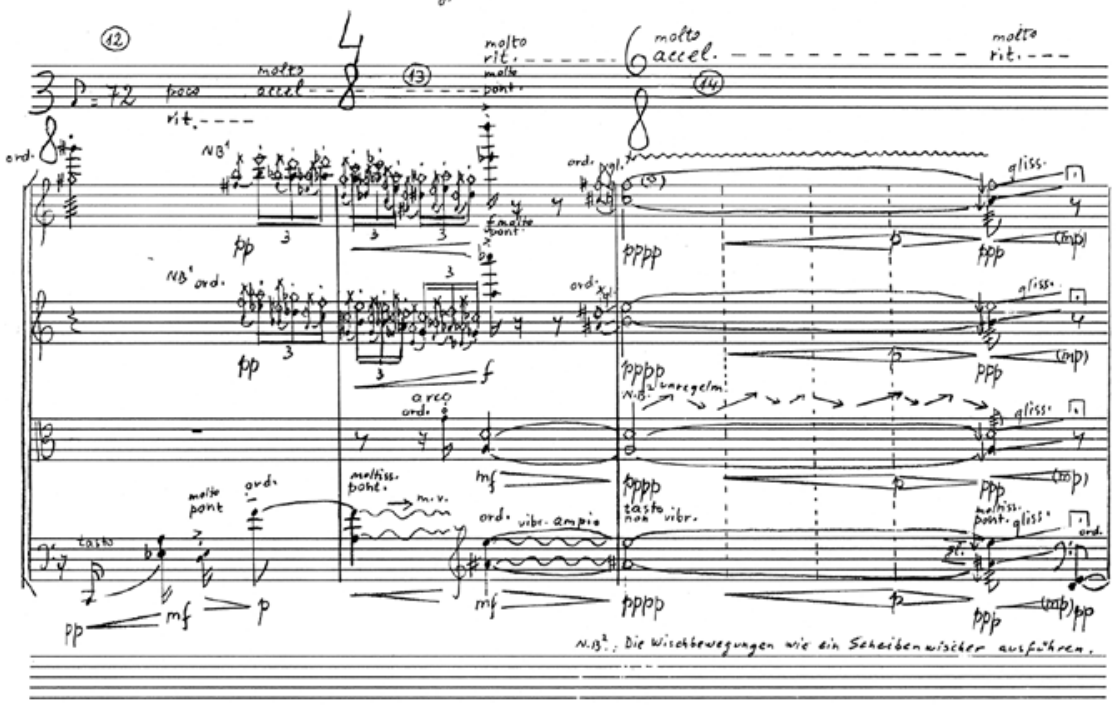

NO': die prëgnanten Figuren sollen sich bei jedem

Streicher individualisieren and vom Klangfeld abheben.

Abb. 26 Adriana Hölszky: Hängebrücken für zwei Streichquartette, 1989, S. 3. 1991 by Breitkopf \& Härtel, Wiesbaden. 

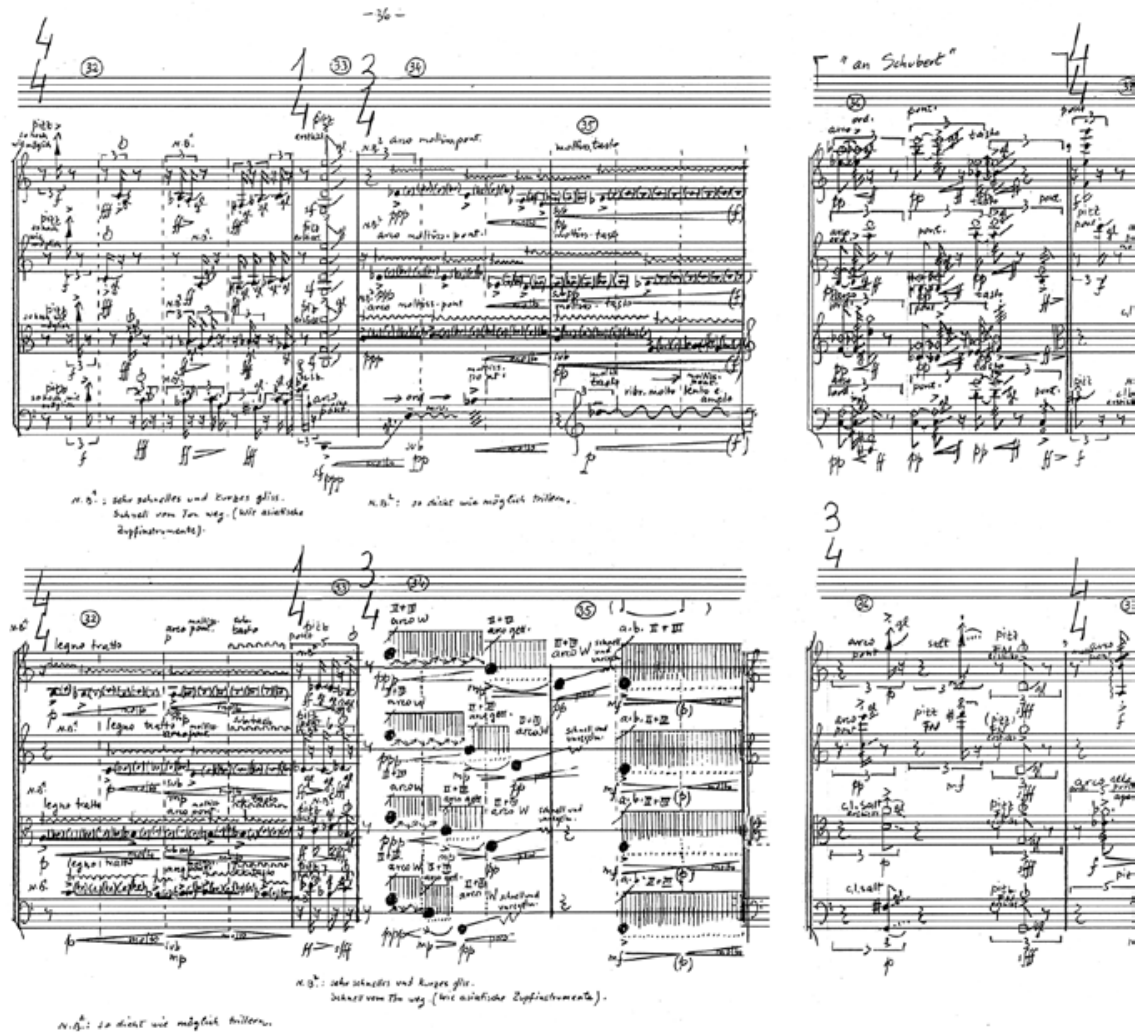

Abb. 27

Adriana Hölszky: Hängebrücken, S. 36 f. (Anschlusstakt). ㄷ 1991 by Breitkopf \& Härtel, Wiesbaden.

Im zweiten und dritten Beispiel verweist die lineare Lesart vom oberen zum unteren System auf die ursprüngliche Gestalt der Felder während des Skizzenstadiums. Hans-Ulrich Schäfer-Lembeck zieht in seinem spekulativen und stark hypothetischen Aufsatz „Du baust Dir eine Stadt ..." die sukzessive Lesart sogar als Aufführungsoption in Betracht, die vom Nomos-Quartett vor der eigentlichen Uraufführung mit dem zweiten Satz am 4. Juni 1989 realisiert worden wäre. ${ }^{63}$

63 Schäfer-Lembeck schlägt den Titel Hängebrücken o für diese Version vor und formuliert die These, die primäre kompositorische Intention des zweiten Satzes, der ja von Hölszky zuerst komponiert wurde, sei eine Langfassung gewesen, in der oberes und unteres System sukzessive gespielt worden seien. Vgl. Hans-Ulrich Schäfer-Lembeck: „Du baust dir eine Stadt ... Überlegungen zu Ästhetik und Didaktik von Adriana Hölszkys Hängebrücken“, in: Hans Bäßler (Hg.), Neue Musik vermitteln. Analysen, Interpretationen, Unterricht, Mainz: Schott, 2004, S. 265-285. Auch wenn diese Interpretation auf den allerersten 

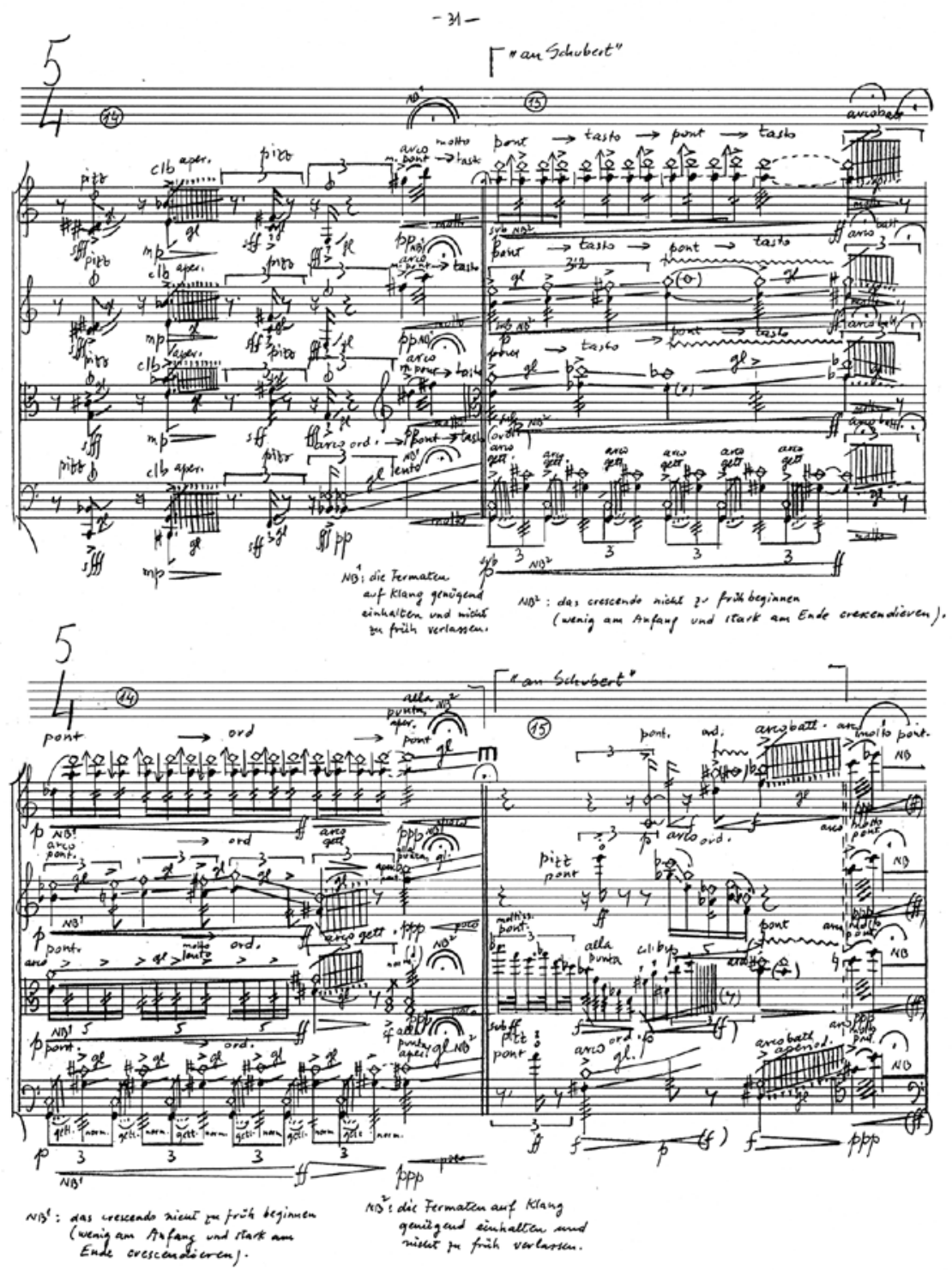

Abb. 28 Adriana Hölszky: Hängebrücken, S. 31. (c) 1991 by Breitkopf \& Härtel, Wiesbaden. 
Das Werk verfolgt verschiedene Ansätze, um Linearität zu brechen: Die Dopplung der Form und der Besetzung, die Verdichtung und die simultane Aufführbarkeit, die Umkehrung linear-kausaler Ketten mit abrupten Abbrüchen prozessualer Entwicklungen und Anschlusspunkten, die Disparatheit des Materials, die Spiegelungen, die Feldhaftigkeit der Abschnitte, aber auch die konsequent diskontinuierliche und unvermittelte abschnittsartige Reihung der einzelnen kurzen Felder, die durch Pausen und Fermaten voneinander separiert sind, wirken einem auf Linearität und Kontinuität ausgerichteten Zeitgefühl entgegen. Zu diesem steht das Werk beim Hören in einem ständigen Spannungsverhältnis. Jeder auch noch kurze Abschnitt ist ein einzelner Raum für sich. Man kann die Hängebrücken als ein Haus oder eine Stadt mit vielen ineinander verschachtelten Räumen interpretieren, durch die man sich auf unterschiedlichen Wegen bewegen kann und die die Mehransichtigkeit und die Koexistenz von verschiedenen Erlebnissen, Strukturen und Empfindungen zulassen. ${ }^{64}$ Mit dieser Projektion eines räumlichen Denkens auf die lineare Zeitvorstellung gewinnt auch das Verständnis einer unendlichen Zeit bei Schubert, ${ }^{65}$ die kein Vorher und Nachher kennt, die eher „einem zeitlichen Ozean ähnelt, in dem man ,mittendrin “"66 ist, an Fasslichkeit. Die Verräumlichung der linearen Zeitvorstellung ist in den Hängebrücken das leitende Schlüsselmoment, das den kompositorischen Prozess entscheidend geprägt hat. Die Werke erweitern sich gegenseitig den Raum, den sie zerklüften. Die Frage der räumlichen Zusammensetzung ist auch hier durch die Komposition nicht vollständig abgeschlossen, sondern setzt sich bis in die Aufführungsform fort. Die Aufstellung der Quartette, ob einander gegenüber als Spiegelung oder etwas weiter voneinander entfernt, prägt die Hörbarmachung der Strukturen und ihr wechselseitiges Verhältnis.

Ähnlich wie im Kubismus werden in den Hängebrücken die ursprünglichen Einheiten zergliedert und gefaltet, um die entstehenden Teilstücke und Teilansichten zu einer neuen geschlossenen Einheit zusammenzusetzen. So verlaufen die „Bruchlinien“ in Hängebrücken auch nicht horizontal zwischen den beiden Quartettschichten, sondern als quartettübergreifende vertikale

Blick verlockend erscheint, ist sie laut Adriana Hölszky zu keinem Zeitpunkt vorgesehen gewesen und widerspräche der Werkintention. Auch eine Aufführung dieser Version durch das Nomos-Quartett hat es nicht gegeben (Adriana Hölszky im Interview mit der Verfasserin am 30.9.2019 in Stuttgart).

64 Eine wichtige Inspirationsquelle war für Hölszky der Roman Le città invisibili von Italo Calvino aus dem Jahre 1972.

65 Siehe Vorwort zur Partitur in: Adriana Hölszky, Hängebrücken. Streichquartette/Doppelquartett an Schubert, 1989/9o, Wiesbaden: Breitkopf \& Härtel.

66 Adriana Hölszky im Interview mit der Verfasserin am 30.9.2019 in Stuttgart. 
Schnitte. Durch Teilung und Dopplung wird der horizontale Verlauf in die Vertikale gefaltet. Aus diesem Grund ist das Werk weder ein Poly-Werk im Sinne einer Polyphonisierung oder Vermehrfachung noch im Sinne einer Gegenüberstellung von unterschiedlichen Werken. Beide Werke stammen aus demselben Material, demselben Ausgangsgedanken, sind aus demselben Holz geschnitzt. Im Kern geht es Hölszky um die Intensivierung des Gleichen, indem gleichwertige Möglichkeiten der äußeren Betrachtung desselben Gegenstands geschaffen werden.

\subsection{Addition heterogener Werke}

Die bisher untersuchten Beispiele homogener Werkkopplungen, einschließlich der Hängebrücken von Adriana Hölszky, basieren eindeutig auf einem gemeinsamen Ursprung im kompositorischen Material. Von innen heraus wird das zugrunde liegende einheitliche Material durch Ableitungs-, Variationsund Transformationsprozesse ins Differierende entwickelt. Umgekehrt simultanisieren heterogene Werkkopplungen mindestens zwei Werkidentitäten, die nicht auf einer gemeinsamen "Ausgangsidee“ basieren, sondern unterschiedlichen Ideen entstammen. ${ }^{67}$ Während die homogenen Werkkopplungen im Prozess der Werkgenese spezifische Differenzen ausbilden, werden bei den heterogenen Werkkopplungen im Prozess der Zusammenführung genau umgekehrt spezifische Möglichkeiten der Verknüpfung erzeugt. Darüber hinaus wird auch bei den heterogenen Werkkopplungen ein gemeinsamer "äußerer" Rahmen geschaffen, der sowohl die Verschiedenheit bewahrt als auch das Potenzial der Verknüpfungsmöglichkeiten ausschöpft und beides in eine Balance bringt. Dieser äußere Rahmen umfasst in erster

67 Bereits das Westberliner Künstlerkollektiv Die tödliche Doris brachte 1984 und 1986 die zwei Alben Unser Debut (Projekt Nr. 4) und Sechs (Projekt Nr. 6) heraus, die gleichzeitig zweikanalig abgespielt eine dritte Version, die sogenannte Unsichtbare LP (Projekt Nr. 5) ergeben. Beide Alben sind einander künstlerisch entgegengesetzt: Unser Debut verkörpert die Annäherung an das Kommerzielle, Sechs dagegen die künstlerische Unabhängigkeit. Nichtsdestotrotz sind beide Alben so konzipiert, dass sie einander auch als Zusammengesetztes ergänzen und miteinander korrespondieren. Die zeitlich getrennte Veröffentlichung sollte ursprünglich an eine räumlich und politisch getrennte Veröffentlichung gekoppelt sein. Sechs sollte in Westdeutschland, Unser Debut in der DDR vom Amiga Label veröffentlicht werden, das allerdings ablehnte. Die resultierende Simultanfassung existiert nicht als materielle LP, sondern nur als „immaterielles“ Resultat, das als Einzelnes nicht käuflich erwerbbar ist. Siehe auch http://www.wolfgangmuellerrr.de/Musik (letzter Aufruf am 4.5.2020). 
Linie die zeitliche Organisation und die Besetzung. Die Besetzung ist entweder einheitlich oder in ihrer Unterschiedlichkeit aufeinander abgestimmt.

Die folgenden beiden Werke liegen in ihrer Klang- und Materialsprache und auch dem Zeitpunkt ihrer Entstehung sehr weit auseinander. Auf der einen Seite handelt es sich bei dem Doppelquartett op. 291 von Darius Milhaud um ein in den Jahren 1948/49 komponiertes Werk, das wohl als das erste Poly-Werk im 2o. Jahrhundert gelten kann. Zwei Streichquartette, die beide auch einzeln aufgeführt werden können, werden simultan miteinander verknüpft. Zum Vergleich wird der Anea Crystal Cycle von Chaya Czernowin aus dem Jahre 2008 vorgestellt, der ebenso zwei Streichquartette aneinanderkoppelt.

\subsubsection{Darius Milhaud-Von der melodisch-harmonischen zur formalen Superposition (zwei Streichquartette II)}

„Bei der Premiere meiner Vierten Symphonie in Paris hatte mir einer meiner Freunde ein kostbar gebundenes grünes Lederbüchlein aus dem Jahre 1848 geschenkt. Seine Seiten waren leer, eine jede enthielt acht Notenzeilen. Ich hatte die Idee, das Büchlein zum Schreiben von zwei Quartetten zu benutzen, die einzeln gespielt werden konnten, die aber, zusammen gespielt, gleichzeitig ein drittes Werk bildeten: ein Oktett, das sich von den beiden Quartetten unterschied. ${ }^{\text {66 }}$

(Darius Milhaud)

Darius Milhaud (1892-1974) füllte das 84-seitige Notenheft bis zur letzten Seite mit den beiden Streichquartetten Nr. 14 \& 15, die zusammen ein Oktett bilden. Seine Vision einer Musik, die sich in einem tonal ungebundenen Kontext aus unterschiedlichen simultanen Elementen zusammensetzt, fand ihren ursprünglichen Auslöser in der Gleichzeitigkeit verschiedener Klänge und Geräusche der Straße, die in seiner Kindheit Abend für Abend auf ihn einströmten.

„De la ,Chambre du Midi', les sons qui me parvenaient avaient un caractère tout différent: le ronron des conversations, les chansons se confondaient avec le bruit léger des fruits tombant dans les corbeilles et le son monotone et berceur des machines qui triaient [...]. Parfois, des veillées ranimaient les mêmes murmures:

68 Darius Milhaud: Noten ohne Musik. Eine Autobiographie, München: Prestel, 1962 (Notes sans musique, Paris: Juillard, 1949), S. 231. 
les résonances des voix, des chants, des camions, jusqu'au moment où je m'endormais ..."69

Diese Eindrücke aus seiner Kindheit schildert Darius Milhaud in seiner Autobiografie Notes sans musique von 1949. Rostand greift in den später mit Milhaud geführten Gesprächen diese Erinnerung noch einmal auf. Direkt dazu befragt, stellt Milhaud einen unmittelbaren Bezug zwischen dieser allabendlich wiederkehrenden Straßenszene, deren quirlige und lebendige Geräuschkulisse zu ihm in sein Zimmer drang, und seiner sich entwickelnden musikalischen Vorstellungskraft her.

\begin{abstract}
„Toujours est-il que ce n'est que bien plus tard, lorsque j'eus fini mes études, en entendant ce que j'avais écrit après avoir poussé mes recherches polytonales dans lesquelles la liberté tonale des lignes mélodiques se déroule sans un contrepoint d'accords, c'est à ce moment-là que j'ait tout à coup réalisé: alors je me suis apercu que c'était là la musique à laquelle je rêvais à quatorze ans, et que j'entendais la nuit résonner au fond de moi-même.. ${ }^{70}$
\end{abstract}

Polytonale Voraussetzungen

Für viele Zeitgenossen Milhauds bestand „Polytonalität“ vor allem in der gelegentlichen Hinzufügung akkord- und tonalitätsfremder Töne, die über einen tonalitätsverfremdenden Klangeffekt kaum hinausführte. Milhaud war einer der wenigen Komponisten, der mit ihren Möglichkeiten systematisch experimentierte und auf dieser Basis eine spezifische harmonische Klangsprache entwickelte, in der die Simultaneität verschiedener Tonarten allgegenwärtig ist. Als harmonisch neues Phänomen wurde „Polytonalität“ in den 2oer Jahren in verschiedenen Beiträgen der Zeitschrift La Revue Musicale als eine der „Atonalität“ ebenbürtige Strömung diskutiert. ${ }^{71}$ Das spätere musiktheoretische und wissenschaftliche Desinteresse lag nach Jens Rosteck darin begründet, dass sie über ihren allgemeinen Status als polytonalité passagère kaum hinauskam. ${ }^{72}$ Gerade auch vor diesem Hintergrund lohnt sich eine Beschäftigung mit diesem kaum bekannten Werkpaar von Milhaud. Als seinerzeit singuläres Experiment vollzog Milhaud den konsequenten Schritt, den

69 Milhaud: Notes sans Musique, S. $16 \mathrm{f}$.

70 Darius Milhaud: Entretiens avec Claude Rostand, Paris: Julliard, 1952, S. 26.

71 Vgl. hierzu Darius Milhaud: „Polytonalité et Atonalité“, in: La Revue Musicale, 1923, S. 29-44; Jean Deroux: „La Musique Polytonale“, in: La Revue Musicale, 1921, S. 251-257; Armand Machabey: „Dissonance, Atonalité, Polytonalité“, in: La Revue Musicale, 1931, S. $35^{-45}$.

72 Jens Rosteck: „Umrisse einer Theorie der Polytonalität bei Darius Milhaud“, in: International Journal of Musicology 3, 1994, S. 235-290, hier: S. $239 \mathrm{f}$. 
zum Beispiel von Ives praktizierten Materialkontrapunkt in einen „Werkkontrapunkt" zu überführen. Die dreisätzigen Streichquartette Nr. 14 \& 15 sind sowohl als Einzelwerke wie auch als gleichzeitiges Doppelquartett komponiert. Die Konsequenz, mit der Milhaud das Potenzial einer bi- und polytonalen Melodik und Harmonik zu erweitern suchte, lässt die 1948/49 geschriebenen Quartette als logische Konsequenz eines kompositorischen Denkens erscheinen, das vielfältig, unkonventionell und bisweilen primitiv Tonarten und melodische Linien in ihrer heterogenen Gleichzeitigkeit übereinanderschichtete. Rosteck konstatiert in diesem Zusammenhang zwei wesentliche Charakteristika der Polytonalität bei Milhaud:

1. „Polytonalität beruht vorrangig auf linearen Vorgängen. Die Schichtung von Einzelstimmen und -linien zu einem polymelodischen Tonsatz wird zur entscheidenden Voraussetzung einer ,polytonalité contrapuntique ${ }^{\text {‘u. }}$.

2. „Für Milhaud ist alles superposable, d. h. schichtbar: Intervalle, unbestimmbare Zusammenklänge, Akkorde. Melodien, sogar verschiedene Werke $[\ldots] . .73$

Beide Prämissen dienen der folgenden Auseinandersetzung mit dem Doppelquartett als Ausgangspunkt. Im Hinblick auf mögliche Deutungen des simultanen Verhältnisses beider Quartette zueinander könnte sich gerade das Verhältnis zwischen linearer Melodik und vertikaler Harmonik als aufschlussreich erweisen. Der Tonsatz beider Quartette ist vorrangig durch linear-dynamische Verläufe statt akkordisch-statische Fortschreitungen geprägt und findet im Ausdruck der polytonalité contrapuntique eine weitere Spezifizierung. Polytonale Harmonik erscheint in diesem Zusammenhang eher als sekundäres Resultat eines primären melodischen Denkens, das auf diese Weise zur unmittelbaren Voraussetzung der Zusammenführung in sich geschlossener linearer Werkverläufe wird.

\section{Analyse des Tonsatzes}

Eine ausführliche Analyse des Werkpaars, die alle drei Sätze berücksichtigte, würde den Rahmen dieser Arbeit sprengen. Sie kann nur einen Einblick in das kompositorische Denken Milhauds geben, soweit es für die übergeordnete Thematik relevant ist. Aus diesem Grund beschränke ich mich in einer satztechnischen Analyse auf den Beginn des ersten Satzes und stelle anschließend noch die Formverläufe der ersten beiden Sätze vor. Aus der Anlage des dritten Satzes konnten keine darüber hinausgehenden Erkenntnisse für das Verständnis des Poly-Werks gezogen werden. Aus diesem Grund bleibt er hier unberücksichtigt.

73 Ebd., S. 26o. 

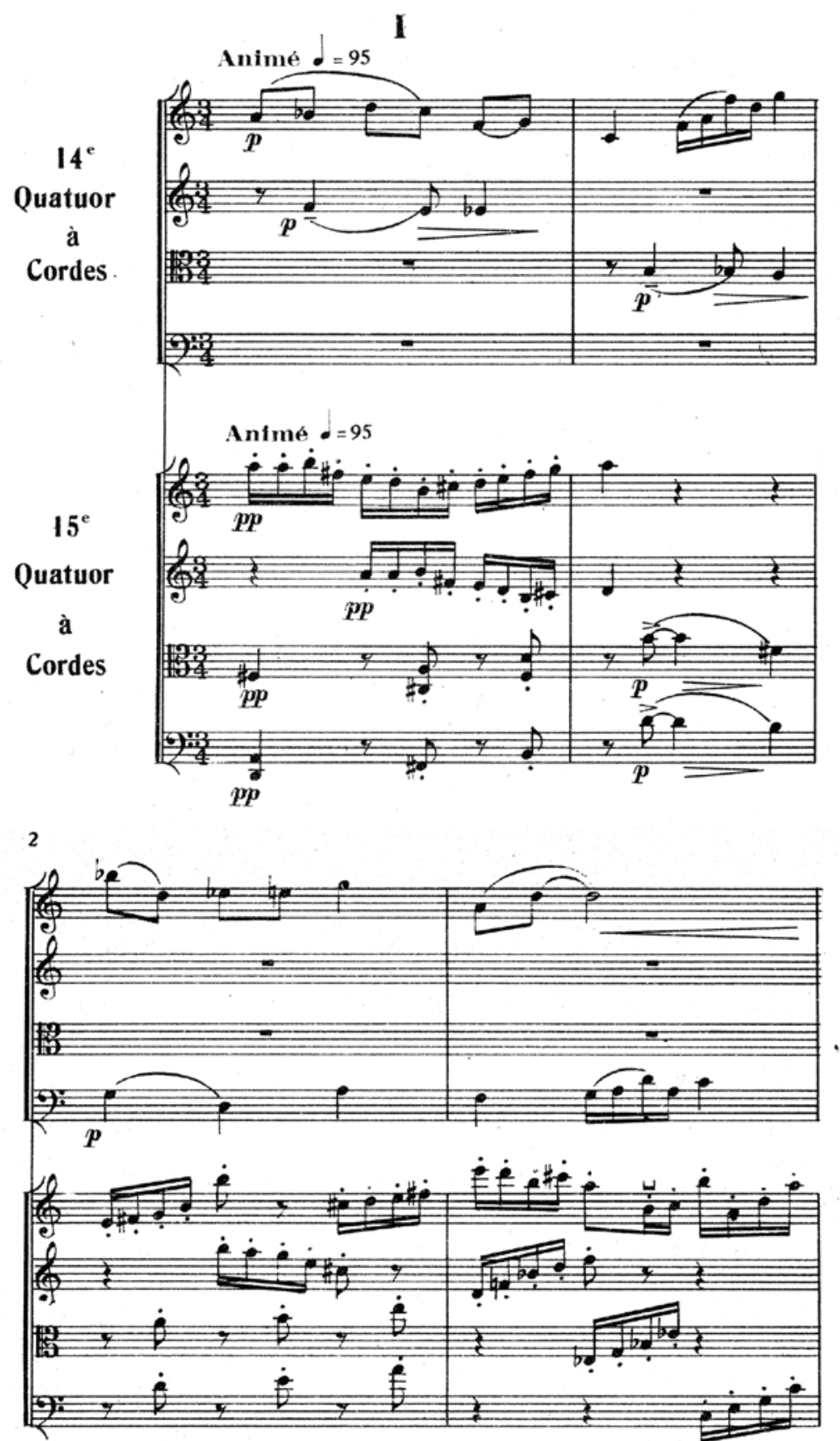

Abb. 29 Darius Milhaud: Quatuor a cordes No. 14 \& 15 op. 291, 1/2, 1949, 1. Satz, Takte 1-4. (C) Editions Heugel. Reprinted by permission of Hal Leonard Europe Limited. 
Das Notenbeispiel in Abb. 29 umfasst die ersten vier Takte beider Quartette in einer simultanen Darstellung. Das Beispiel zeigt zwei in ihrem Charakter unterschiedliche Werke, die jedoch in ihrem Metrum, ihrer Dauer und im Tempo synchronisiert sind. In beiden Quartetten stehen sich zwei kontrastierende thematische Einheiten gegenüber, die jeweils durch die ersten Violinen eingeführt werden. Der Charakter des thematischen Hauptgedankens des ersten Quartetts ist im Legatostil melodisch-bewegt gehalten und durch das Fließen einer vorwärtsdrängenden raumgreifenden Achtelbewegung geprägt. Lediglich eine zweimalige viernotige Sechzehntelkette schlägt unauffällig eine rhythmische Brücke zum zweiten Quartett. Die Tonhöhen der Violine in Takt 2 des ersten Quartetts werden in der Cellostimme in Takt 4 permutativ aufgegriffen und tragen so zu einer auf Schließung angelegten Wirkung dieser kurzen Phrase bei. Im zweiten Quartett durchlaufen staccatohafte Sechzehntelläufe die D-Dur-Skala und lösen sich im 3. und 4. Takt in eine Klangfläche auf, die einen öffnenden Charakter besitzt. Im Gegensatz zum ersten Quartett ist der Tonsatz hier akkordhaft und weniger melodisch.

Das Thema des ersten Quartetts steht in F-Dur und das des zweiten Quartetts in D-Dur. Das Verhältnis dieser beiden tonalen Durzentren ist durch ein Kleinterzverhältnis gekennzeichnet, das sich durch die harte Wirkung beider Harmonien über einen hohen Dissonanzgrad charakterisiert. Trotzdem gibt es auch harmonisch punktuelle Verknüpfungen: Der Ton a als gemeinsamer Anfangston der Themen ist als dritter Dreiklangston in F-Dur und als fünfter Dreiklangston in D-Dur ein punktueller Verbindungston beider Tonarten. Die harmonische Fortschreitung des zweiten Quartetts verläuft von D-Dur in Takt 1 eindeutig zu einem kleinen $\mathrm{h}-\mathrm{d}$-fis-a-Septakkord in Takt 2 und wird so unterterzt. Auch im ersten Quartett bildet der kleine Mollseptakkord $\mathrm{d}-\mathrm{f}-\mathrm{a}-\mathrm{c}$ das harmonische Gerüst der Violinstimme in Takt 2 und stellt damit von F-Dur kommend und parallel zur Entwicklung des zweiten Quartetts eine Unterterzung der Ausgangstonart dar. Die chromatische Linie in Takt 2 in der Bratsche gehört bis auf den Durchgangston b von ihren Tonhöhen her harmonisch zum zweiten Quartett, mit dem sie auch als rhythmischsynkopische Figur quartettübergreifend zu einem Rhythmus verschmilzt. Der zweite Takt ist ein Beispiel für die Vieldeutigkeit der Harmonik, die durch die verschiedenen Kontexte entsteht und die Ambiguität der polytonalen Klangsprache weiter verschärft. In der einzelnen Quartettsituation handelt es sich bei der kurzen chromatischen Linie der Bratsche des ersten Quartetts um eine reine chromatische Durchgangsbewegung gegenläufig zur Violinenstimme. In der Simultanversion verschmilzt diese mit dem zweiten Quartett zu einem harmonischen Block und wird so neu funktionalisiert. Für den weiteren 
harmonischen Verlauf kann gesagt werden, dass beim ersten Quartett der Gebrauch der b-Tonarten und beim zweiten Quartett der Gebrauch der Kreuztonarten klar überwiegt. Tendenziell werden die beiden Akzidentienregionen in den Quartetten einander gegenübergestellt.

Beide Themen bilden für sich einen thematischen Kern. Man könnte von Soggetti sprechen, die sich über den weiteren Satz ausbreiten und in diesen hineinfließen. In einem mehrstimmigen Geflecht wird abgeleitetes oder neues thematisches Material netzartig immer weiter variiert, transponiert oder untereinander ausgetauscht und durch melodische Versatzstücke miteinander verbunden. Während das erste Quartett in seinem thematischen Verlauf sehr homogen und in sich schlüssig ist, ist das zweite Quartett sehr viel heterogener, versatzstückartiger und offener. Durch die Vielfalt an aufeinanderfolgenden melodischen Linien und Segmenten ähnelt der Satz einem musikalischen Flickenteppich mit unzähligen kleingliedrigen Elementen und Wendungen. Zusammenfassend kann im Hinblick auf die Themengestaltung und den weiteren Verlauf der Quartette festgehalten werden, dass Milhaud heterogene Materialien, die in bewusster Abgrenzung zueinander konzipiert sind, konstruktiv gegeneinandersetzt, aber im Detail ebenso Brücken und Übergänge schafft.

Interformale Gestaltung

Auch der Blick auf die formale Entwicklung sagt etwas über das Verhältnis beider Quartette zueinander aus. Neben der instrumentalen Besetzung, der Dauer, der Metrik und dem Tempo haben beide Quartette auch den formalen Rahmen gemeinsam.

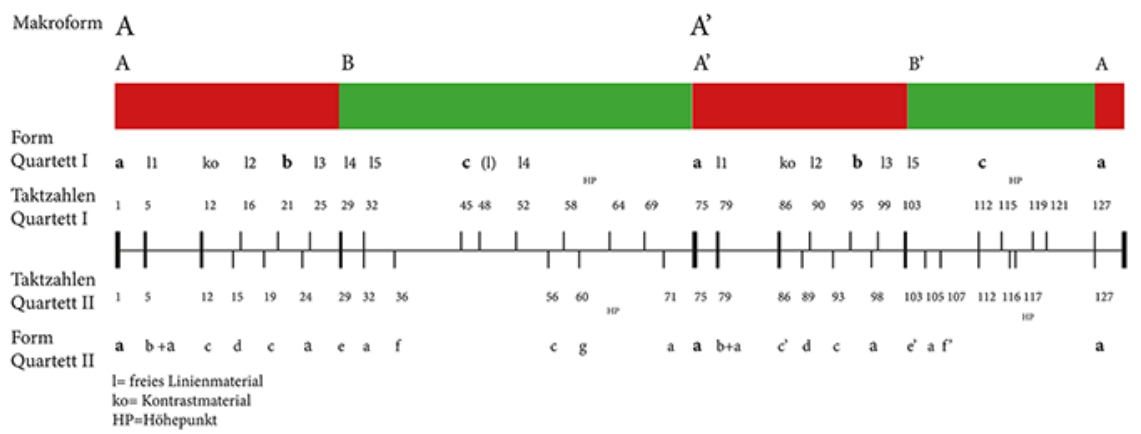

Abb. 30 Darius Milhaud: Formübersicht über den ersten Satz der Streichquartette Nr. 14 $\& 15$. 
Abbildung 30 zeigt eine grafische Formübersicht über den ersten Satz. Beide Quartette sind in zwei große Teile A und A' geteilt. Der zweite Teil stellt eine leicht verkürzte und variierte Wiederholung des ersten Teils dar. Beide Hälften sind wiederum in die beiden Abschnitte A und B beziehungsweise $A^{\prime}$ und B' unterteilt. Die Großform ist mit A-B-A'-B'-A also für beide Quartette gleich. Die Abbildung zeigt, wie die formale Gliederung in beiden Quartetten auf einer großformalen Ebene zusammenfällt und an ihren Binnenzäsuren synchronisiert ist. Innerhalb der Binnenabschnitte weichen die thematischen und formalen Zäsuren allerdings immer wieder voneinander $a b$ und sind in den meisten Fällen um ein bis zwei Takte gegeneinander verschoben. Auf einer kleingliedrigen Ebene divergiert der formale Verlauf also immer wieder. Die großformale, für beide Quartette einheitliche Proportionierung ist keine Aufteilung nach Themen oder einander kontrastierendem Formteilen. Thematische Kontraste entstehen weniger in der horizontalen Richtung als vielmehr in der vertikalen Simultaneität.

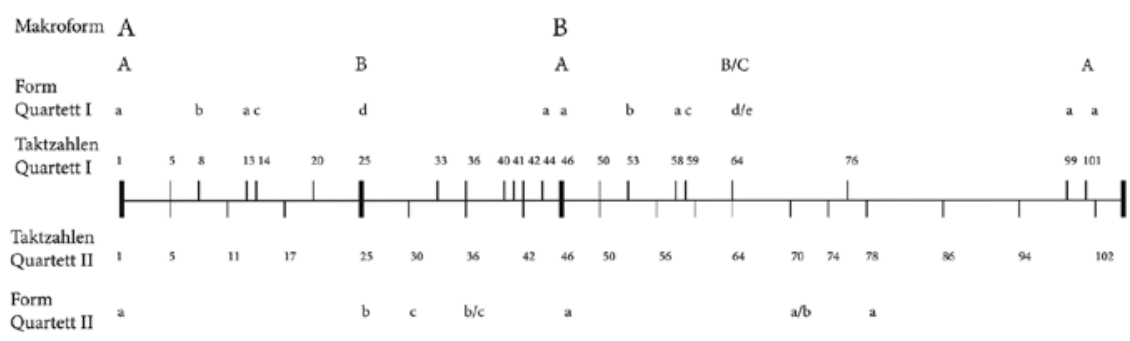

Abb. 31 Darius Milhaud: Formübersicht über den zweiten Satz der Streichquartette Nr. 14 $\& 15$.

Auch der zweite Satz lässt sich quartettübergreifend in zwei große Strecken teilen (vgl. Abb. 31). Jedoch ist in diesem Satz die Abgrenzung einzelner Themen, die im Verlauf exponiert werden, eindeutig und fällt in beiden Quartetten mit der formalen Gliederung zusammen. Wie der erste Satz endet der zweite Satz in beiden Quartetten mit einem kleinen Epilog (a), der den Anfang wieder aufgreift. Die spannungsgeladene Synchronisierung zweier unabhängiger Entwicklungsbögen wird hier durch einen thematischen Rahmen zur formalen Auflösung gebracht. Während im ersten Satz der Schlussakkord eine Schichtung der Tonarten Es-Dur, F-Dur und D-Dur ist, die allerdings in ihrer Klangwirkung durch die leise Dynamik miteinander verschmelzen, vereinigen sich beide Quartette im zweiten Satz im Schlusstakt zu einem B-Dur-Akkord. Darauf, dass der erste Fall eher eine Ausnahme ist und der zweite Fall typisch für Milhaud, weist Rosteck in seinem bereits erwähnten 
Artikel hin, „denn selbst Sätze mit extremer Dissonanzhäufung laufen bei Milhaud oft in einen tonal ,befriedigenden' , accord parfait' oder einen Einklang aus - möglicherweise ein Zugeständnis an traditionelle Hörgewohnheiten, das den skeptischen Rezipienten mit einer ,versöhnlichen' finalen Wendung berücksichtigt ${ }^{\text {"74 }}$.

\title{
Zusammenfassung
}

Synchrone Zäsuren, übereinstimmende formale Rahmenbedingungen (beide Werke teilen dasselbe formale Gefäß, dasselbe Tempo, dieselbe Metrik) und nicht zuletzt die identische Instrumentalbesetzung von zwei mal vier Streichern fördern als konsonante Klammer zwar immer wieder einen Verschmelzungsprozess zwischen beiden Quartetten. Die dissonante Wirkung des polytonalen Tonsatzes wird durch die Superposition aber insgesamt heraufgesetzt, da beide Quartette melodisch, thematisch, rhythmisch und harmonisch in unterschiedliche Richtungen divergieren, wobei es immer wieder zu punktuellen Überschneidungen kommt. Auch der Verlauf der Gesamtform bewegt sich in einem ständigen Spannungsverhältnis zwischen synchronisierten großformalen Zäsuren und divergierenden kleingliedrigen Formverläufen.

\subsubsection{Chaya Czernowin-Kontextualisierung und Perspektivierung durch Dialog im Anea Crystal Cycle (zwei Streichquartette III)}

\author{
„Das zweite Stück ist wie das zweite Kind. Sie müssen \\ zusammen leben. Aber trotzdem kann es ein starker \\ Charakter werden.“ ${ }^{75}$
}

(Chaya Czernowin)

Der Anea Crystal Cycle von Chaya Czernowin (geboren 1957 in Haifa, Israel) aus dem Jahr 2008 umfasst die zwei einzeln stehenden Streichquartette Seed I und Seed II, die entweder separat oder auch simultan aufgeführt werden können. Die Werke sind Teil des größeren Zyklus Shifting Gravity, der außerdem noch die Werke Sahaf und Sheva umfasst.

Der Komposition des Anea Crystal Cycle geht die Komposition der ersten drei Fassungen der Winter Songs aus den Jahren 2002-2003 voraus. In diesem

\footnotetext{
74 Rosteck: „Umrisse einer Theorie der Polytonalität bei Darius Milhaud“, S. 263.

75 Chaya Czernowin in einem Interview mit der Verfasserin am 18.5.2019 in Freiburg (im Breisgau).
} 
Zyklus wird ein tief besetztes Septett in jeder Fassung neu kontextualisiert. ${ }^{76}$ Die Kontextualisierung gleicht hier einem Palimpsest, das das Septett mit jeder fortschreitenden Version durch Überschreibung immer tiefer unter sich vergräbt, bis es nur noch als bruchstückhafte Erinnerung an Vergangenes die neue Werkidentität mitkonstituiert. Der Anea Crystal Cycle unterscheidet sich davon grundsätzlich. Auch hier werden zwei Quartette in ihrer Zusammenführung neu kontextualisiert, allerdings nicht durch Überschreibung und Fortkomposition, sondern durch eine In-Dialog-Setzung zweier gleichgewichtiger Werkidentitäten.

Beschreibung

Anea ist in sechs Abschnitte A, B, C, D, E und F unterteilt. A, C und E sind die Hauptabschnitte, in denen sich die thematische Entwicklung vollzieht. B, D und F fungieren als statische Zwischenabschnitte, die einerseits beide Quartette formal und materiell aneinanderkoppeln, aber ebenso eine innehaltende Fensterfunktion besitzen (vgl. Abb. 38).

Das erste Quartett Seed I entstand im Kompositionsprozess zuerst und lässt in seiner Einzelfassung nur die Abschnitte A, C und E aufeinanderfolgen. Das zweite Quartett, die Zwischenfenster B, D und F sowie das Zusammentreffen beider Quartette in Takt 136 (Seed I) und Takt 83 (Seed II) wurden erst in den nächsten Schritten konzipiert. Der Komposition des zweiten Streichquartetts Seed II ging also das Wissen um die Orte der Verknüpfung beider Stücke voraus. Es war Chaya Czernowin nach eigenen Worten sehr wichtig, dass sich das zweite Quartett vom ersten Quartett unterschied:

„Es ging darum, sich eine Freiheit zu schaffen und etwas zu machen, was nicht zum ersten Quartett gehört. [...] Wir lernen immer, dass wir nach Einheit suchen müssen. Aber es ist nicht mehr wahr. Die Stücke stehen zu Beginn mit dem Rücken zueinander."77

Beide Quartette sind in ihrem Charakter als dialektische Zweiheit angelegt. Ihre Individualität manifestiert sich einerseits in den unterschiedlichen

76 In der ersten Version Pending Light wird das Septett mit einem im Ircam (Institut de recherche et coordination acoustique/musique, Paris) produzierten Tonband und in der zweiten Version Stones mit einer Perkussionsschicht kombiniert. In der dritten Version Roots werden die drei Schichten Septett, Tonband und Percussion zusammengeführt. Die zwei letzten Fassungen Wounds/Mistletoe und Forgotten Light aus dem Jahr 2014 greifen das Septett abermals auf, integrieren es aber nicht mehr als Ganzes, sondern nur noch in Teilen in einen neuen instrumentalen und vokalen Kontext.

Chaya Czernowin im Interview mit der Verfasserin am 18.5.2019 in Freiburg. 
Materialideen, die beiden Quartetten zugrunde liegen, und andererseits in der Asynchronität auf der zeitlich-organisatorischen Ebene in den Abschnitten A, C und E. Während die metrische Unterteilung in Seed II größtenteils in einfachen Brüchen erfolgt, sind die Takteinheiten in Seed I vorwiegend mittels komplizierterer Doppelbruchnotation gruppiert (vgl. Abb. 32). Auch die Tempi bewegen sich unabhängig voneinander. In Teil A sind die beiden Tempi 69 und 60 in beiden Stücken unterschiedlichen Materialebenen zugeordnet: die gestischen, figurativen Passagen werden im Tempo 69, die nichtfigurativen, diffusen, feldhaften Passagen in Tempo 6o gespielt.

Die Materialentwicklung in den Abschnitten A, C und E

Das erste Quartett beginnt mit einer solistischen Pizzicatolinie der Viola, deren fragiler und singender Charakter durch Tonrepetitionen, minimale Tonschritte, eng kreisende Bewegungen innerhalb eines engen Tonraumes und eine leise Dynamik geprägt ist (vgl. Abb. 32). In die versandende Bewegung dieser Linie stößt in Takt 1o plötzlich das zweite Quartett mit seiner schroffen Körperlichkeit (vgl. Abb. 33). Durch ausholende und kurvige Glissandi innerhalb eines weiten Tonraumes entstehen starke physische Gesten, die, geformt durch häufige dynamische Wechsel innerhalb einer Skala von $p p$ bis ff, an ihren Rändern durch leise Einwürfe immer wieder ausfransen. In einer homophonen, blockhaften Anlage verstärken sich die vier Stimmen des Quartetts gegenseitig und münden in einem einzigen großen formalen Bogen organisch in eine gemeinsame flächige Bewegung ab Takt 24. Die formale Entwicklung in Seed $I$ ist dagegen kleinbögiger. Die Pizzicatolinie der Viola, die sich ab Takt 12 erneut in die abebbende Welle des zweiten Quartetts einfädelt, wird ab diesem Punkt immer wieder durch kurze Tremoloflächen, die als „Flüstern“ interpretiert werden können, gebrochen. Permanente Wechsel in der Metrik und im Tempo unterstreichen diesen Verlauf.

Der dialektische Charakter des Quartetts im Abschnitt A artikuliert sich auch im differenten Ausdrucksspektrum des Werks: Die unwillentlich um sich selbst kreisende Pizzicatolinie der Viola des ersten Quartetts, die nach Beschreibung Czernowins ${ }^{78}$ mit dem beiläufigen Gesang einer alten Frau in einem Dorf beim Waschen der Wäsche assoziiert werden kann, wird den stark determinierten Gesten des zweiten Quartetts gegenübergestellt. Die engen Tonschritte des Beginns von Quartett I verweisen in ihrem lyrischen und liedhaft-vokalen Charakter auf die Stimme des Menschen. Spätere Abschnitte in Seed I können als „Flüstern“ (Tremoloflächen beispielsweise in Takt 14, 18, 21, 68) und als „Sprechen“ (polyphone und homophone Glissandi in Teil C,

78 Im Interview mit der Verfasserin am 18.5.2019 in Freiburg. 


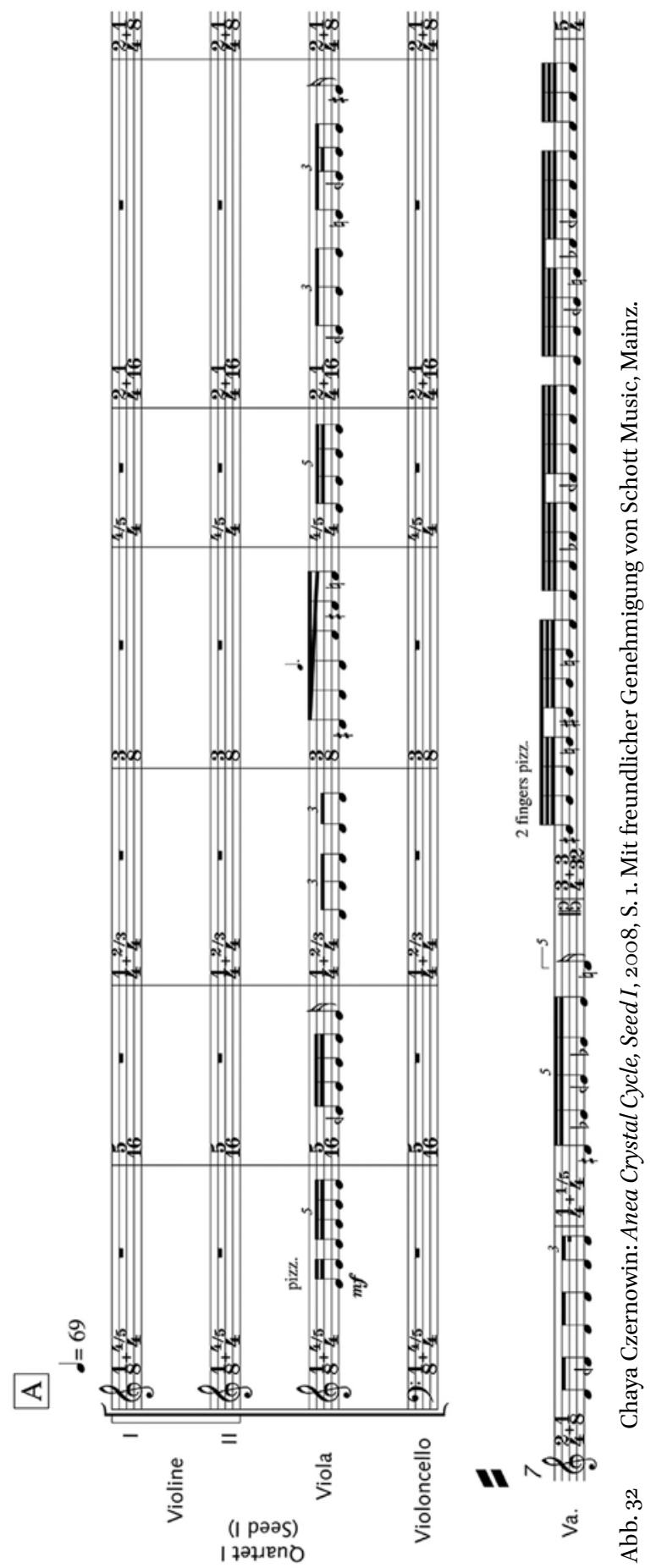




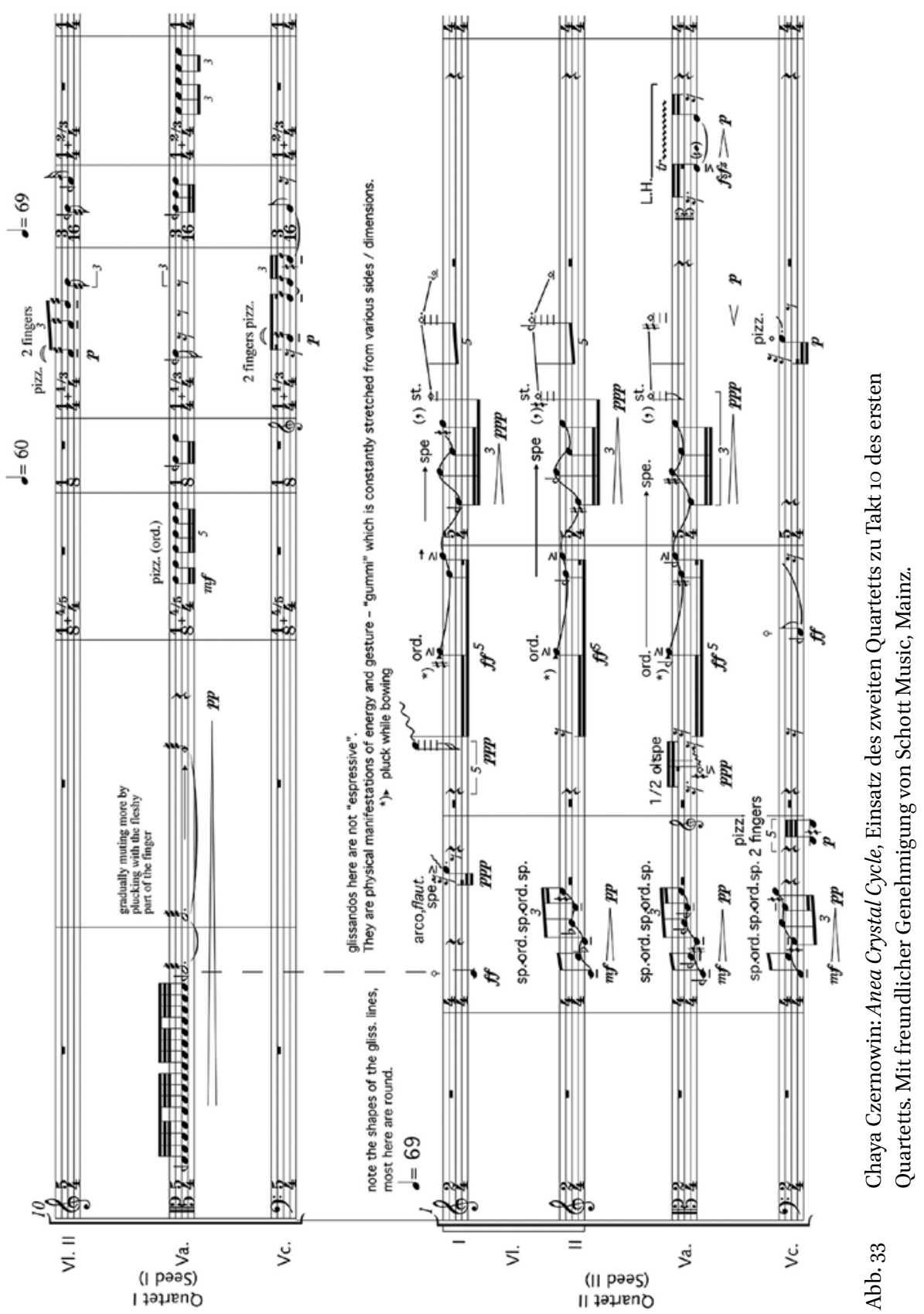


Takte 64-137) gedeutet werden. Die weiten Tonabstände des zweiten Quartetts (vgl. z. B. Abb. 33, Takte 2-5) unterstreichen dagegen den instrumentalen Charakter von Seed II. Czernowins Vorstellung eines pflanzlich-organisch sich entfaltenden Wachstumsvorgangs lässt sich hier gut nachvollziehen.

Die in Teil A etablierte Dualität wird für den weiteren Verlauf nicht als solche fortgesetzt. Ab Abschnitt B wird ein Annäherungsprozess zwischen beiden Quartetten in Gang gesetzt, allerdings auf zwei verschiedenen Wegen, die wiederum eine unterschiedliche Entwicklung aufweisen: Einmal über die kontinuierliche Entfaltung des Materials in den Hauptteilen A, C und E und parallel dazu über eine stufenweise Zusammenführung des Materials und der Ensembleeinheiten in den eingeschobenen Brückenabschnitten B, D und F.

„Treffpunkt" der Quartette

In Teil C von Seed I wird ein "sprechendes“ Element in Gestalt glissandierender Gesten eingeführt (ab Takt 64). Diese werden ab Takt 78 in eine polyphon gegeneinander verschobene Satztechnik geführt, auf die ab Takt go eine homophon geführte Bewegung folgt. Auch in Seed II durchläuft das Material zwischen den Takten 70 und 82 eine polyphone Entwicklung, die schließlich zum Ende des C-Abschnitts mit der Entwicklung des ersten Quartetts zusammengeführt wird. In Takt 136 des ersten Quartetts und Takt 83 des zweiten Quartetts, ungefähr zum Zeitpunkt des Goldenen Schnittes, werden beide Stücke schließlich metrisch und im Tempo synchronisiert (vgl. Abb. 34). Auch der gestische Charakter wird aneinander angeglichen.

Diesem singulären Moment der Annäherung folgt in Teil E ein gestischer Auflösungsprozess. Beide Quartette entwickeln sich in ihrer Charakteristik wieder auseinander. Seed I mündet in statische Liegeklänge, die durch ihre dynamische Intensität an die physische Präsenz des Beginns von Seed II erinnern, um sich anschließend in eine frei vibrierende Fläche aufzulösen. Die Gesten aus Seed II werden in Teil E nur noch als unverbundene, vereinzelte Aktionen ausgeführt, die ihre synchron-kollektive körperliche Energetik verloren haben.

Die Materialzusammenführung in den Abschnitten B, D und F

Die Abschnitte B, D und F sind für sich stehende statische Fenster, die in ihrer sukzessiven Abfolge einen von den Hauptteilen unabhängigen Prozess der Symbiose herbeiführen. Beide Quartette sind in den drei kurzen Abschnitten metrisch und im Tempo synchronisiert (vgl. Abb. 35-37). Das im A-Teil exponierte konträre Themenmaterial wird im achttaktigen Teil B strukturell in ein neues drittes Thema überführt, das vom zweiten Quartett gespielt wird 


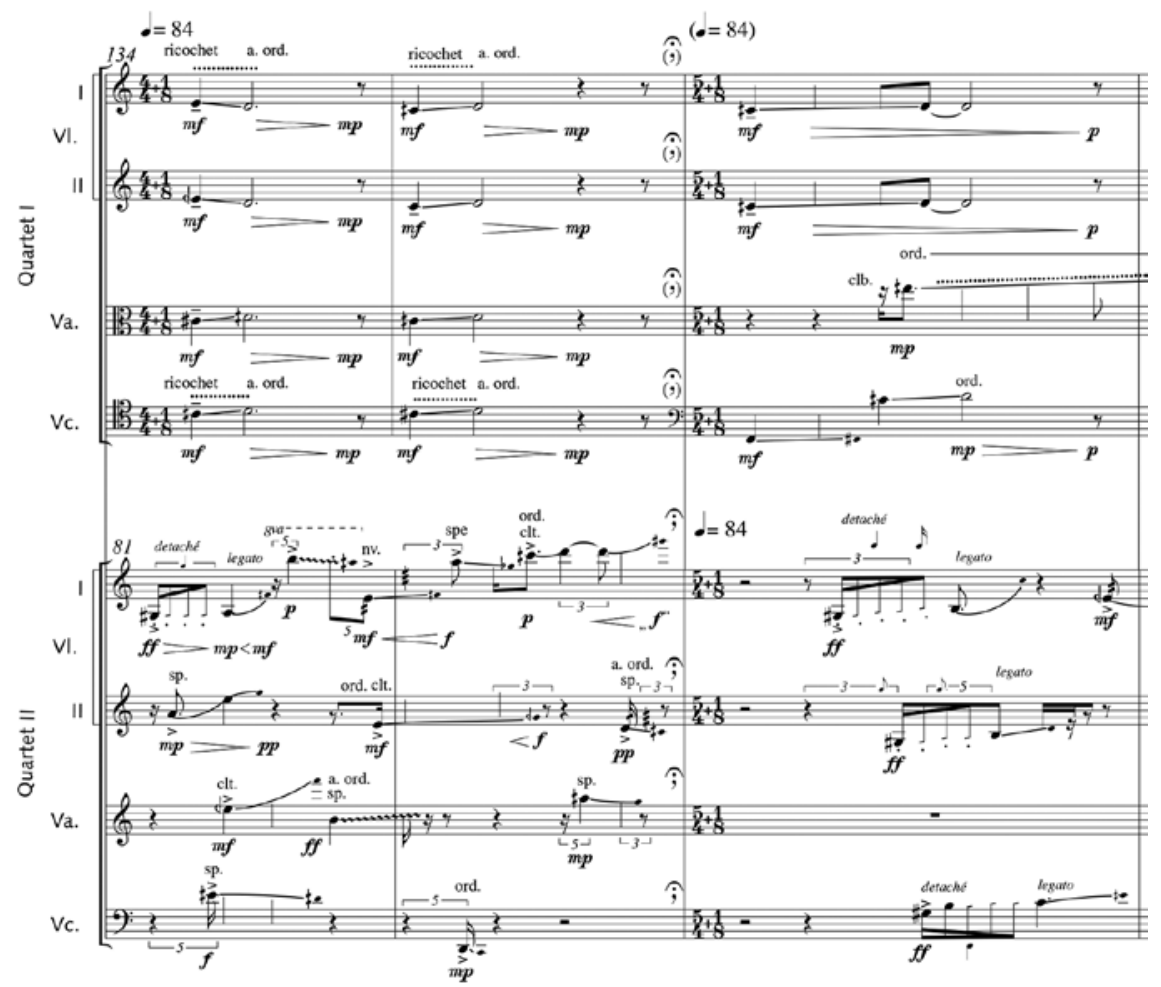

Abb. 34 Chaya Czernowin: Anea Crystal Cycle, „Treffpunkt“ beider Stücke in Teil C. Mit freundlicher Genehmigung von Schott Music, Mainz.

und aus der Pizzicatolinie des Beginns den repetitiven Charakter, die kleinen Tonschritte innerhalb eines engen Tonraums und die untere Dynamik übernimmt. Gleichzeitig behält das zweite Quartett aus dem eigenen Materialfundus die homophone, blockhafte Stimmführung bei und verbindet sie mit kurzen, seufzerartigen Portamenti. Es entsteht ein lamentoartiger Sprachgesang im mitteltiefen Register des Streichquartetts, der den Eintritt einer dritten neuen Ebene in die Gesamtform markiert (vgl. Abb. 35). Das bis dahin auf Gegensatz ausgerichtete dialektische thematische Material wird aus einer gewissen Distanz heraus zu einer neuen thematischen Einheit transformiert. Das alte Material wird auf neue Weise kontextualisiert und findet darüber hinaus zu einer neuen Qualität. Aber auch diese neu entstehende Einheit wird wiederum einem leise gespielten Liegecluster im ersten Quartett als Materialkontrapunkt gegenübergestellt, dessen granulierte Klangfarbe als Variation der repetitiven Linie des Beginns interpretiert werden kann. 


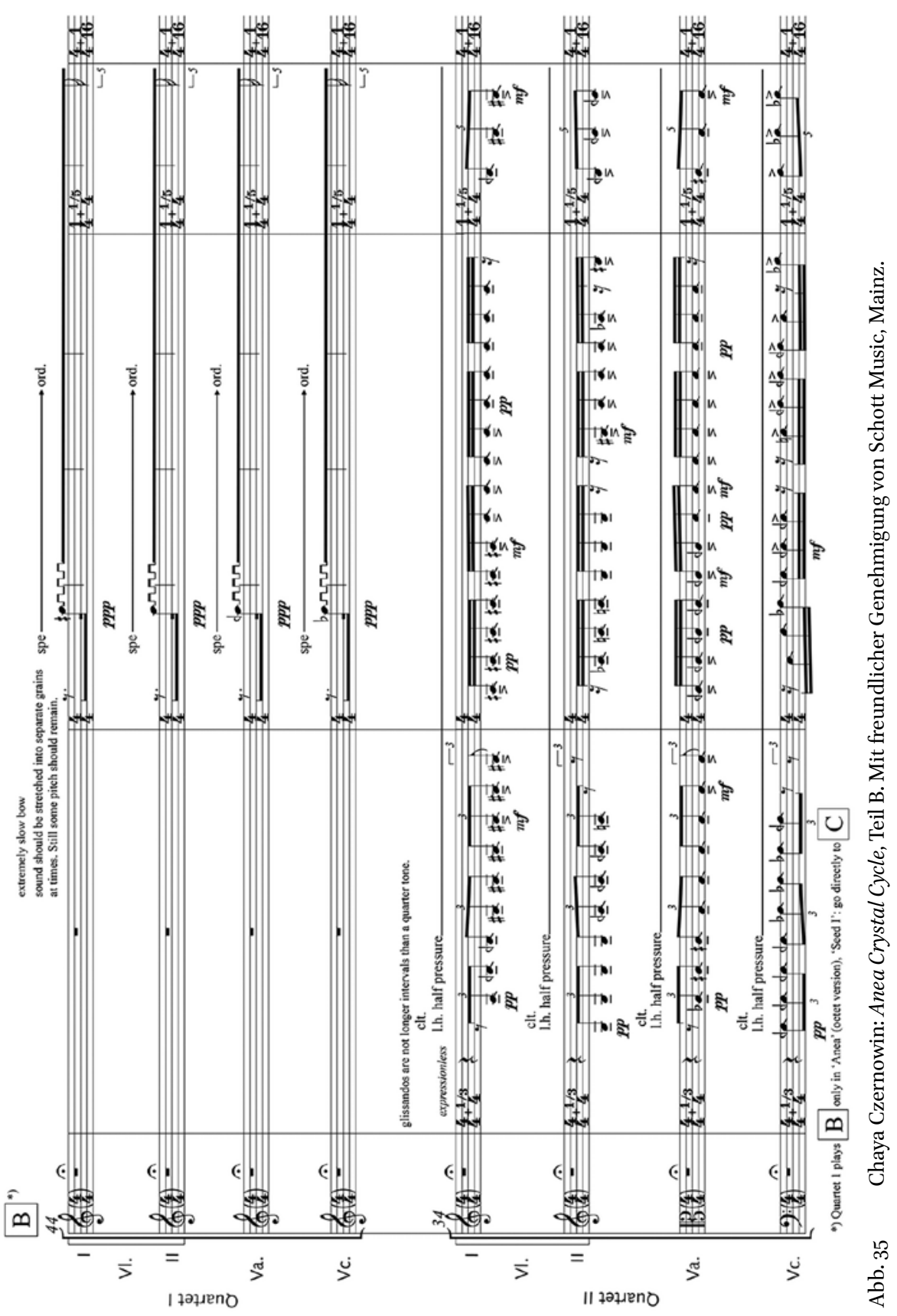




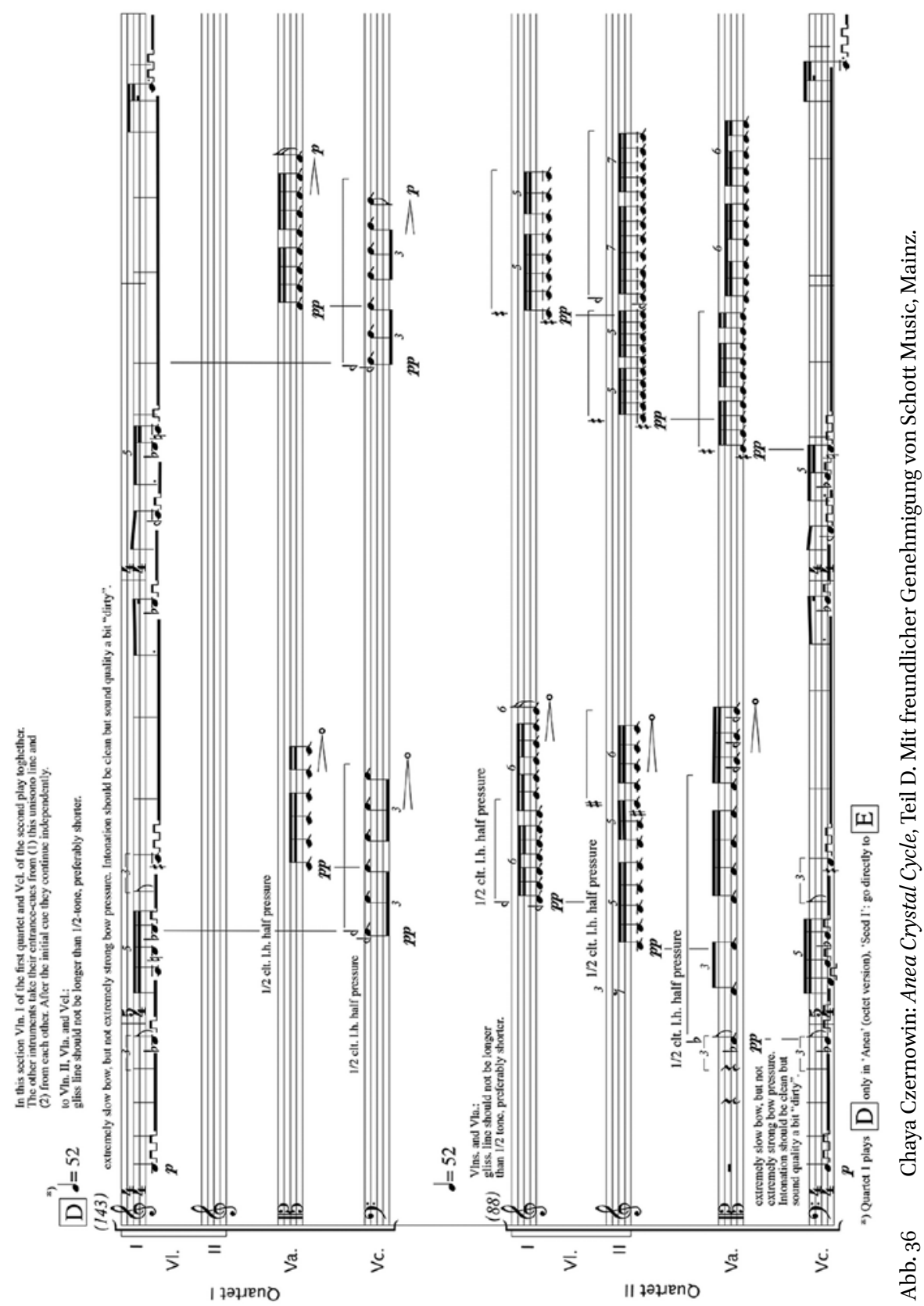




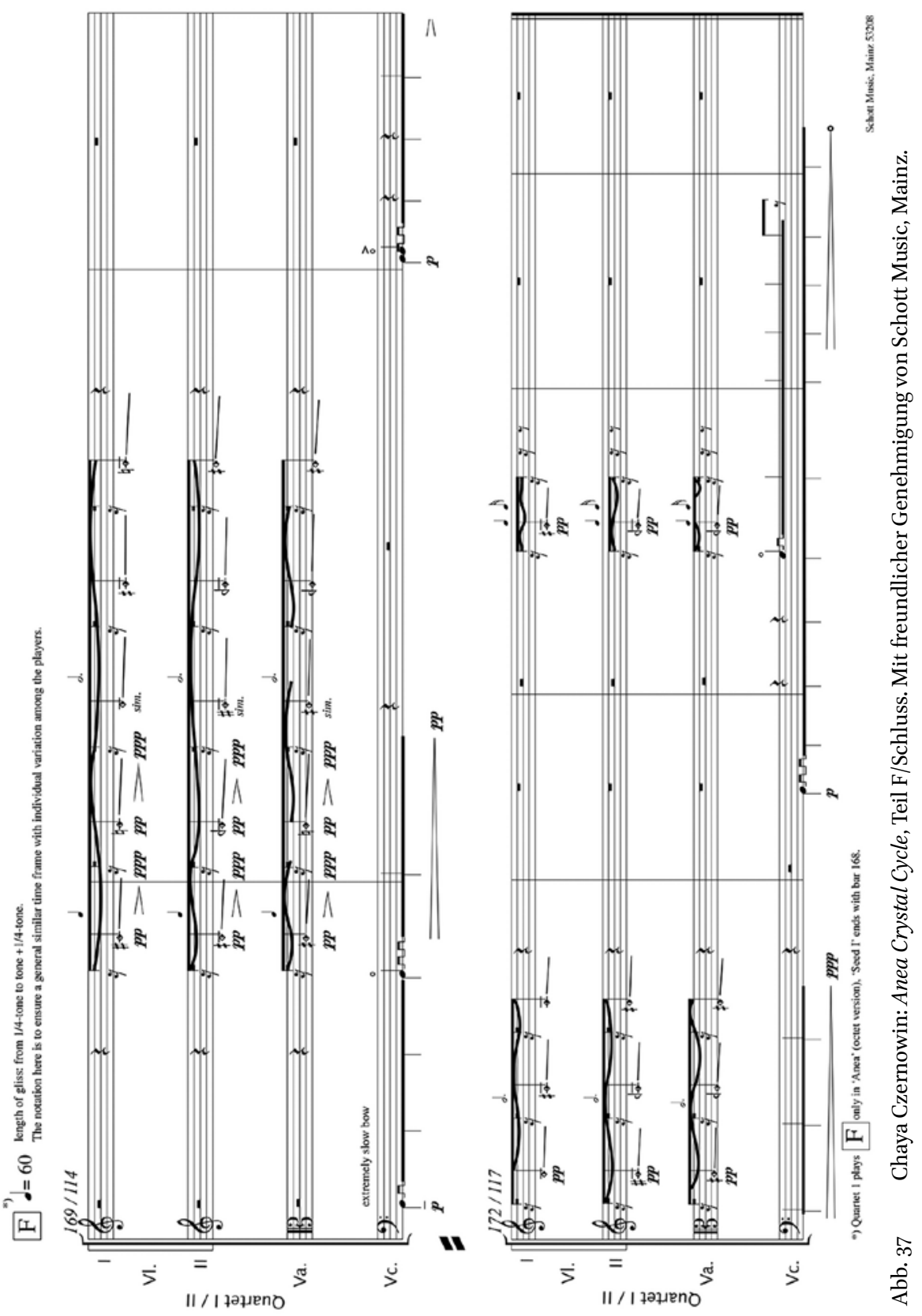


Abschnitt D treibt den Vereinigungsprozess beider Quartette weiter voran (vgl. Abb. 36). Das in B noch ensemblehaft getrennte Material wird auf beide Quartette verteilt, indem sich die Violine I des ersten Quartetts und das Cello des zweiten Quartetts unisono eine tiefe Linie im Oktavabstand teilen, die eine Melodisierung des Liegeclusters aus Teil B darstellt. Auch der Lamentogesang wird auf Stimmen beider Quartette aufgeteilt. Im letzten, auch achttaktigen Abschnitt F (vgl. Abb. 37) findet die Synthese beider Streichergruppen schließlich ihren Abschluss. Beide Quartette sind komplett vereinheitlicht. Sie spielen synchron die als thematische Reste übrig gebliebenen Liegeklänge im Cello und die Lamentostruktur in ihrer leisen, flageolettgefärbten Variante in den oberen drei Streichern. Wie am Ende des E-Teils hat auch hier das Material seine scharfen und eindeutigen Konturen aus dem B-Teil verloren. Es wirkt aufgelöst und durch die Flageoletttöne flüchtig und transzendiert.

Die Interform der Quartette

Beide Werke haben die gleiche äußere Gesamtform der zwei mal drei Abschnitte, die sukzessiv ineinander verschachtelt sind (vgl. Abb. 38). Die inneren formalen und thematischen Entwicklungen sind vielfältig. Es existieren zwei parallel verlaufende und voneinander unabhängige Prozesse der Annäherung, die über die formalen Entwicklungsstufen A, C, E und B, D, F verlaufen.

A, C und E stehen für die drei Hauptteile, in denen das Material von den am weitesten entfernt liegenden Positionen zu Beginn einen Annäherungsprozess durchläuft, der in Teil $\mathrm{C}$ einen Höhepunkt erreicht, indem sich die Wege ungefähr zum Zeitpunkt des Goldenen Schnittes treffen. In Teil C entfernen sich beide Quartette in ihrer thematischen Entwicklung wieder voneinander (vgl. Abb. 39).

Die Abschnitte B, D und F sind kürzere Brückenabschnitte. In Teil B wurden die beiden thematischen Positionen aus dem A-Teil bereits zu einer neuen dritten thematischen Einheit in Seed II eingeschmolzen. Da Seed I dem zweiten Quartett Seed II einen Materialkontrapunkt gegenüberstellt, ist ein Annäherungsprozess zwischen den beiden Quartetteinheiten noch offen. Dieser wird über Teil D und Teil F vollzogen. Beide Quartetteinheiten erreichen am Schluss den Punkt der vollständigen Symbiose. Aus einem achtstimmigen Doppelquartett wird ein einstimmiges Streichquartett, das synchron von beiden Ensembles gespielt wird (vgl. Abb. 37). 


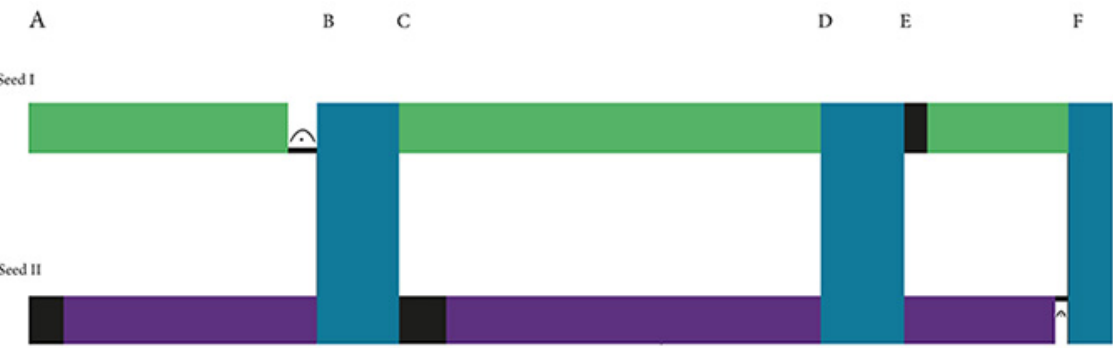

Abb. $38 \quad$ Gesamtformplan der Abschnitte A-F im Anea Crystal Cycle.

A

C
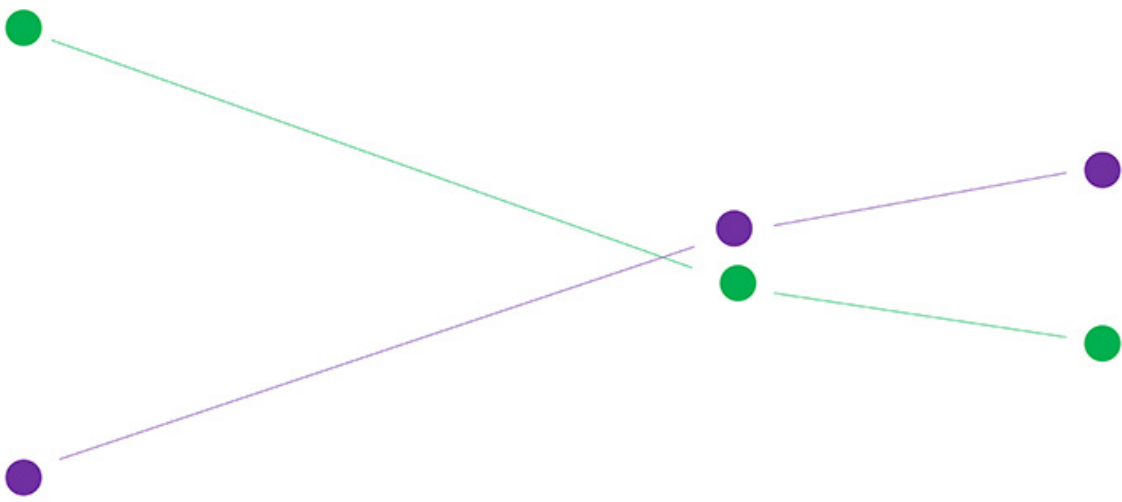

Abb. 39 Gesamtentwicklung des Verhältnisses beider Werke zueinander über die Teile A, C und E.

B

D

Abb. 40 Gesamtentwicklung des Verhältnisses beider Werke zueinander über die Teile B, D und F. 


\section{Zusammenfassung}

Das Werk lebt von seinem dialektischen Wesen, das sich auf verschiedenen Ebenen wie der Morphologie, der Metrik, dem Tempo, der Gestik und des Ausdrucks zeigt. Der morphologischen Zersplitterung und der Doppelbruchmetrik des ersten Quartetts steht die morphologisch einheitliche und eher in sich geschlossene Entwicklung und die metrische Geradtaktigkeit des zweiten Quartetts gegenüber. Während sich das erste Stück an stimmlich-menschliche Ausdruckselemente anlehnt, ist das zweite Stück einer biologisch-pflanzlichen Materie verbunden. Aber die Gegenüberstellungen betreffen nicht nur die Werkopposition, sondern sind auch innerhalb der einzelnen Werke zu finden. So stehen konkrete plastische Gesten eher feldhaften und diffusen Abschnitten gegenüber. Verschiedene Tempi werden nicht nur simultan kontrastiert, sondern auch sukzessiv nebeneinandergestellt. Das komplexe Beziehungsgeflecht wird nicht vollständig aufgelöst. Auch wenn es in F zu einer Symbiose beider Ensembles kommt, bleibt die Disparität des Materials auch am Schluss des vierstimmigen Quartettsatzes noch bestehen.

Trotz dieser dialektischen Gegenüberstellungen gibt es quartettübergreifend auch eine Verwandtschaft des Materials. Diese basiert auf einer einzigen Geste und wird durch das Glissando verkörpert. Es ist das eigentliche Grundelement des Werkes und in den verschiedensten Varianten durchweg präsent. Sogar die eingangs gezupfte kreisende Pizzicatolinie kann in ihrer sukzessiven Aushöhlung des engen Tonraums als (gestuftes) Glissando gedeutet werden. Es handelt sich beim Glissando selbst um eine Geste des Verbindens, die auf einer elementare Ebene zwei Ecktöne miteinander verbindet und hier für eine Geste steht, die zwei Werke formübergreifend in ihrem Ursprung und ihrer Entwicklung zusammenführt. Das Glissando ist wie eine verborgene und imaginäre Wurzel zweier unterschiedlicher Bäume, deren Kronen sich wieder berühren.

Der eindeutig dialektischen Exposition mit ihren klar gegensätzlichen Charakteren zu Beginn folgt der Aufbau eines komplexen Beziehungsgeflechts, der einen Prozess der Annäherung in der Beziehung beider Werkidentitäten in Gang setzt. Um was für eine Beziehung es sich handelt, ist letztlich auch eine Interpretationsfrage. Wird der Anea Crystal Cycle von zwei verschiedenen Quartetten gespielt, dann ist die Spannung zwischen den Werken höher, als wenn die Interpretation nur durch ein einziges Quartett erfolgt. Das ist zum Beispiel dann möglich, wenn Seed II als aufgenommenes Tonbandstück parallel zur Liveaufführung von Seed I abgespielt wird. Diese Variante ist im Vorwort zur Partitur auch aufgeführt. Auf diese Weise würde das Werkpaar als innere Aufspaltung einer einzigen Entität eine Umdeutung erfahren. Die Form der Beziehung beider Werke zueinander ist durch die Komposition nicht 
endgültig fixiert, sondern kann durch die Interpretation nochmals hinterfragt werden.

\subsubsection{Die Simultaneisierung von heterogenen Streichquartetten-Milhaud und Czernowin im Vergleich}

Die Werke von Milhaud und Czernowin stammen aus unterschiedlichen stilistischen und ästhetischen Kontexten des 20. Jahrhunderts. Gerade aus diesem Grund ist eine vergleichende Darstellung mit einer Thematisierung formaler Aspekte reizvoll. Denn vor dem Hintergrund übergreifender Merkmale kann das jeweils Individuelle nochmals ganz anders in Erscheinung treten.

In den Beispielen von Hölszky, Milhaud und Czernowin haben die einzelnen Quartette die Dauer und die Makroform gemeinsam, also den äußeren formalen Rahmen. Alle drei Werke haben eine sehr klare und plastische Form mit gut voneinander abgrenzbaren Formteilen, denen im Verlauf der motivisch-thematischen Entwicklungsstadien jeweils eine eigene Funktion zugeordnet werden kann. Auch die Instrumentation der Quartette ist identisch und in sich homogen.

Die Streichquartettformation als anspruchsvollste Gattung der klassischromantischen Tradition ${ }^{79}$ wird hier mit einer Dopplung ihrer selbst in einen neuen Bezugsrahmen gesetzt. Der klassische Diskurscharakter eines Streichquartetts wird so von einer Dialogsituation zwischen zwei Quartetten, die in ihrer Instrumentation identisch und in sich geschlossen sind, überlagert. Diese diskursive Doppelstruktur, die bei Milhaud und Czernowin zusätzlich mit der Exposition unterschiedlichen thematischen Materials zu Beginn der Stücke einhergeht, drückt ein dialektisches Denken aus, das eine andere wirkmächtige Tradition in der Musikgeschichte durchspüren lässt und an nichts weniger als an das Prinzip einer Sonatenform anknüpft. 80

Die Übertragung des Sonatenprinzips auf eine zeitgenössische heterogene Werksimultaneisierung erscheint trotz der historischen Distanz als eine sehr adäquate und konstruktive Formgestaltungsstrategie. Beiden ist die Exposition von Gegensätzlichem, Widersprüchlichem und Dialektischem,

79 Gerade Milhauds Streichquartettschaffen umfasste 18 Quartette, die im Zeitraum von 1912 bis 195 o entstanden. Er war in dieser Gattung nicht nur äußerst produktiv, sondern wagte in ihr auch immer wieder stilistische, polytonale und auch polyformale Experimente. Letzteres beispielsweise im 12. Quartett von 1945. Vgl. zur Schichtung von Formmodellen auch Rosteck: „Umrisse einer Theorie der Polytonalität bei Darius Milhaud“, S. 269-272. Im dritten Quartett brach er wie Schönberg die Instrumentation durch Hinzufügen einer Singstimme auf.

8o Sonatenform wird hier gleichbedeutend mit Sonatenhauptsatzform verwendet. 
die „beziehungsreiche[...] Vielfältigkeit" ${ }^{\text {«1 }}$, der Weg der Auseinandersetzung, aber auch die Möglichkeit zur Lösung immanent. Lediglich die logischsukzessiv-lineare Abfolge der formalen Entwicklungsstufen wird um die Möglichkeit der Simultaneität aufgebrochen und erweitert. Allerdings lässt gerade dieser Kniff das Konfliktäre nochmals stärker hervortreten, da die unterschiedlichen Themen und Charaktere ungeschützt aufeinanderprallen und nicht durch Überleitungen linear vermittelt werden. Letztendlich ergibt die Synthese eines traditionellen Formmodells mit einer zeitgenössischen Formensprache nur dann einen Sinn, wenn nicht restaurativ vorgegangen, sondern das ursprüngliche Prinzip auf seine Kernphasen kondensiert wird, um damit den „traditionellen Formprinzipien zu neuer Substanzialität im veränderten Gefüge der Mittel zu verhelfen“82. Die Kernphasen umfassen hier die Exposition eines Konflikts und die Phase der Auseinandersetzung, die die Möglichkeit einer Annäherung als dritte Phase beinhalten kann. Diese drei müssen nicht zwingend aufeinanderfolgen. Sie könnten sich auch überlagern oder gleichzeitig stattfinden. Während beispielsweise die thematischen Charaktere über weite Strecken ihre Gegensätzlichkeit beibehalten, nähern sich die Metren oder formalen Verläufe bereits einander an. Die Möglichkeit der Simultaneisierung eröffnet hier ein ganz neues Feld an Möglichkeiten, diese drei Entwicklungsstadien in einen diskursiven Verlauf zu bringen und damit wiederum neue formale Mehrdeutigkeiten und Ambiguitäten zu erzeugen. So kann die Pizzicatolinie der Viola zu Beginn des Anea Crystal Cycle nicht einfach nur als erste lyrische Themenlinie gehört werden, sondern in der Simultanfassung ebenso als elftaktige lyrische Einleitung zum Aufeinanderprallen der Quartette in Takt 1o. Damit wäre dieser Beginn formambigue und besäße je nach Kontextualisierung zwei verschiedene Funktionen.

Der Verweis auf die Sonatenform soll im Kontext der Analyse eine mögliche Perspektive darstellen, die über formale Entwicklungen nochmals Erkenntnisse befördern kann. Die Exposition mit ihrem Dichotomiecharakter ist sowohl für die Quartette von Milhaud als auch für den Anea Crystal Cycle eindeutig bestimmbar. Im ersten Satz des Doppelquartetts von Milhaud sind trotz einer zeitlich klar bestimmbaren Reprise als einer verkürzten Wiederholung des ersten Teils alle drei Kernphasen Konflikt, Auseinandersetzung und Annäherung als sich überlagernde Schichten permanent präsent. Dagegen können im Anea Crystal Cycle diese drei Phasen linear nachvollzogen

\footnotetext{
81 Hartmut Fladt: Zur Problematik traditioneller Formtypen in der Musik des frühen zwanzigsten Jahrhunderts (= Berliner musikwissenschaftliche Arbeiten, Bd. 6), München: Katzbichler, 1974, S. 23.

82 Ebd., S. 16.
} 
werden: Teil A ist die Exposition, ab Teil B beginnt über die beiden Formentwicklungen $\mathrm{B}-\mathrm{D}-\mathrm{F}$ und $\mathrm{C}-\mathrm{E}$ die Phase der Auseinandersetzung, die auch gleichbedeutend mit einem Prozess der Annäherung ist. Jeder Formteil stellt im Beziehungsgefüge ein neues Entwicklungsstadium dar. Eine eindeutige, klassische Reprise als Wiederholung der Exposition fehlt. Diese Negation gibt dem Werk sowohl linear als auch in der interformalen Beziehung einen offeneren Formcharakter, denn die Annäherung wurde ja trotz fehlender eindeutiger Reprise vollzogen.

Obwohl es in Bezug auf den Form- und Werkbegriff im 2o. Jahrhundert mehrere Paradigmenwechsel gab, erscheint die Anwendung der Sonatenform als dialektisches Grundmodell naheliegend. Für Milhaud, dessen Streichquartettschaffen in der ersten Hälfte des 20. Jahrhundert liegt, ist die Anknüpfung an tradierte Formen noch selbstverständlich und entspricht einer verbreiteten Praxis. Der Anea Crystal Cycle stammt dagegen vom Beginn des 21. Jahrhunderts. Zu diesem Zeitpunkt würde die Sonatenform in einem Monowerk als antiquiert und rückwärtsgewandt erscheinen. Im Kontext dieses Poly-Werks mutiert sie dagegen zu einer fruchtbaren und offenen Projektionsfläche in Bezug auf das Verhältnis der Werke zueinander. Trotzdem umfasst die Sonatenform auch hier nie das Ganze, sondern erwächst nur generativ als mögliche Variante innerhalb einer mehrbödigen formalen Situation und gerade nicht als linear gedachte und fixierte Form im Einzelwerk. Das PolyWerk erscheint so wiederum als vermittelnder Formkomplex, der in der Lage ist, traditionsreiche Form- und Gattungskulturen als adäquate Antwort auf die Herausforderungen des 21. Jahrhunderts kritisch zu reaktivieren und ihnen neues Leben einzuhauchen, ohne sie aber lediglich affirmativ zu wiederholen.

\subsubsection{Simultane Überlappung in den Protuberanzen für Orchester von Klaus Huber}

Das Gesamtœuvre von Klaus Huber (1924-2017) entwickelte sich teilweise auf der Grundlage von Eigenbearbeitungen, Materialbezügen und Rekompositionen. ${ }^{83}$ Ähnlich wie das Poly-Werk verweisen diese Verfahren auf Aspekte des Unabgeschlossenen und der Neukontextualisierung. Ein zentrales Werk ist ... Plainte ... für Viola d'Amore, das seit den goer Jahren im Kontext von wechselnden Erweiterungs-, Bearbeitungs-, Dialog- und Reduktionsprozessen eine tiefe Spur durch das Spätwerk gräbt und eine Vielzahl von Werken miteinander verbindet. Verschiedene Rekompositionen bewegen sich im fließenden Übergang zwischen Bearbeitung und Poly-Werk und beruhen eher

83 Siehe hierzu auch Till Knipper: „Klage um Klage. ,Rekomposition‘ in Klaus Hubers Spätwerk“, in: MusikTexte. Zeitschrift für Neue Musik 123, 2009, S. 61-68. 
auf einer homogenen Werkkonstellation. Poly-Werke gibt es bei Klaus Huber bereits seit den 7oer Jahren. Zu nennen sind die Schattenblätter (1975) und die Triominiatur Oiseaux d'argent, von Huber 1977 für drei Flöten komponiert. Oiseaux d'argent kann entweder als Trio, in verschiedenen Duoversionen oder als solistisches Stück, das alle drei Stimmen in beliebiger Reihenfolge sukzessive verbindet, aufgeführt werden. Die einzelnen Triostimmen, simultan als Partitur komponiert, sind also sukzessive aufklappbar. Huber gesteht zwar der einzelnen Stimme keinen autonomen Status zu, da die Soloversion lediglich im linearen Zusammenhang aller drei Stimmen hintereinander aufzuführen ist, dennoch erprobt er hier auch eine Form der Flexibilität, die lineare Abfolgen und simultane Vertikalität als zwei austauschbare Seiten des Kontrapunktischen ansieht.
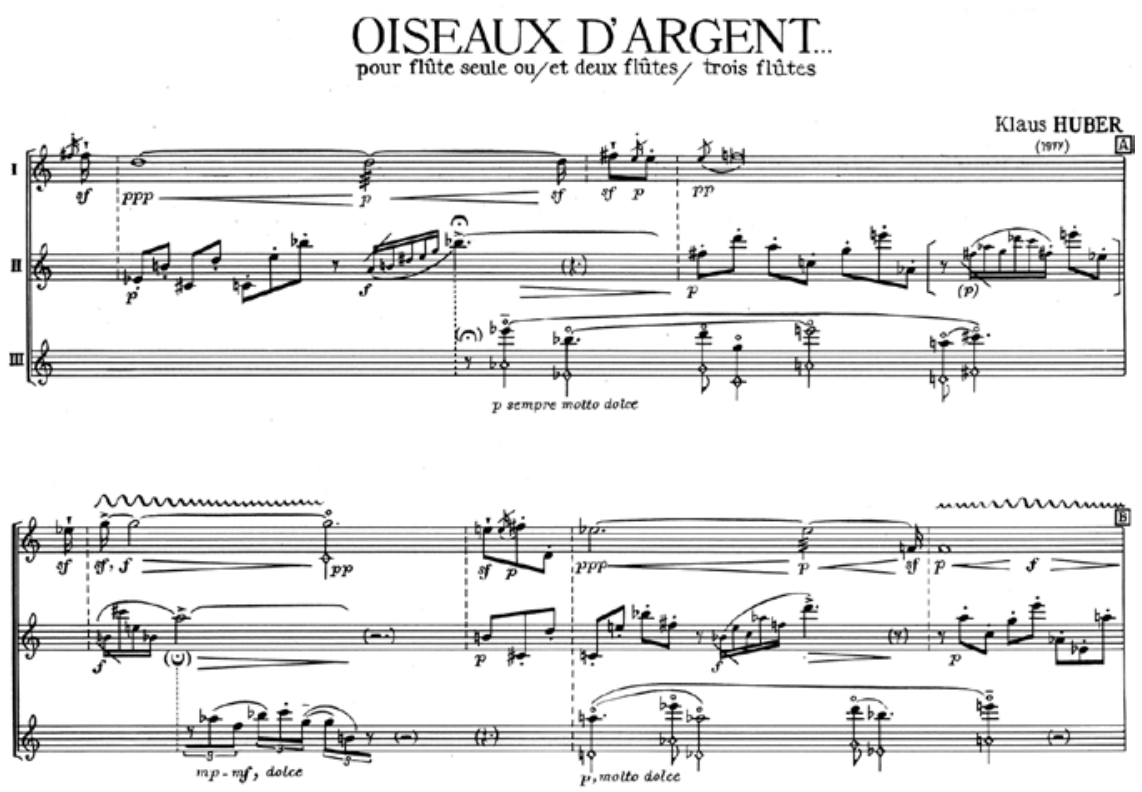

Abb. 41 Klaus Huber: Oiseaux d'argent für drei Flöten, 1977, S. 1. @ Edition Transatlantiques. Reprinted by Permission of Hal Leonard Europe Limited.

Protuberanzen für Orchester

Bei den Protuberanzen aus den Jahren 1985-1986 handelt es sich wiederum um drei Miniaturen für Orchester. Auf sehr konzentriertem Raum bieten diese die Möglichkeit eines wahlweise linearen oder simultanen Ablaufs. Die drei unterschiedlich besetzten Miniaturen, die zusammen eine komplette Orchesterbesetzung ausfüllen, können sowohl einzeln als auch einander überlappend 
aufgeführt werden. Diese Überlappung von Werken ist ebenfalls eine Form der Simultaneisierung, wenngleich sie im Unterschied zur vollständigen Vergleichzeitigung an der ursprünglichen linearen Reihenfolge festhält.

Die drei Stücke entstanden im Auftrag des Komponisten und Dirigenten Hans Zender mit der Bedingung größtmöglicher Kürze, um mit wenig Proben auszukommen. Klaus Huber fühlte sich durch diese Vorgabe provoziert und entwarf das Stück in zwei Versionen: In der ersten Version werden die drei Stücke sukzessive nacheinander gespielt. In der zweiten Version werden sie simultan überlappend gespielt und benötigen dadurch zwar weniger Aufführungszeit als die sukzessive Version, allerdings auch mehr Probenzeit. Gemeinsam ist allen drei Stücken, dass es verschiedene Auf- und Abbauprozesse auf dynamischer, harmonischer und klangfarblicher Ebene gibt, die auf einen zentralen Umkehrpunkt bezogen sind.

Jede Miniatur vertritt jeweils einen spezifischen Typus klangfeldlichen Denkens. Das erste Stück Die Enge des Marktes ist ein polyphones, das zweite Stück Implosion ein homophones und das dritte Stück Stäubchen aus Licht ein fluktuierendes Klangfeld. Durch die Kürze und Zuspitzung der kompositorischen Ideen kann man in allen drei Fällen von ausgeprägten Charakterstücken sprechen. ${ }^{84}$

Beschreibung

Insgesamt besteht das ganze Werk in der simultanen Fassung aus 237 Zeiteinheiten. ${ }^{85}$ Die Enge des Marktes hat eine Dauer von 118 Zeiteinheiten, Implosion besteht aus 80 und Stäubchen aus Licht aus 138 Zeiteinheiten. Die drei Stücke laufen für 18 Einheiten, von Einheit 100 bis 118, parallel. Tempomäßig sind die Stücke insofern synchronisiert, als die Achteldauern im ersten Stück dem Metronomwert 100 und damit den Viertelnoten $($ Viertel $=50$ ) des zweiten Stückes entsprechen. Der ursprüngliche Plan, Polytempi zu verwenden, wurde von Huber aus aufführungspraktischen Gründen verworfen.

Im ersten Stück Die Enge des Marktes wird mit kanonischen Techniken ${ }^{86}$ sukzessive ein polyphones Klangfeld aus fünf Instrumentenpaaren aufgebaut, die jeweils durch einen perkussiven Impuls ausgelöst werden. Aufgrund der sukzessiven kanonischen Einführung der Stimmen, der perkussiven Signale und der kräftigen Fortedynamik haben die ersten zehn Takte einen eröffnenden

84 Klaus Huber hat die Stücke und seine Vorgehensweise ausführlich beschrieben. Diese Darstellung ist sowohl der Partitur (Ricordi, 1986) vorangestellt als auch im Schriftenband Umgepflügte Zeit zu finden. Siehe Huber/Nyffeler (Hg.): Umgepflügte Zeit, S. 201-214. Eine leicht gekürzte Fassung findet sich auch in Huber: Von Zeit zu Zeit, S. 133-138.

85 Eine Zeiteinheit entspricht dem Wert einer Viertelnote.

86 Es handelt sich um einen fünffachen Doppelkanon in Prolation. 


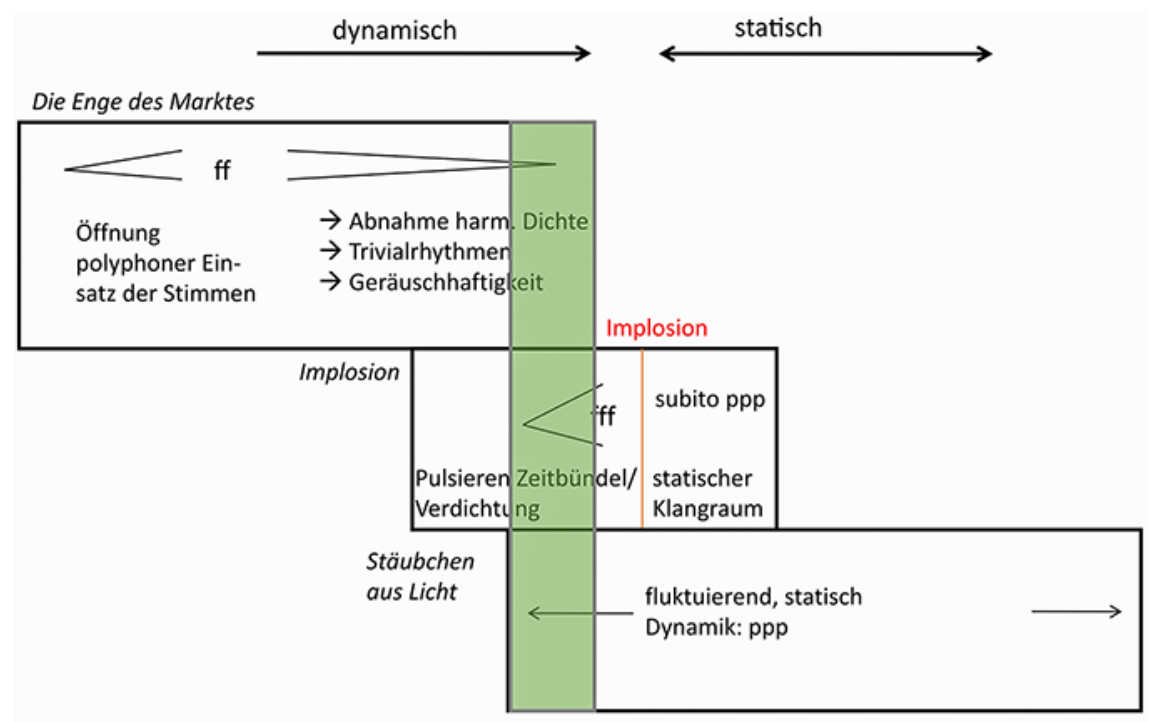

Abb. 42 Formübersicht über die Protuberanzen von Klaus Huber.

Charakter. Ab Takt 11, bei Erreichung des Tutti, schreibt Huber in der Partitur ein „allmähliches, beinahe unmerkliches Diminuendo bis zum Schluss“ vor. Dem Tuttidiminuendo sind auf klanglicher, rhythmischer und klangfarblicher Ebene Reduktionsprozesse übergelagert, durch die das Stück den Charakter eines komponierten Verfallsprozesses erhält. Dieser gewollte Verfallsprozess läuft auf verschiedenen Ebenen auf eine Vereindeutigung, im wahrsten Sinne des Wortes auf "die Enge des Marktes" hinaus: Auf formaler Ebene geht der polyphone Satz in ein „Märschlein mit Trio'chen“ über. Gleichzeitig vereinfacht sich die markante Rhythmik der einzelnen Stimmen zu Trivialrhythmen, und der ständige metrische Wechsel des Beginns zwischen geraden und ungeraden Takten $(6 / 8,7 / 8,5 / 8)$ geht in einen durchgehenden $2 / 4$-Takt über. Die längeren melodischen Einheiten des Beginns lösen sich nach und nach in kurze Gesten auf. Auch die harmonische Dichte nimmt sukzessive ab. Ausgehend von einem zwölfstimmigen Akkord vollzieht sich in zehn Schritten ein klanglicher „Einschmelzungsprozess" des harmonischen Materials zu einer großen Sekunde und fünf Vierteltönen. Auf klangfarblicher Ebene werden einzelne Töne zunehmend in Geräusche umgewandelt, und die Dynamik reduziert sich vom $f$ bis zum ppp. Die markanten Signale des Beginns werden zu leeren, kraftlosen Impulsen. Der Verfallsprozess überlagert sich in der simultanen Fassung mit dem Einsatz des zweiten Stückes Implosion, welches das dichteste und das kürzeste der drei Stücke ist. Es besteht aus 8o Einheiten. In der 20. Einheit setzt in der simultanen Fassung das dritte Stück Stäubchen aus Licht ein. 
In der symmetrischen Mitte, bei Zeiteinheit 40, ist in der simultanen Fassung Die Enge des Marktes zu Ende. Die Zeiteinheit 49 markiert den Umkehrpunkt, die Implosion, und teilt das zweite Stück im Verhältnis des Goldenen Schnittes (vgl. Abb. 42).

Im zweiten Stück ist die Übereinanderschichtung verschiedener klanglicher und zeitlicher Prozesse sehr genau auf die formale Dramaturgie der gesamten Anlage ausgerichtet. Es handelt sich gleichsam um eine Art Knotenpunkt, in dem die verschiedenen harmonischen, dynamischen und klangfarblichen Stränge zusammenlaufen und gebündelt werden. In diesem zweiten Stück gibt es keinen rhythmischen oder melodischen Verlauf im engeren Sinn, sondern ein bei Huber oft eingesetztes „Pulsieren der Zeit in Zeit-Bündeln“87. Damit ist ein rein impulshaftes Schwingen von Klangräumen in verschiedenen instrumentalen Schichten gemeint. Zur Stützung des harmonischen und formalen Verlaufs wurden zusätzlich zwei weitere geometrisch entworfene Impulsnetze - die ihre größte Dichte zum Zeitpunkt der Implosion in Zeiteinheit 49 erreichen - über das Stück gelegt und durch ein sich steigerndes Crescendo zum ffff unterstrichen. ${ }^{88}$ Der zentrale Impuls des Zusammenbruches erfolgt abrupt durch den Einsatz des dritten harmonischen Stadiums im ppp, das mit der klangfarblichen Auflösung aller Impulse in Geräusche und Flageolette einhergeht. Analog zum Ende des ersten Stückes wird in Implosion ein reduzierter Klangraum geschaffen, in den sich das folgende Stück einfädeln und vor dem es sich entfalten kann.

Das dritte Stück Stäubchen aus Licht ist solistisch besetzt und das subtilste der drei Stücke. Die vorgeschriebene Grunddynamik, die nicht verlassen werden darf, ist ppp. Parallel zum harmonisch-zyklischen Akkordverwandlungsprozess findet ein klangfarblicher Verwandlungs- und Auflösungsprozess statt, indem der Klangraum zunehmend durch Mikrointervalle, Mikroglissandi, Vierteltoncluster und verschiedene Spieltechniken verfremdet wird.

Die zeitliche Organisation der Tonhöhen ist ähnlich wie der harmonische Verlauf nicht zielgerichtet und entwickelnd, sondern kreist in sich selbst. Dafür entwarf Huber grafische Wellenbewegungen, die er übereinanderlegte und deren Verlauf er anschließend in rhythmische Werte übersetzte. Auf diese Weise entsteht ein freies Fluktuieren und Ineinanderströmen der einzelnen klanglichen Aktionen. ${ }^{89}$

Die drei Grundkategorien von Klaus Hubers Zeitgestaltung - 1. Prolatio als proportionale Zeitgestaltung, 2. geometrisch konzipierte Zeitnetze und 3. frei

87 Klaus Huber, „Werkbeschreibung“ (Partitur, S. 3).

88 Siehe ebd.

89 Vgl. ebd. 
entworfene Wellenverläufe - werden in den Protuberanzen jeweils in einem Einzelstück exemplarisch eingesetzt. ${ }^{90}$ Die Entwicklung der Impulsidee erlebt im Verlauf des Stückes eine ebenso in Auflösung übergehende Entwicklung wie die übrigen Parameter. Handelt es sich in Die Enge des Marktes um verschiedene markante Signale, die die Bewegung der einzelnen Stimmen auslösen, so wird im zweiten Stück mit Impulsfeldern und -dichten gearbeitet, die die Bewegung an sich darstellen. Im dritten Stück erfolgt die Auflösung in ein freies Pulsieren.

Form und Simultaneisierung

Obwohl die formale Planung und Kalkulation der verschiedenen Prozesse sehr genau auf den zentralen Umkehrpunkt als klassischen „Höhepunkt“ ausgerichtet ist und es zu einer werkhaften Synthese kommt, wird der individuelle Charakter der drei Stücke in der simultanen Fassung nicht aufgehoben. Auch lassen sich alle drei Stücke in ihrer linearen Reihenfolge, die durch die Überlappung ja nicht aufgehoben wird, in einen kausalen Zusammenhang bringen, der auf seine Weise eine kritische Reaktion auf den Musikbetrieb und gesellschaftliche Prozesse ist: Der Titel Die Enge des Marktes lässt sich auch als Seitenhieb auf die zeitliche Rahmenbedingung des Auftrags verstehen, ein "möglichst kurzes Stück für ein großes Orchester ${ }^{491}$ zu schreiben, um Proben- und Aufführungszeit zu sparen. Auch das zweite Werk Implosion bezieht sich auf gesellschaftliche Zeitaspekte und das sich immer mehr beschleunigende Tempo technischen Fortschritts. Mit Hubers eigenen Worten ausgedrückt, ist es konkret „die zunehmende Implosion der Zeitdimension [...]: in immer kürzerer Zeit eine immer größere Zerstörungskraft. [...] In der Zeit komponierend, wollte ich eine ,Implosion' versuchen, die, indem sie nach innen explodiert, so etwas wie Befreiung schafft. ${ }^{\text {“92 }}$ Das dritte Stück verkörpert nach Huber so etwas wie Hoffnung, die aber nur „stäubchenweise“ vorhanden ist.

Die Tendenz zur Simultaneisierung unterschiedlicher musikalischer Texte ist für Huber nichts weniger als, „eine der Grundfragen der Musik unseres

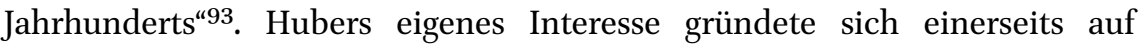
kompositionstechnische Fragestellungen, auf die Entwicklung individueller Techniken der Polyphonisierung und der Synchronisierung, aber andererseits auch auf die offenen Fragen der Hörerfahrung.

$90 \quad$ Vgl. Huber: Von Zeit zu Zeit, S. 132.

91 Huber/Nyffeler (Hg.): Umgepflügte Zeit, S. 430.

92 Ebd., S. $430 \mathrm{f}$.

93 Ebd., S. 430. 
„Was geschieht beim Hören, wenn gegensätzliche musikalische Inhalte gleichzeitig erklingen, sich übereinanderschieben? Wie steht es mit der Transparenz, mit den Verdeckungsphänomenen? [...] Ist der Eindruck einer Simultanaufführung eine Art Summe der Teilaufführungen, oder entsteht dabei etwas anderes, etwas Neues, ,Protuberanzen'?"94

\section{Auch im Gespräch mit Claus-Steffen Mahnkopf wirft Huber die Frage auf,}

„wie sich denn eine ,Summe $A+B+C$ verhält oder ob nicht durch die Überlagerung ein gänzlich Anderes als eine bloße Summe entsteht. Ein Qualitätssprung, oder eben auch nicht. Eine andere Aura entsteht sowieso, aber darüber hinaus wird eine andere Weise der Rezeption gefordert, sowohl von seiten der Interpretation, aber auch und vor allem von den Hörern.“95

Wie auch andere Komponisten findet Huber einen bildhaften Vergleich aus der Naturwissenschaft, der titelgebend für die Simultanversion ist und der sich wiederum von dem eher systemkritischen Titel Die Enge des Marktes klar abhebt: Das Bild der Protuberanzen, die nur bei einer Sonnenfinsternis sichtbar sind. Dieses bezieht sich wiederum nicht auf den kompositorischen Überlagerungsvorgang an sich, wie beispielsweise das Bild der Zwiebelschichten bei Berio, sondern vielmehr auf das transformatorische Potenzial, das als neue Qualität im Vorgang der Interpretation und Rezeption aus einer Werküberlagerung hervorgehen könnte.

\subsubsection{Simultane Verschachtelung in den Echoräumen für vier Ensembles von Ulrich Kreppein}

Die Echoräume (2016/17) von Ulrich Kreppein (geboren 1979) bestehen aus vier Werken, die jeweils einzeln und auch simultan einander überlagernd aufgeführt werden können. Die vier Einzelwerke Wutraum, Flüsterraum, Angstraum und Spielraum sind kammermusikalisch besetzt und korrespondieren bisweilen in der Besetzung. Idealerweise werden die Spieler um das Publikum herum positioniert:

1. Wutraum: hoher Sopran, Akkordeon, Klavier, Schlagzeug

2. Flüsterraum: zwei Gitarren(Gitarre II ist einen Viertelton tiefer gestimmt)

3. Angstraum: Sopran, (Alt-)Flöte, Violoncello

4. Spielraum: Viola und Akkordeon

94 Ebd.

95 Huber: Von Zeit zu Zeit, S. 157. 
Beschreibung

Der Formplan sieht vor, dass die Einzelkompositionen über den Gesamtablauf von circa zwanzig Minuten durch Schnitte mehrmals unterbrochen werden, sodass nicht permanent alle vier Ensembles gleichzeitig zu hören sind (vgl. Abb. 43). Mithilfe von Zeitangaben können sich die Musiker im Ablauf orientieren und ihre Einsatzzeiten finden. Metrum, Tempo und Form der vier Ensembles sind unabhängig voneinander gestaltet. Die vorgegebenen Tempi dienen nur der Orientierung, eine gewisse Freiheit und Flexibilität in der Tempogestaltung ist möglich. Auch Material und Form sind für jedes einzelne Stück individuell gestaltet. Im Hinblick auf den Zusammenhang verhalten sie sich komplementär zueinander und fungieren als wechselseitige Resonanzräume. Die jeweils mit einem Sopran besetzten Ensemblestücke Wutraum und Angstraum werden durch die stimmliche und textliche Präsenz als führend wahrgenommen.

Das in Wutraum vertonte Gedicht ist das erste Gedicht aus der Sammlung 10 Gedichte des koreanischen Autors Yi Sang (1910-1937). Die Aufzählungsreihung des repetitiven Gedichtes schlägt sich in der variativ geprägten Serienbildung der zweitaktigen ausbruchsartigen Phrasen nieder, die jeweils durch Pausen getrennt und bruchstückhaft aneinandergereiht werden. Unterbrochen und kontrastiert wird die Aufzählungsreihung von geräuschhaften mehrtaktigen Einheiten, die statisch-formale Pendants zu den eher dramatischen Ausbrüchen sind und in ihrer Materialität mit dem Gitarrenduo Flüsterraum korrespondieren. Die Entwicklung der ausbruchartigen Phrasen hin zu einem „Tief“ bei Minute 12:5o folgt einer linearen Logik: Die gestischen Tongruppen schrauben sich nach und nach von der Höhe in die Tiefe, die Dynamik nimmt ab, und das Tempo reduziert sich. Der Neubeginn wird durch einen instrumental geprägten Abschnitt eingeleitet. Er ist mit regelmäßigen eintaktigen Einwürfen des Soprans gespickt, die ihre Abstände zueinander stufenweise verringern und sich durch weite Sprünge und Stufendynamik in eine gewisse Dramatik hineinsteigern, bis zwischen Minute 14:56 und 15:53 ein Maximum an Intensität erreicht wird, auf das ein geräuschartiger Schlussabschnitt folgt. Die dramatische Entwicklung der Musik steht in einem Spannungsverhältnis zu dem surrealistischen repetitiven Text und verwandelt das Stück Wutraum in eine exzentrische und absurde Groteske.

Komplementär zum Stück Wutraum ist das Stück Angstraum als eine fließende melodische Entwicklung gestaltet. Vertont wird in Angstraum das spanische Gedicht Ciudad sin sueño (Nocturno del Brooklyn Bridge) aus dem Jahre 1929/30 von Federico García Lorca (1898-1936). Die in sich kreisenden lyrischen Bögen steigern sich kontinuierlich und wellenartig. Analog zu Wutraum schließen sie mit einem leise gehaltenen Epilog als Reprise des 
Anfangs. Das Stück ist weitgehend geprägt von der melodischen Bewegungsparallelisierung dreier verschiedener Stimmen: der Sängerin, der Flöte und des Cellos.

Die beiden Texte von Angstraum und Wutraum entstanden an unterschiedlichen Orten zu ähnlichen Zeiten, die Stücke vergleichzeitigen daher auch auf dieser Ebene etwas Ungleichzeitiges. Wie die vertonten Sopranlinien einerseits weitgehend aneinander vorbeisingen, dynamisieren sich die beiden Stimmen andererseits in ihrer lyrisch-dramatischen Anlage gegenseitig. Ihre jeweiligen Entwicklungsbögen werden durch die in sich konsistente Gesamtdramaturgie bei 15:00-15:05 zusammengeführt. Der darauffolgende formale Bruch wird aufgefangen durch die beiden Duos Flüsterraum und Spielraum. Im Vergleich mit den anderen beiden Stücken, sind sie in ihrem Verlauf weniger linear und zielgerichtet konzipiert. Das Gitarrenduo Flüsterraum ist in sich als Echokomposition konzipiert, da die Einsätze der beiden Gitarren oft kanonisch sind. Die zweite Gitarre ist vierteltönig scordatiert und reichert dadurch das harmonische Spektrum an.

Das vierte Stück Spielraum für Akkordeon und Bratsche ist für sich genommen ein sehr spielfreudiges Duo. Im Kontext des Poly-Werks gerät es zu einer vibrierenden Unruhefläche und bekommt durch diese Kontextualisierung eine Doppelcodierung. Seinen Formaufbau gewinnt es durch die Übertragung selbstähnlicher, fraktaler Zusammenhänge auf die musikalischen Strukturen und Dauernverhältnisse. Abgesehen von einigen episodenartigen Einschüben ist das Stück stark konzentrisch und von zentralmotivischen Phrasen und Abschnitten ausgehend gedacht.

Form und Interform

Die Form des Gesamtwerks unterscheidet sich von der Form der Einzelstücke. Jedes Werk hat seine eigene Zeitgestalt. Der Formbogen der Metaform ist stark von der zielgerichteten Linearität der textvertonten Stück geprägt. Deren großformale Entwicklungen sind im Hinblick auf die Metaform aufeinander abgestimmt. Dennoch bewegen sich die Binnenentwicklungen sehr frei und flexibel voneinander, geben sowohl Raum für Annäherungen als auch für Reibungen. Sie opfern den Kommunikationsgedanken letztlich einem flexiblen Nebeneinander. So wird die Zielgerichtetheit der Stücke Wutraum und Angstraum zum einen durch die Gegenüberstellung mit den nichtteleologischen Formverläufen in Flüsterraum und Spielraum und zum anderen generell durch die gegenseitige Konfrontation der vier verschiedenen Formbögen relativiert und gebrochen. Der lineare Charakter des Ganzen erfährt durch das Nebeneinander der verschiedenen Linearitäten eine starke Aufweichung. 


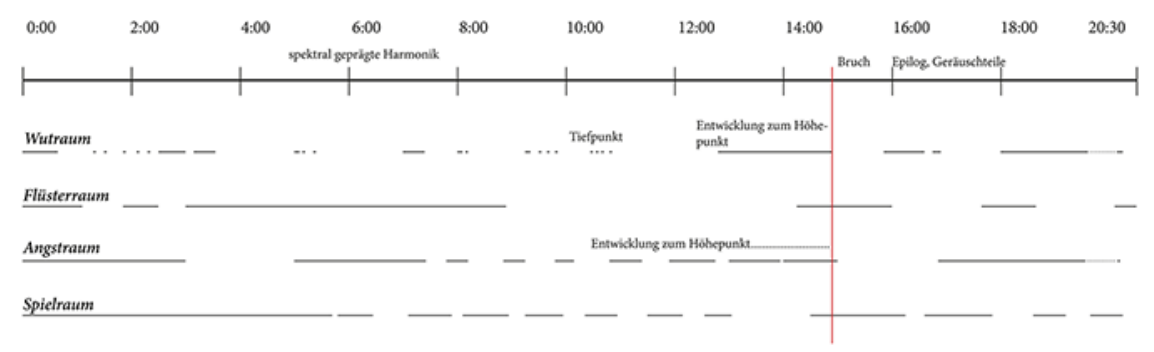

Abb. 43 Form- und Verteilungsplan der vier Werkteile der Echoräume.

Harmonische Bezüge

Ein weiterer interessanter Aspekt ist das harmonische Interverhältnis der Stücke. Nach dem eher unspezifischen Beginn und dem folgenden Geräuschteil beginnen die Stücke ab ca. 5:oo harmonisch aufeinander zu reagieren. Der folgende Abschnitt zwischen 5:00 und 8:0o ist in seiner Harmonik von spektralen Akkorden geprägt. Der spektrale Akkord über C beispielsweise ist bei 5:00 am eindeutigsten in Angstraum gegeben (vgl. Abb. 46), aber auch in der Akkordeonstimme von Spielraum und in Bestandteilen in der ersten Gitarre von Flüsterraum präsent (vgl. Abb. 47 und 45). Das um einen Viertelton vertiefte a der zweiten Gitarre in Flüsterraum passt zur Flötenstimme in Angstraum. Die Harmonik von Wutraum dagegen ist von Clusterakkorden geprägt (vgl. Abb. 44). Konzeptionell passen diese sich aber in das spektrale Denken ein, da jeder harmonische Klang in seinem Spektrum auch über Clusterbestandteile verfügt. Über die verschiedenen Werkversionen findet also ein Funktionswechsel vom freien Cluster hin zum spektralen Bestandteil eines Durakkordes statt. Die zeitliche Flexibilität in Bezug auf die Synchronisation, das Tempo, die räumliche Trennung und die Lautstärke sowie die Lage, Zusammensetzung und Bewegung der Cluster insgesamt machen es allerdings unwahrscheinlich, dass die Wahrnehmung so gedreht werden kann, dass die Cluster in der Gesamtversion tatsächlich als auf den Grundton C bezogen gehört werden könnten. Der Gedanke dahinter ist trotzdem sinnfällig, denn er sieht in erster Linie eine rein konzeptionelle Korrespondenz vor und keine harmonische Zwangsjacke.

Form und Kommunikation

Alle Stücke zeichnen sich durch eine starke und voneinander unterscheidbare Identität aus. Sie verhalten sich komplementär zueinander. Durch die Vergleichzeitigung in der Simultanversion geben sie zwar einen Teil ihrer Identität auf, dafür tritt das Verhältnis zwischen den Stücken als eine neu gewonnene Qualität in den Vordergrund. Die Frage nach dem Verhältnis 
4:57 Min.
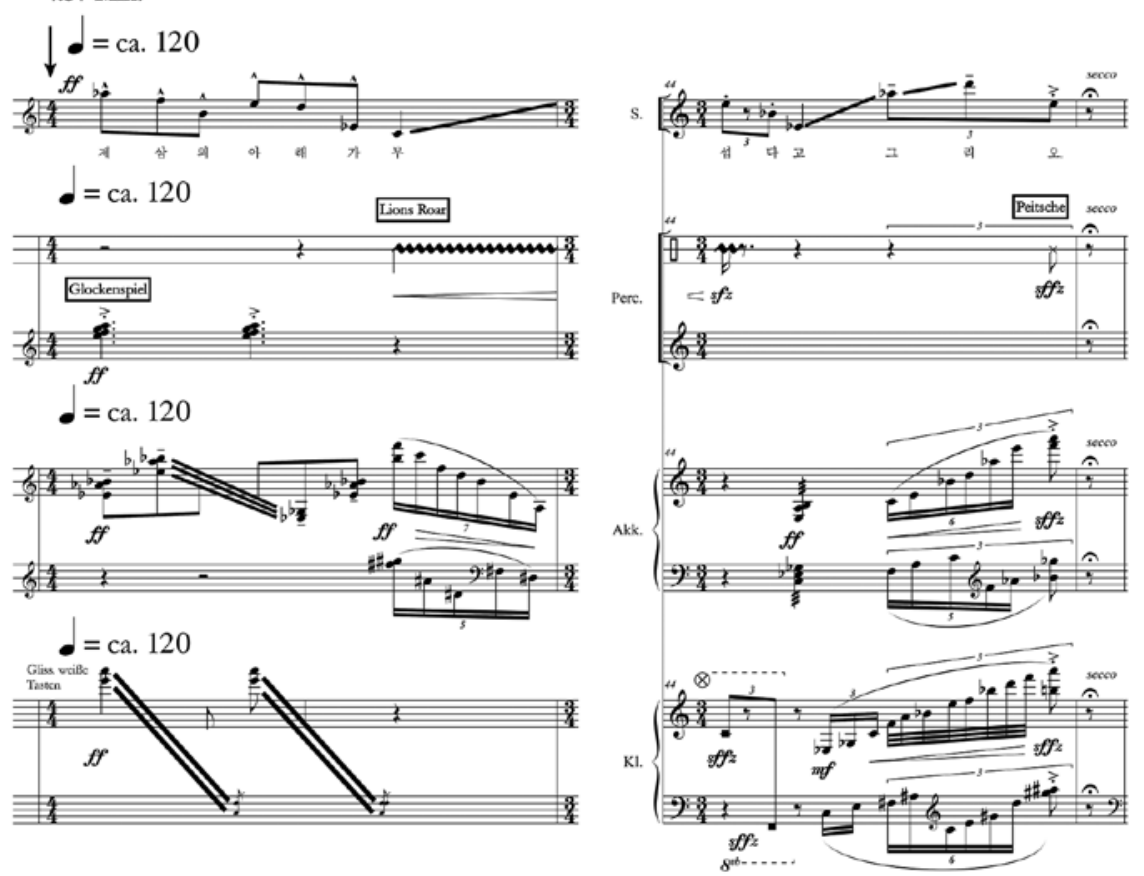

Abb. $44 \quad$ Ulrich Kreppein: Auschnitt aus Wutraum für Sopran, Percussion, Akkordeon und Klavier, 2016, Min. 5:oo. (c) Edition Juliane Klein, Berlin.

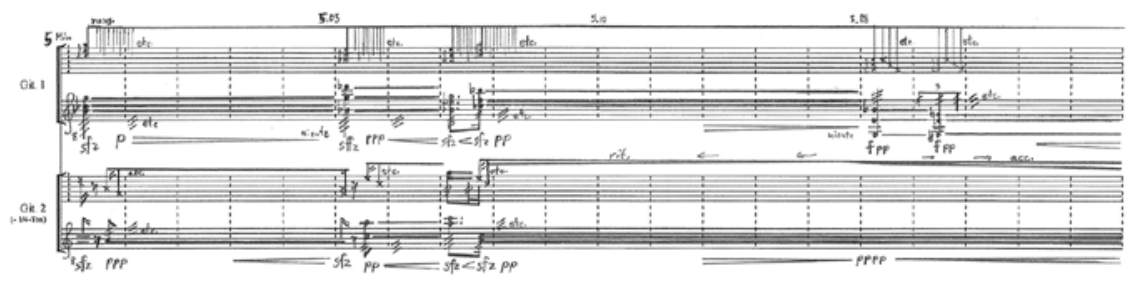

Abb. 45 Ulrich Kreppein: Ausschnitt aus Flüsterraum für zwei Gitarren, 2016, Min. 5:oo. (C) Edition Juliane Klein, Berlin.

der Stücke greift laut Kreppein ${ }^{96}$ ein enthierarchisiertes gesellschaftliches Modell des Nebeneinanders verschiedener gesellschaftlicher Gruppen und Wirklichkeiten auf, die einerseits zwar nicht bewusst und intentional miteinander kommunizieren, aber dennoch aufeinander reagieren. Trotz der simultanen Vergleichzeitigung wird keine eigentliche Synthese angestrebt. Aus kompositorischer Sicht geht es für Kreppein um die Integration des

96 Der Komponist im Interview mit der Verfasserin am 2.8.2019 in Weimar. 


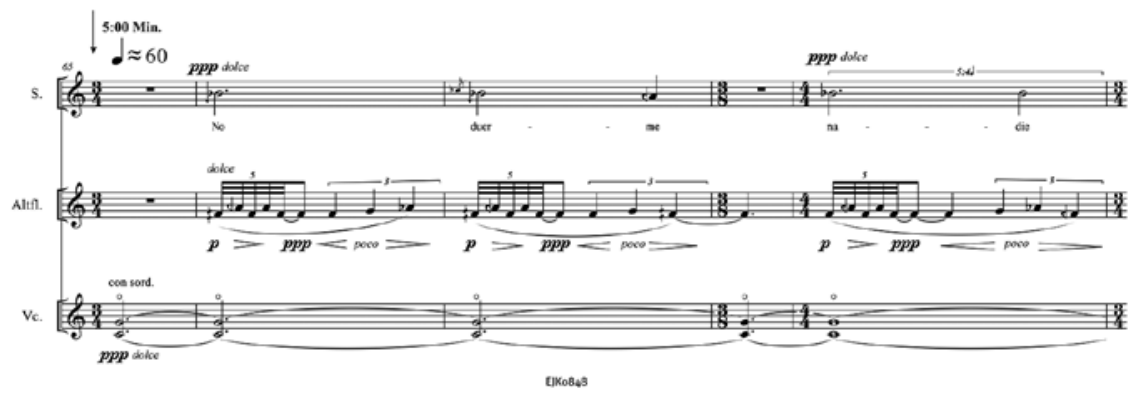

Abb. $46 \quad$ Ulrich Kreppein: Ausschnitt aus Angstraum für Sopran, Altflöte und Violoncello, 2016, Min. 5:oo. (C) Edition Juliane Klein, Berlin.
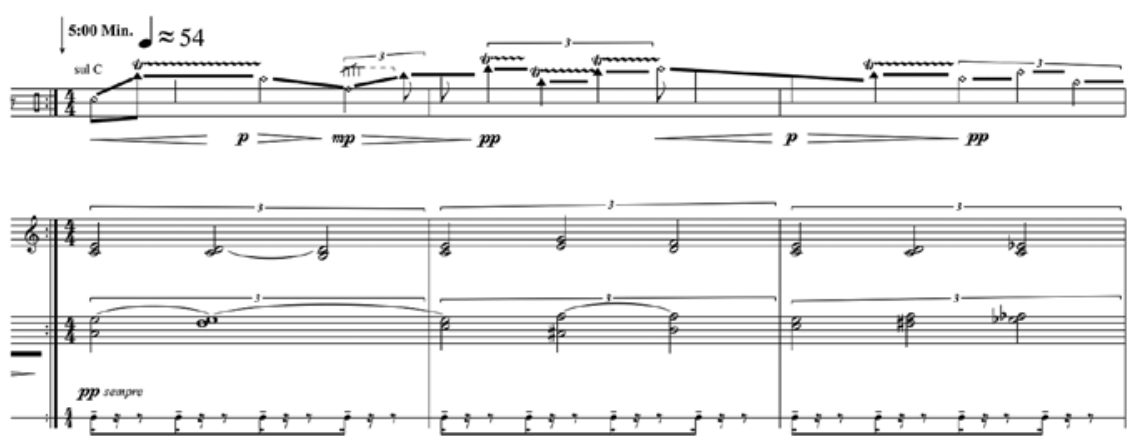

Abb. $47 \quad$ Ulrich Kreppein: Ausschnitt aus Spielraum für Bratsche und Akkordeon, 2016, Min. 5:oo. (C) Edition Juliane Klein, Berlin.

Verschiedenartigen und um eine Wahrnehmungserfahrung, die das Auseinanderhören dieses Verschiedenartigen, wenn es sich im Zusammen befindet, ermöglicht. Das Stück zielt in der Einheit nicht auf Einheit. Doch selbst wenn man die Gruppen nicht auseinanderhören kann, weil durch die Simultaneität auch noch so verschiedene Ereignisse vom Hörer aufeinander bezogen würden, dann würde die Intention des „Getrenntseins im Zusammensein" auf andere Weise eine erweiterte Hörerfahrung einschließen. Im Gegensatz zu seinem früheren Lehrer Tristan Murail, der die These vertritt, es gebe keinen Kontrapunkt ${ }^{97}$, sieht Kreppein das Konzept von Polyphonie und Kontrapunkt vor allem als eine produktive Utopie:

97 Kreppein bezog sich im Interview auf seinen Lehrer Tristan Murail, der diese These vertreten habe. 
„Selbst wenn es keine Polyphonie gibt, ist die fehlerhafte Annahme, dass es sie gäbe, für die Musik immer besser. Sie erzeugt ein Klangergebnis, das vielleicht nicht tut, was es soll, denn vielleicht höre ich es nicht auseinander, aber dafür gibt sie einem Klang Tiefe und Vielfältigkeit.“98

\section{Zusammenfassung}

Die vier heterogenen Werke setzen sich aus den zwei vokal geführten Kammermusikensembles I und III - von denen das eine eher einen extrovertierten, das andere einen lyrisch-melodischen Charakter hat - und zwei unterschiedlichen Instrumentalduos zusammen. Beide Ensembletypen haben in der Gesamtfassung unterschiedliche Funktionen. Die vokal geführten Stücke werden als führend wahrgenommen und verleihen dem ganzen Stück einen stark musikdramatischen Anstrich. Die zwei monologartigen Gesangspartien bilden eine Art Hauptbühne. Sie verhalten sich zwar weder diskursiv noch dialogartig, treiben sich in ihrem divergierenden Nebeneinander dennoch gegenseitig voran und erfahren durch die eindringliche Präsenz des anderen eine Intensivierung. Im Gesamtkontext bilden die Instrumentalduos dagegen eine Art Hinterbühne, die den Klangraum weiter verdichtet. Vor allem das Gitarrenduo hat eher eine subkutane Funktion und bildet einen murmelnden Teppich. Trotz dieser auf den ersten Blick unterschiedlichen akustischen Gewichtung werden durch die pausendurchsetzte Verschachtelung der Werkabschnitte über den Gesamtablauf fensterartige Strecken ermöglicht, die die introvertierten Abschnitte immer wieder durchscheinen lassen. Für das Ganze entsteht dadurch ein spannungsvolles Spiel der Konstellationen, ein permanentes Fluktuieren und Ineinandertauchen in der zeitlichen und räumlichen Sichtbarmachung und Präsenz der einzelnen Werkstränge.

Auch die zeitliche Unabhängigkeit der Stücke und ihre imperfekte Synchronisation unterstreichen das Nebeneinander der Stränge und damit die Autarkie der Ensembles. Andererseits werden die voneinander unabhängigen innerformalen Entwicklungen und Zeitcharaktere in der Gesamtform durch die Schnitte und die entsprechende dramaturgische Verteilung der Abschnitte auf eine Metaform mit einem übergreifenden Hoch- und Tiefpunkt und einem gemeinsam auslaufenden Schluss ausgerichtet. Neben diesen formalen Brücken gibt es auch in der Instrumentation mit ihren vielfältigen klangfarblichen Korrespondenzen und der Harmonik gemeinsame Bezugspunkte wie die Spektralklänge, deren konsonante und dissonante Komponenten als harmonisches Material auf die Stücke verteilt werden. Die so erzeugten Brücken zwischen den Ensembles sind nur lose Verbindungen, die Bezüge

98 Zitat des Komponisten während des Interviews am 2.8.2019 in Weimar. 
ermöglichen, das Verhältnis von Freiheit und Bindung ausbalancieren und der Divergenz der Werkverläufe eine gemeinsame Richtung zu weisen vermögen.

\subsection{Raum und Form}

Die Simultaneisierung im Poly-Werk bringt die verschiedenen Werkstränge nicht nur in einen gemeinsamen Zeitrahmen, sondern ebenso in einen gemeinsamen räumlichen Rahmen. Für ein entsprechendes Hörerlebnis ist daher auch die Form der räumlichen Inszenierung entscheidend. Sowohl der Raum als integrales Ganzes als auch die Aufführungsorte innerhalb des Raumes und ihre Beziehung zueinander sind aufführungspraktische Parameter, die für die Interpretation und die Wahrnehmung des Poly-Werks nicht zu unterschätzen sind. Durch den realen physischen Raum und eine differenzierte und raumspezifische Aufstellung wird das Werk noch einmal geformt. Die räumliche Disposition, also die Verteilung der Spielorte im Raum, kann dabei auch zum Interpretationsschlüssel der oft mehrdeutigen Werkbeziehungen werden. Da sie das Mit-, Neben-, Gegen- oder Ohneeinander der Spieler prägt und untermauert, kann sie auch den Eindruck der Verbunden- beziehungsweise Getrenntheit der Werkebenen beeinflussen. So schreibt Klaus Huber für die Trioversion seines Stückes Schattenblätter aus dem Jahre 1975 eine räumliche Separierung der drei Spieler bei der Aufführung vor: „In der Trioversion bewahrt die räumliche Trennung der Spieler auf der Bühne sie davor, zu einem Körper zu verschmelzen, auch wenn sie einander gewahr sind. ${ }^{49}$ Die Instrumentalstimmen Klavier, Cello und Bassklarinette können außer in der Triofassung in drei Duofassungen gespielt werden. Darüber hinaus bildet auch der Klavierpart ein autonomes Solowerk. Bereits die räumliche Trennung der Performer in der Trioversion, ihre nur lose Verbindung verstärkt den Eindruck von Einsamkeit und Isolation der einzelnen Stimmen und ist eine Art vorbereitender Schritt in Richtung einer zeitlichen Trennung der Instrumentalschichten, die die implizite Isolation der Spieler noch weiter verschärft.

Wie in vielen Kompositionen des 20. Jahrhunderts, in denen die formale Logik nicht der kausalen und zeitlichen Logik einer teleologischen Gerichtetheit folgt, gewinnt - wie einst in der venezianischen Mehrchörigkeit und im Frühbarock - die räumliche Interpretation an Bedeutung und Ausdruckskraft. Da bei vielen Simultankonstellationen und Poly-Werken das überblickbare Ganze in Form einer Partitur nicht mehr selbstverständlich ist, ist auch die Frontalsituation des Konzertsaals, die dem Auge ähnlich wie die Partitur 
einen Überblick über die Bühnensituation liefert, in vielen Fällen nicht mehr sinnvoll. Sie sollte aufgegeben werden zugunsten einer räumlichen Hörpraxis, wie sie in der zeitgenössischen Musikpraxis zum Teil bereits selbstverständlich geworden ist. Die Stücke up down strange charm des Komponisten Robert HP Platz wurden für spezifische Räume komponiert und sollen der besseren Durchhörbarkeit der polyphonen Schichtungen wegen als Raummusik aufgeführt werden. ${ }^{100}$ Der Komponist Bernd Franke nutzt für seinen Zyklus halfway house - Solo xfach den Raum für choreografische Figurenbildungen der Musiker. Ulrich Kreppein befürwortet darüber hinaus eine Beweglichkeit der Hörer. Sie sollten nicht mehr in eine fixe Hörsituation gezwungen werden, sondern das Ohr könne selbst als Orientierungsorgan fungieren. Ihre Körper könnten sich anhand des eigenen und individuellen Hörens durch die Räume leiten lassen. So könne die Entscheidung über die Hörperspektive selbst getroffen, der zu hörende Weg durch das Ganze selbst gestaltet werden. Auch verwinkelte Räume kämen laut Komponist in Betracht. Sie unterstützten die getrennte Wahrnehmung der Stücke. ${ }^{101}$ Auch der Komponist Valerio Sannicandro reflektierte im Gespräch verschiedene räumliche Aufführungsformen seiner beiden Orchesterwerke Windströme und Seelenströme, die entweder einzeln oder gleichzeitig gespielt werden können. ${ }^{102}$ Für ihn ist es ebenso denkbar, dass beide Werke in zwei voneinander getrennten Räumen aufgeführt werden, wobei einzelne Instrumente auch elektronisch in den jeweils anderen Raum übertragen werden könnten. Das müssten nicht alle Instrumente sein. Der Klangregisseur sei frei, darüber zu entscheiden. Das entgegengesetzte Modell sei die Aufführung beider Orchesterstücke in einem einzigen Raum. Hier wäre für den Komponisten auch eine ineinander verschränkte Sitzordnung der Musiker beider Werke denkbar, die die zwei Werke in den Zustand einer einzelnen Werkentität führen würde.

Auch wenn die räumliche Ebene durch den Komponisten in der Regel offengelassen und nicht spezifiziert wird, kann die Funktion des Räumlichen für die Interpretation des Poly-Werks nicht hoch genug eingeschätzt werden. Einerseits führt die Überlagerung der einzelnen Werkräume zu einer Intensivierung des physischen Raumgefühls. Andererseits ist es erst die räumliche Disposition, die die Kon- und Divergenzen unterstreicht und die Interpretation des Verhältnisses plastischer erfahrbar macht. Der Komponist Vinko Globokar beispielsweise empfiehlt, den zeitlich frei wählbaren Formablauf

100 Vgl. Robert HP Platz, Werkkommentar zu up down strange charm, https://www.rhpp.de/ index.cfm?id=36o7 (letzter Aufruf am 1.1.2021).

101 Ulrich Kreppein im Interview mit der Verfasserin am 2.8.2019 in Weimar.

102 Valerio Sannicandro im Gespräch am 12.8.2019 in Zürich. 
in seinem Werk Laboratorium ${ }^{103}$ - einer Sammlung von 55 Stücken für zehn Instrumente, welche auch diverse Möglichkeiten einer sich überlappenden und verschachtelten Anordnung bietet - an den Aufführungsraum und den Aufführungszweck anzupassen.104 Tendenziell evoziere eine traditionell frontale Konzertsituation eher eine lineare und sukzessiv orientierte Fassung. Sei das Publikum im Raum anders verteilt und könnten sich die Musiker frei im Raum bewegen, spreche das eher für eine Form, die die Stücke auch simultan hervorbringe. ${ }^{105}$ In diesem Fall forme der Raum die Zeit, denn der spezifische Konzertsaal werde zu einem maßgeblichen Faktor, der konkrete Auswirkungen auf die zeitliche Ordnung habe.

103 Laboratorium von Vinko Globokar ist in erster Linie eine lose Sammlung von 55 Stücken, die im Rahmen einer zehnköpfigen Maximalbesetzung mit Violine (alternativ Viola), Kontrabass (alternativ auch Cello oder E-Bassgitarre), Oboe (auch Englischhorn/Flöte), Klarinette (auch Bassklarinette/Saxophon), Trompete oder Horn, Posaune oder Tuba, zwei Schlagzeugern, Klavier und Harfe unterschiedlich instrumentiert und durch elektronisches Equipment ergänzt werden. Die Größe der Besetzung verhält sich zahlenmäßig umgekehrt zur Häufigkeit ihres Vorkommens. So gibt es zehn Solos, neun Duos, acht Trios usw... . Das Partiturbild ist eine Mischung aus traditioneller Notation, Grafik, Text und detaillierter Symbolnotation mit sowohl freier als auch gebundener Metrik. Indem die Stücke auf der Ebene der Tonhöhen auf einer einzigen Reihe basieren und auch das rhythmische Material auf einem gemeinsamen Fundus von zehn rhythmischen Ausgangstakten zurückgreift, verfügen die Stücke über eine gemeinsame Wurzel. Ihre spezifische Identität ziehen sie primär aus einer bestimmten thematischen Auseinandersetzung mit dem Thema der Aufführungspraxis. Auf elementaren und komplexen Ebenen werden Themen wie Klangerzeugung, Spieltechniken und die Kommunikation zwischen den Spielern, aber auch zwischen Spieler und Publikum konzentratartig beleuchtet. Sie werden musikalisch, experimentell, textlich, performativ, pädagogisch und körperlich reflektiert, demonstriert und dem Publikum teilweise auch erklärend vermittelt. Stücke wie Res/As/Ex/Inspirer, Échanges, Toucher, Voix instrumentalisées, Corporel und Limites sind im Werkverzeichnis als eigenständige Werke aufgeführt. Sämtliche Stücke sind jeweils in sich abgeschlossen und beim Verlag auch als Einzelkompositionen erhältlich. In der Partitur sind sie zu einer durchnummerierten Sammlung von „Werkstattstücken“ zusammengefasst. Sie können sowohl einzeln als auch im frei zu wählenden Verbund mit anderen Stücken gleichermaßen sukzessive, überlappend oder verschachtelt aufgeführt werden. Aufgrund des verbindenden Tonhöhen- und Rhythmusmaterials gibt Globokar die Option an, jedes einzelne Stück auch simultan mit jedem anderen Stück zu spielen. Dadurch eröffnet sich ein unendliches Möglichkeitsfeld, die Stücke untereinander zu kombinieren.

104 Siehe Vorwort zur Partitur: Vinko Globokar: Laboratorium, 1973-1985, Leipzig: Edition Peters.

105 Siehe ebd. 
„In principle, $n+1$ times can exist $[\ldots]^{106}$

(Georges Gurvitch)

„Social Time is the time of the convergengy and divergency of movements of the total social phenomena [... ]“107

(Georges Gurvitch)

Die Relation von Gleichzeitigkeit und Ungleichzeitigkeit im Bezug auf räumliche Verhältnisse verweist auf eine ambigue Vielförmigkeit der Kategorien Raum und Zeit. Die im vorigen Kapitel diskutierte räumlich-physische Gestaltung eines Poly-Werks ist vorrangig performativer Natur. Sie wird durch die Form und Gestalt des Aufführungsortes und die Kreativität der Musiker geprägt. Die zeitliche Struktur ist dagegen primär eine kompositorische Kategorie. Sie ist einerseits im Spannungsverhältnis der Zeitordnungen sukzessiv und simultan angesiedelt, andererseits auch in Bezug auf das Verhältnis von Gleichzeitigkeit und Ungleichzeitigkeit zu sehen, die in den meisten Fällen deckungsgleich mit der Idee der Vergesellschaftung und der Vereinzelung ist. Auf der Ebene der Zeiterfahrung verschränken sich im Poly-Werk die Bedeutungsdimensionen aller drei Begriffspaare. Denn immer wird die sukzessive Zeiterfahrung des einen Stückes in die simultane Zeiterfahrung mehrerer Stücke überführt. Jedes Poly-Werk vereinigt in sich demzufolge beide Möglichkeiten der Vergleichzeitigung und der Verungleichzeitigung. Auf der Ebene der interformalen Metakonstellation gibt es aber mehrere Abstufungen (vgl. Kapitel 3.4): Die vereinzelte Aufführung, die sukzessive Aufführung, die sukzessiv-simultane Aufführung und die simultane Aufführung. Die simultane Aufführbarkeit gilt im Poly-Werk als Bedingung. Für die meisten Poly-Werke stehen die Möglichkeiten der Einzel- und der Simultanaufführung zur Auswahl. Für eine sukzessive Ordnung der Stücke im Fall dass sie nacheinander gespielt werden, sind typischerweise keine Hinweise in den Partituren zu finden. Lediglich für Werke, die sich nur teilweise überlappen, existiert eine sukzessive Ordnung, die auch in der Vergleichzeitigung maßgeblich bleibt, so in Klaus Hubers Orchesterwerk Protuberanzen (vgl. Kapitel 4.3.4). Eine vereinzelte Aufführung der Miniaturen schließt Huber zwar nicht explizit

106 Georges Gurvitch: „The Problem of Time“ (1964), in: John Hassard (Hg.): The Sociology of Time, Hampshire/London: The Macmillan Press, 1990, S. 35-44, hier: S. 37.

107 Georges Gurvitch: „Varieties of Social-Time“ (1964), in: Hassard (Hg.): The Sociology of Time, S. 67-76, hier: S. 67 . 
aus, ${ }^{108}$ aber aus der Partitur ist herauszulesen, dass er vor allem zwischen einer sukzessiven (statt einer einzelnen) Folge der Stücke und einer simultanen die letztlich eine sukzessiv-simultane ist - unterscheidet.

Die Möglichkeit, einerseits zwischen der einzelnen, der sukzessiven und der simultanen Zeit zu wechseln oder diese andererseits auch miteinander zu verbinden, verstärkt den mehrdimensionalen Charakter von Zeit. In Anlehnung an den Diskurs über „Soziale Zeit“109 in den Sozialwissenschaften ist zeitliche Gestaltung im Poly-Werk vor allem auch im Kontext des Zusammenhangs von innerer Ausdifferenzierung der Eigenzeit eines Werkstrangs und interzeitlichen Verhältnissen im Metawerk zu sehen. Das interzeitliche Verhältnis setzt sich aus der technischen Synchronisation und der qualitativen Vernetzung der verschiedenen Linearitäten zusammen.

Da bereits die Eigenzeit eines einzelnen Werkes aus dem Zusammenspiel mehrerer Parameter heraus gestaltet wird, ist auch die translineare Zeitgestaltung von der Relation der einzelnen Zeitfaktoren geprägt. Ein wesentlicher zeitlicher Parameter ist das metrische Raster, das - zusammen mit der Tempoangabe - ein Musikstück in zeitlich-diskrete Basiseinheiten gliedert, die musikalischen Bewegungen koordiniert und den Interpreten eine zeitliche Orientierung ermöglicht. Auch wenn die musikalische Metrizität in neuer Musik in vielen Fällen nicht Gleichmaß bedeutet, sondern asymmetrisch angelegt ist, ist ihre strukturierende Funktion ungefähr vergleichbar mit der objektiven Uhrzeit, die den Tagesablauf in gleichmäßige Zeiteinheiten unterteilt und dadurch die Synchronisation verschiedener Tätigkeiten ermöglicht. In die ordnende Rhythmizität des metrischen Rasters sind die rhythmischen Strukturen eingebettet. Je nach Gestaltgebung und Differenzierungsgrad kann für den Hörer der Nachvollzug der metrischen Ordnung entweder betont oder verschleiert sein. Doch selbst wenn das Taktgerüst als solches nicht direkt erfahrbar ist, strukturiert es die Temporalität des Materials, koordiniert die Konvergenz und Divergenz der musikalischen Bewegungen verschiedener Instrumente, prägt und (in)stabilisiert die rhythmischen Strukturen, die noch mal in größere syntaktische Einheiten und mikro- und makroformale Prozesse eingebettet sind. Auch diese bilden wiederum zeitliche Raster und Strukturen ab, die dem Hörer zeitliche Orientierung ermöglichen. Das Zusammenspiel all dieser Faktoren erzeugt ein zeitliches Bezugssystem und formt die individuelle Eigenzeit eines Werks.

\footnotetext{
108 Vgl. Huber: Von Zeit zu Zeit, S. 157.

109 Einen Einstieg in den von Émile Durkheim ausgehenden Diskurs bietet das von John Hassard herausgegebene Buch The Sociology of Time, das verschiedene Schriften u. a. von Pitirim Sorokin und Robert Merton (Social-Time. A Methodological and Funcional Analysis, 1937) oder Georges Gurvitch (Varieties of Social-Time, 1964) versammelt.
} 
Die Konvergenz oder Divergenz der einzelnen Werkstränge artikuliert sich - außer in der Materialbehandlung - im Wesentlichen über die Gestaltung zeitlicher Verhältnisse. Da sich die Eigenzeit eines Werkes bereits aus verschiedenen Zeitfaktoren zusammensetzt, können einzelne Faktoren auf die Konvergenz der Werke zielen, während andere Faktoren auf eine Divergenz ausgerichtet sind. Beispielsweise können zwei Streichquartette isochron sein (das heißt über die gleiche Dauer verfügen) und eine identische Makroform besitzen, aber in der metrischen Unterteilung und in der Tempowahl voneinander abweichen, wie es im Anea Crystal Cycle von Chaya Czernowin der Fall ist (vgl. Kapitel 4.3.2). Umgekehrt kann die Übereinstimmung des Taktgerüsts mit dem Aus- und Zueinanderstreben zeitlich-formaler Prozesse einhergehen, wie es Milhaud in seinen beiden Streichquartetten praktiziert (vgl. Kapitel 4.3.1). Zeitliche Spannungsverhältnisse werden in beiden Fällen erzeugt. Sie ziehen ihre Wirkung immer aus der individuellen Verknüpfung einer synchronen oder asynchronen Organisation und der in ihnen eingebetteten konvergierenden und divergierenden musikalischen Prozesse.

Die analysierten Werke bilden eine breite Palette der Zeitgestaltung ab. Auf der einen Seite schöpft der Zyklus Next To Beside Besides von Simon Steen-Andersen seine Kraft aus einer extremen Synchronisation metrischer, rhythmischer, formaler und kinetischer Musterbildungen und bildet auf der zeitlichen Ebene gar keine Differenzen aus. Auf der anderen Seite entsteht der Reiz derEchoräume von Ulrich Kreppein aus einer hochgradigen Polytemporalität, die heterogene Metren, Rhythmen und Formprozesse in ein fragiles Verhältnis bringt. Aber auch hier sorgen bewusst kalkulierte Fluchtpunkte dafür, dass sich die divergierend bewegenden Linearverläufe harmonisch und formal schneiden, sich aus verschiedenen Richtungen auf einen gemeinsamen Hochund Tiefpunkt zubewegen. Der schmale Grat zwischen Freiheit und Bindung wird dadurch nachvollziehbar ausbalanciert und eine stabilisierende Metaform des Ganzen geschaffen.

Die meisten Poly-Werke verfügen über ein in Tempo und Metrum einheitliches Zeitraster. Es ist zu vermuten, dass polytemporale Raster zwischen den Werken größtenteils auch deswegen vermieden werden, weil sie in der Koordination verschiedener Tempi aufführungspraktische Erschwernisse mit sich bringen. Beispielsweise gibt Klaus Huber im Gespräch mit Claus-Steffen Mahnkopf an, dass er bei den Protuberanzen Polytempik in Erwägung zog, aber diese Idee aus pragmatischen Gründen verwarf. Stattdessen entschied er sich für sehr einfache Tempiverhältnisse wie Achtel $=100$ und Viertel $=5^{0} .{ }^{110}$ Die 2/4-Takte 29-47 des Märschleins aus dem ersten Stück werden in das

110 Siehe hierzu Huber: Von Zeit zu Zeit, S. 156. 
5/4-Metrum der Implosion übertragen, wodurch die beiden Stücke in der überlappenden Fassung eine identische Metrum- und Tempoangabe besitzen.

Erst in jüngerer Zeit werden technische Tools entwickelt, die eine unkomplizierte Synchronisation verschiedener Tempi auf der Bühne ermöglichen und zukünftig auch die Möglichkeiten der Zeitgestaltung im Poly-Werk erweitern werden.111 Bisher werden die einzelnen Werkstränge tendenziell über abweichende mikro- oder makroformale Prozesse in ein zeitliches Spannungsverhältnis gebracht und auf diese Weise polytemporale Wirkungen erzeugt. Beispielsweise ist der Zusammengang von Solo- und Ensembleschicht in den Chemins II auf Einheitlichkeit gerichtet. Dennoch trennen sich die Wege beider Spuren im Abschnitt O (vgl. Kapitel 4.1.1). Das Ensemble übernimmt die Texturen der Violaschicht. Die Viola verfolgt ab $\mathrm{O}$ eine melodische Linie (vgl. Abb. 48).

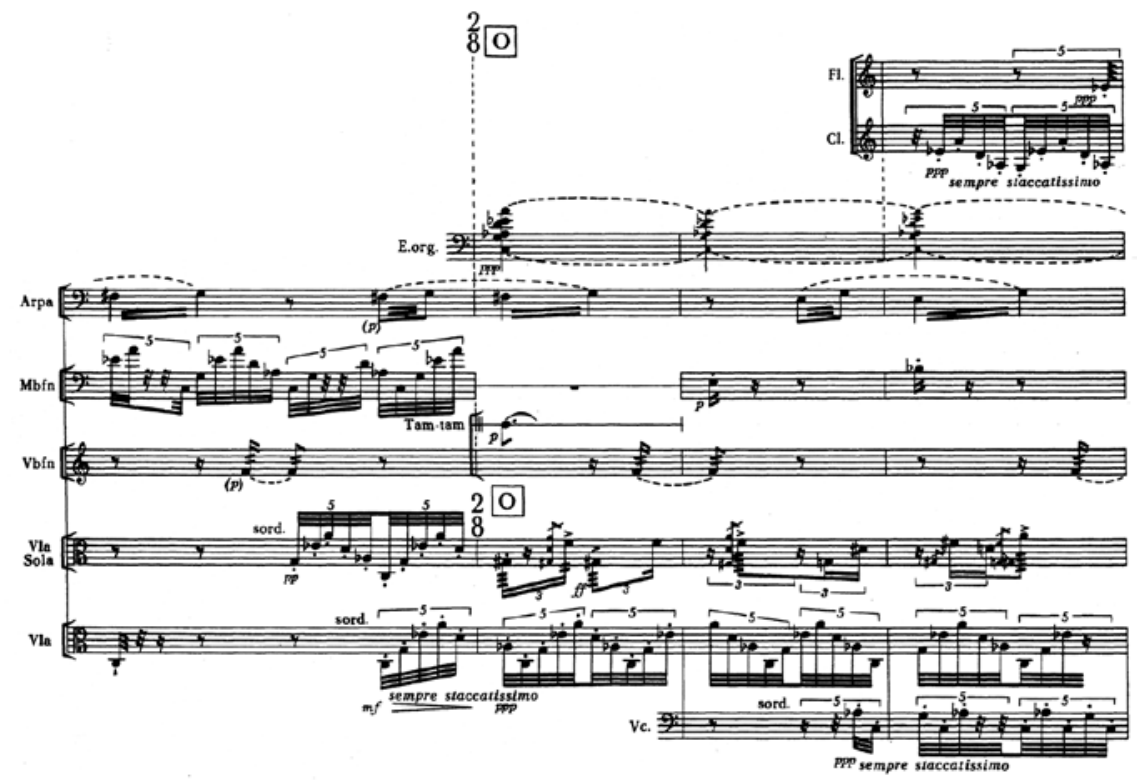

Abb. 48

Luciano Berio: Chemins II su Sequenza VI, 1967, Takte 191-194. ( 1972 by Universal Edition (London), Ltd., London, (C) assigned to Universal Edition A. G., Wien.

111 Siehe hierzu Philippe Kocher: „Visuelle Synchronisierung. Musizieren mit computergestützter Tempovermittlung“, in: Neue Zeitschrift für Musik 3, 2018, S. 42-45, sowie The Polytempo Network und The Polytempo Composer, https://polytempo.zhdk.ch/ (letzter Aufruf am 1.1.2021). 
In den beiden Streichquartetten Nr. 14 \& 15 von Darius Milhaud, in denen Dauer, Taktung, Tempo und Makroform übereinstimmen (vgl. Kapitel 4.3.1), berühren und brechen sich die Stimmen der Quartette immer wieder in ihren rhythmischen Bewegungszügen, synchronisieren sich im gemeinsamen Puls, streifen sich für den Moment einer Synkope und stoßen sich auf Treffpunkten gemeinsamer Impulse umso kraftvoller wieder voneinander ab. Zwischen den punktuellen Momenten der Anziehung im Kleinen und dem großen gemeinsamen Zeithorizont ist der Zusammengang der Quartette durchgehend geprägt von mikroformalen Reibungen und den Verschiebungen syntaktischer Einheiten. In diesen zeitlichen Ambivalenzen spiegelt sich die konfliktäre Themen- und Motiventwicklung wider.

Auch in den Streicherstücken aus dem Yuunohui Cycle von Julio Estrada dient ein gleichmäßiges, dem Sekundpuls nachempfundenes Zeitraster der simultanen Koordination der verschiedenen Soli. Dieses abstrakte, im Hintergrund strukturierende und dennoch als solches nicht offensichtliche Zeitraster findet seine Entsprechung in der inneren, abstrakten Materialstruktur, die in ihrer einheitlichen Logik als solche nicht hörbar ist, aber dennoch die verschiedenartige Gestalt- und Formenbildung der Solostücke determiniert und verknüpft (vgl. Kapitel 4.2.1.2.1).

In vielen Poly-Werken korrelieren die konfliktären Formprozesse mit dem Aufbrechen des Materials, werden aber an ein übergreifendes homogenes Raster gekoppelt, das die auseinanderstrebenden Material- und Formprozesse synchronisiert und zusammenhält. Klaas Coulembier bezeichnet das für alle Werkstränge einheitliche Zeitraster im Medusa-Zyklus von Claus-Steffen Mahnkopf als stärkste verbindende Kraft. ${ }^{112}$ Das Raster wurde von Mahnkopf für das Oboensolo Gorgoneion am Beginn des Kompositionsprozesses entworfen und dann auf den gesamten Zyklus angewendet. Auf der Grundlage dieses Top-down-Ansatzes wurden dann die individualisierten Materialund Formentwicklungen der Stücke weiterkomponiert und auf diese Weise divergierende Eigenzeiten geschaffen. ${ }^{113}$

Zusammenfassend lässt sich im Zusammenhang zwischen Materialund Zeitgestaltung eine eindeutige Tendenz feststellen: Je gleicher sich

\footnotetext{
112 Vgl. hierzu Coulembier: Multi-temporality, S. 179: „The temporal grid as defined by the time signatures and tempos is the strongest unifying force of Medusa."

113 Interessanterweise wählt Mahnkopf im Kammerzyklus eine noch formalistischere Vorgehensweise. Auch hier sind das metrische Raster und die Tempoverhältnisse der einzelnen Stücke in der simultanen Aufführungsform identisch. Jedoch ändert er neben der Dynamik und der Artikulation auch die Tempoangaben in den herausgeeinzelten Fassungen, während Metrik, Rhythmik und Tonhöhenverlauf als innerhalb des Notensystems festgeschriebene Parameter deckungsgleich kopiert werden.
} 
die Werkstränge in ihrem Material sind, desto höher ist auch der zeitliche Synchronisationsdruck. Die Anwendung einer tatsächlichen heterogenen Metrisierung betrifft nur wenige Werke, die dann zumeist auch in ihrer Materialität inhomogen und nicht auf einen gemeinsamen Ausgangsgedanken zurückführbar sind. So entwickelt Chaya Czernowin im Anea Crystal Cycle in den Abschnitten A, C und E zwei unterschiedliche Materialstränge und unterstreicht die Ungleichheit der Stücke Seed I und Seed II durch eine voneinander abweichende und unabhängige Metrisierung und Polytempik. Die Abschnitte B, D und F, die wiederum eine Symbiose beider Materialien vollziehen und zu einem für beide Quartette einheitlichen Material führen, stimmen auch in ihrer Metrik, Tempik und Rhythmik exakt überein (vgl. Kapitel 4.3.2).

Auch Ulrich Kreppein wählt für seine vier in ihrer Materialität inhomogenen und unabhängigen Echoräume konsequent Polytempik und individuelle metrische Raster. Dadurch erzeugt er eine tatsächliche Koexistenz von vier selbstständigen und divergierenden Eigenzeiten. Zusätzlich intensiviert er das Nebeneinander der Werkstränge durch die Angabe von Orientierungszeiten, die von den Musikern approximativ zu nehmen sind. Im vorgegebenen Rahmen wird den Interpreten dadurch ein individueller Spielraum für die zeitliche Gestaltung ermöglicht. Auch Bernd Franke nutzt diese Möglichkeit und gibt in seinem Zyklus Orientierungszeiten an, von denen bis zu fünf Sekunden abgewichen werden kann. Die Aufhebung der Starrheit metrischtemporaler Vorgaben bei Kreppein geht mit dem Verzicht auf ein Dirigat einher, befördert die Ästhetik einer imperfekten Synchronisation zwischen den Werken und unterstützt damit die zeitliche Unabhängigkeit. Zwischen der Dichotomie einer streng synchronisierten Gleichzeitigkeit auf der einen Seite und der Ungleichzeitigkeit auf der anderen Seite tut sich so ein neuer Raum einer imperfekten Gleichzeitigkeit auf, die sich dem Synchronitätsgedanken widersetzt und für jene Differenzierungen zwischen „Fast-Gleichzeitigkeit und Ungleichzeitigkeit" sensibilisiert, die der Komponist Sandeep Bhagwati in einem Essay geradezu beschwört:

„Wäre es nicht besser zu genießen wie vielfältig schillernd verschiedene Zeitströme aneinander vorbeigleiten? Zu lernen, ihre Differenziale wie feine Gewürze zu erschmecken? Zu unterscheiden, wie verschiedene Arten von Fast-Gleichzeitigkeit und Ungleichzeitigkeit sich nicht nur quantitativ, sondern auch qualitativ unterscheiden? Wenn es eine Kunst gäbe, die sich genau diesem Lernen, Unterscheiden, Genießen verschiedenster Zeitströme im und jenseits des Menschlichen widmen würde?"114

114 Sandeep Bhagwati: „Anti-Kairos oder:Vom Aushalten des Ungleichzeitigen“, in:Positionen. Texte zur aktuellen Musik 123, 2020, S. 43-53, hier: S. 52 . 
Die Verschiedenheit der Eigenzeitcharaktere, die sich in heterogenen PolyWerken in der Vergleichzeitigung der Werkstränge als zentrale Erfahrung artikuliert, ist in vielen Poly-Werken auch im Spannungsfeld zwischen der Vergleichzeitigung und der Vereinzelung erfahrbar. Analog zur Zunahme der Besetzungsgröße finden zeitliche Verdichtungsprozesse statt, die zu einer höheren zeitlichen Aktivität führen, so wie umgekehrt die Auseinanderfaltung zeitlicher Verläufe in die Ungleichzeitigkeit eine Entdichtung nach sich zieht.

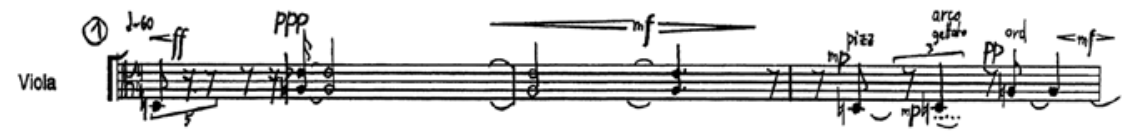

$\mathrm{Va}$.
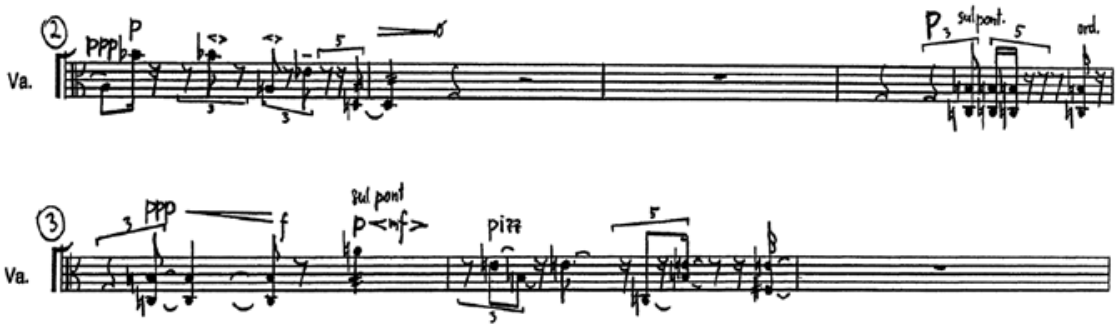

Abb. 49 Georg Friedrich Haas: „... aus freier Lust ... verbunden ... “ für Viola solo, 1994/95, Takte 1-10. (C) 1995/96 by Universal Edition A. G., Wien.

In den Zyklen „... Einklang freier Wesen ..." von Georg Friedrich Haas und Aus der Wand die Rinne von Juliane Klein ist der Grad der Verdichtung noch sehr ausgewogen, was auf die teilweise extrem langsamen und ruhigen Geschwindigkeiten, die vielen Pausen und das gelassene Ineinandergreifen der Einzelstücke zurückgeht (vgl. Abb. 49 und Abb. 5o). Sind die Einzelstücke bereits in einer mittleren bis hohen Temporalität angesiedelt, wird in der simultanen Fassung folglich eine zeitlich extrem dichte Aktivität erreicht. Hier geht die Intensivierung des Aktivitätsgrades innerhalb der beibehaltenen Zeitdauer für den Hörer mit einem Überangebot an Eindrücken einher, die in der gestauchten Zeit der Simultanfassung indifferent werden können. Adriana Hölszkys auf Schubert bezogene Metapher einer „unendlichen (horizontalen) Zeit, die in die Vertikale umgekippt werden kann" und zu einer pulsierenden und vibrierenden Energetik führt, ${ }^{115}$ bedeutet daher auch Kondensation und Komprimierung von Zeit. Noch unmissverständlicher inszeniert Klaus Huber die Komprimierung der sukzessiven Zeit, den Zusammenfluss von

115 Adriana Hölszky: Hängebrücken. Streichquartette/Doppelquartett an Schubert, S. 2. 


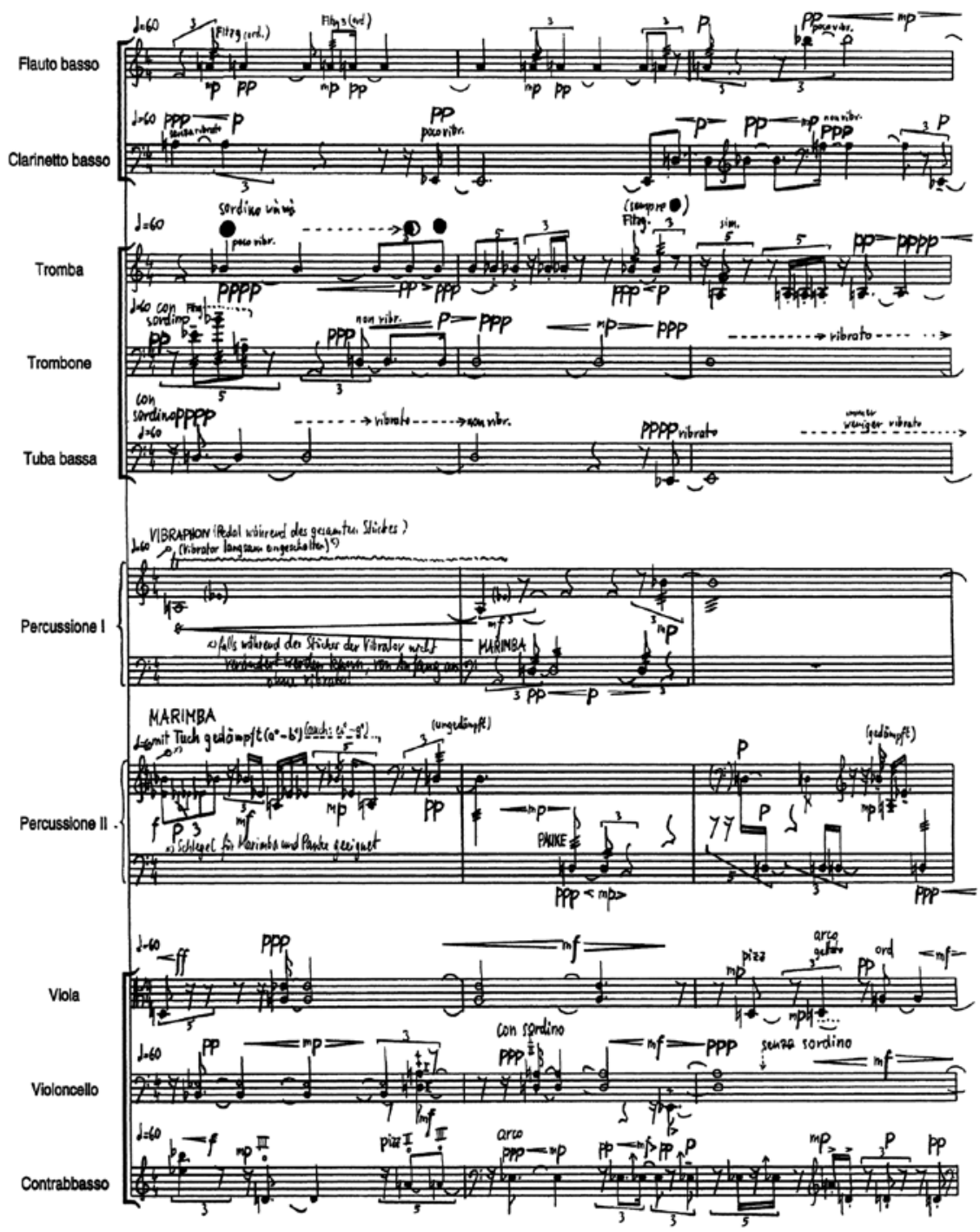

Abb. $5^{\circ} \quad$ Georg Friedrich Haas: „... Einklang freier Wesen ...., 1994/95, Takte 1-3. (C) 1995, 1996 by Universal Edition A. G., Wien. 
Vergangenheit, Gegenwart und Zukunft im kontraktierenden Zeitstrudel der „Implosion“ als tatsächlichen „Zusammenfall“ der sukzessiven Zeit(en).

Die für Poly-Werke typische dissoziierende Zeitbehandlung entwickelt ein kompositorisches Terrain weiter, das Adorno als „Dissoziation der musikalischen Zeit", als eine "Verräumlichung des Zeitverlaufs" mit einem „zeitlich disparaten Nebeneinander" fasste. ${ }^{116}$ Dieses zeitliche Nebeneinander zerlegt allerdings nicht einfach nur die sukzessive Zeitdimension und bedeutet folglich auch keine einfache Brechung derselben. Die Erfahrung zeitlicher Diskontinuität erwächst hier aus der simultanen Figuration verschiedener Zeitlogiken, die sich im Interdependenzgeflecht verschiedener Zeitskalen, -domänen, Raster und Ereignisverläufe sowohl bekräftigen und vernetzen als auch irritieren, ablenken und aneinanderbrechen können. Zeit wird als soziales Zusammenspiel komponiert. Als solches geht sie aus dem Spannungsverhältnis der koexistierenden Werke mit ihren volatilen Wechselwirkungen, Kongruenzen, Arhythmien und allseitigen Irritationen ebenso hervor, wie sie diese gleichermaßen produziert.

116 Siehe auch Theodor W. Adorno: Philosophie der neuen Musik, Frankfurt am Main: Suhrkamp, 2017 (1978), S. 62, 81, 171 und 173. 
Karin wetzel - 978-3-8467-6674-3

Downloaded from Fink.de@4/26/2023 03:14:51PM via free access 


\section{Die Umkehrungsformen des Additiven im Poly-Werk}

Um ein umfassendes Verständnis zum Thema zu entwickeln, verfolge ich hier einen gemischten Forschungsansatz, der auch das künstlerische Forschungspotenzial miteinfließen lässt. Indem Forschung selbst kreativ wird und künstlerische Experimente wagt, sollen neue Handlungs- und Erfahrungsräume erschlossen werden. Ein rein musiktheoretischer oder musikwissenschaftlicher Forschungsansatz würde die Theoriebildung ausschließlich auf eine vergangene Entwicklung stützen und bei diesem Thema Gefahr laufen, das Poly-Werk als rein expandierende Werkform aufzufassen, da das Gros der Werkzyklen in ihrer Entstehungsrichtung additiv auf Zuwachs und Vergrößerung angelegt ist. Außerdem wäre der kompositorische Prozess, der neuerdings auch die Gestaltung des interformalen Raums zwischen den Werken umfasst und als ein „Gestalten in der Differenz" beschrieben wurde, nicht sichtbar. Aus diesem Grund habe ich eigene Kompositionen entwickelt, die sowohl parallel zum als auch in Verschränkung mit dem wissenschaftlichen und analytischen Teil entstanden.

Grundsätzlich hat sich das Poly-Werk in den vergangenen Jahrzehnten tatsächlich als eine kumulative Werkform weiterentwickelt, die das Verhältnis zwischen verschiedenen individuellen Werken und Werkgruppen verschiedener Größe vielfältig und teilweise komplex modelliert. Im Vergleich zu den sich ebenso einseitig vergrößernden Werkerweiterungen und Simultanaufführungen, die vor allem das „quantitative Mehr“ beschwören, wurde durch die Verzahnung der Werke im (prä-)kompositorischen Prozess bereits eine Wende zu einem „qualitativen Plus“ vollzogen. Dennoch verdeckt diese Entwicklung ein weiteres Potenzial des Poly-Werks, das in seinem Kern eigentlich keine additive, sondern eine extrem ambigue Werkform ist, die ebenso auch andere Entstehungsrichtungen - wie beispielsweise Reduktion, Subtraktion, Spaltung oder Kreuzung - verfolgen kann. Diese weiteren denkbaren Differenzierungen sind im Vergleich allerdings viel weniger verfolgt worden oder oft nicht eindeutig zuzuordnen, da Additivität und Subtraktivität in vielen Fällen zwei Seiten einer Medaille sind. Dazu kommt, dass - je nach Hörerfahrung - auch unterschiedlich wahrgenommen werden kann, ob etwas als 
ursprüngliche Zusammenschließung oder als tatsächliche Splittung konzipiert war. Bereits diese Ambiguität konstituiert einen kreativen Rahmen, innerhalb dessen weitere Synthese-, Anwendungs- und Wandlungsmöglichkeiten von Ganzheit im Poly-Werk ausgelotet werden können.

\subsection{Zwischen Dividuum und Dyade - Die Erschließung des Poly-Werks aus einer performativen Perspektive}

Als Ganzheit ist das Poly-Werk nie eindeutig, da jede Ganzheit sowohl in sich selbst als - teilbare oder unteilbare - Ganzheit existiert als auch Teil einer größeren Ganzheit sein kann. Die kleinste unteilbare Einheit ist immer ein in sich geschlossenes Werk. Als kleinstmögliche, nicht mehr weiter teilbare Ganzheit kommt in der bisherigen Entwicklung des Poly-Werks das Solostück mit einem einzelnen Instrument, gespielt von einem einzelnen Spieler in Betracht. Aus meiner künstlerischen Perspektive war es spannend, gerade diese vermeintliche Untergrenze in den Blick zu nehmen und die bis dahin integrale Instrumentaleinheit - und damit die integrale Solokomposition aufzuspalten. Das im Rahmen des Forschungsprojekts von mir komponierte Violinenstück Dividuum geht beispielsweise diesen Schritt. Die Komposition besteht aus zwei Solostücken für Violine, die sich zu einem neuen dritten Solo verbinden können. Die Aufspaltung der Soloeinheit in der Werkganzheit erweitert den kompositorischen Handlungsraum um eine neue performative Dimension. Denn nicht mehr nur die Werkeinheit ist ambigue, auch der Interpret geht diesen Schritt. Er ist jetzt nicht mehr nur Individuum einerseits oder Teil eines größeren Kollektivs andererseits, sondern der Raum der Differenz verschiebt sich in das Individuum hinein. Diese Möglichkeit eröffnet neue Zugänge zu einer mannigfaltigen Werkmehrung jenseits von instrumentalen Besetzungserweiterungen.

Der im folgenden vorgestellte Zyklus X-Pieces, der im Rahmen des Forschungsprojekts eine Art Labor für die unterschiedlichen Möglichkeiten und Richtungen der Werkkombination darstellte, reduziert die Besetzung auf zwei Soloinstrumente und Spieler, die sowohl einzeln als auch in verschiedenen Formationen zusammenkommen können. Die Duokonstellation bildet als Zweierbeziehung die kleinste Form einer Gruppe und damit einen konzentrierten Versuchsrahmen für die verschiedenen engen oder weiten Formen von Zusammen- und Getrenntheit. 


\subsection{X-Pieces für zwei Blockflöten (2017)}

Der Zyklus X-Pieces für zwei Blockflöten ist ein Zyklus aus mehreren Werken und Fassungen, der auf zwei Solostücken für Blockflöte basiert. Die Solostücke heißen Slash und Backslash. Sie sind die beiden Säulen, die den Zyklus tragen. Abbildung 51 zeigt die ersten fünf Takte in einer simultanen Darstellung.

Die oberen beiden Systeme gehören zum Stück Slash, die unteren beiden Systeme zum Stück Backslash. Die Notation für jedes Stück untergliedert sich in je zwei Systeme, wobei das obere System der Artikulation und das untere System der Grifftechnik zugeordnet ist. Das Tonhöhensystem repräsentiert nicht die eigentlichen Tonhöhen. Es handelt sich um eine reine Griffnotation, da die resultierende Tonhöhe auf der Blockflöte im Zusammenspiel von Griff, Dynamik und Artikulation entsteht. Die Separierung und Modularisierung ermöglicht auch eine Aufteilung der Spielaktionen unter den Spielern.

\section{Addition und Subtraktion}

Ausgehend von den beiden Solostücken existieren verschiedene Richtungen der simultanen Überlagerung (siehe Abb. 52). Die einfachste Form der Simultaneisierung wird durch eine einfach additive Duoversion verkörpert, bei der sich die beiden Solostücke Slash und Backslash als Ganzes begegnen. Diese Version trägt den Titel $V$. Weitere Möglichkeiten der simultanen Kombination ergeben sich aus der Aufspaltung der Artikulations- und der Griffebene, die in den beiden Solostücken von vornherein angelegt war. Beispielsweise können die „Fingerstimmen“ - traditionell gelesen - aus dem Notentext herausgeeinzelt werden und bilden abgelöst von der Artikulationsstimme nun zwei weitere autonome Solostücke aus. Diese Stücke tragen den Werktitel Hidden Piece. Beide Stücke können aber auch wieder miteinander addiert werden zum Duo Hidden $V$.

\section{Kreuzung}

Drei weitere Werkvarianten entstehen aus einer Spielpraxis, die die Stücke und die Körper der Spieler miteinander verschränkt. Die Versionen $N_{1}$ und $N_{2}$ setzen voraus, dass das Mittel- und Kopfstück der Blockflöte um neunzig Grad gegeneinander gedreht werden. Dadurch ergibt sich eine neue Position für die Spieler. Sie macht es möglich, die Artikulationsstimme eines Solos mit der Fingerstimme des anderen Solos zu kombinieren und auf diese Weise das Spiel auf einer Flöte unter den Spielern aufzuteilen (siehe Abb. 53 links). Die Artikulationsebene von Slash in Kombination mit der Griffebene von 

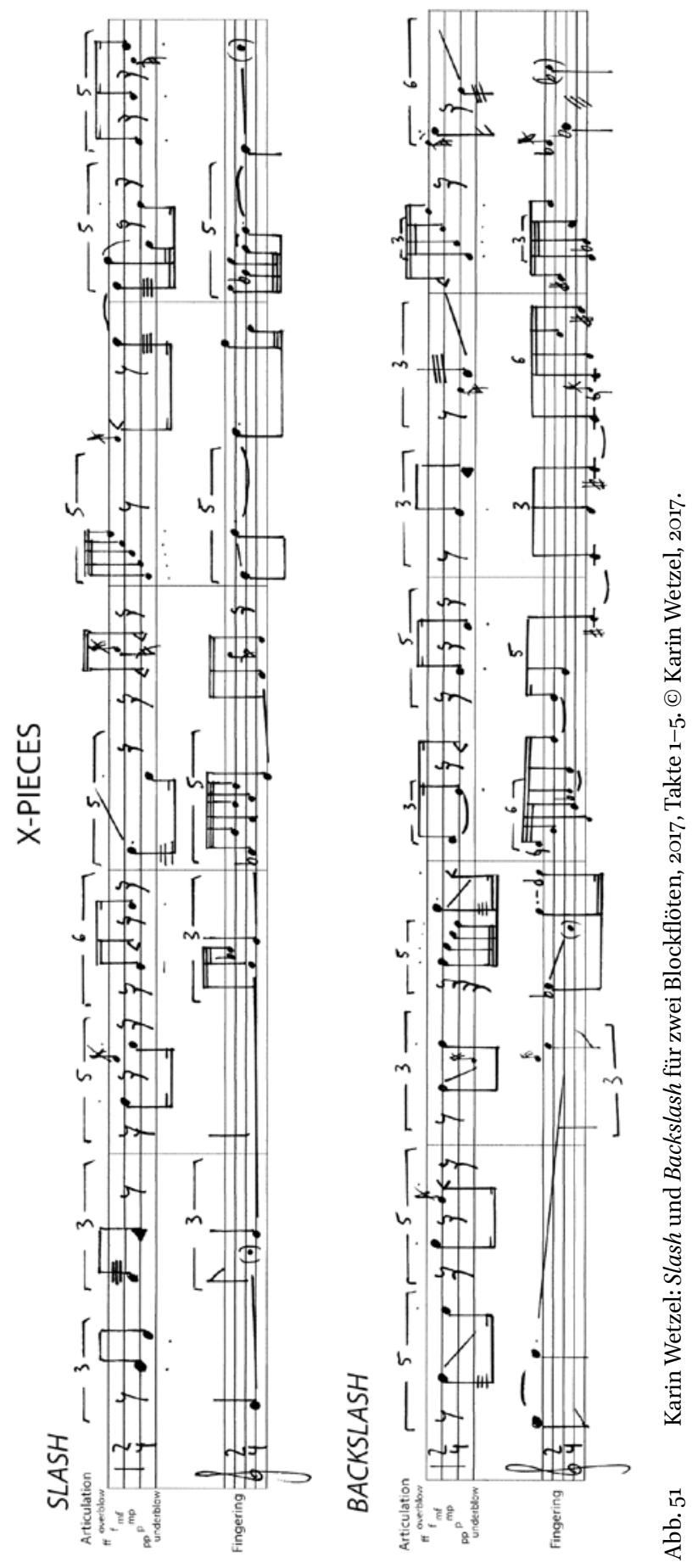


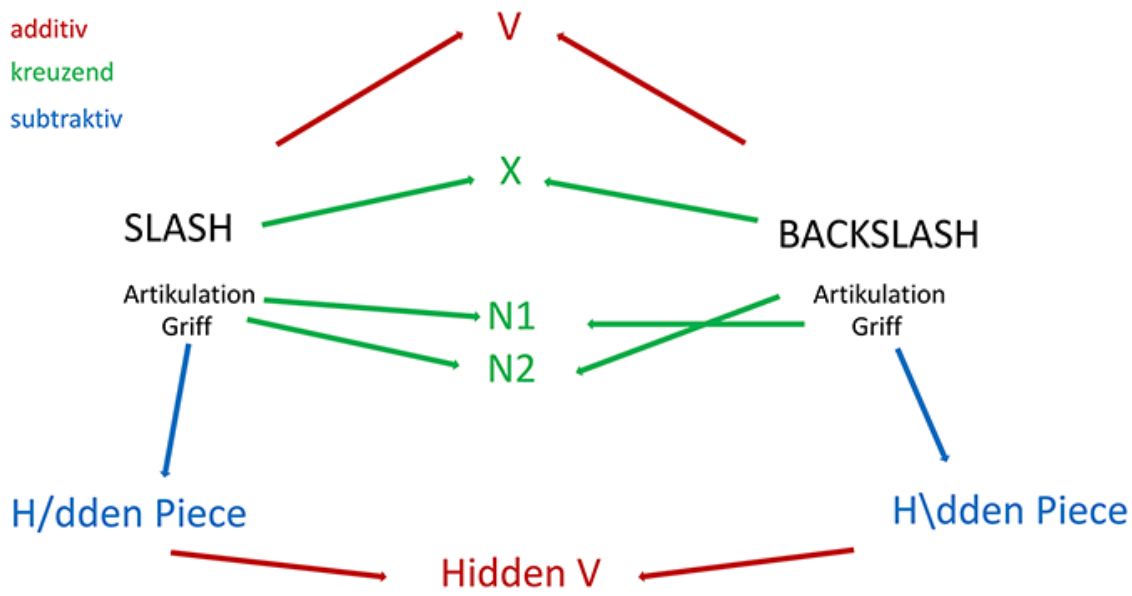

Abb. $5^{2}$ Übersicht möglicher Werkformen in X-Pieces.

Backslash bildet die Version N1. Die Artikulationsebene von Backslash in Kombination mit der Griffebene von Slash entsprechend die Version N2. Beide Versionen stellen ein Duo auf einem Instrument dar.

Für die Aufführung der $X$-Version werden Mund- und Mittelstücke der Instrumente um 180 Grad gegeneinander gedreht. Beide Musiker sitzen sich frontal gegenüber, blasen in die eigene Flöte, greifen aber die Grifflöcher der Flöte des Partners und überkreuzen ihre Flöten ungefähr in Form eines X. In dieser neuen Position verschränken beide ihre Soloversionen (siehe Abb. 53 rechts).
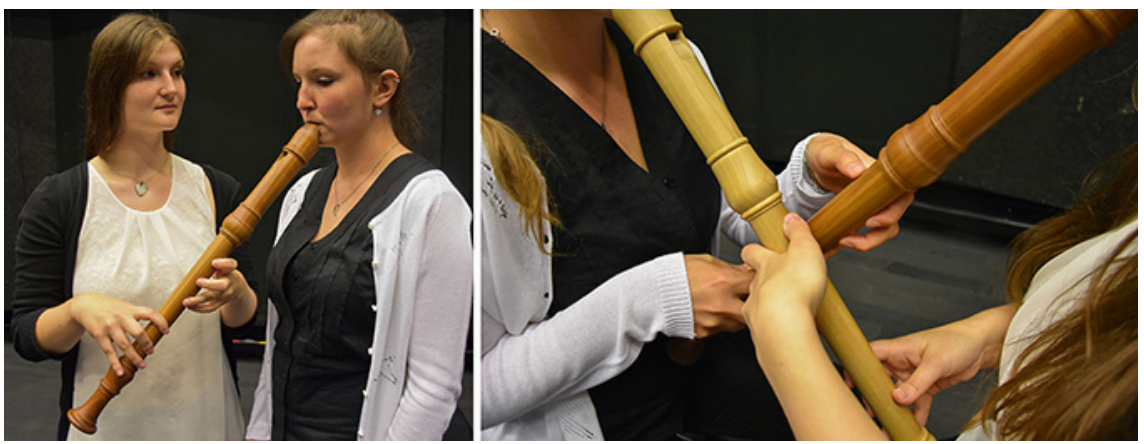

Abb. 53

Dividuales Spiel in $N$ (links), dividuales Spiel in $X$ (rechts). Lydia Dietrich und Laura Kalchofner, Blockflöten. Printed with permission. 


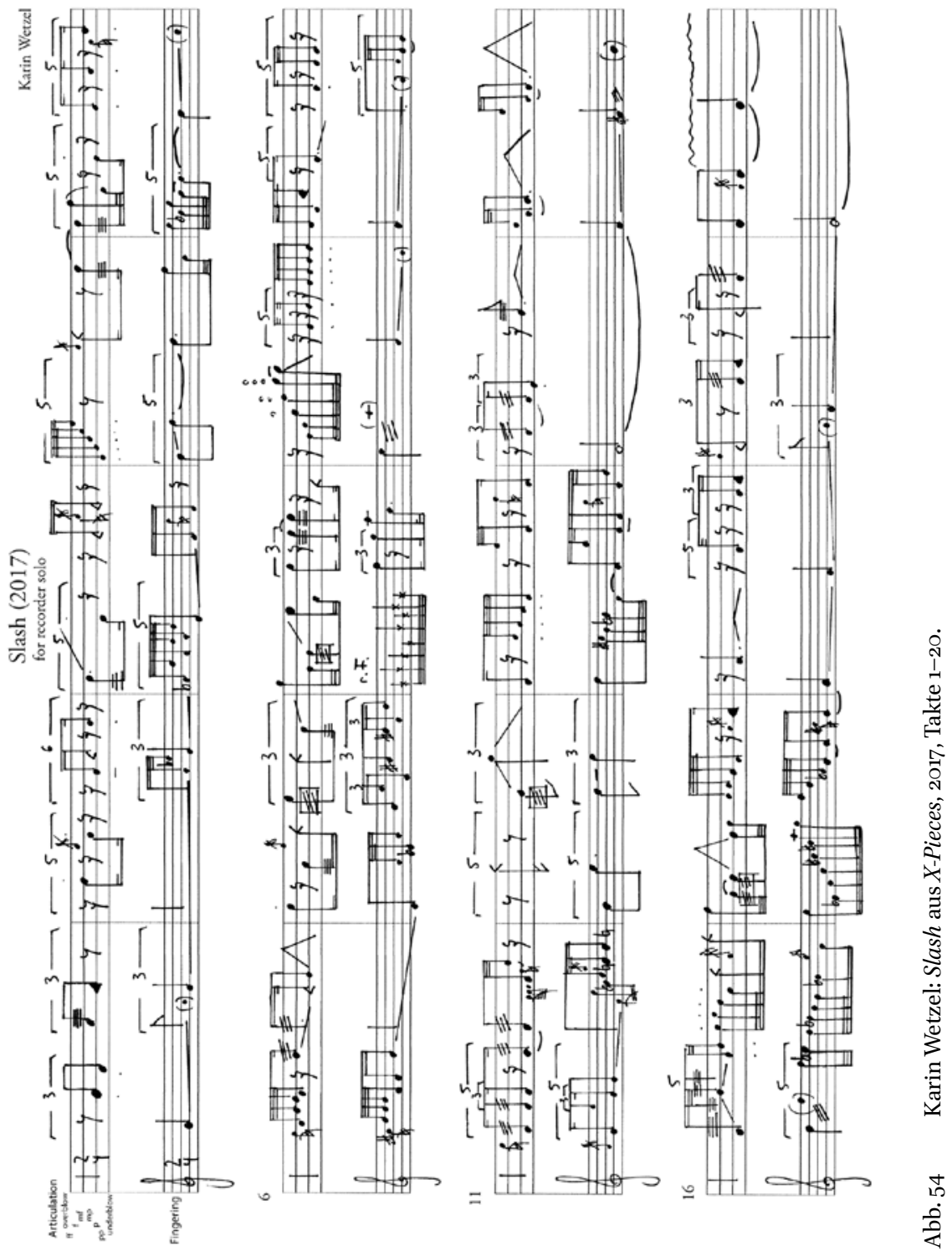




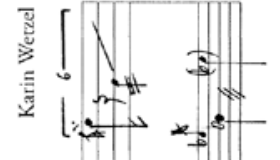

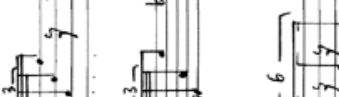

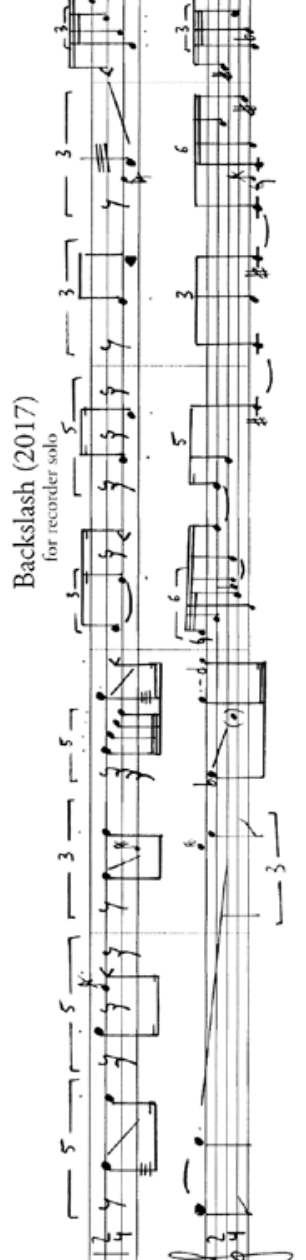

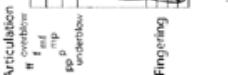
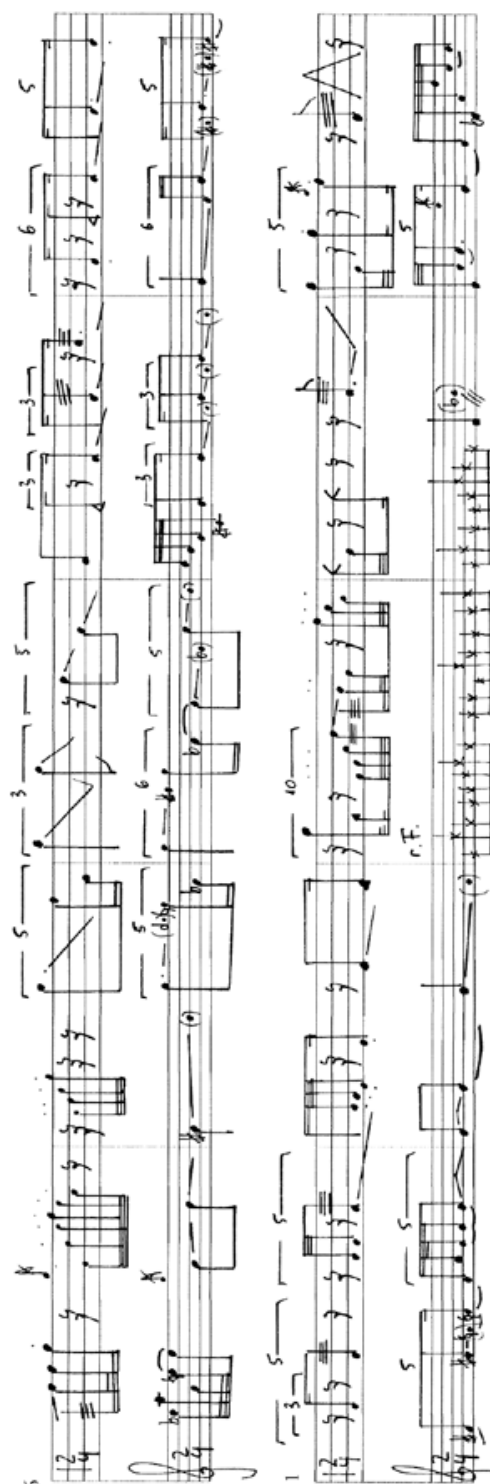
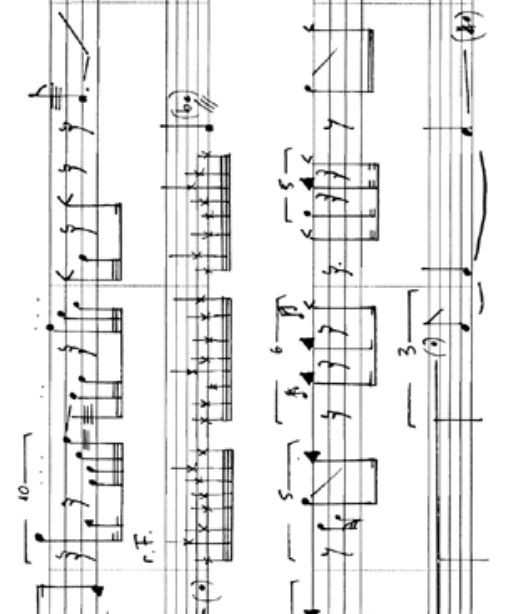

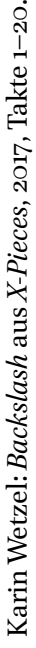

占 

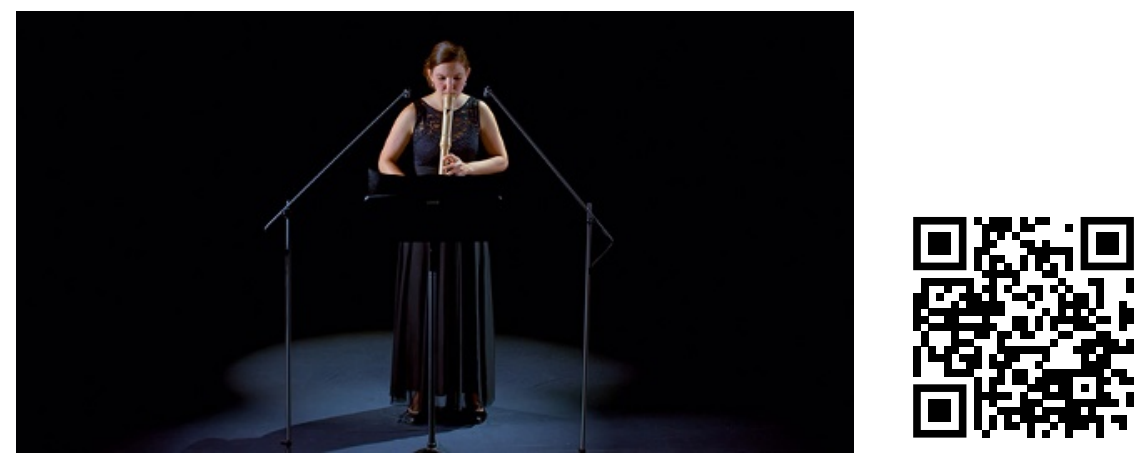

Abb. $5^{6} \quad$ Karin Wetzel: Slash aus X-Pieces für Blockflöte, 2017. Lydia Dietrich, Blockflöte. Printed with permission. Zur Aufnahme: https://vimeo.com/640829212.
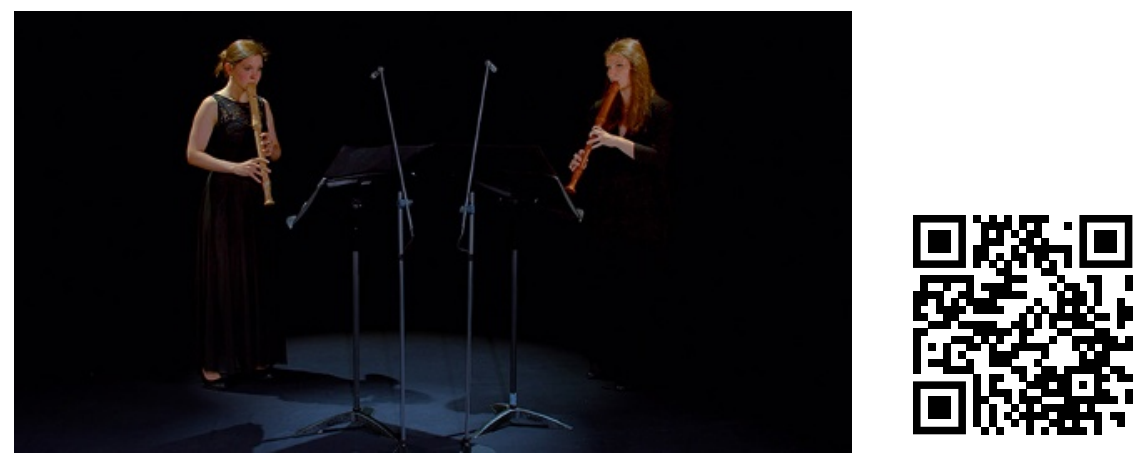

Abb. 57 Karin Wetzel: $V$ aus X-Pieces für zwei Blockflöten, 2017. Lydia Dietrich und Laura Kalchofner, Blockflöten. Printed with permission. Zur Aufnahme: https://vimeo.com/64030436o.
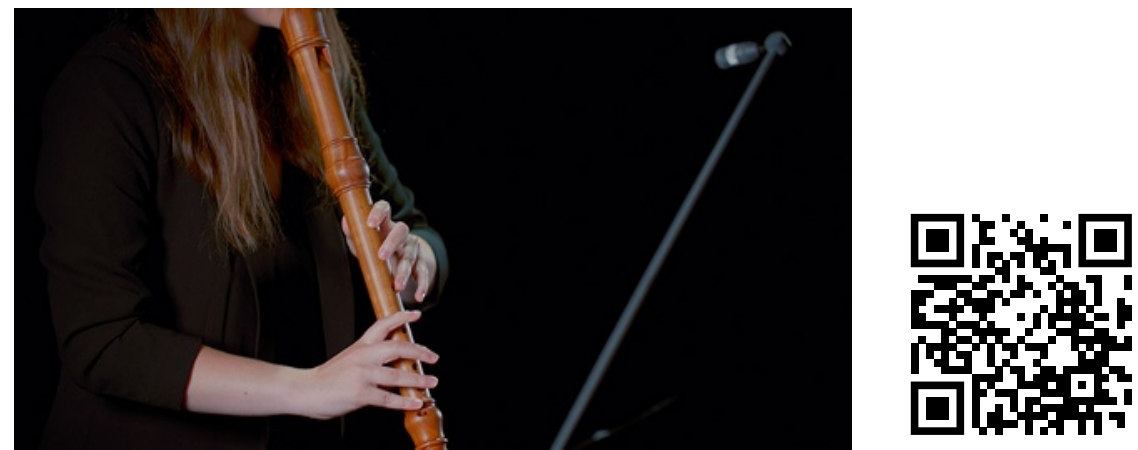

Abb. $5^{8} \quad$ Karin Wetzel: Hidden Piece aus X-Pieces für Blockflöte, 2017. Laura Kalchofner, Blockflöte. Printed with permission.

Zur Aufnahme: https://vimeo.com/640273936. 

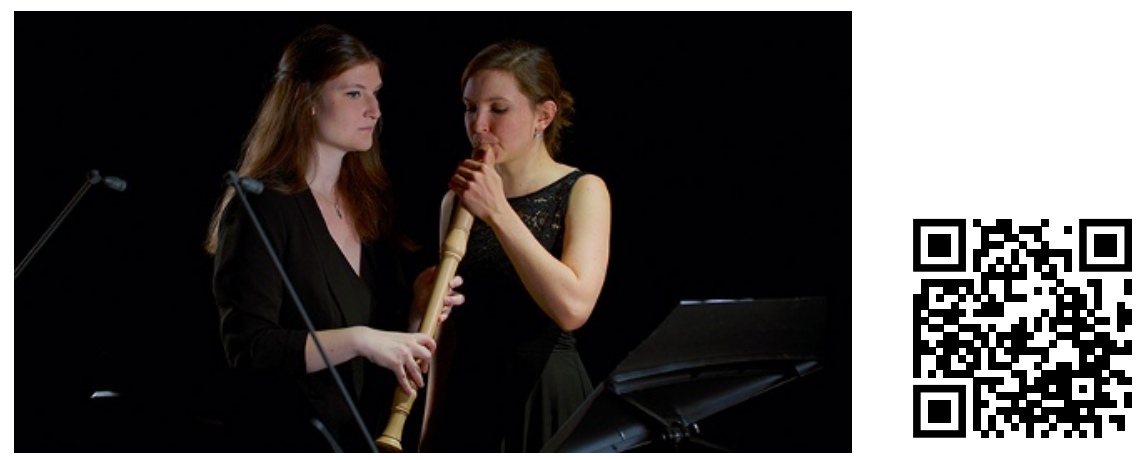

Abb. 59 Karin Wetzel: $N$ aus X-Pieces für Blockflöte, 2017. Lydia Dietrich und Laura Kalchofner, Blockflöte. Printed with permission. Zur Aufnahme: https://vimeo.com/640278455.
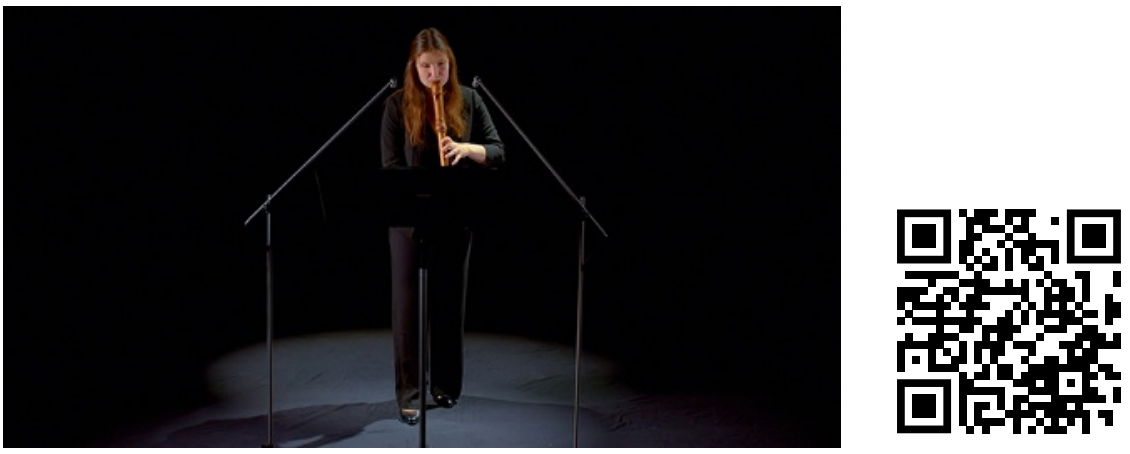

Abb. 6o Karin Wetzel: Backslash aus X-Pieces für Blockflöte, 2017. Laura Kalchofner, Blockflöte. Printed with permission. Zur Aufnahme: https://vimeo.com/640269631.

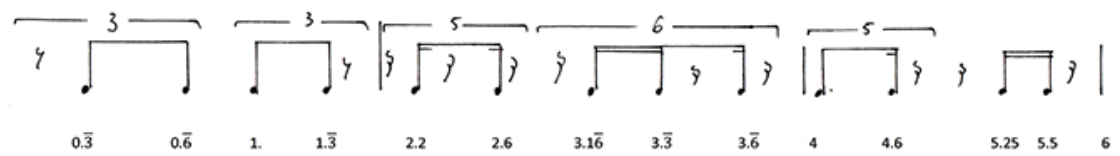

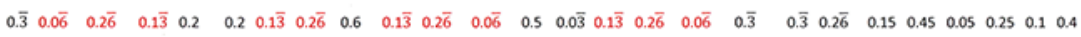

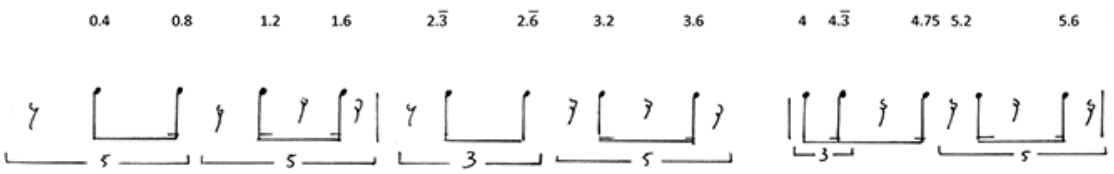

Abb. 61 Rhythmische Notenwerte und ihre numerischen Verhältnisse in Slash und Backslash, Takte 1-3. 
Der interformale Raum

Die beiden Solostücke Slash und Backslash als tragende Pfeiler der Komposition sind unabhängig voneinander aufführbar und haben ihren individuellen Verlauf. Auf einer rhythmischen Ebene sind sie aber auch sehr stark miteinander verschränkt. Um eine große rhythmische Vielfalt zu erhalten, habe ich im Vorfeld festgelegte Zahlenfolgen in Notenwerte übersetzt und folgendes Prinzip angewandt:

Abbildung 61 zeigt drei Zahlenreihen. Der Wert der Zahl 1 entspricht einer Viertelnote. Die obere Zahlenreihe entspricht dem Gerüstrhythmus ${ }^{1}$ der Artikulationsebene von Slash. Die untere Zahlenreihe entspricht dem Gerüstrhythmus der Artikulationsebene von Backslash. Die mittlere Reihe ist die Differenz zwischen den Werten der oberen und der unteren Zahlenreihe. Sie ist die Ausgangsreihe der Komposition. Das Ziel bestand darin, eine Ausgangsreihe $\mathrm{zu}$ entwickeln, in der identische Zahlensequenzen unterschiedliche rhythmische Texturen nach beiden Seiten generieren können. Bedingung für die Auswahl der Zahlen war, dass die Werte der resultierenden Zahlenreihen einem Notenwert entsprechen. Beispielsweise entspricht die Zahl o.4 dem zweiten Quintolensechzehntel einer Viertelnote, 1.2 dem zweiten Quintolensechzehntel der folgenden Viertelnoteneinheit usw. Gleiche Zahlenfolgen können beispielsweise auf die Instrumente neu verteilt werden. In Takt 2 generiert die Zahlenfolge $0.1 \overline{3}, 0.2 \overline{6}$, o.o $\overline{6}$ einen Quintolenrhythmus von 2.2. und 2.6 beziehungsweise 3.2 und 3.6 sowie einen dagegenstehenden Triolenrhythmus von $2 . \overline{3}$ und $2 . \overline{6}$ beziehungsweise $3 \cdot \overline{3}$ und $3 \cdot \overline{6}$. Gleiche Zahlenfolgen generieren hier zwar gleiche Rhythmen, werden aber über die Instrumente hinweg ausgetauscht. Identische Zahlenmuster können jedoch auch andere rhythmische Muster erzeugen, wenn sie innerhalb der Vierteleinheit beispielsweise unterschiedlich einrasten. Rastet die Zahlensequenz $0.1 \overline{3}, 0.2 \overline{6}, 0.0 \overline{6}$ einen Achtelwert später bei x.7 (statt x.2) ein, dann entstehen die rhythmischen Werte: $0.7,0.8 \overline{3}, 1.1,1.1 \overline{6}$. Die zeitlichen Intervalle zwischen den Impulsen sind in beiden Fällen identisch, die rhythmische Gestaltung wird jedoch weiter

1 Gerüstrhythmus bedeutet, dass die Zahlenwerte nur den Impulseinsatz darstellen, also nichts über die Dauer einer Note aussagen. Diese wurde frei von mir gestaltet und folgt keinem festgelegten Plan. Auch Zahlenketten mit sehr kurzen Notenwerten, kleiner als eine Sechzehntelnote, können frei in das Gerüst eingefügt werden. In diesem Fall zählt der Impulseinsatz der ersten Note der Kette. Die Länge der Notenkette und die Anzahl ihrer Notenwerte sind ebenfalls frei gestaltet. Auch Vorschläge sind frei zugefügt und unterliegen keinem rationalen System. An einigen Stellen habe ich mir Freiheiten genommen und bin vom Schema abgewichen. Vergleiche beispielsweise Takt 2, zweite Zählzeit von Backslash mit der Partitur. 
differenziert, denn statt in Triolen und Quintolen erfolgt die rhythmische Auflösung nun in Sextolen und Zehntolen. Durch die Verschiebungen identischer Zahlensequenzen innerhalb des Viertelrasters und immer neue Aufteilungen der rhythmischen Werte auf beide Instrumente entsteht eine große rhythmische Vielfalt, obwohl die zugrunde liegende numerische Abfolge in sich begrenzt und wiederholbar ist. Auch werden die beiden Stücke auf einer rhythmischen Ebene sehr eng miteinander verzahnt.

Die mittlere Ausgangszahlenkette, die an sich noch kein Rhythmus ist, hat folgende Form: ABA' CBC' AB'A' ABA'. ${ }^{2}$ Ich nenne diese Form eine interformale Brücke, die im Zwischenraum der Stücke existiert. Sie steuert lediglich die Verteilung der rhythmischen Impulse für beide Stücke auf der Artikulationsseite und ist dadurch als solche niemals für den Spieler oder Hörer wahrnehmbar.

Die rhythmische Ebene folgt sehr präzise gesetzten Parametern, kann von den Musikern in jeder Version kontrolliert werden und ist daher ein konstantes Merkmal des Stückes. Dagegen ist der Parameter Tonhöhe eine relative Variable und kein absolut gesetzter Wert. Er ist bereits in den Solofassungen schwer zu kontrollieren, deswegen könnte man ihn als emergent beschreiben. Da die Intonation und die resultierende Tonhöhe auf der Blockflöte von der Zusammenwirkung von Artikulation und Grifftechnik abhängig sind, kommt es durch die Teilung der Ebenen bereits in den Solofassungen - und mehr noch in den verschränkten Duofassungen mit ihrer physischen Desynchronisation zu unregelmäßigen und schwer vorhersehbaren Registerbrüchen in der Tonhöhenlinie.

Performance und Form

Artikulation und Greifen sind beim Spiel auf der Blockflöte zwei Prozesse, die normalerweise genau aufeinander abgestimmt sind. Die Desynchronisation von Artikulation und Grifftechnik bedeutet in den diagonalen Fassungen auch eine körperliche Trennung. Diese bringt verschiedene Konflikte mit sich. Beide Spieler finden sich in einer Situation wieder, in der ihnen die Kontrolle über Klang und Intonation permanent entgleitet und das Zusammenspiel zwischen Artikulation und Grifftechnik neu erschlossen werden muss. Gleichzeitig sind die Spieler als aktive Interpreten permanent dem Spiel des anderen Spielers passiv ausgesetzt. Erika Fischer-Lichte schreibt in ihrem Einführungsbuch zur Performativität:

2 Apostroph bedeutet, die Zahlenkette läuft rückwärts. 
„Wenn in performativen Prozessen die beteiligten Subjekte sowohl ihren Verlauf mitbestimmen als auch sich von ihm mitbestimmen lassen, ihnen agency sowohl verliehen als auch entzogen wird, erscheinen sie einerseits als aktiv Handelnde und zugleich andererseits als passiv die Wirkungen der Handlungen Anderer Erleidende." ${ }^{\text {3 }}$

Den aktiven Aspekt der Handlung und das passive Geschehenlassen sieht sie als zwei unterschiedliche Aspekte, die die Ambivalenz und die Unvorhersehbarkeit eines performativen Prozesses kennzeichnen und zu der Maxime führen, „daß das Handeln eine Bereitschaft einschließen solle, sich bestimmen zu lassen..4 Das in der westlichen Kultur als Gegensatz gedachte Begriffspaar "autonom" versus „fremdbestimmt" wird nach Fischer-Lichte in einer performativen Aufführung nicht als „Entweder-oder“, sondern als „Sowohl-alsauch“5 erlebt. Innerhalb des Werkzyklus findet also eine Transformation von einem autonomen zu einem heteronomen Spiel statt. Dadurch entwickelt sich das Stück weg von der Präsenz eines Konzertstückes, hin zu einer Performancesituation, die eine neue Form des Zusammenspiels erfordert und in der die Inszenierung des performativen, körperlichen Aktes in den Vordergrund rückt. Durch diesen Kniff kippt das Werk in einen anderen Zustand. Es kommt zu neuen Wechselwirkungen zwischen den einzelnen Faktoren, die auch bestimmte Konflikte aufwerfen. Auf der physischen Ebene erfordert die körperliche Verbindung beider Spieler einen neuen Zugang zu Spielpraxis, Technik, Haltung und Zusammenspiel. Auf der instrumentalen Ebene erfährt das Instrument Blockflöte eine Umdeutung. Die in sich gedrehte Flöte ist für den Spieler nicht mehr der vertraute Gegenstand. Die Blockflöten verbinden die Spieler physisch miteinander und mutieren durch die Drehung zu einem Knotenpunktim Spielernetzwerk. Auf derpsychologischen Ebene repräsentiert die Verschränkung eine extrem intime kammermusikalische Situation. Die Spieler spielen nicht nur gleichzeitig, sondern rücken auch räumlich in die denkbar dichteste Position zueinander. Beide Spielorte fallen zusammen und werden miteinander verschränkt. Aus diesem Grund müssen neue Wege der Kommunikation und Interaktion und vor allem eine neue Herangehensweise an das Proben gefunden werden. Bei den Proben zur Uraufführung des Stückes lautete daher die Kernfrage: Was probt man eigentlich in den verschränkten Versionen? Folgende Punkte schälten sich im Probenprozess heraus: Neben der Haltung - die Flöten müssen stabil und im Mund bleiben - ist es vor allem

3 Erika Fischer-Lichte: Performativität. Eine Einführung, Bielefeld: Transcript, 2013, S. 87.

4 Hans Ulrich Gumbrecht: „Die Emergenz der Emergenz“, in: Frankfurter Allgemeine Zeitung, Nr. 92, 19.4.2003, S. 38 .

5 Fischer-Lichte: Performativität, S. 68. 
die tatsächliche Trennung von Greifen und Artikulieren. Für die Solofassungen ist es noch vergleichsweise einfach, Finger und Artikulation zusammenzusetzen. Aber auf einer Flöte zu greifen, auf der man selbst nicht spielt, ist etwas komplett anderes und auch Irritierendes. Darüber hinaus musste eine Strategie des konsequenten Bei-sich-selbst-Bleibens entwickelt werden.

Gerade in Bezug auf den letzten Punkt zeigt sich eine Analogie zwischen der Performerebene und der Werkebene: Musiker, die sich für ein Ensemble zusammenfinden, sind Individuen. Außerhalb des Ensemblekontextes agieren sie als Personen unabhängig voneinander, verschmelzen aber idealerweise während der Aufführung zu einem Klangkörper. Werk und Ausführende haben beim Poly-Werk also die Merkmale Unabhängigkeit und Individualität sowie die Möglichkeit des Zusammenschlusses gemeinsam. Der Aspekt der Selbststabilisierung im Zusammenschluss als Grundlage für die Öffnung für das Gegenüber wird in X-Pieces sowohl auf der Werkebene als auch auf einer menschlich-performativen Ebene vollzogen.

\subsection{Komponieren in der Differenz}

Der künstlerische Anspruch in X-Pieces konzentrierte sich auf eine Entwicklung verschiedener Kombinationsformen, die über das rein schichtende und additive Prinzip hinausgehen und ebenso subtraktive und kreuzende Verfahren miteinbeziehen. Die Unterschreitung der bis dahin kleinsten Einheit einer Instrumentalstimme wird nicht nur auf das Werk, sondern ebenso auf den Körper des Musikers selbst übertragen. Die Zuordnung Solostück - Solist bildet nicht mehr die unterste Werk- und Instrumentalstufe, typischerweise gefolgt von der nächsten Stufe Duett - Duo. Der Rahmen differenziert sich weiter und erschließt ebenso dem Raum zwischen dem „Dividuum“ als einem in sich geteilten Wesen und der "Dyade“ als einer extrem engen und überindividuellen Duostruktur, sodass die Werkstufung jetzt Dividuum Individuum - Dyade - Duo lautet. Der schrittweise Transformationsprozess wird nicht durch ein rein additives Vorgehen erreicht, sondern durch eine Mischung additiver, subtraktiver, spaltender und kreuzender Verfahren sowohl auf den Ebenen des Werks als auch des Körpers. Eine eindeutige Addition ist dabei für die Zusammenführung der Solostücke Slash und Backslash zum Duo $V$ gegeben. Eine eindeutige Subtraktion findet in der Reduktion der Solostücke auf die nächstkleineren Soli Hidden Pieces statt. Die Soli Slash und Backslash bilden dabei selbst ein Poly-Werk, einen Schnittpunkt verschiedener Kreuzungen, in dem verschiedene Kontextualisierungsrichtungen angelegt sind. Das Hidden $V$ ist eine Addition subtrahierter Soli, die Version $X$ eine 
additive Kreuzung, in den Versionen $N$ geht die Addition beider Solostücke mit einer Spaltung und Kreuzung auf der Werk- und der Körperebene einher.

Meine beiden Solostücke Slash und Backslash würde ich als Zwillingswerke bezeichnen, die in ihrer Materialität und Rhythmik auf denselben Ursprung zurückgehen, denselben Grad an Unbestimmtheit aufweisen und identisch in der Instrumentation sind. Trotzdem sind sie einzeln aufführbar, besitzen ihre eigene Form, ihren eigenen Flow und ihre eigene charakteristische Physiognomie. Das Stück Backslash gewinnt seine Energie aus den kraftvollen Impulsen in $f$-bis ff-Dynamik, von denen sich die Linie immer wieder neu abstoßen kann (z. B. Takte 17-20, Takt 34, Takte 65-70, Takte 72-73). Dadurch ist es ein Stück weit perkussiverund rhythmischer als das SchwesterstückSlash, das sich aus dem wiederkehrenden Ausgangsmotiv (Takt 1, Takte 31/32, Takte 51/52, Takt 101) immer neu entwickelt. Die $V$-Version beider Stücke betont vor allem den divergierenden und kontrapunktischen Charakter zweier sich selbstständig bewegender Linien. Im Gegensatz zum traditionellen Kammermusikund Ensemblespiel soll die Aufführung nicht zwingend auf ein musikalisch genau aufeinander hörendes und perfekt abgestimmtes Zusammenspiel von zwei funktionalisierten Stimmen hinauslaufen. Die Spieler sollen sich vorrangig auf das eigene Spiel konzentrieren und sich des Spiels des anderen bewusst sein. Das soll aber nicht ausschließen, dass die Spieler den Kontakt zueinander suchen können und abschnittsweise zusammen musizieren. Die Entscheidung darüber soll individuell, spontan und zufällig erfolgen. Je nach Raum und räumlichem Abstand wird bei einem kleinen räumlichen Intervall eher ein linear-kontrapunktischer Effekt der Zweistimmigkeit, bei einer entfernten Vergleichzeitigung idealerweise ein räumlicher Moiréeffekt erzeugt. Die Versionen $N$ und $X$ stellen die physische Desynchronisation der Spielaktionen und die körperliche Neuverbindung der Spieler in den Vordergrund. Sie teilen sich die Flöten, rücken körperlich sehr eng zusammen und erleben eine Verschmelzung zu einer gebrochenen Einheit.

Die typische Zusammensetzung eines Poly-Werks basiert immer auf der Bestimmung kleinster integraler Werkeinheiten - bestehend aus einer oder mehreren Stimmen -, die eine Werkidentität bilden. Ihnen können weitere Werkeinheiten hinzugefügt werden, die eine Neukontextualisierung der Werkidentität ermöglichen. Die unterste Möglichkeit einer kleinsten, unteilbaren Einheit bildete dabei normalerweise das Solo. In X-Pieces ist auch dieses teilbar und trägt als Solo-Poly-Werk eine Differenz in sich. Die ausgeschriebene Artikulationsstimme erzeugt in ihrer Interaktion mit der - auch als ganzwertig aufzufassenden - Fingerstimme eine völlig neue Kontextualisierung derselben. Das zeigt, dass die Gattung Poly-Werk nicht nur in der Lage ist, eine Öffnung und Neukontextualisierung von Werkidentität im Zusammenhang 
zwischen Werkindividuum und Werkkollektiv zu vollziehen, sondern diese Kontextualisierungsrichtung auch umzukehren. Während die additive Entstehungsrichtung immer eine Wandlung und Neusituierung der Werkidentität in verschiedenen kollektiven Kontexten ist, stellt die subtraktive Entstehungsrichtung eine Befragung der kollektiven Kontexte im Einzelnen dar. In X-Pieces werden ausgehend von den Soli Slash und Backslash beide Richtungen verfolgt und zusätzlich noch miteinander kombiniert. Meine Ausgangsfrage nach der Herausforderung der Identität im Verschiedenen kehrte sich letztlich um zu einer Befragung des Verschiedenen innerhalb einer Identität. Die Praxis des „Komponierens in der Differenz" ist dabei der eigentliche Schlüssel, um die verschiedenen Kontexte vom Moment ihrer Entstehung an so ineinander zu verknüpfen, dass die möglichen Versionen in jeder einzelnen Version von Anfang an präsent sind. Auf diese Weise wird die Erweiterung und Komplementierung der individuellen Werkidentität zu einer sozialen Werkidentität bereits im Einzelnen selbst vollzogen. 
Karin wetzel - 978-3-8467-6674-3

Downloaded from Fink.de@4/26/2023 03:14:51PM via free access 


\section{Zusammenfassung und Schlussresümee}

Das Poly-Werk verkörpert den Anspruch, neue Formen zu finden, die die zeitgleiche Vereinbarung verschiedener Stränge im selben Medium ermöglichen, ohne zwingend auf eine Synthese, eine Einheit zu zielen. Wie kaum eine andere Form in der Musik greifen Poly-Werke die Teilbarkeit und Flexibilität der Kreativität und der Aufmerksamkeit auf. Beide sind durchaus in der Lage, sich verschiedener linearer Verläufe bewusst zu sein, sie sowohl zu erdenken als auch zu verfolgen, sie zu bündeln oder zu selektieren. Die mehrfachen Möglichkeiten der sowohl einzelnen als auch - in mindestens einer Konstellation - simultanen Anordnung erzeugen kompositorisch Mehrdeutigkeit und Ambiguität.

Obgleich Poly-Werke sich wandelnde Wahrnehmungsweisen aufgreifen und das Werkobjekt verschiedenen Perspektiven aussetzen, erfolgte ihre Entwicklung in den vergangenen siebzig Jahren vergleichsweise unbemerkt vom Neue-Musik-Diskurs. Über den gesamten Zeitraum gesehen, treten sie zwar zunehmend mit einer gewissen Konstanz auf, jedoch niemals geballt. Ihre Geschichte setzt sich vor allem aus vereinzelten und voneinander unabhängigen Kompositionsansätzen zusammen, die auf den ersten Blick ein uneinheitliches, zersplittertes, vielfältiges Bild abgeben. Eine zeitlich progressive Entwicklung des Poly-Werks gibt es nicht. Ihre Verortung stützt sich deswegen vor allem auf die individuellen Ansätze, die die formalen Gestaltungsmöglichkeiten in verschiedene Richtungen leiteten. Dies machte eine Darstellung nach systematischen Kriterien erforderlich. Im Zentrum der vorliegenden Arbeit stehen Analysen ausgewählter Werke, die das kaleidoskopartige Spektrum der Möglichkeiten sichtbar machen und dieses nach bestimmten formalen Gesichtspunkten auch zu strukturieren versuchen. Bereits durch die Gruppierung der Werke zeigen sich latente und unterschwellige Verbindungen und Bezüge, die einen Vergleich auf der formalen Ebene ermöglichen. Neben dieser systematischen Erfassung war es ein wesentliches Ziel, die werkästhetischen Vorbedingungen und künstlerischen Prozesse zu reflektieren, aus denen das Poly-Werk hervorging.

Die Kernthese der Untersuchung war, dass das Poly-Werk den Werkgedanken zwar einerseits wahrt, ihn aber andererseits öffnet und die Einsheit des traditionellen Werkkonzepts relativiert und neu befragt. Ebenso wie die sogenannten „offenen Formen“ verkörpert das Poly-Werk ein relativistisches Denkmodell, das der Eindeutigkeit und Abgeschlossenheit des Werkkonzepts 
die Ambivalenz des Sowohl-als-auch an die Seite stellt. Um die für das PolyWerk spezifische Relativierung des Werkkonzepts zu verstehen und einzuordnen war es nötig, den Bedeutungshorizont des Begriffes „Offenheit“ aufzuschlüsseln. Auf diese Weise konnte eine Abgrenzung zu anderen offenen Werkkonzepten vorgenommen werden.

Die komplementäre Zusammensetzung verschiedener Teilwerke im PolyWerk führt zu einer der „offenen Form“ ähnlichen konstellativen Werkentität, die wie diese mehrere formale Möglichkeiten bietet, das Werk aufzuführen. Sowohl bei der "offenen Form“ als auch bei einem simultan aufgeführten "Circus" steht tendenziell eher die Quantität, die möglichst hohe Vielzahl an austauschbaren Möglichkeiten im Vordergrund. „Offene Formen“ betonen das Unverbindliche, das Nichtfestgelegte, das Streben nach „Unendlichkeit“. Dabei birgt eine Indifferenz der Möglichkeiten - ebenso wie die klare Eindeutigkeit die Gefahr, Mehrdeutigkeit und Ambiguität zu verhindern. Hier liegt meines Erachtens die entscheidende Weggabelung zwischen dem künstlerischen Ansatz von John Cage und der Theoriebildung von Umberto Eco. Cage legte es nicht darauf an, Bedeutung herbeizuführen. Seine Stücke sollten möglichst bedeutungsimmun sein. Dagegen interpretiert Eco die „offene Form“ so, dass sie durch eine Vielzahl an Möglichkeiten einen Bedeutungsüberschuss erzeugt. Durch die Unterscheidung zwischen Unbestimmtheit und Überbestimmtheit weist sein Konzept der „offenen Form“ in der Rückschau in vielerlei Hinsicht auf die Möglichkeiten des Poly-Werks treffender hin als auf die offenen Formen der Musik seiner Zeit.

Während die „offene Form“ ins „Unendliche“ weist, ein simultan aufgeführter „Circus" beliebig oder spontan entstehen kann, sind die Stränge im Poly-Werk idealerweise ausformuliert und in sich konsistent. Die Öffnung im Poly-Werk ist nicht unbegrenzt und damit auch nicht indifferent. Es handelt sich um eine "gebundene“ Öffnung, die sich sinnhaft auf einzelne konkrete andere Werkstränge bezieht, die auch konträre Eigenschaften besitzen können. Die Unverbindlichkeit von Beziehung wird in eine Exklusivität von Beziehung überführt. Im Gegensatz zur Indifferenz wird die Differenz zum Anderen hier explizit anerkannt und gesucht und ebenso die bewusste Auseinandersetzung, das Vornehmen eines Perspektivwechsels in Bezug auf die Wahrnehmung des Eigenen und des Anderen. Die Folge ist kein Verlust und keine Fragmentierung der Identität. Indem die eine Werkidentität in der Differenz zum Anderen entwickelt wird und als stabiler Faktor präsent ist, erfährt sie durch ihre situative und kontextuelle Einbettung auf einer weiteren Werkebene eine sinnhaltige Erweiterung und Komplementierung.

Im Gegensatz zur Simultanaufführung als einer primär interpretatorischen Praxis sind Poly-Werke von vornherein als Vergleichzeitigung verschiedener 
musikalischer Stränge angelegt. Zwar gilt Letzteres auch für die Werke von John Cage, der die Vergleichzeitigung seiner Werke selbst vorsah, dabei aber den konkreten Zusammengang offen ließ und nicht unbedingt spezifizierte. Die Simultanaufführung nahm einen zentralen Platz in seinem Schaffen ein. Sie war kein singuläres Experiment, sondern Teil seines Anliegens, den Formbegriff zu revidieren und gestaltete Formbeziehungen systematisch durch konstellative Beziehungen zu ersetzen. Dieser neue rezeptive Beziehungstypus ist auch für die Interpretationsästhetik späterer Poly-Werke, die das Nebeneinander der Werkstränge betonen, äußerst relevant. In Hinblick auf die Produktionsästhetik ist diese rezeptive Einstellung hingegen nicht übertragbar und markiert einen Scheideweg. Während die Simultanaufführung bei Cage auch ein Mittel war, den kompositorischen Werkbegriff beiseitezuschieben, zielt die Komposition eines Poly-Werks auf seine produktive Erweiterung und dialogische Komplementarität. Dies macht auch eine aktiv geführte Formgebung, die das Beziehungsgeflecht konkret plant und gestaltet und es nicht einfach geschehen lässt, erforderlich.

Die Erweiterung des Werks von der Einsheit zur Vielheit geht mit einer konzeptuellen Erweiterung des Polyphonie- und des Werkbegriffs einher. Sie bedeutet die Übertragung eines rein satztechnischen polyphonen Denkens auf den Werkverlauf an sich und geht mit der Ausweitung der Polysierung auf verschiedene musikalische Parameter einher. Diese Ausdehnung polyphonen Denkens auf neue Kontexte bedeutet immer auch eine Erweiterung ihres Terrains, die Zuspitzung ihrer Extreme und die Möglichkeit ihrer Umkehrung. Polyphonie muss keine Vervielfältigung im Sinne einer additiven Praxis sein. Auch die Verungleichzeitigung einer Werkentität als dissoziierende Praxis kann als Polysierung aufgefasst werden. Diese Polysierung, gleich ob additiv oder dissoziierend, stellt die Unteilbarkeit des Werks infrage, führt eine Art „dialogical turn“ für den Werkbegriff herbei. Die Teilbarkeit wiederum führt zu verschiedenen Werkidentitäten. Die Gestaltung aus der Differenz heraus scheint dabei eine notwendige Haltung zu sein, um nicht nur eine rein additive Werkschichtung herzustellen, die die Wechselwirkungen zwischen den Werken im Unbestimmten lässt, sondern die verschiedenen Werke und die Form ihrer Verknüpfung bereits im Moment ihrer Entstehung so zu antizipieren, dass alle möglichen Versionen und Entstehungsrichtungen in jeder einzelnen Version von Anfang an präsent sind. Auf diese Weise entsteht die Erweiterung und Komplementierung des Einzelnen zu einer sozialen Werkidentität bereits im individuellen Werk selbst. Die Reflexion des künstlerisches Prozesses durch die Erfahrung des Komponierens selbst lässt dabei jenen Raum im Dazwischen der Werke als einen zu gestaltenden Korridor greifbar werden, von dem aus die Beziehung der Werke zueinander bestimmt und gestaltet werden kann. 
So wird der einsinnig zu erdenkende Werkverlauf sowohl durch die Gesamtheit der weiteren Werkverläufe als auch durch ihre Beziehung untereinander komplementiert. Dies hat wiederum Konsequenzen für die Form, die sich nun in drei verschiedenen Ebenen artikuliert: erstens als innerformale Ebene, die auf das lineare Geschehen im Einzelwerk gerichtet ist; zweitens als interformale Ebene der vertikalen Beziehung zum anderen Werk; drittens als Metaform, die die verschiedenen horizontalen und vertikalen Formbeziehungen vereint.

Die verschiedenen formalen Gestaltungsmöglichkeiten wurden hier anhand eines interformalen Modells zusammengefasst, das auf die wechselseitige Beziehung der Stücke gerichtet ist. Dieses Modell ersetzt keine tiefergehende Analyse, bildet als Profil vor allem eine Art Schlüssel, um im ersten Schritt die generalisierbaren Tendenzen zu reduzieren und zu überschauen.

Auf der Basis dieses Modell war die Analyse der Formen und ihre Einordnung in homogene und heterogene Werkbildungen ein weiterer Schwerpunkt der Arbeit. Vor allem anhand der Arbeiten von Julio Estrada, Simon Steen-Andersen, Darius Milhaud und Chaya Czernowin konnten diese beiden entgegengerichteten Tendenzen sehr klar herausgearbeitet werden. Diese Modellbildung könnte dann an Grenzen stoßen, wenn es einen homogenen Ursprung im Material gibt, die Stücke aber trotzdem sehr unterschiedlich und heterogen sind. Als Orientierung ist die Unterscheidung homogen/heterogen für eine Systematisierung dennoch zentral, auch wenn man argumentieren könnte, dass es sich bei homogenen Werken nicht in gleicher Weise um PolyWerke handelt wie bei heterogenen Werken. Homogene Werke sind in erster Linie Vervielfältigungen einer Ausgangsidee. Doch gerade weil die Werke auf eine gemeinsame Wurzel zurückgehen und diese variieren oder bearbeiten, sollte bei vielen Werken die Wahrnehmung explizit auch auf die Differenzen zwischen den einzelnen Versionen gerichtet werden. Die Synthese heterogener Werke ist im Gegensatz dazu von vornherein auf eine Dialektik angelegt. Sie entsteht nicht aus der Vermehrfachung einer Idee, sondern aus unterschiedlichen Initialideen.

Es war mir wichtig, auch Werke in die Analyse einzubeziehen, in denen der Fokus der Komposition auf das freie kollektive Zusammenspiel der Musiker gerichtet ist, wie bei den Werken von Juliane Klein, Bernd Franke und Georg Friedrich Haas. Sie sind in ihrer Gestaltung in erster Linie aus der kollektiven Identität des Ensembles heraus gedacht und konzipiert. Da aber auch hier die Möglichkeit besteht, die Einzelstimmen autonom aufzuführen, erfahren sie ebenso wie das Poly-Werk eine Aufspaltung ihrer Identität in eine individuelle und eine soziale. Für ein möglichst breites Bild der Formmöglichkeiten wählte ich auch Beispiele aus, die Stücke nur in eine Richtung integrieren oder bei 
denen die Stücke nicht komplett übereinandergelegt sind, sondern sich nur für einen Teilabschnitt überlappen. Meines Erachtens handelt es sich auch hier um simultane Kontextualisierungen, die den Spagat zwischen einem Abschluss des Werkes und seiner spezifischen Öffnung für ein konkret anderes Werk verwirklicht haben. Nicht zuletzt ist eine große Bandbreite an unterschiedlichen Beispielen die Voraussetzung, um allgemeine Tendenzen in diesem inhomogenen Feld ausmachen zu können.

Es wäre zu kurz gegriffen, Simultaneität im Poly-Werk als ein einfaches Gegenmodell zur Linearität zu konstruieren. Denn die lineare Formbildung wird ja nicht aufgegeben. Sukzessivität und Simultaneität werden ebenso zusammen gedacht und müssen ebenso miteinander vereinbart werden wie die Erscheinungsformen des Gleichzeitigen und des Ungleichzeitigen. Das Poly-Werk ist der Spannung dieser verschiedenen Zeitmodi ausgesetzt. Dies spiegelt sich in der zeitlich-formalen Organisation vieler Werke in einer Ausbalancierung zwischen synchronisierten und asynchronen Prozessen wider, sei es, dass die Werke beispielsweise in ihrem Metrum, ihrem Tempo und ihrer Makroform ein gemeinsames Raster teilen, aber in ihrem mikroformalen Verläufen nicht einheitlich agieren oder umgekehrt Tempo und Metrum voneinander abweichen, die Formzäsuren jedoch einheitlich sind. Bisweilen gibt es auch verschiedene Grade von Synchronität. Die perfekte Synchronität verweist noch auf ein traditionelles Ensemblespiel, das sich in seinem zeitlichen Fortschreiten exakt synchronisiert. Daneben gibt es aber auch die imperfekte Synchronität, die die Stücke nur im Groben koordiniert und den Spielern einen zeitlichen Spielraum lässt. In vielen Werken korreliert der Grad der Synchronisation der Werke mit ihrer Materialdisposition. Tendenziell gilt: Je homogener das Material, desto einheitlicher ist die Zeitgestaltung. Je offener und heterogener das Material, desto heterogener ist auch die Organisation der Zeit.

Aus menschlicher Sicht ist der Zusammenschluss von Individuen $\mathrm{zu}$ Paaren, Gruppen oder Massen und der damit immer einhergehende Rollenund Funktionswechsel etwas ganz Natürliches. Auf der Werkebene ist das in dieser Form etwas Besonderes. Das Poly-Werk ist ein Modell, das einerseits Werkidentität als etwas Festgeschriebenes und Determiniertes anerkennt und andererseits trotzdem eine Öffnung zu anderen kollektiven Kontexten vollzieht und damit auch eine Chance zur Transformation nutzt. Für die Analyse und Deutung hätte sicher auch eine weitere Auseinandersetzung mit außermusikalischen Modellen, die oft von den Komponisten selbst für ihre jeweiligen Stücke in Anspruch genommen wurden, ein großes Potenzial. Sowohl in der eigenen künstlerischen Erfahrung, die ich im Rahmen dieser Arbeit gesammelt habe, als auch in den Gesprächen, die ich mit einigen 
Komponisten, deren Werke ich analysiert habe, führen durfte, wurde die Inspiration und Orientierung an außermusikalischen Modellen und Bildern immer wieder offenbar. Die Vielzahl an einfachen und komplexen Beispielen der Vergesellschaftung aus der Natur, der Gesellschaft und der Wissenschaft kann für zukünftige Kompositionen, Analysen, Forschungen und die Formenlehre sicher noch weiter fruchtbar gemacht werden und sollte auf keinen Fall ausgeklammert bleiben. Kürzlich bin ich so zum Beispiel auf den Dictyostelium discoideum gestoßen, einem Schleimpilz, der sowohl als Einzeller wie auch als vielzelliger Organismus existieren kann und dadurch besonders anpassungsfähig ist.

Die Simultaneität im Poly-Werk spiegelt die parallel existierenden Zeitlichkeiten unserer Welterfahrung und der Gesellschaft im räumlichen Beieinander mit ihren Parallelen, Konflikten, Gemeinsamkeiten, Vernetzungen und Ambivalenzen wider. Das Werk im Poly-Werk wird zum Ort, an dem die verschiedenen Zeitstränge akkumuliert und verknüpft werden können, zusammen- und wieder auseinandergehen, als eins und mehrere zugleich erfahrbar sind. Dieses Geschehen vollzieht sich nicht intermedial, sondern im selben Reich der Töne und Klänge. Es lässt das Konvergente sich noch näher kommen, aber auch das Divergente noch dissonanter aufeinanderprallen. 


\section{Literatur- und Quellenverzeichnis}

\section{Partituren $^{1}$}

Berio, Luciano: Sequenza II für Harfe, 1963, London: Universal Edition

Berio, Luciano: Chemins I für Harfe und Orchester, 1965, London: Universal Edition

Berio, Luciano: Sequenza VI für Viola, 1967, London: Universal Edition

Berio, Luciano: Chemins II für Viola und neun Instrumente, 1967, London: Universal Edition

Berio, Luciano: Chemins III für Orchester, 1968, London: Universal Edition

Berio, Luciano: Sequenza VII für Oboe, 1969, London: Universal Edition

Berio, Luciano: Chemins IIb, c für Orchester, 1970/72, London: Universal Edition

Berio, Luciano: Chemins IV für Oboe und 11 Streicher, 1975, London: Universal Edition

Berio, Luciano: Récit für Altsaxophon und Orchester, 1996, London: Universal Edition Czernowin, Chaya: Anea Crystal Cycle, 2009, Mainz: Schott

Estrada, Julio: Yuunohui'yei, 1983, Paris: Editions Salabert/Juliusedimus

Estrada, Julio: Yuunohui'nahui, 1985, Paris: Editions Salabert/Juliusedimus

Estrada, Julio: Yuunohui'se, 1989, Paris: Editions Salabert/Juliusedimus

Estrada, Julio: Yuunohuiome, 199o, Paris: Editions Salabert/Juliusedimus

Estrada, Julio: Yuunohui'tlapoa, 1999, Paris: Editions Salabert/Juliusedimus

Estrada, Julio: Yuunohui'ehecatl, 2012, o. O.: Juliusedimus

Estrada, Julio: Yuunohui'sa, 2018/20, o. O.: Juliusedimus

Fells, Nick: Other Islands, 20o9, Selbstverlag

Franke, Bernd: Solo 7 fach - in Distanz, 1996, Leipzig: Edition Peters

Franke, Bernd: ... in Annäherung für Klavier solo, 1997/98, Leipzig: Edition Peters

Franke, Bernd: Solo 2fach - in Annäherung (I-IV), 1997-2001, Leipzig: Edition Peters

Franke, Bernd: Solo 4fach - überlagernd, 1999/20oo, Leipzig: Edition Peters

Franke, Bernd: Solo 5 fach - zerbrechend, 1998/99, Leipzig: Edition Peters

Franke, Bernd: Solo xfach - tape (I-IV), 200o, Leipzig: Edition Peters

Franke, Bernd: Solo gfach - ins Unendliche, 2001, Leipzig: Edition Peters

Franke, Bernd: Solo 8fach - in Bewegung, 2003, Leipzig: Edition Peters

Globokar, Vinko: Laboratorium, 1973-1985, Leipzig: Edition Peters

Haas, Georg Friedrich: „... aus freier Lust ... verbunden ...“ für Viola, 1994-1996, Wien: Universal Edition

Haas, Georg Friedrich: „... aus freier Lust ... verbunden ... “für Bf, Bkl, 2 Perc, Vla, Vc, Kb, 1994-1996, Wien: Universal Edition

1 Es werden nur Partituren aufgeführt, auf die in der Arbeit näher eingegangen wird. 
Haas, Georg Friedrich: „... aus freier Lust ... verbunden ... “ für Vla, Vc, Kb, 1996, Wien: Universal Edition

Haas, Georg Friedrich: „... Einklang freier Wesen ... “für 10 Instrumente, 1996, Wien: Universal Edition

Hölszky, Adriana: Hängebrücken. Streichquartette/Doppelquartett an Schubert, 1989/9o, Wiesbaden: Breitkopf \& Härtel

Huber, Klaus: Ein Hauch von Unzeit I-VIII, 1972, Wiesbaden: Breitkopf \& Härtel

Huber, Klaus: Schattenblätter für Bkl, Vc, Pno, 1975, Berlin: Ricordi

Huber, Klaus: Oiseaux d'argent für drei Flöten, 1977, Paris: Editions Musicales Transatlantiques

Huber, Klaus: Protuberanzen für Orchester (sukzessive Version), 1986, Berlin: Ricordi Huber, Klaus: Protuberanzen für Orchester (simultane Version), 1986, Berlin: Ricordi

Klein, Juliane: Aus der Wand die Rinne 1-14, 1996-2014, Berlin: Edition Juliane Klein

Kreppein, Ulrich: Echoräume für vier Ensembles, 2016/17, Berlin: Edition Juliane Klein

Mahnkopf, Claus-Steffen: Medusa-Zyklus für Oboe und Orchester, 1990-1992, Kassel: Bärenreiter

Mahnkopf, Claus-Steffen:Kammerzyklus für Klavier und Ensemble, 1996/96, Hamburg: Sikorski

Milhaud, Darius: Octuor à cordes (14e et 15e Quatuors), 1949, Paris: Heugel

Sannicandro, Valerio: Windströme für Orchester, 2012, Mailand: Edizoni Suivini Zerboni Sannicandro, Valerio: Seelenströme für Orchester, 2013, Selbstverlag

Sannicandro, Valerio: Tactile Songs I für Bfl, Vc, Gui, Perc, 2017, Selbstverlag

Sannicandro, Valerio: Tactile Songs II für Bfl, Kl, Vla, Perc, 2018, Milano: Edizoni Suivini Zerboni

Steen-Andersen, Simon: Next To Beside Besides 0-11, 2003-2007, Frederiksberg: Edition-S

\section{Sekundärliteratur}

ABLINGER, Peter: „Das Alte im Neuen. Über den Umgang mit musikalischer Weltliteratur in der Musik des 2o. Jahrhunderts“, Radiovortrag vom 7.12.1991, Deutschlandsender Kultur, https://ablinger.mur.at/docs/altneu.pdf (letzter Aufruf am 27.4.2020)

ADORNO, Theodor W.: Philosophie der neuen Musik, Frankfurt am Main: Suhrkamp, $2017(1978)$

AMON, Reinhard: Lexikon der Harmonielehre, Wien/München: Doblinger/Metzler, 2005

AMON, Reinhard/GRUBER Gerold: Lexikon der Musikalischen Form, Wien/München: Doblinger/Metzler, 2011 
ANSELM, Sigrun: „Identifizierung und Selbstbehauptung. Überlegungen zu einer aktuellen Dimension des Anerkennungskonflikts“, in: Heiner Keupp/Renate Höfer (Hg.): Identitätsarbeit heute. Klassische und aktuelle Perspektiven der Identitätsforschung, Frankfurt am Main: Suhrkamp, 1998, S. 135-148

BAUER, Thomas: Die Vereindeutigung der Welt. Über den Verlust an Mehrdeutigkeit und Vielfalt, Stuttgart: Reclam, 2018

BECK, Sabine: Vinko Globokar. Komponist und Improvisator (= Systematische Musikwissenschaft und Musikkulturen der Gegenwart, Bd. 3), Marburg: Tectum, 2012

BERGSON, Henri: Dauer und Gleichzeitigkeit, Hamburg: Philo Fine Arts, 2014 (Durée et simultaneité. À propos de la théorie de Einstein, Paris: Félix Alcan, 1922)

BHAGWATI, Sandeep: „Anti-Kairos oder: Vom Aushalten des Ungleichzeitigen“, in: Positionen. Texte zur aktuellen Musik 123, 2020, S. 43-53

BIANCHI, Paolo: „Das LKW. Vom Gesamtkunstwerk zum Lebenskunstwerk oder ästhetisches Leben als Selbstversuch (Teil 1)“, in: Kunstforum 142, 1998, S. 50-61

BLOCH, Ernst:Subjekt-Objekt.Erläuterungenzu Hegel, Frankfurt am Main:Suhrkamp, 1962

BLÜMLE, Claudia: „Augenblick oder Gleichzeitigkeit. Zur Simultaneität im Bild“, in: Simultaneität, Modelle der Gleichzeitigkeit in den Wissenschaften und Künsten, hg. von Philipp Hubmann und Till Julian Huss, Bielefeld: Transcript, 2013, S. 37-55

BOEHMER, Konrad: „Werk - Form - Prozess“, in: Musik auf der Flucht vor sich selbst, hg. v. U. Dibelius, München: Hanser, 1969, S. 55-77

BOEHMER, Konrad:Zur Theorie der offenen Form in der neuen Musik, Diss. Köln, 1966

BOHR, Niels: „Erkenntnistheoretische Probleme in der Atomphysik“, in: Albert Einstein als Philosoph und Naturforscher, hg. von Paul Arthur Schilpp, Stuttgart: Kohlhammer, 1955, S. $115^{-15}$ O

BOULEZ, Pierre: Alea, Vortrag bei den Darmstädter Ferienkursen, 1957, in: Rainer Nonnenmann (Hg.): Mit Nachdruck. Texte der Darmstädter Ferienkurse für Neue Musik, Mainz: Schott, 2010, S. 173-185

CAGE, John: Silence. Lectures and Writings by John Cage, Cambridge: The MIT Press, 1967

CAGE, John: Für die Vögel. Gespräche mit Daniel Charles, hg. von Daniel Charles, Berlin: Merve, 1984 (Originaltitel: Pour les oiseaux. Entretiens avec Daniel Charles, Paris: Editions Pierre Belfond, 1976)

CAGE, John: A Year from Monday. New Lectures and Writings by John Cage, London: Boyars, 1985 (Middletown, CT: Wesleyan University Press, 1967)

CAGE, John: „Es wird niemals Stille geben .... Ein bisher unveröffentlichter Briefwechsel zwischen Helen Wolff und John Cage“, in: MusikTexte. Zeitschrift für Neue Musik 106, 2005, S. 47-50

CAGE, John: „From Where'm'Now'. Eine autobiographische Skizze“, in: MusikTexte. Zeitschrift für Neue Musik 106, 2005, S. 21-26 
CAGE, John: Silence, hg. von Ernst Jandl, 9. Aufl., Frankfurt am Main: Suhrkamp, 2017 (1995) (Originalausgabe: Silence, Middletown, CT: Wesleyan University Press, 1961) CANCINO, Juan Parra (Hg.): „Historical contextualization in live electronic music. Reconstructing Aria/Fontana Mix by John Cage“, in: ders. (Hg.): Metacage. Essays on and around Freeman etudes, Fontana mix, Aria, Leuven: Leuven University Press, 2009, S. 17-42

CHARLES, Daniel: „Poétique de la simultanéité“, in: John Cage (= Revue d'esthétique 13-15), Toulouse: Editions Privat, 1988, S. 123-139

COULEMBIER, Klaas: Multi-temporality - Analyzing simultaneous time layers in selected compositions by Elliott Carter and Claus-Steffen Mahnkopf, Diss. Universität Leuven, 2013

DAHLHAUS, Carl: „,Plädoyer für eine romantische Kategorie. Der Begriff des Kunstwerks in der neuesten Musik“, in: ders.: Gesammelte Schriften in zehn Bänden, Bd. 8: 20. Jahrhundert. Historik - Ästhetik - Theorie - Oper - Arnold Schönberg, hg. von Herrmann Danuser u. a., Laaber: Laaber-Verlag, 2005, S. 216-224

DANUSER, Herrmann/KÄMPER, Dietrich/TERSE, Paul (Hg.): Amerikanische Musik seit Charles Ives. Interpretation, Quellentexte, Kompositionsmonographien, Laaber: Laaber-Verlag, 1993 (1987)

DE BENEDICTIS, Angela Ida: „Indeterminacy and Open Form in the United States and Europe. Freedom from Control vs. Control of Freedom“, in: Crosscurrents. American and European Music in Interaction, 1900-2000, hg. von Felix Mayer, Carol J. Oja, Wolfgang Rathert und Anne C. Shreffler, Woodbridge: The Boydell Press, 2014, S. 411-424

DEROUX, Jean: „La Musique Polytonale“, in: La Revue Musicale, 1921, S. 251-257

DOBRETSBERGER, Barbara: Formenlehre. Formen der Instrumentalmusik, Salzburg: Kulturverlag Polzer, 2014

DÖHL, Frédéric: Mash Up in der Musik. Fremdreferenzielles Komponieren, Sound Sampling und Urheberrecht, Bielefeld: Transcript, 2016.

DREES, Stefan/VON FISCHER, Kurt: „Art. Variation. Das 20. Jahrhundert, Variation in der Musik nach 1945“, in: MGG Online, hg. von Laurenz Lütteken, Kassel/Stuttgart/ New York, 2016 ff., veröffentlicht November 2016, https://www.mgg-online.com/ mgg/stable/57672 (letzter Aufruf am 3.5.2020)

ECO, Umberto: Das offene Kunstwerk, Frankfurt am Main: Suhrkamp, 1977 (1973) (Originalausgabe: Opera aperta, Mailand: Bompiani, 1962)

ERDMANN, Martin: Untersuchungen zum Gesamtwerk von John Cage, Diss. Bonn, 1993

ESTRADA, Julio: „Freiheit und Bewegung. Transkriptionsmethoden in einem Kontinuum von Rhythmus und Klang“, in: MusikTexte. Zeitschrift für neue Musik 55, 1994, S. 57-63 
ESTRADA, Julio: „Zerstört und wiedererschaffen. Das Entstehen des Mythos als Erklärung“, in: MusikTexte. Zeitschrift für Neue Musik 55, 1994, 45-51

FISCHER-LICHTE, Erika: Performativität. Eine Einführung, Bielefeld: Transcript, 2013 FLADT, Hartmut: Zur Problematik traditioneller Formtypen in der Musik des frühen zwanzigsten Jahrhunderts (= Berliner musikwissenschaftliche Arbeiten, Bd. 6), München: Katzbichler, 1974

FOUCAULT, Michel: „Andere Räume“ (1967), in: Aisthesis. Wahrnehmung heute oder Perspektiven einer anderen Ästhetik. Essais, hg. von Karlheinz Barck, 7. Aufl., Leipzig: Reclam, 2002 (1992), S. 34-46

FÜRST-HEIDTMANN, Monika: „Auf der Suche nach der unverstellten Imagination. Der mexikanische Komponist Julio Estrada“, in: MusikTexte. Zeitschrift für Neue Musik 55, 1994, S. 39-45

GAMM, Gerhard: „Das rätselvoll Unbestimmte“, in: Das unendliche Kunstwerk. Von der Bestimmtheit des Unbestimmten in der ästhetischen Erfahrung, hg. von Gerhard Gamm und Eva Schürmann, Hamburg: Philo, 2007, S. 23-57

GARTMANN, Thomas: ... dass nichts an sich jemals vollendet ist. Untersuchungen zum Instrumentalschaffen von Luciano Berio (= Publikationen der Schweizerischen Musikforschenden Gesellschaft, Serie 2, Bd. 37), Bern: Paul Haupt, 1994

GIESELER, Walter: Komposition im 20. Jahrhundert, Celle: Moeck, 1975

GILBERT, Anne: „Leere Rahmen. Das Unsichtbare des Sichtbaren sichtbar machen“, in: Rahmenbrüche Rahmenwechsel, hg. von Uwe Wirth, Berlin: Kadmos, 2013, S. $217-237$

GUMBRECHT, Hans Ulrich: „Die Emergenz der Emergenz“, in: Frankfurter Allgemeine Zeitung, Nr. 92, 19.4.2003, S. 38

GURVITCH, Georges: „The Problem of Time“ (1964), in: John Hassard (Hg.): The Sociology of Time, Hampshire/London: The Macmillan Press, 199o, S. 35-44

GURVITCH, Georges: „Varieties of Social-Time“ (1964), in: John Hassard (Hg.): The Sociology of Time, Hampshire/London: The Macmillan Press, 199o, S. 67-76

HASSARD, John (Hg.): The Sociology of Time, Hampshire/London: The Macmillan Press, 1990

HIEKEL, Jörn Peter/UTZ, Christian (Hg.): Lexikon Neue Musik, Stuttgart: Metzler/ Kassel: Bärenreiter, 2016

HILLER, Egbert: „Formpolyphonie als Zukunftsmusik. Der Komponist Robert HP Platz“, in: Neue Zeitschrift für Musik 6, 2005, S. 54-55

HOBAN, Wieland: „On the Methodology and Aesthetics of Form-Polyphony“, in: The Foundations of Contemporary Composing (= New Music and Aesthetics in the 21st Century, Bd. 3), hg. von Claus-Steffen Mahnkopf, Hofheim: Wolke, 2004

HOFMANN, Werner: Die Moderne im Rückspiegel. Hauptwege der Kunstgeschichte, München: Beck, 1998 
HOLZER, Andreas: Zur Kategorie der Form in neuer Musik (= Musikkontext, Bd. 5), Wien: Mille-Tre, 2011

HUBER, Klaus: Von Zeit zu Zeit. Das Gesamtschaffen. Gespräche mit Claus-Steffen Mahnkopf, Hofheim: Wolke, 2009

HUBER, Klaus/NYFFELER Max (Hg.): Umgepflügte Zeit. Schriften und Gespräche (= Edition MusikTexte, Bd. 6), Köln: MusikTexte, 1999

HUBMANN, Philipp/HUSS, Till Julian (Hg.): Simultaneität. Modelle der Gleichzeitigkeit in den Wissenschaften und Künsten, Bielefeld: Transcript, 2013

IDDON, Martin:John Cage and David Tudor. Correspondence on Interpretation and Performance, Cambridge: Cambridge University Press, 2013

IDDON, Martin: New Music at Darmstadt. Nono, Stockhausen, Cage, and Boulez, Cambridge: Cambridge University Press, 2013

JUNG, Carl Gustav: Über Synchronizität, Reprint, Zürich: Buchclub Ex Libris, 1972

KEUPP, Heiner u. a. (Hg.): Identitätskonstruktionen. Das Patchwork der Identitäten in der Spätmoderne, Hamburg: Rowohlt, 2002 (1999)

KEUPP, Heiner/HÖFER, Renate (Hg.): Identitätsarbeit heute. Klassische und aktuelle Perspektiven der Identitätsforschung, Frankfurt am Main: Suhrkamp, 1998 (1997)

KNAUS, Herwig/SCHOLZ Gottfried: Formen in der Musik, Wien: Österreichischer Bundesverlag, 1988/89

KNIPPER, Till: „Klage um Klage. „Rekomposition“ in Klaus Hubers Spätwerk“, in: MusikTexte. Zeitschrift für Neue Musik 123, 2009, S. 61-68

KOCHER, Philippe: „Visuelle Synchronisierung. Musizieren mit computergestützter Tempovermittlung“, in: Neue Zeitschrift für Musik 3, 2018, S. 42-45

KOSTELANETZ, Richard: John Cage im Gespräch. Zu Musik, Kunst und geistigen Fragen unserer Zeit, Köln: DuMont, 1989

KOSTELANETZ, Richard: Conversing with Cage, New York/London: Routledge, 2003 (1989)

KRAPPMANN, Lothar „Die Identitätsproblematik nach Erikson aus einer interaktionistischen Sicht“, in: Keupp, Heiner/Höfer, Renate (Hg.): Identitätsarbeit heute. Klassische und aktuelle Perspektiven der Identitätsforschung, Frankfurt am Main: Suhrkamp, 1998, S. 66-92

KRÜMMEL, Clemens: „Der Popsong und sein Double. Zu Peter Tillessens Quodlibets“, in: Tania Prill und Peter Tillessen (Hg.): Whatever. Über doppelte Musik, Leipzig: Spector Books, 2020, S. 45-53

KÜHN, Clemens: Formenlehre der Musik, Kassel: Bärenreiter, 2007 (1987)

LANDON, Howard C. Robbins: Haydn. chronicle and works, in five volumes, London: Thames and Hudson, 1976-1980

LIGETI, György: „Wandlungen der musikalischen Form“, in: Gesammelte Schriften, Bd. 1, hg. von Monika Lichtenfeld (= Veröffentlichungen der Paul Sacher Stiftung, Bd. 10/1), Basel/Mainz: Schott, 2007, S. 85-104 (Erstveröffentlichung in: Die Reihe 7, Wien: Universal Edition, 1960, S. $5^{-17}$ ) 
LINKE, Cosima: Konstellationen - Form in neuer Musik und ästhetische Erfahrung im Ausgang von Adorno. Eine musikphilosophische und analytische Untersuchung am Beispiel von Lachenmanns „Schreiben. Musik für Orchester“, Mainz: Schott, 2018

LUHMANN, Niklas: Die Kunst der Gesellschaft, Frankfurt am Main: Suhrkamp, 1997

MACHABEY, Armand: „Dissonance, Atonalité, Polytonalité“, in: La Revue Musicale, 1931, S. 35-45

MAHNKOPF, Claus-Steffen: „Kundgabe. Komplexismus und der Paradigmenwechsel in der Musik“, in: MusikTexte. Zeitschrift für Neue Musik 35 (199o), S. 20-35

MAHNKOPF, Claus-Steffen: Kritik der neuen Musik. Entwurf einer Musik des 21. Jahrhunderts, Kassel: Bärenreiter, 1998

MAHNKOPF, Claus-Steffen: „Der Zerfall der musikalischen Zeit. Prolegomena zu einer Theorie der Atonalität“, in: Musik in der Zeit. Zeit in der Musik, hg. von Richard Klein, Eckehard Kiem und Wolfram Ette, Weilerswist: Velbrück, 200o, S. 354-372

MAHNKOPF, Claus-Steffen: „Der Strukturbegriff der musikalischen Dekonstruktion“, in: Musik und Ästhetik 21, 2002, S. 49-68

MAHNKOPF, Claus-Steffen (Hg.): Polyphony \& Complexity (= New Music and Aesthetics in the 21st Century, Bd. 1), hg. von Claus-Steffen Mahnkopf, Hofheim: Wolke, 2002

MAHNKOPF, Claus-Steffen: „Medusa. Concerning Conception, Poetics and Technique“, in: Polyphony \& Complexity (= New Music and Aesthetics in the 21st Century, Bd. 1), hg. von Claus-Steffen Mahnkopf, Hofheim: Wolke, 2002, S. $245^{-265}$

MAHNKOPF, Claus-Steffen: „Theory of Polyphony“, in: Polyphony \& Complexity (= New Music and Aesthetics in the 21st Century, Bd.1), hg. von Claus-Steffen Mahnkopf, Hofheim: Wolke 2002, S. 38-53

MAHNKOPF, Claus-Steffen: „Reflexion, Kritik, Utopie, Messianizität. Kriterien moderner Musik - oder: Wie weit trägt die Idee musikalischer Dekonstruktion?“, in: MusikTexte. Zeitschrift für Neue Musik 99, 2003, S. 17-24

MAHNKOPF, Claus-Steffen: Die Humanität der Musik. Essays aus dem 21. Jahrhundert, Hofheim: Wolke, 2007

MAHRENHOLZ, Simone: „Art. Zeit in der Musik des 20. Jahrhunderts“, in: $M G G$ Online, hg. von Laurenz Lütteken, Kassel/Stuttgart/New York 2016, veröffentlicht online November 2016, https://www.mgg-online.com/article?id=mgg1626o\&v=1.0 \&rs=mgg1626o (letzter Aufruf am 2.1.2021)

METZGER, Christoph: John Cage - abstract music. Zwölf Vorlesungen, Saarbrücken: Pfau, 2011

METZGER, Heinz-Klaus: Die freigelassene Musik. Schriften zu John Cage, hg. von Rainer Riehn, Wien: Klever, 2012

MILHAUD, Darius: „Polytonalité et Atonalité“, in: La Revue Musicale, 1923, S. 29-44

MILHAUD, Darius: Notes sans musique, Paris: Juillard, 1949 (Noten ohne Musik. Eine Autobiographie, München: Prestel, 1962) 
MILHAUD, Darius: Entretiens avec Claude Rostand, Paris: Julliard, $195^{2}$

NASSEHI, Armin:Die Zeit der Gesellschaft. Auf dem Weg zu einer soziologischen Theorie der Zeit, Wiesbaden: VS Verlag für Sozialwissenschaften, 2008 (1993)

NATTIEZ, Jean-Jaques (Hg.): Dear Pierre - Cher John. Pierre Boulez und John Cage - der Briefwechsel, Hamburg: Europäische Verlagsanstalt, 1997 (Originalausgabe: Pierre Boulez, John Cage: Correspondances et documents, Winterthur: Amadeus Verlag, 1990)

NONNENMANN, Rainer (Hg.): Mit Nachdruck. Texte der Darmstädter Ferienkurse für Neue Musik, Mainz: Schott, 2010

NONNENMANN, Rainer: „Form“, in: Jörn Peter Hiekel und Christian Utz (Hg.): Lexikon Neue Musik, Stuttgart: Metzler, 2016, S. 233-238

NYFFELER, Max (Hg.): Klaus Huber: Umgepflügte Zeit. Schriften und Gespräche, Köln: MusikTexte, 1999

PAGNUTTI, Alana: Reception. The Radio-Works of Robert Rauschenberg and John Cage, Brooklyn: Smith + Brown, 2016

Die Parallelwelt. Eine Simultanaufführung zwischen Berliner Ensemble und Schauspiel Dortmund, Programmheft, Berlin, 2018

PRILL, Tania und TILLESSEN, Peter (Hg.): Whatever. Über doppelte Musik, Leipzig: Spector Books, 2020

RECK, Hans Ulrich: Grenzziehungen. Ästhetiken in aktuellen Kulturtheorien, Würzburg: Königshausen und Neumann, 1991

RIEGER, Stefan: „Multitasking. Zur Ökonomie der Spaltung“, in: Simultaneität. Modelle der Gleichzeitigkeit in den Wissenschaften und Künsten, hg. von Philipp Hubmann und Till Julian Huss, Bielefeld: Transcript, 2013, S. 91-110

ROSENBERG, Jesse: The Experimental Music of Pietro Raimondi, Diss. New York, 1995 ROSS, Alex: The Rest is Noise. Das 20. Jahrhundert hören, München: Piper, 2009 (2007) ROSTECK, Jens: „Umrisse einer Theorie der Polytonalität bei Darius Milhaud“, in: International Journal of Musicology 3, 1994, S. 235-29o

RUANO-BORBALAN, Jean-Claude: L'identité. L'individu, le groupe, la societé, Paris: Sciences Humaines Éditions, 1998

SANIO, Sabine/SCHEIB Christian: Form. Luxus, Kalkül und Abstinenz. Fragen, Thesen und Beiträge zu Erscheinungsweisen aktueller Musik, Saarbrücken: Pfau, 1999

SCHÄFER-LEMBECK, Hans-Ulrich: „Du baust dir eine Stadt ... Überlegungen zu Ästhetik und Didaktik von Adriana Hölszkys Hängebrücken“, in: Hans Bäßler (Hg.): Neue Musik vermitteln. Analysen, Interpretationen, Unterricht, Mainz: Schott, 2004, S. $265^{-285}$

SCHÄFFLER, Philipp: Die Idee der Bildung im Schaffen von John Cage, Mainz: Schott, 2009

SCHAUB, Mirjam: „Larger than life?!“, in: Uwe Wirth (Hg.): Rahmenbrüche, Rahmenwechsel, Berlin: Kadmos, 2013, S. 179-197 
SCHEIB, Christian: „Musikgeschichten“, in: Programmbuch der Wittener Tage für Neue Musik 1991, hg. von F. Hilberg und Harry Vogt, Saarbrücken: Pfau 1991

SCHRÖDER, Julia: „Konzeptueller Umgang mit präexistenter Musik“, in: Zitieren, appropriieren, sampeln. Referentielle Verfahren in den Gegenwartskünsten, hg. von Frédéric Döhl und Renate Wöhrer, Bielefeld: Transcript, 2014, S. 183-199

STOIANOVA, Ivanka: Luciano Berio - Chemins en musique (= La Revue Musicale 375377), Paris: Richard-Masse, 1985

TADDAY, Ulrich (Hg.): Adriana Hölszky (= Reihe Musik-Konzepte, Bd. 16o/161), München: Edition Text + Kritik, 2013

THOMAS, Ernst: Darmstädter Beiträge zur Neuen Musik, Band X: Form in der Neuen Musik, Mainz: Schott, 1966

TOOP, Richard: „Immer weiter. Formale Polyphonie und Robert HP Platz' Donaueschinger Zyklus“, in: Musik \& Ästhetik 2, 6, 1998, S. 61-76

WELSCH, Wolfgang: „Einleitung“, in: Wege aus der Moderne. Schlüsseltexte der Postmoderne-Diskussion, hg. von Wolfgang Welsch, Weinheim: VCH, 1988, S. 1-43 WÖLFFLIN, Heinrich: Kunstgeschichtliche Grundbegriffe. Das Problem der Stilentwicklung in der neueren Kunst, München: Bruckmann, 1915/Basel: Schwabe, 1963

\section{Online-Quellen}

http://aaroncassidy.com/product/the-green-is-either/ (Mai 2020) http://berndfranke.de/werke-2/solo-xfach/ensemble/ (Mai 2020)

https://cagecomp.home.xs4all.nl/ (Mai 2020)

https://cageconcert.org/performing-the-concert/solo-for-piano/\#preparing (Mai 2020)

http://exhibitions.nypl.org/johncage/node/37 (Mai 2020)

https://www.film-tv-video.de/productions/2015/11/14/simultankonzert-acht-orgelnein-werk-acht-organisten/ (Mai 202O)

https://johncage.org/pp/John-Cage-Works.cfm (Mai 2020)

http://www.klaushuber.com (Mai 2020)

https://www.mdw.ac.at/schostakowitsch/ (Mai 2020)

http://www.olganeuwirth.com/text26.php (Mai 2020)

https://polytempo.zhdk.ch/ (Januar 2021)

https://www.rhpp.de (Mai 2020)

https://www.tillessen.info/whatever (Mai 2020)

https://www.universaledition.com/georg-friedrich-haas-278/werke/einklang-freierwesen-16 (Mai 2020)

http://www.wolfgangmuellerrr.de/Musik (Mai 2020) 


\section{Diskografie}

BERIO, Luciano: Chemins II, IV, Corale, Ensemble Intercontemporain, Pierre Boulez, Sony, 1990

BERIO, Luciano: Sequenzae, Ensemble Intercontemporain, Deutsche Grammophon, 1998

BERIO, Luciano: Chemins, Récit Luciano Berio, Ensemble Quaerendo Invenetis, David Vincent, Aeon, 2007

CAGE, John: Concert for Piano and Orchestra, Atlas Eclipticalis, The orchestra of the S. E. M. Ensemble, Petr Kotik, Joseph Kubera, Wergo, 1993

CAGE, John: 108, 109, 110, Chance Philharmonic, OgreOgressProductions, 2010

CAGE, John: The Ten Thousand Things Project, MicroFest Records, 2013

CZERNOWIN, Chaya: Anea Crystal Cycle, Quatour Diotima, Wergo 2011

ESTRADA Julio: Chamber Music for Strings, Arditti Quartett, Stefano Scodanibbio, Montaigne, 1995

HAAS, Georg-Friedrich: „... Einklang freier Wesen ...“, Klangforum Wien, Sylvain Cambreling, Kairos, 2002

HÖLSZKY, Adriana: Hängebrücken, Nomos Quartett, Pellegrini Quartett, CPO, 1990

HUBER, Klaus: Protuberanzen, Basler Sinfonie Orchester, Jürg Wyttenbach, Timpani, 1994

KLEIN, Juliane: Aus der Wand die Rinne, Edition Zeitgenössische Musik, Wergo 2004

MAHNKOPF, Claus-Steffen: Edition Zeitgenössische Musik, Wergo, 2000

MILHAUD, Darius, Octour à Cordes op. 297, SWR Archivaufnahme, 1949 


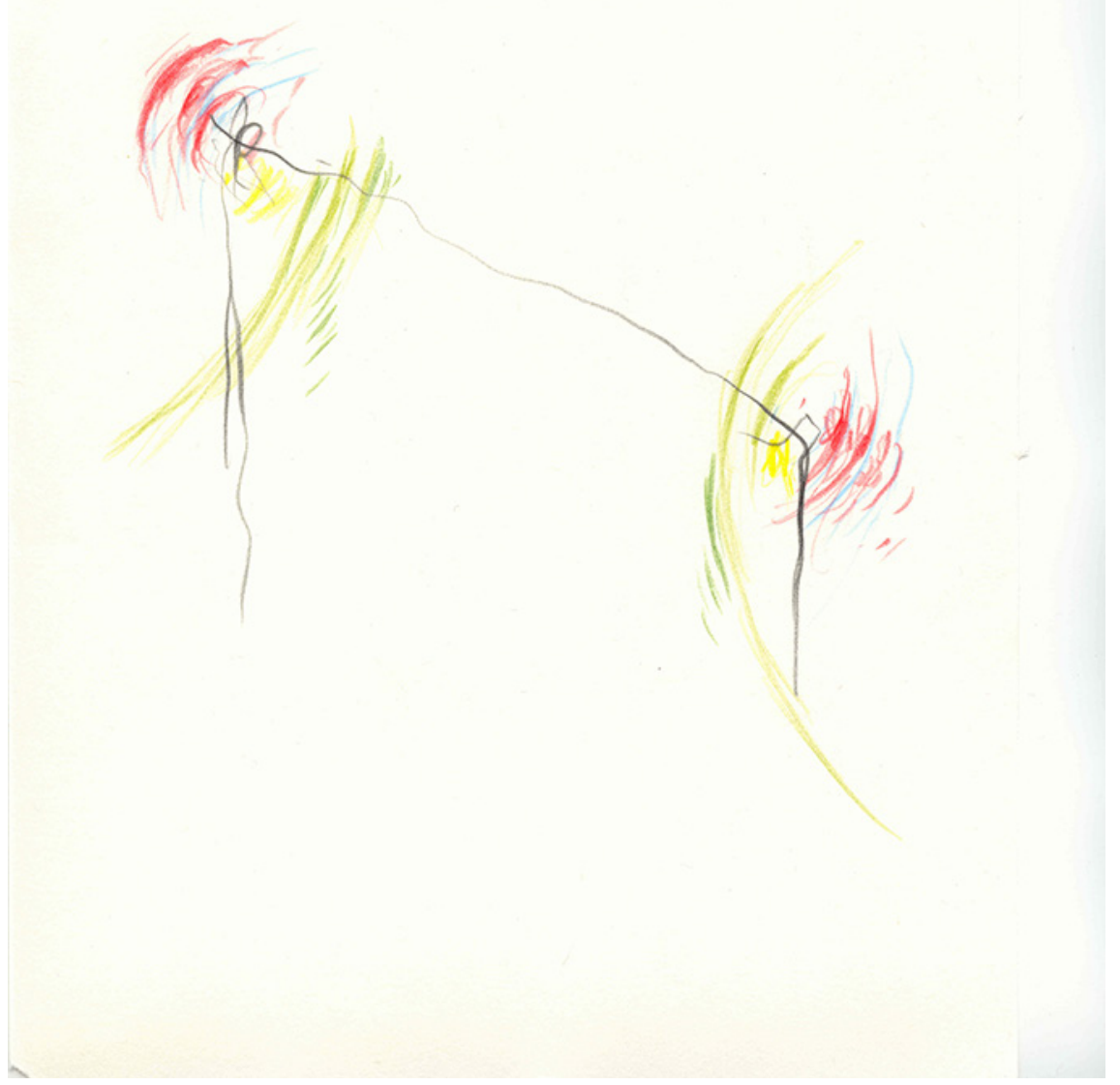

Abb. 62 Wolfgang Müller: Die unsichtbare LP, 2007. Modellskizze einer immateriellen Vinylscheibe, die in der Vorstellung des Hörers beim Abspielen der beiden LPs Unser Debüt und Sechs entsteht. Mit freundlicher Genehmigung von Wolfgang Müller, http://www.wolfgangmuellerrr.de/Musik (letzter Aufruf am 4.5.2020). 